\title{
Associação entre doença cardiovascular e demência: um estudo clinicopatológico
}

Tese apresentada à Faculdade de Medicina

da Universidade de São Paulo para obtenção do título de Doutor em Ciências

Área de concentração: Patologia Orientador: Prof. Dr. Carlos Augusto Pasqualucci

São Paulo 
Dados Internacionais de Catalogação na Publicação (CIP)

Preparada pela Biblioteca da

Faculdade de Medicina da Universidade de São Paulo

Creprodução autorizada pelo autor

Suemoto-Zoriki, Claudia Kimie

Associação entre doença cardiovascular e demência : um estudo clinicopatológico / Claudia Kimie Suemoto-Zoriki. -- São Paulo, 2010.

Tese (doutorado)--Faculdade de Medicina da Universidade de São Paulo. Departamento de Patologia.

Área de concentração: Patologia.

Orientador: Carlos Augusto Pasqualucci.

Descritores: 1.Demência 2.Aterosclerose 3.Lesões das artérias carótidas 4.Cardiomiopatias

USP/FM/SBD-049/10 


\section{DEDICATÓRIA}

Ao Sérgio, meu marido, por ter me apoiado e incentivado em todas as etapas desta tese e em boa parte de minha vida.

À Isa, minha filha, por ter dado outro sentido a tudo que faço.

Aos meus pais, Alfredo e Neusa, pelo amor, incentivo e dedicação. 


\section{AGRADECIMENTOS}

- Ao Professor Carlos Augusto Pasqualucci por ter me acolhido de forma incondicional. Este trabalho teria sido impossível sem a sua orientação precisa e generosa. Agradeço pela paciência e bom humor que marcaram toda a trajetória desta tese.

- Ao Professor Wilson Jacob Filho que me apresentou a Geriatria e sempre me estendeu a mão quando precisei. Obrigada por ter me aberto as portas do Laboratório de Fisiopatologia no Envelhecimento.

- Aos amigos Lea Grinberg, José Marcelo Farfel, Renata Ferretti e Renata Leite, por terem me acolhido, incentivado e contribuído para minha formação junto ao Grupo de Estudos em Envelhecimento Cerebral.

- Ao Professor Ricardo Nitrini pelas valiosas sugestões que iluminaram este trabalho.

- Ao Professor Paulo Rossi Menezes por todo conhecimento que me transmitiu durante minha graduação e pós-graduação. Agradeço pela generosidade em me ajudar prontamente em todos os momentos que precisei.

- Ao Professor Júlio César Pereira por ter me feito entender o porquê desta tese ter tantos números! Agradeço a profunda inspiração que o senhor é capaz de despertar em seus alunos.

- Ao Sr. Luis Carlos Pereira da Silva por ter organizado todo o material cardiovascular que utilizei. Sem a sua ajuda eu jamais teria terminado este trabalho!

- À Katia Oliveira, Juliana Ferranti e Miriam Aparecida, alunas do Projeto Envelhecimento Cerebral, por terem me ajudado a processar parte do material utilizado nesta tese. 
- À Jarita Carvalho que ajudou a fotografar e processar parte do material desta tese.

- À Marta Suemoto e à Mariana Mitre pela amizade e ajuda com as figuras desta tese.

- À amiga Ana Carolina Caldas Alves pelo incentivo e companhia.

- Aos alunos do Projeto Envelhecimento Cerebral, pelo empenho e dedicação, que contribuem para o sucesso do nosso grupo.

- Aos funcionários do Serviço de Verificação de Óbitos da Capital da Universidade de São Paulo pela colaboração com este projeto de pesquisa.

- A todos os professores e alunos do curso de pós-graduação que tive a felicidade de conhecer. Obrigada por terem compartilhado comigo tanta sabedoria.

- Aos colegas do Serviço de Geriatria da Faculdade de Medicina da USP pelos inestimáveis conhecimentos que me transmitiram.

- Aos familiares de todos os participantes deste estudo, pela generosidade em colaborar num momento de perda tão difícil. 
Esta tese está de acordo com as seguintes normas, em vigor no momento desta publicação:

Referências: adaptado de International Committe of Medical Journals Editors (Vancouver)

Universidade de São Paulo. Faculdade de Medicina. Serviço de Biblioteca e Documentação. Guia de apresentação de dissertações, teses e monografias. Elaborado por Annelise Carneiro da Cunha, Maria Julia de A. L. Freddi, Mara F. Crstana, Marinalva de Souza Aragão, Suely Campos Cardoso, Valéria Vilhena. $2^{a}$ Ed. São Paulo: Serviço de Biblioteca e Documentação; 2005.

Abreviaturas dos títulos dos periódicos de acordo com List of Journals Indexed in Index Medicus. 


\title{
Sumário
}

\author{
Lista de Siglas \\ Lista de Tabelas \\ Lista de Figuras
}

Resumo

Summary

1. INTRODUÇÃO 1

1.1. Envelhecimento populacional e doenças crônico-degenerativas ......................................... 2

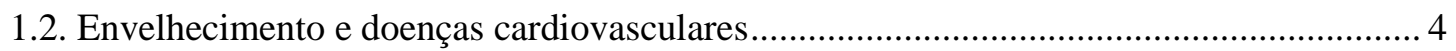

1.3. Envelhecimento e doenças neurodegenerativas: síndrome demencial ............................... 7

1.4. Principais causas da síndrome demencial: Doença de Alzheimer e demência vascular .. 10

1.5. DA e DV: mudanças ao longo de um século..................................................................... 12

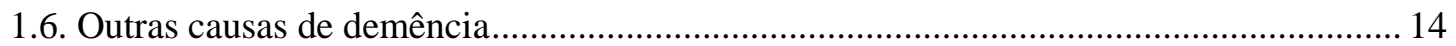

1.7. Interação entre fatores de risco cardiovascular (FRCV) e demência: evidências

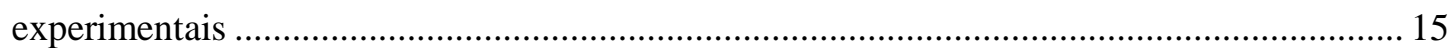

1.8. Interação entre FRCV e demência: evidências clínicas .................................................. 16

1.9. Interação entre doenças cardíacas e demência .................................................................. 19

1.10. Associação entre os principais FRCV e demência.......................................................... 20

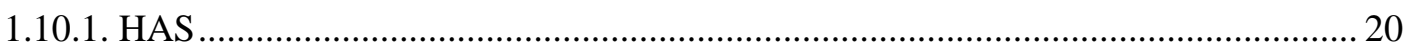

1.10.1.1. Hipertrofia miocárdica como medida de HAS sem controle adequado ........... 24

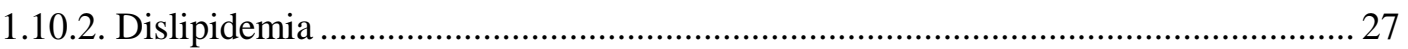

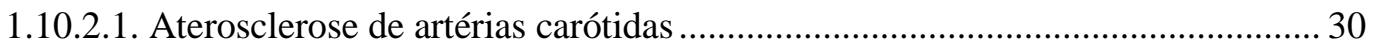

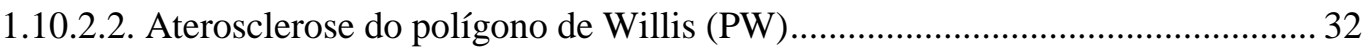

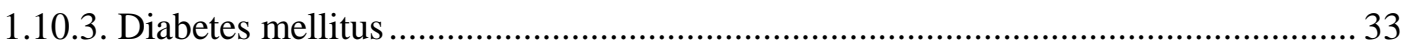

1.11. Interação entre fatores de risco cardiovascular, doença cardiovascular e demência:

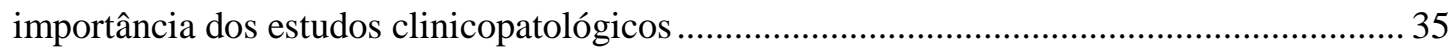

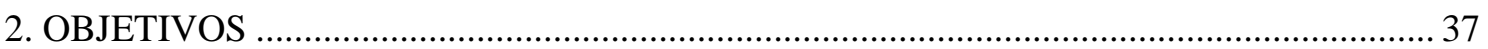

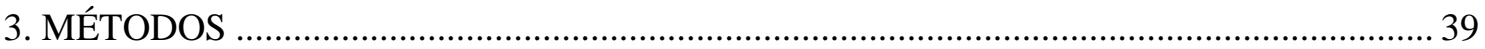

3.1. Grupo de Estudos em Envelhecimento Cerebral............................................................... 40

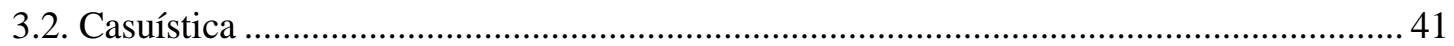

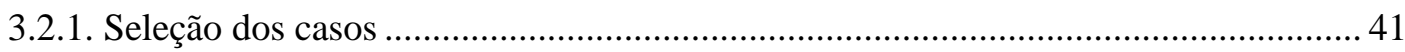




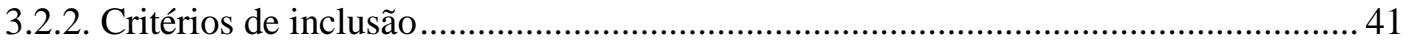

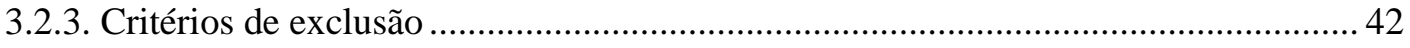

3.3. Avaliação do perfil demográfico e do perfil de risco cardiovascular ................................. 43

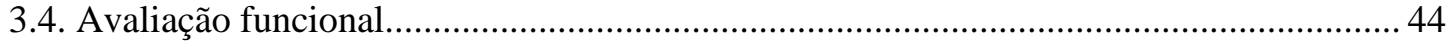

3.5. Avaliação da função cognitiva ..................................................................................... 45

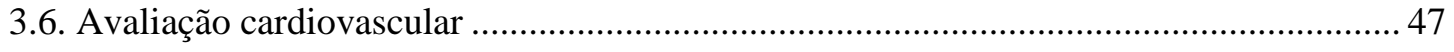

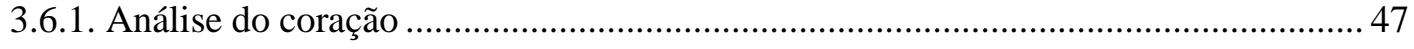

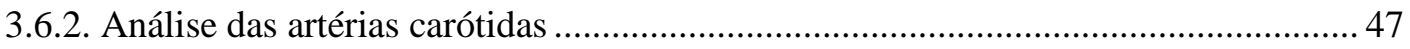

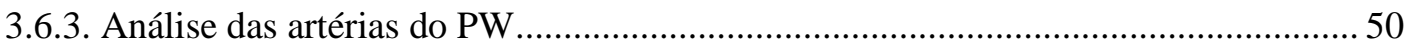

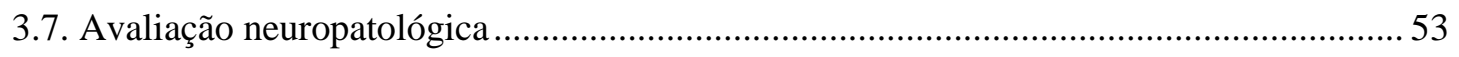

3.7.1. Diagnóstico neuropatológico das doenças neurodegenerativas ................................. 56

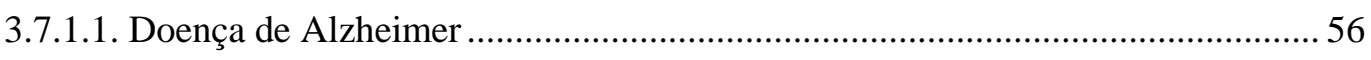

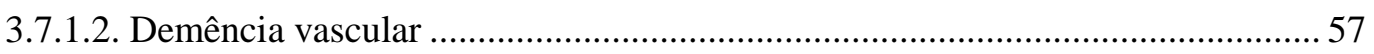

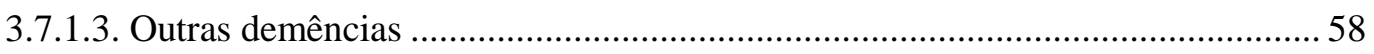

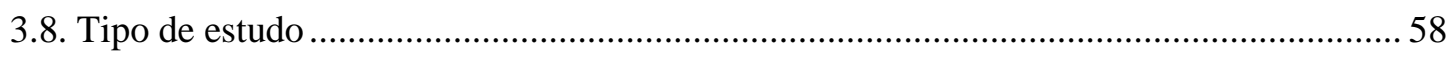

3.9. Determinação dos grupos de estudo de acordo com critérios clínicos e neuropatológicos

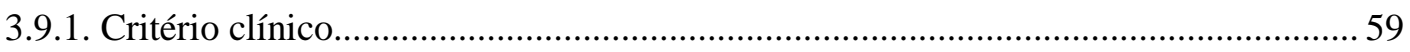

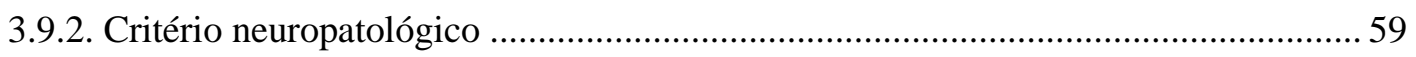

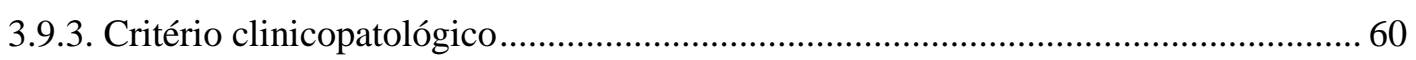

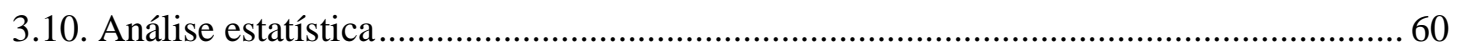

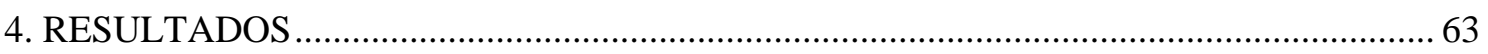

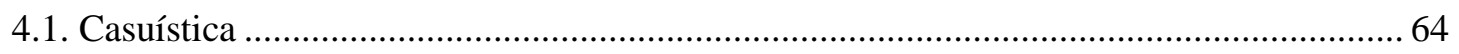

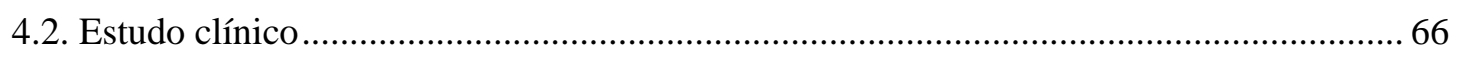

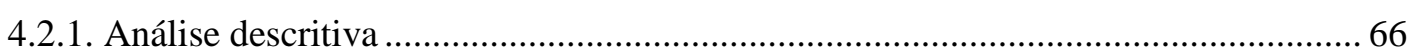

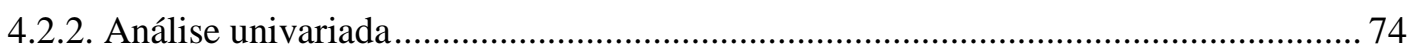

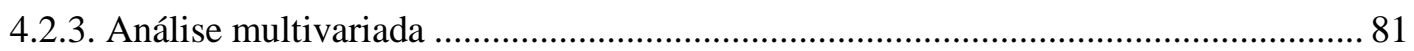

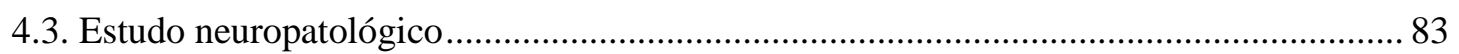

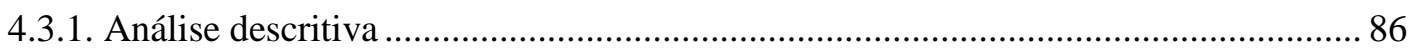

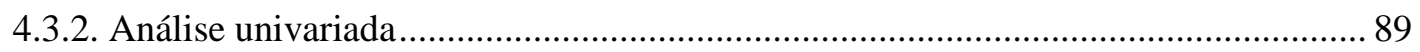

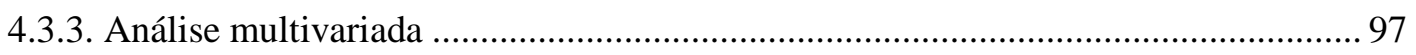

4.4. Correlação entre a presença de lesões neuropatológicas e doença cardiovascular.......... 100

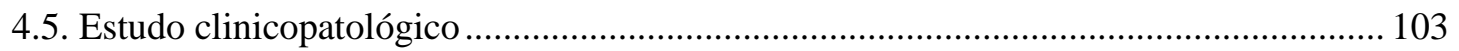

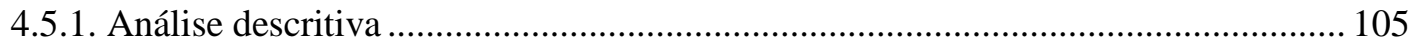

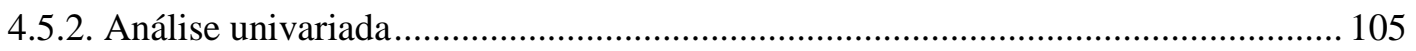

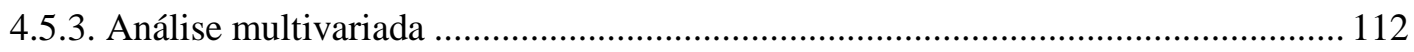




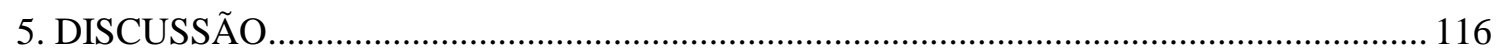

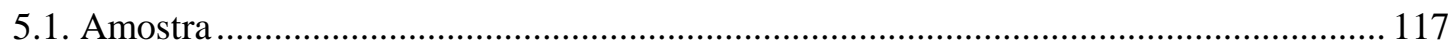

5.2. Perfil demográfico e FRCV ...................................................................................... 118

5.3. Doença cardiovascular anatomicamente comprovada ................................................... 125

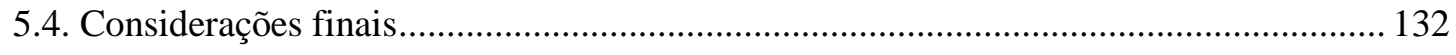

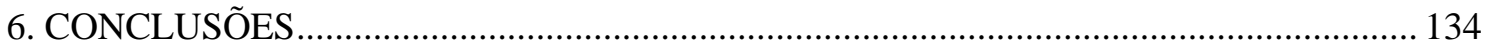

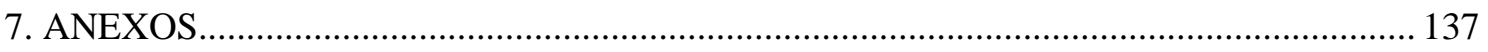

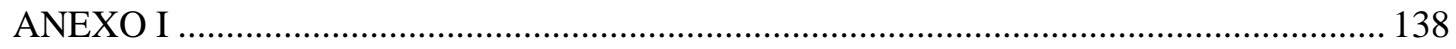

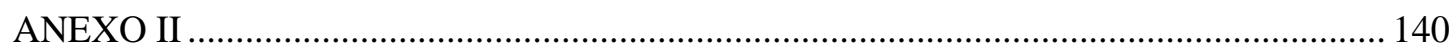

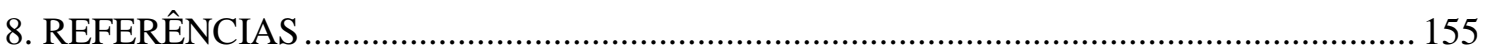




\section{LISTA DE SIGLAS}

ABIPEME Associação Brasileira de Institutos de Pesquisa de Mercado

ABVD

Atividades básicas de vida diária

AIVD

Atividades instrumentais de vida diária

AVC

Acidente vascular cerebral

$\mathrm{BEH}$

Banco de Encéfalos Humanos

CDR

Clinical Dementia Rating

CERAD

Consortium to Establish a Registry for Alzheimer's Disease

DA

Doença de Alzheimer

DAC

Doença arterial coronariana

DCA

Doença cerebral assintomática

$\mathrm{DCV}$

Doença cerebrovascular

$\mathrm{DM}$

Diabetes mellitus

DV

Demência vascular

EIM

Espessamento íntima-média

FMUSP

Faculdade de Medicina da Universidade de São Paulo

FRCV

Fatores de risco cardiovascular

GEEC

Grupo de Estudos em Envelhecimento Cerebral

HAS

Hipertensão arterial sistêmica

HVE

Hipertrofia ventricular esquerda

IADL

Instrumental Activities of Daily Life

IC $95 \%$

Intervalo de confiança 95\%

IMC

Índice de massa corpórea

IQCODE

Informant Questionnaire on Cognitive Decline in the Elderly

OR

Odds ratio

PPA

Proteína precursora de amilóide

PW

Polígono de Willis

$\mathrm{RM}$

Ressonância magnética 
SVOC-USP

VE
Serviço de Verificação de Óbitos da Capital

Ventrículo esquerdo 


\section{LISTA DE TABELAS}

Tabela 1 - Domínios avaliados na entrevista clínica e as respectivas escalas utilizadas. BEH-GEEC-FMUSP, 2005 a 2008

Tabela 2 - Protocolo de imunoistoquímica utilizado, mostrando as áreas cerebrais analisadas e os respectivos anticorpos utilizados. BEH-GEEC-FMUSP, 2005 a 2008

Tabela 3 - Método imunoistoquímico utilizado. BEH-GEEC-FMUSP, 2005 a 2008

Tabela 4 - Comparação entre os indivíduos incluídos e excluídos do estudo clínico em relação a variáveis demográficas. BEH-GEEC-FMUSP, 2005 a 2008

Tabela 5 - Dados demográficos dos participantes do estudo clínico (n=603). BEHGEEC-FMUSP, 2005 a 2008

Tabela 6 - Fatores de risco cardiovascular nos participantes do estudo clínico $(n=603)$. BEH-GEEC-FMUSP, 2005 a 2008

Tabela 7 - Peso cardíaco, espessura de ventrículo esquerdo e hipertrofia miocárdica de acordo com sexo, entre os participantes do estudo clínico $(n=603)$. BEH-GEECFMUSP, 2005 a 2008

Tabela 8 - Porcentagem de obstrução arterial por aterosclerose em artérias carótida segundo região representada ( $\mathrm{n}=603)$. BEH-GEEC-FMUSP, 2005 a 2008

Tabela 9 - Espessura íntima-média em milímetros de artérias carótidas comum e interna dos participantes do estudo clínico (n=603). BEH-GEEC-FMUSP, 2005 a 2008

Tabela 10 - Porcentagem de obstrução da luz das artérias que compõem o PW dos participantes do estudo clínico (n=603). BEH-GEEC-FMUSP, 2005 a 2008 
Tabela 11 - Porcentagem de obstrução arterial do PW, número de artérias com ateroma por caso e número de artérias com obstrução arterial maior do que $50 \%$ por $\mathrm{PW}$ dos participantes do estudo clínico (n=603). BEH-GEEC-FMUSP, 2005 a 2008

Tabela 12 - Dados demográficos de indivíduos sem demência (controle) e com demência. Estudo clínico (n=603). BEH-GEEC-FMUSP, 2005 a 2008

Tabela 13 - Fatores de risco cardiovascular nos grupos sem demência (controle) e com demência. Estudo clínico (n=603). BEH-GEEC-FMUSP, 2005 a 2008

Tabela 14 - Variáveis cardíacas nos grupos sem demência (controle) e com demência. Estudo clínico (n=603). BEH-GEEC-FMUSP, 2005 a 2008

Tabela 15 - Obstrução por aterosclerose em artérias carótidas nos grupos sem demência (controle) e com demência. Estudo clínico (n=603). BEH-GEEC-FMUSP, 2005 a 2008

Tabela 16 - Odds ratio para demência, de acordo com obstrução arterial por aterosclerose em artérias carótidas. Estudo clínico (n=603). BEH-GEEC-FMUSP, 2005 a 2008

Tabela 17 - Espessura íntima-média de artérias carótidas nos grupos sem demência (controle) e com demência. Estudo clínico (n=603), BEH-GEEC-FMUSP, 2005 a 2008

Tabela 18 - Aterosclerose do polígono de Willis (PW) nos grupos sem demência (controle) e com demência. Estudo clínico (n=603), BEH-GEEC-FMUSP, 2005 a 2008

Tabela 19 - Média (desvio padrão) da porcentagem de obstrução arterial nas artérias do polígono de Willis (PW) nos grupos sem demência (controle) e com demência. Estudo clínico (n=603), BEH-GEEC-FMUSP, 2005 a 2008

Tabela 20 - Odds ratio para demência, segundo características demográficas e fatores de risco cardiovascular, de acordo com modelo de regressão multivariável. Estudo clínico ( $\mathrm{n}=603)$, BEH-GEEC-FMUSP, 2005 a 2008 
Tabela 21 - Odds ratio para demência, segundo variáveis cardíacas, carotídeas e do polígono de Willis (PW), ajustado para idade, sexo e escolaridade, de acordo com modelo de regressão multivariável. Estudo clínico (n=603), BEH-GEEC-FMUSP, 2005 a 2008

Tabela 22 - Comparação entre participantes incluídos e excluídos do estudo neuropatológico em relação a variáveis demográficas BEH-GEEC-FMUSP, 2005 a 2008

Tabela 23 - Dados demográficos dos participantes do estudo neuropatológico $(n=183)$. BEH-GEEC-FMUSP, 2005 a 2008

Tabela 24 - Fatores de risco cardiovascular nos participantes do estudo neuropatológico $(\mathrm{n}=183)$. BEH-GEEC-FMUSP, 2005 a 2008

Tabela 25 - Variáveis cardíacas, carotídeas e relacionadas ao polígono de Willis dos participantes do estudo neuropatológico $(\mathrm{n}=183)$. BEH-GEEC-FMUSP, 2005 a 2008

Tabela 26 - Perfil demográfico de indivíduos controle, portadores de doença de Alzheimer (DA) e demência vascular (DV). Estudo neuropatológico ( $n=183)$, BEHGEEC-FMUSP, 2005 a 2008

Tabela 27 - Fatores de risco cardiovascular dos indivíduos controle, portadores de doença de Alzheimer (DA) e demência vascular (DV). Estudo neuropatológico ( $n=183)$, BEH-GEEC-FMUSP, 2005 a 2008

Tabela 28 - Variáveis cardíacas do grupo controle, portadores de doença de Alzheimer (DA) e demência vascular (DV). Estudo neuropatológico $(n=183)$, BEH-GEECFMUSP, 2005 a 2008

Tabela 29 - Média (desvio padrão) da porcentagem de obstrução em artérias carótidas no grupo controle, doença de Alzheimer (DA) e demência vascular (DV). Estudo neuropatológico ( $\mathrm{n}=183)$, BEH-GEEC-FMUSP, 2005 a 2008 
Tabela 30 - Frequência de obstrução arterial $\geq 75 \%$ em artérias carótidas comum, interna, direita e esquerda entre o grupo controle, portadores de DA e DV. Estudo neuropatológico (n=183), BEH-GEEC-FMUSP, 2005 a 2008

Tabela 31 - Odds ratio para doença de Alzheimer (DA), de acordo com porcentagem de obstrução arterial de artérias carótidas. Estudo neuropatológico $(\mathrm{n}=155), \mathrm{BEH}-\mathrm{GEEC}$ FMUSP, 2005 a 2008

Tabela 32 - Odds ratio para demência vascular (DV), de acordo com porcentagem de obstrução arterial de artérias carótidas. Estudo neuropatológico $(n=152)$, BEH-GEECFMUSP, 2005 a 2008

Tabela 33 - Média (desvio padrão) da espessura íntima-média (EIM) de artérias carótidas nos grupos controle, doença de Alzheimer (DA) e demência vascular (DV). Estudo neuropatológico ( $\mathrm{n}=183)$, BEH-GEEC-FMUSP, 2005 a 2008

Tabela 34 - Aterosclerose do polígono de Willis (PW) nos indivíduos controle, portadores de doença de Alzheimer (DA) e demência vascular (DV). Estudo neuropatológico (n=183), BEH-GEEC-FMUSP, 2005 a 2008

Tabela 35 - Média (desvio padrão) da porcentagem de obstrução arterial nas artérias do polígono de Willis nos indivíduos controle, portadores de doença de Alzheimer (DA) e demência vascular (DV). Estudo neuropatológico ( $\mathrm{n}=183)$, BEH-GEEC-FMUSP, 2005 a 2008

Tabela 36 - Odds ratio para doença de Alzheimer (DA) em relação a controles e para demência vascular (DV) em relação a controles, segundo características demográficas e fatores de risco cardiovascular, de acordo com modelo de regressão multivariável. Estudo neuropatológico ( $\mathrm{n}=183)$, BEH-GEEC-FMUSP, 2005 a 2008

Tabela 37 - Odds ratio para doença de Alzheimer (DA) em relação a controles, segundo aterosclerose carotídea e do polígono de Willis (PW), ajustado para idade, sexo e escolaridade, de acordo com modelo de regressão multivariável. Estudo neuropatológico ( $n=155)$, BEH-GEEC-FMUSP, 2005 a 2008 
Tabela 38 - Odds ratio para demência vascular (DV) em relação a controles, segundo aterosclerose carotídea e do polígono de Willis (PW), ajustado para idade, sexo e escolaridade, de acordo com modelo de regressão multivariável. Estudo neuropatológico (n=152), BEH-GEEC-FMUSP, 2005 a 2008

Tabela 39 - Presença de infarto lacunar, arteriosclerose hialina e angiopatia amilóide entre os participantes do estudo neuropatológico $(n=183)$, BEH-GEEC-FMUSP, 2005 a 2008

Tabela 40 - Variáveis cardíacas, carotídeas e do polígono de Willis, segundo presença de infarto cerebral lacunar, entre os participantes do estudo neuropatológico $(n=183)$. BEH-GEEC-FMUSP, 2005 a 2008

Tabela 41 - Perfil demográfico de indivíduos controle, portadores de doença cerebral assintomática (DCA) e de demência. Estudo clinicopatológico $(n=183)$, BEH-GEECFMUSP, 2005 a 2008

Tabela 42 - Fatores de risco cardiovascular dos indivíduos controle, portadores de doença cerebral assintomática (DCA) e de demência. Estudo clinicopatológico $(n=183)$, BEH-GEEC-FMUSP, 2005 a 2008.

Tabela 43 - Variáveis cardíacas dos indivíduos controle, portadores de doença cerebral assintomática (DCA) e de demência. Estudo clinicopatológico (n=183), BEH-GEECFMUSP, 2005 a 2008

Tabela 44 - Média (desvio padrão) da porcentagem de obstrução em artérias carótidas no grupo controle, doença cerebral assintomática (DCA) e de demência. Estudo clinicopatológico ( $\mathrm{n}=183)$, BEH-GEEC-FMUSP, 2005 a 2008

Tabela 45 - Odds ratio para demência, de acordo com porcentagem de obstrução arterial de artérias carótidas. Estudo clinicopatológico (n=171), BEH-GEEC-FMUSP, 2005 a 2008

Tabela 46 - Média (desvio padrão) da espessura íntima-média (EIM) de artérias carótidas nos grupos controle, doença cerebral assintomática (DCA) e demência. Estudo clinicopatológico ( $\mathrm{n}=183)$, BEH-GEEC-FMUSP, 2005 a 2008 
Tabela 47 - Aterosclerose do polígono de Willis (PW) dos indivíduos controle, portadores de doença cerebral assintomática (DCA) e de demência. Estudo clinicopatológico ( $\mathrm{n}=183)$, BEH-GEEC-FMUSP, 2005 a 2008

Tabela 48 - Média (desvio padrão) da porcentagem de obstrução arterial nas artérias do polígono de Willis (PW) dos indivíduos controle, portadores de doença cerebral assintomática (DCA) e de demência. Estudo clinicopatológico (n=183), BEH-GEECFMUSP, 2005 a 2008

Tabela 49 - Odds ratio para doença cerebral assintomática (DCA) em relação a controles e odds ratio para demência em relação a controles, segundo dados demográficos e fatores de risco cardiovascular, de acordo com modelo de regressão multivariável. Estudo clinicopatológico (n=183), BEH-GEEC-FMUSP, 2005 a 2008

Tabela 50 - Odds ratio bruto e ajustado para demência, segundo aterosclerose de artérias carótidas interna e esquerda. Estudo clinicopatológico $(n=171)$, BEH-GEECFMUSP, 2005 a 2008

Tabela 51 - Odds ratio para demência, segundo aterosclerose do polígono de Willis (PW), ajustado para idade, sexo e escolaridade. Estudo clinicopatológico $(\mathrm{n}=171)$, BEH-GEEC-FMUSP, 2005 a 2008 


\section{LISTA DE FIGURAS}

Figura 1. Porcentagem da população mundial e brasileira com 60 anos ou mais, durante o período de 1950 a 2050

Figura 2. Expectativa de vida ao nascer no Brasil (em anos) em homens e mulheres, durante o período de 1950 a 2050

Figura 3. A. Prevalência de hipertensão (Pressão arterial sistólica $\geq 140 \mathrm{mmHg}$, pressão diastólica $\geq 90 \mathrm{mmHg}$, ou uso atual de anti-hipertensivos). B. Incidência de acidente vascular cerebral (AVC) isquêmico, por 1000 pessoas/ano por idade e sexo. C. Incidência de doença arterial coronariana (DAC), 1000 pessoas/ano, por idade e sexo, estudo de Framingham

Figura 4. Mudanças no sistema cardiovascular associadas ao envelhecimento podem ser consideradas fatores de risco para doenças, levando a alterações cardíacas e cerebrais em idosos

Figura 5. Número de pessoas (em milhões) com demência em países desenvolvidos e em desenvolvimento, em 2001 e projeções para 2020 e 2040

Figura 6. Aspectos microscópicos da doença de Alzheimer. A. imunomarcação para proteína $\beta$-amilóide (cinza). Seta: placa neurítica. Córtex temporal. 400x. Imunoistoquímica anti- 4G8. B. Emaranhado neurofibrilar (marrom) na área CA1 do hipocampo. 40x. Imunoistoquímica anti-PHF-1.

Figura 7. A. Corpúsculo de Lewy corado com hematoxilina e eosina. B. Corpúsculo de Lewy corado com $\alpha$-sinucleína. Aumento 400X.

Figura 8. A. Prevalência de hipertrofia ventricular esquerda (\%) de acordo com a pressão arterial sistólica e idade em mulheres. Pressão arterial sistólica em mmHg. B. Prevalência de hipertrofia ventricular esquerda (\%) de acordo com a pressão arterial sistólica e idade em homens. 
Figura 9. A. Prevalência (\%) de hipertrofia ventricular esquerda de acordo com índice de massa corpórea (IMC) e idade em mulheres. IMC expresso em $\mathrm{kg} / \mathrm{m}^{2}$. B. Prevalência (\%) de hipertrofia ventricular esquerda de acordo com índice de massa corpórea (IMC) e idade em homens.

Figura 10. A. Representação histológica de artéria carótida comum sem a injeção de ágar, parcialmente colapsada. B. Representação histológica de artéria carótida comum após a injeção de ágar. Coloração de Verhoeff. Barra de calibração=2 mm

Figura 11. A. Artéria carótida direita e os quatro cortes representados

Figura 12. A. Corte transversal de artéria cerebral posterior sem a injeção de ágar, parcialmente colapsada. B. Corte transversal de artéria cerebral posterior após a injeção de ágar. Barra de calibração=1 mm.

Figura 13. Polígono de Willis.

Figura 14. Corte transversal de artéria basilar, componente do polígono de Willis. Linha vermelha delimita a área interna à parede externa do vaso e a linha azul, a área do lúmen. Barra de calibração=1mm.

Figura 15. Números de participantes (total), corações, artérias carótidas e PW coletados durante o período de 2005 a 2008.

Figura 16. Fluxograma dos participantes do estudo clínico.

Figura 17. Distribuição dos valores de IQCODE de acordo com a classificação pela escala CDR nos indivíduos que apresentaram material cardiovascular completo.

Figura 18. Frequência absoluta (n) e relativa (\%) dos 603 participantes do estudo clínico, distribuídos de acordo com a escala CDR.

Figura 19. Atividades básicas (A) e instrumentais (B) de vida diária em portadores de CDR 0, 1, 2 e 3. 
Figura 20. Graus progressivos de obstrução da luz por aterosclerose em artérias carótidas. Artéria carótida comum esquerda com 29,2\% (A); 43,2\% (B) e 91\% (C) de obstrução da luz. Barra de calibração=2 mm.

Figura 21. Graus progressivos de obstrução da luz por aterosclerose de artérias do PW. A. Artéria carótida interna esquerda com $25,6 \%$ de obstrução; B. Artéria cerebral posterior direita com 47,2\% de obstrução; C. artéria basilar com 80,3\% de obstrução. Barra de calibração=1 mm.

Figura 22. (A) Porcentagem de obstrução arterial nos grupos sem e com demência. (B) Número de artérias com ateroma por PW nos grupos sem e com demência. (C) Número de artérias com obstrução maior do que $50 \%$ por PW nos grupos sem e com demência.

Figura 23. Fluxograma dos participantes do estudo neuropatológico.

Figura 24. Frequência absoluta (n) e relativa (\%) dos 183 participantes do estudo neuropatológico.

Figura 25. (A) Porcentagem de obstrução arterial nos grupos controle, doença de Alzheimer (DA) e demência vascular (DV). (B) Número de artérias com ateroma/PW nos três grupos. (C) Número de artérias com obstrução maior do que 50\%/PW nos três grupos.

Figura 26. A - Frequência absoluta dos participantes em cada estágio da classificação de Braak e Braak. B - Frequência absoluta dos participantes em cada estágio da classificação do CERAD

Figura 27. Fluxograma dos participantes do estudo clinicopatológico.

Figura 28. Frequência absoluta (n) e relativa (\%) dos 183 participantes do estudo clinicopatológico. DCA=doença cerebral assintomática

Figura 29. (A) Porcentagem de obstrução arterial nos grupos controle, doença cerebral assintomática (DCA) e demência. (B) Número de artérias com placas de ateroma nos 3 grupos. (C) Número de artérias com porcentagem de obstrução arterial maior do que $50 \%$ nos 3 grupos 


\section{RESUMO}

Suemoto-Zoriki CK. Associação entre doença cardiovascular e demência: um estudo clinicopatológico [tese]. São Paulo: Faculdade de Medicina, Universidade de São Paulo; 2010. 170p.

INTRODUÇÃO: Recentemente, fatores de risco cardiovascular (FRCV) e doenças cardíacas têm sido associados à demência, doença de Alzheimer (DA) e demência vascular (DV). O objetivo deste trabalho é investigar a associação entre doença cardiovascular comprovada anatomicamente e demência, definida por critérios clínicos, neuropatológicos e clinicopatológicos. MÉTODOS: Trata-se de estudo transversal com material do Banco de Encéfalos Humanos do Grupo de Estudos em Envelhecimento Cerebral. Aterosclerose de artérias carótidas e do polígono de Willis (PW) e hipertrofia miocárdica foram avaliados em material de autópsia e relacionados à prevalência de demência. Dados demográficos e FRCV também foram comparados quanto à presença de demência. Esta foi definida por três critérios: (1) clínico - de acordo com escalas cognitivas aplicadas ao informante do falecido; (2) neuropatológico - de acordo com critérios aceitos para a classificação de DA e DV; (3) clinicopatológico - de acordo com a avaliação cognitiva e com a presença de lesões cerebrais associadas à DA e DV. RESULTADOS: No estudo clínico, foram incluídos 603 indivíduos maiores de 50 anos de idade com avaliação cognitiva e cardiovascular. Demência esteve associada a obstruções críticas $(\geq 75 \%)$ em artérias carótidas, a menor peso cardíaco e a menor espessura da parede ventricular esquerda. Os portadores de demência definida por critérios clínicos eram mais idosos e apresentaram maior proporção de acidente vascular cerebral (AVC) referido pelo informante, sedentarismo, insuficiência cardíaca e menor índice de massa corpórea do que os indivíduos sem demência. No estudo neuropatológico, foram avaliados 183 indivíduos que se dividiram em três grupos: controles $(n=124)$, portadores de DA $(n=31)$ e DV $(n=28)$. Indivíduos com DA apresentaram maior proporção de obstruções $\geq 75 \% \mathrm{em}$ artérias carótidas do que controles. Os portadores de DV, além de maior gravidade da aterosclerose carotídea, também apresentaram maior obstrução em artérias do PW do que controles. Quanto aos dados demográficos e FRCV, a idade foi maior em indivíduos com DA e DV em relação a controles e AVC referido foi mais prevalente entre os portadores de DV. No estudo clinicopatológico, foram incluídos 124 controles, 12 portadores de doença cerebral assintomática (DCA) e 47 dementados. Maior gravidade da aterosclerose carotídea e das artérias do PW foi observada em portadores de demência em relação a controles. Quanto aos dados demográficos e FRCV, indivíduos com DCA e demência eram mais idosos do que controles. A escolaridade de portadores de DCA foi maior do que controles e AVC referido foi mais prevalente entre dementados em relação a controles. CONCLUSÕES: Doença cardiovascular, particularmente aterosclerose de artérias carótidas e do PW, estão associados à maior chance de demência. Medidas preventivas que visem retardar a progressão da aterosclerose podem ser eficientes para diminuir a incidência de demência.

Descritores: 1.Demência; 2.Aterosclerose; 3.Artérias carótidas; 4.Cardiomiopatias; 5. Círculo arterial do cérebro 


\section{SUMMARY}

Suemoto-Zoriki CK. Association between cardiovascular disease and dementia: a clinicopathological study [thesis]. São Paulo: Faculty of Medicine, University of Sao Paulo; SP (Brazil); 2010. 170p.

INTRODUCTION: Recently, cardiovascular risk factors (CVRF) and cardiac diseases have been associated with dementia, Alzheimer disease (AD) and vascular dementia (VD). The aim of this study was to investigate the association between anatomicallyproven cardiovascular disease and dementia, defined by clinical, neuropathological and clinicopathological criteria. METHODS: This was a cross-sectional study using material drawn from the Human Brain Bank of the Aging Brain Study Group. Carotid artery and Circle of Willis (CW) atherosclerosis as well as myocardial hypertrophy were evaluated in autopsy material and compared for the prevalence of dementia. Demographics and CVRF were also compared for the presence of dementia. This was defined by three criteria: (1) clinical - according to cognitive scales applied to the informant of the deceased individual; (2) neuropathological - according to accepted criteria for the classification of $\mathrm{AD}$; (3) clinicopathological - according to cognitive evaluation and the presence of AD and VD-associated cerebral lesions. RESULTS: The clinical study included 603 individuals older than 50 years, who underwent cognitive and cardiovascular evaluation. Dementia was found to be associated with a high degree $(\geq 75 \%)$ of obstruction in carotid arteries, lower heart weight and thinner left ventricle wall. Individuals with clinically-defined dementia were older and had more informantreported strokes, greater physical inactivity and heart failure and lower body mass index than subjects without dementia. The neuropathological study involved 183 individuals who were evaluated and divided into three groups: control group $(n=124), A D(n=31)$ and VD $(n=28)$. Individuals with AD showed a higher degree of obstruction $\geq 75 \%$ in the carotid arteries than controls. Subjects with VD, besides presenting greater severity of carotid atherosclerosis, also had a greater degree of obstruction in the arteries of the CW than controls. Regarding demographics and CVRF, age was higher in individuals with $\mathrm{AD}$ and VD compared to controls, while informant-reported stroke was more prevalent among individuals with VD. The clinicopathological study included 124 control individuals, 12 patients with asymptomatic brain disease (ABD) and 47 demented subjects. Greater severity of carotid and CW artery atherosclerosis was observed in individuals with dementia compared to controls. In terms of demographics and CVRF, individuals with ABD were older than control individuals. Years of education were higher in subjects with ABD compared to controls and informant-reported stroke was more prevalent among demented persons than controls. CONCLUSIONS: Cardiovascular disease, particularly carotid artery and $\mathrm{CW}$ atherosclerosis, are associated with higher risk for dementia. Preventive measures aimed at slowing the progression of atherosclerosis may be effective in decreasing the incidence of dementia.

Descriptors: 1. Dementia; 2. Atherosclerosis; 3. Carotid arteries; 4. Cardiomyopathy; 5. Circle of Willis 


\section{INTRODUÇÃO}


Introdução

\subsection{Envelhecimento populacional e doenças crônico-degenerativas}

Os idosos representam $10 \%$ do total da população brasileira, correspondendo a mais de 19 milhões de pessoas com 60 anos ou mais (DATA SUS, 2009). As estimativas para os próximos 50 anos indicam que a população idosa brasileira poderá exceder 64 milhões de pessoas ao final deste período, chegando a representar $29 \%$ da população (World Population Prospects, 2008). Este crescimento acelerado em nosso país tem ocorrido em poucas décadas, ao contrário do observado em países desenvolvidos, que tiveram mais tempo para se adaptar a esta nova realidade (Figura1).

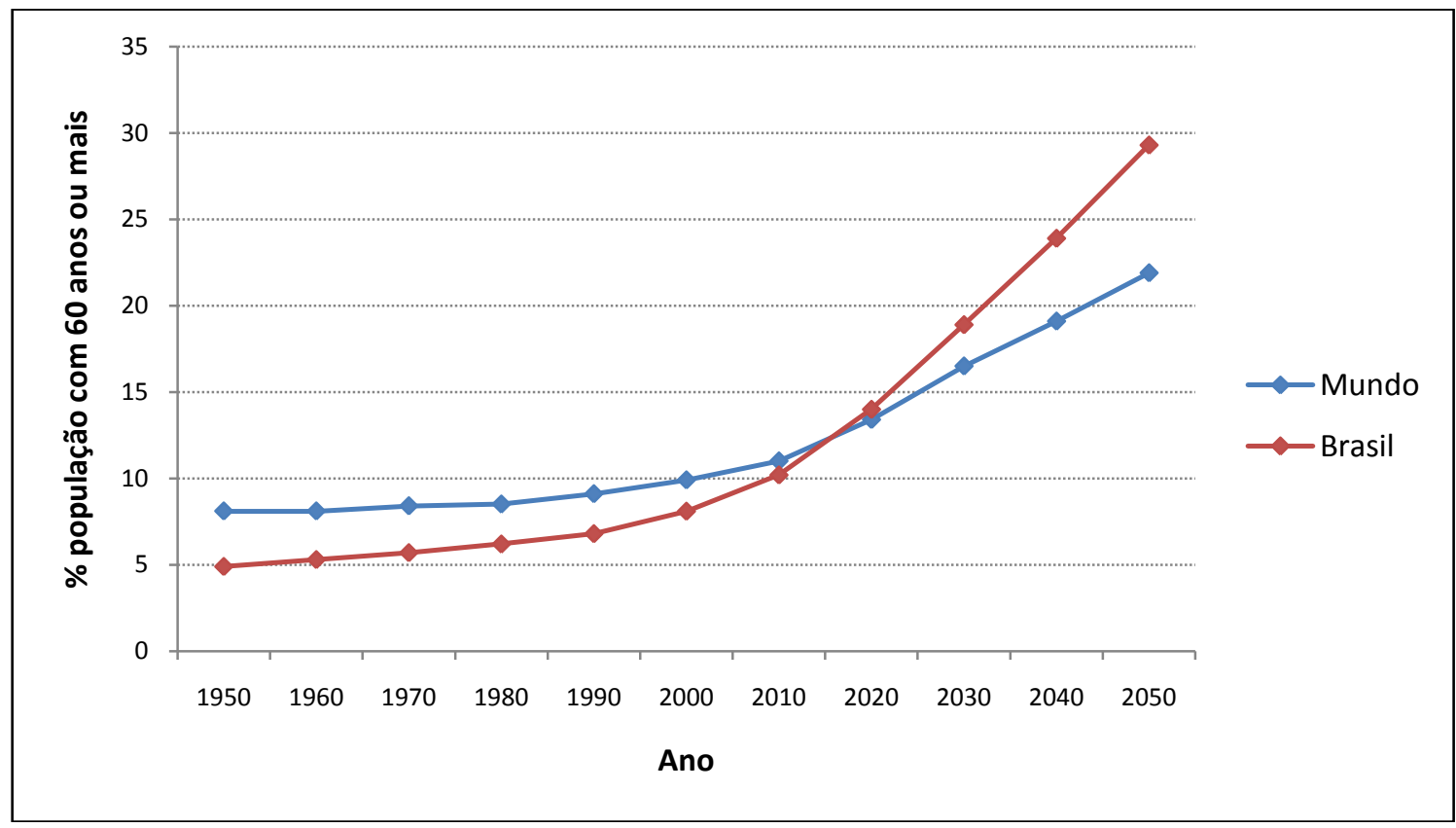

Figura 1. Porcentagem da população mundial e brasileira com 60 anos ou mais, durante o período de 1950 a 2050. Fonte: World Population Prospects, 2008

O envelhecimento populacional é fruto do aumento da expectativa de vida e da diminuição das taxas de fecundidade (Figura 2). Esta condição, conhecida como transição demográfica, é acompanhada por mudanças da morbimortalidade, com aumento da prevalência de doenças crônicas e diminuição das doenças infecciosas. Este fenômeno é conhecido como transição epidemiológica (Kalache, 1987). 
Introdução

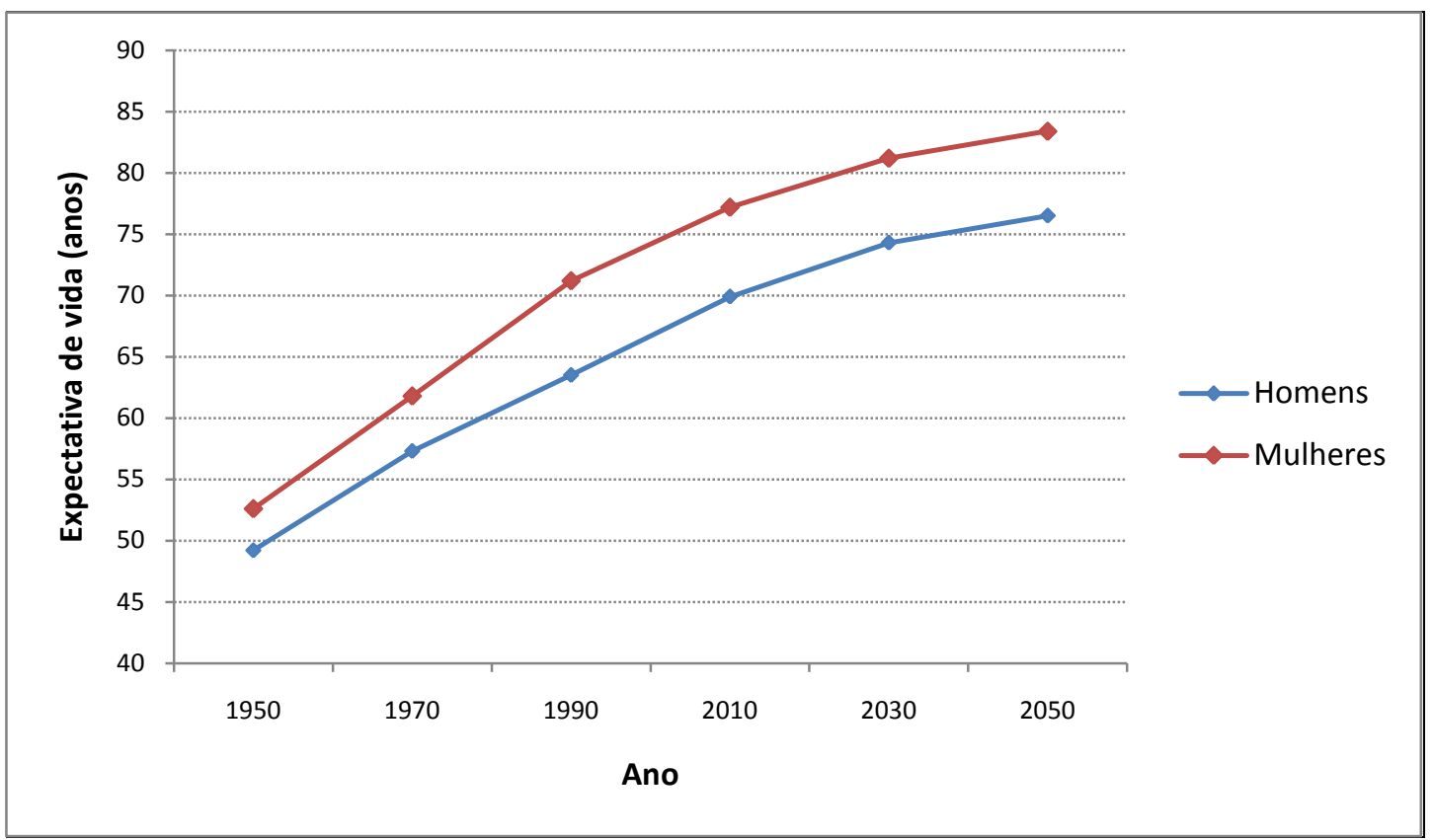

Figura 2. Expectativa de vida ao nascer no Brasil (em anos) em homens e mulheres, durante o período de 1950 a 2050. Fonte: World Population Prospects, 2008

Embora, alguns possam festejar a maior longevidade da população brasileira, o aumento da expectativa de vida, ainda nos dias atuais, pode significar uma prevalência elevada de doenças crônico-degenerativas, levando à maior incapacidade e dependência. Segundo censo demográfico realizado pelo IBGE em 2000, o número de indivíduos com 65 anos ou mais portadores de algum tipo de deficiência atinge mais de 5 milhões (IBGE, 2000).

O envelhecimento pode ser definido como um processo que leva a uma diminuição da reserva fisiológica global, trazendo um aumento exponencial de vulnerabilidade a doenças. A interação entre alterações secundárias à idade e o maior tempo de exposição a fatores de risco para diversas doenças explicam a maior morbidade nas faixas etárias mais avançadas (Miller, 2003). Embora, seja um fenômeno universal, há uma grande heterogeneidade observada entre aqueles que envelhecem. A busca de conhecimentos que expliquem as diferenças entre o envelhecimento bem 
Introdução

sucedido, pautado na independência e autonomia, e o envelhecimento mal sucedido, permeado de incapacidades, é de importância vital em nossa sociedade contemporânea.

\subsection{Envelhecimento e doenças cardiovasculares}

Entre as doenças crônico-degenerativas, destaca-se o aumento da prevalência de doenças cardiovasculares (Figura 3). A idade é o principal fator de risco para estas doenças (Lakatta e Levy, 2003a). Com o passar dos anos, é documentado espessamento e rigidez da parede arterial não relacionado à aterosclerose em indivíduos saudáveis. Estas alterações são o substrato para o desenvolvimento das doenças cardiovasculares altamente prevalentes no envelhecimento.

A rigidez arterial está relacionada à maior prevalência de hipertensão arterial sistêmica (HAS), hipertrofia ventricular esquerda e aterosclerose. Além disso, observase uma alteração da regulação do tônus vascular, secundária a diminuição da produção de óxido nítrico, o que também contribui para piora da rigidez vascular (Lakatta e Levy, 2003a). 
Introdução
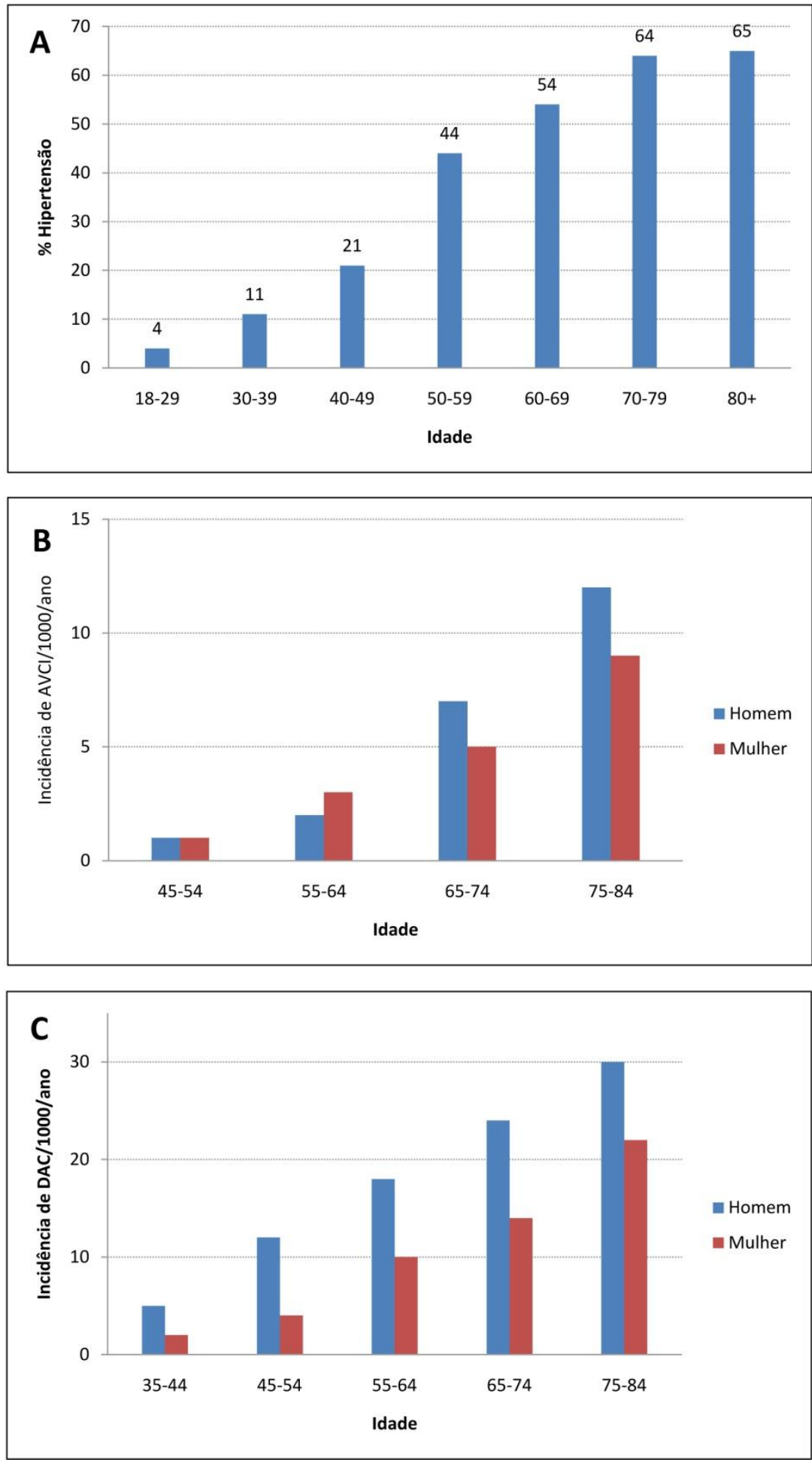

Figura 3. A. Prevalência de hipertensão (Pressão arterial sistólica $\geq 140 \mathrm{mmHg}$, pressão diastólica $\geq 90 \mathrm{mmHg}$, ou uso atual de anti-hipertensivos) (Burt et al., 1995). B. Incidência de acidente vascular cerebral (AVC) isquêmico, por 1000 pessoas/ano por idade e sexo (Wolf et al., 1993). C. Incidência de doença arterial coronariana (DAC), 1000 pessoas/ano, por idade e sexo, estudo de Framingham (Kannel et al., 1987). Fonte: Lakatta e Levy, 2003a. 
Introdução

Da mesma forma, o envelhecimento cardíaco é substrato para muitas doenças (Lakatta e Levy, 2003b). Com o avançar da idade, é observado o aumento da espessura da parede de ventrículo esquerdo em indivíduos sem HAS ou doença cardiovascular aparente. Isto ocorre porque, embora o número total de miócitos diminua, o aumento do tamanho dos mesmos causa a hipertrofia miocárdica. Esta também está relacionada ao índice de massa corpórea e ao sexo do indivíduo (Levy et al., 1988). O aumento da espessura da parede ventricular pode levar à insuficiência cardíaca. Observa-se também um aumento atrial esquerdo, secundário às alterações ventriculares, que elevam a pressão e o volume do átrio. A maior prevalência de fibrilação atrial e outras arritmias atriais em idosos se deve a este motivo (Lakatta e Levy, 2003b). As mudanças estruturais e funcionais associadas ao envelhecimento do sistema cardiovascular associam-se a maior tempo de exposição aos fatores de risco cardiovascular (FRCV), determinando o limiar, gravidade e prognóstico das doenças cardiovasculares em idosos (Figura 4). 


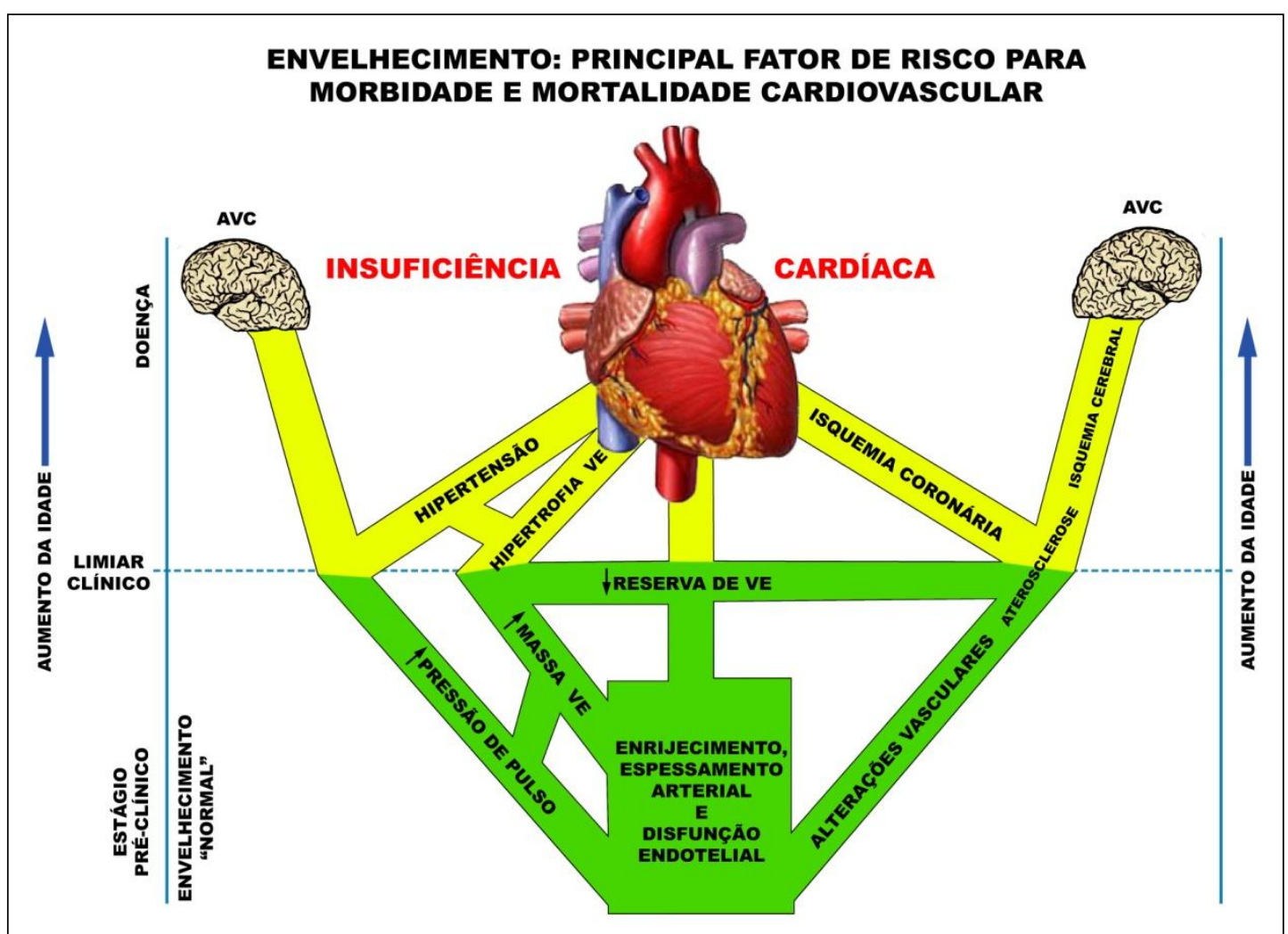

Figura 4. Mudanças no sistema cardiovascular associadas ao envelhecimento podem ser consideradas fatores de risco para doenças, levando a alterações cardíacas e cerebrais em idosos. Fonte: Lakatta e Levy, 2003b

\subsection{Envelhecimento e doenças neurodegenerativas: síndrome demencial}

Assim como as doenças cardiovasculares, as doenças neurodegenerativas mostram um crescimento acelerado com o envelhecimento. Entre as doenças neurodegenerativas, destaca-se a síndrome demencial. Esta é definida por múltiplos déficits cognitivos, que incluem comprometimento da memória e de, pelo menos, mais uma função cognitiva (afasia, apraxia, agnosia ou disfunção executiva). Os déficits apresentados devem ser suficientemente graves para comprometer o funcionamento ocupacional ou social do indivíduo e representar um declínio em relação a um nível anteriormente superior de funcionamento (American Psychiatry Association, 2000). Sintomas neuropsiquiátricos, como depressão, ansiedade, alterações do sono e 
Introdução

agressividade são comuns (Cummings, 2005). Embora muitas vezes difícil, é importante diferenciar a demência do declínio cognitivo no envelhecimento normal, que tende a afetar a velocidade de processamento mental e, conseqüente, recuperação tardia (Anstey e Low, 2004).

Estima-se que 24 milhões de pessoas são portadores de demência no mundo. Este número deve dobrar a cada 20 anos, chegando a 42 milhões em 2020 e 81 milhões em 2040, assumindo que não haja mudanças na mortalidade e que nenhum tratamento preventivo ou curativo seja descoberto (Kalaria et al., 2008). Entre os dementados, 58\% vivem em países em desenvolvimento, provavelmente atingindo 72\% em 2040 (Figura 5). Acredita-se que os países latino-americanos, entre 2001 e 2040, irão vivenciar um aumento de 393\% no número de pessoas com demência (Kalaria et al., 2008).

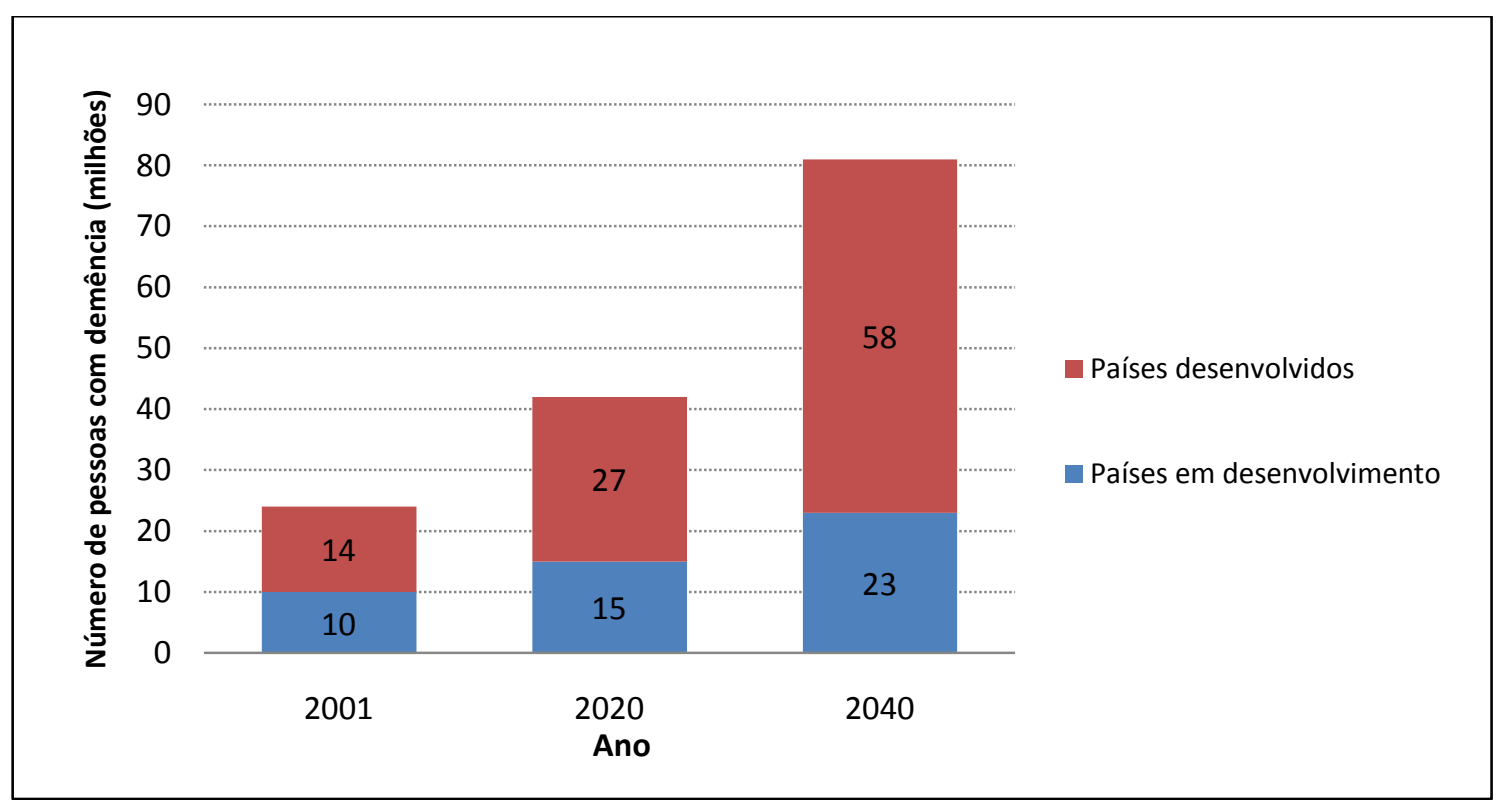

Figura 5. Número de pessoas (em milhões) com demência em países desenvolvidos e em desenvolvimento, em 2001 e projeções para 2020 e 2040. Fonte: Kalaria et al., 2008

A prevalência de demência aumenta dramaticamente com o envelhecimento. Corresponde a $1 \%$ aos 60 anos e dobra a cada cinco anos, chegando a 30\% aos 85 anos de idade (Geldmacher et al., 1996). Dados sobre o Brasil confirmam o aumento da prevalência de demência com a idade. Em Catanduva, município do estado de São 
Introdução

Paulo, a prevalência de demência foi de $7,1 \%$. A prevalência de demência foi de $1,6 \%$ dos 65 aos 69 anos, elevando-se para 36,9\% nas idades superiores a 84 anos (Herrera Junior et al., 1998). O mesmo grupo de pesquisadores encontrou uma incidência de demência de 13,8 para 1000 pessoas-ano em maiores de 65 anos (Nitrini et al., 2004). Bottino et al. (2008) relata uma prevalência de demência ligeiramente mais elevada no município de São Paulo (8,12\%), sendo também progressivamente maior com o avançar da idade. Estudo recente englobando dados de oito coortes populacionais da América Latina, sendo três delas brasileiras, sugere algumas particularidades. Embora a prevalência geral seja semelhante à de países desenvolvidos $(7,1 \%)$, nos países latinoamericanos há maior prevalência de demência nos grupos relativamente mais jovens (65 a 69 anos). Além disso, ressalta a alta taxa de analfabetismo nestes países, sendo que a prevalência de demência em analfabetos é duas vezes maior do que nos não analfabetos (Nitrini et al., 2009).

Demência pode resultar em incapacidade, dependência e aumento da mortalidade. Segundo a Organização Mundial de Saúde, em 2003 (WHO, 2003), a demência contribuiu com 11,2\% dos anos vividos com incapacidade em maiores de 60 anos de idade, seguida por acidente vascular cerebral (AVC) $(9,5 \%)$, doenças músculoesqueléticas $(8,9 \%)$, doenças cardiovasculares $(5 \%)$ e todas as formas de câncer $(2,4 \%)$. No estudo populacional de Catanduva, a síndrome demencial foi o maior preditor de mortalidade (Nitrini et al., 2005), sendo mais importante que idade, história de AVC, insuficiência cardíaca e HAS grave. 
Introdução

\subsection{Principais causas da síndrome demencial: Doença de Alzheimer e demência vascular}

A síndrome demencial pode ser uma manifestação comum a diversas doenças. A doença de Alzheimer (DA) é a causa mais comum, correspondendo a cerca de $60 \%$ dos casos em países em desenvolvimento, com prevalência de 3,4\% (IC 95\% 1,6-5,0) (Kalaria, 2008). Tem como característica neuropatológica a deposição de proteína $\beta$ amilóide no cérebro, na forma de placas neuríticas e, acúmulo de proteína tau, formando os emaranhados neurofibrilares (Mudher e Lovestone, 2002). Placas neuríticas são definidas como depósitos amilóides que contém neuritos distróficos, vistos na coloração anti ß-amilóide. Os emaranhados neurofibrilares são identificados através da imunoistoquímica anti-PHF1 na forma de depósitos fibrilares intracitoplasmáticos (Figura 6). Clinicamente, a DA é caracterizada por alteração precoce, progressiva e insidiosa da memória episódica (Dubois et al., 2007). Com o avançar da doença leva à deterioração da linguagem e déficits visuoespaciais. Alterações motoras e sensoriais, distúrbios de marcha e convulsões são incomuns antes de estágios avançados da doença (Cummings, 2004).

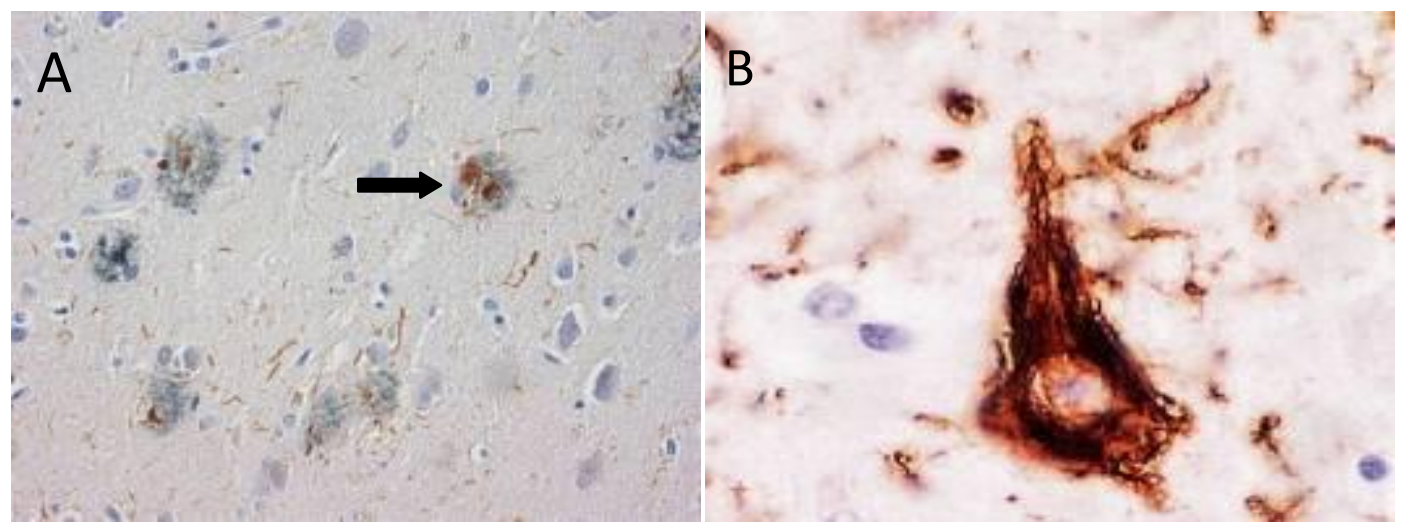

Figura 6. Aspectos microscópicos da doença de Alzheimer. A. imunomarcação para proteína $\beta$-amilóide (cinza). Seta: placa neurítica. Córtex temporal. 400x. Imunoistoquímica anti- 4G8. B. Emaranhado neurofibrilar (marrom) na área CA1 do hipocampo. 40x. Imunoistoquímica anti-PHF-1. Fonte: BEH-GEEC-FMUSP, 2005 a 2008. 
A segunda causa mais comum é a demência vascular (DV), responsável por $26 \%$ dos casos de demência e prevalência de $0,9 \%$ (IC 95\% 0,06-1,78) em países em desenvolvimento (Kalaria et al., 2008). Engloba déficit cognitivo secundário à doença cerebrovascular isquêmica ou hemorrágica. As lesões isquêmicas são divididas em doença de grandes vasos ou de pequenos vasos. A DV de grandes vasos inclui: demência secundária a infarto córtico-subcortical de artéria única, (frequentemente em artéria cerebral posterior direita, artéria cerebral anterior ou artéria do giro angular esquerdo) e demência multi-infarto (englobando infartos trombóticos ou embólicos em múltiplas grandes artérias córtico-subcorticais). A DV de pequenos vasos pode ser secundária à infarto único em área estratégica (tálamo, gânglios da base e hipocampo) ou à doença microvascular subcortical, que é a forma mais freqüente. A DV subcortical inclui os estados lacunares (múltiplos infartos lacunares) e a doença de Biswanger (também conhecida como leucoencefalopatia periventricular) (Román, 2003) Devido às diferentes causas e localizações possíveis, a DV pode ter quadros clínicos diferentes, o que dificulta a padronização do diagnóstico clínico e neuropatológico (Jellinger, 2008). O quadro clínico da DV pode ser caracterizado por início abrupto (DV cortical) ou gradual (DV subcortical), com progressão em degraus (DV cortical) ou insidiosa (DV subcortical). A memória não é tão afetada inicialmente, como na DA, sendo mais característica uma disfunção executiva grave. Distúrbios de marcha são frequentes e a associação com FRCV e doença cardiovascular prévia é comum (Román, 2003).

Embora a DA e a DV sejam abordadas separadamente em estudos clínicos, há evidências de que, principalmente em idosos, as lesões cerebrais associadas a estas duas doenças ocorram simultaneamente e interajam, aumentando a expressão do declínio cognitivo (Petrovitch et al., 2005 e Chui et al., 2006). Dados de um estudo multicêntrico 
Introdução

britânico com 209 autópsias mostram que as alterações vasculares são muito comuns e que em 58\% dos participantes classificados clinicamente como portadores de DA coexistiram lesões neurodegenerativas e vasculares (Fernando e Ince, 2004).

Em estudo de autópsias em 102 freiras, a presença de infartos cerebrais esteve associada a pior desempenho em testes cognitivos realizados em vida e à demência clínica. Infartos cerebrais e lesões neuropatológicas típicas de DA coexistiram em 47\% dos casos. Infartos lacunares em gânglios da base, tálamo e substância branca profunda foram responsáveis por maior expressão clínica de demência. Nos casos com infartos cerebrais, a DA manifestou-se com menor quantidade de lesões neuropatológicas típicas, como os emaranhados neurofibrilares, do que nos casos sem lesões isquêmicas. Aterosclerose do polígono de Willis esteve associada a infartos cerebrais maiores e lacunares (Snowdon et al., 1997).

\subsection{DA e DV: mudanças ao longo de um século}

Durante o século XIX e na maior parte do século XX, a doença cerebrovascular era tão comum em pacientes com degeneração mental senil, que a arteriosclerose cerebral, o nome original da DV, era considerada a principal causa de demência. Nessa época, era relativamente incomum viver até idades avançadas suficientes para o desenvolvimento da DA. Além disso, FRCV, como por exemplo, HAS, ainda não eram diagnosticados e tratados e, portanto, a demência vascular era mais freqüente (Reed, 2004).

A primeira descrição clínica da DV foi feita por Thomas Willis, o mesmo que descreveu a constituição do polígono de Willis, em 1684. Willis caracterizou muito do 
Introdução

que hoje consideramos serem aspectos clínicos da DV, ao citar que "a paralisia motora é seguida de um embotamento da mente e esquecimento e, então aparece a estupidez e a insensatez" (Willis, 1684).

Alois Alzheimer (1894) propõe que a degeneração por aterosclerose era uma forma de demência senil, com características e sintomas distintos da paresia secundária a acidentes vasculares cerebrais. Ele descreveu sintomas, como o curso em degraus, alterações de humor e relativa "preservação da inteligência", antecipando em 80 anos muitos critérios descritos por Hachinski (Hachinski et al., 1975). Desde então ganhou força a idéia de que a demência senil seria secundária à aterosclerose.

Em 1907, Alois Alzheimer descreveu o achado de placas senis e emaranhados neurofibrilares no cérebro da paciente August (Alzheimer, 1907). Desde esta época, considerações sobre a verdadeira prevalência de DA aumentou consideravelmente. Após a publicação do estudo de Tomlinson et al. (1970) sobre as características neuropatológicas da demência em idosos, a DA foi considerada a principal causa de demência e a doença vascular foi relegada a segundo plano.

Recentemente, foi demonstrado que fatores de risco para doença cerebrovascular também são também fatores de risco para DA (Skoog et al., 1996; Hofman et al., 1997). Estas descrições reacenderam o interesse na contribuição vascular para o surgimento de demência. Atualmente, procura-se entender a interação entre as lesões neuropatológicas de DV e DA e estabelecer se há uma via comum entre os mecanismos patogênicos destas entidades. 


\subsection{Outras causas de demência}

Outras causas da síndrome demencial incluem doenças mais raras, que correspondem a menos de $10 \%$ das causas de demência (Adelman e Daly, 2005). Os sintomas cognitivos podem estar associados ao parkinsonismo (rigidez, bradicinesia, tremor e instabilidade postural), tanto na demência por corpúsculos de Lewy quanto na demência secundária à doença de Parkinson. Acredita-se que a demência por corpúsculos de Lewy seja uma causa importante de demência, com prevalência de cerca de $20 \%$ dos casos, embora ainda seja pouco diagnosticada (Ferman e Boeve, 2007). Clinicamente, caracteriza-se por déficit cognitivo acompanhado de delirium (flutuações do nível de consciência), alucinações visuais, parkinsonismo e sensibilidade ao uso de neurolépticos. A demência secundária à doença de Parkinson é menos comum (3\% dos casos de demência) e caracteriza-se pela presença de déficit cognitivo que se manifesta cerca de 10 anos após o início dos sintomas parkinsonianos (Goetz et al., 2008). Neuropatologicamente, a demência por corpúsculos de Lewy e a demência secundária à doença de Parkinson caracterizam-se pela presença de corpúsculos de Lewy (Figura 7), que são estruturas imunocoradas com anticorpos contra $\alpha$-sinucleína.

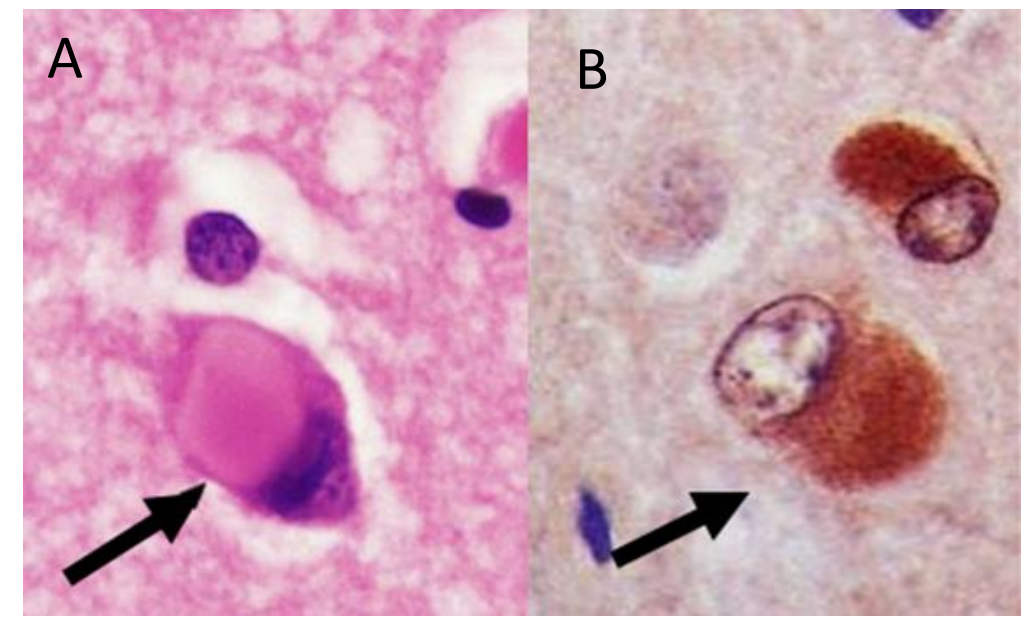

Figura 7. A. Corpúsculo de Lewy corado com hematoxilina e eosina. B. Corpúsculo de Lewy corado com $\alpha$-sinucleína. Aumento 400X. Fonte: BEH-GEEC-FMUSP, 2005 a 2008. 
Introdução

Outra causa de demência inclui a degeneração lobar frontotemporal. Neuropatologicamente, engloba as taupatias, incluindo a doença de Pick, degeneração córtico-basal, paralisia supranuclear progressiva, demência frontotemporal e doença por grãos argirofílicos. Clinicamente, caracteriza-se por alterações de comportamento (demência frontotemporal), de linguagem (afasia progressiva primária e demência semântica) e motoras (degeneração córtico-basal) (Morris, 2005).

\subsection{Interação entre fatores de risco cardiovascular (FRCV) e demência: evidências experimentais}

Atualmente, pesquisas mostram que a doença cerebrovascular (DCV) e a DA, tradicionalmente consideradas entidades clínicas e fisiopatológicas distintas, podem partilhar características comuns. Estudo em modelo animal mostra que o acúmulo do peptídeo $A \beta$ provoca perda neuronal, levando ao processo demencial (Sinha, 2002). Além do seu efeito citotóxico, o peptídeo $A \beta$ parece ter efeito na regulação cerebrovascular (Pike et al., 1991 e Yin et al., 2002). O fluxo sanguíneo basal está reduzido no córtex cerebral e no hipocampo em ratos com expressão aumentada da proteína precursora de amilóide (PPA). Além disso, esses animais são incapazes de manter o fluxo sanguíneo cerebral constante em situações de hipotensão ou hipertensão moderadas. O aumento no fluxo sanguíneo observado em situações de ativação neuronal está atenuado significativamente nesses ratos. Essas alterações ocorrem mesmo na ausência de deposição amilóide no cérebro e nos vasos, bastando a presença de PPA, e estão presentes antes do aparecimento de disfunção cognitiva. A resposta vascular 
Introdução

diminuída limita o suprimento de substratos e oxigênio aos neurônios, resultando em alterações do microambiente cerebral e piorando a disfunção neuronal (Niwa, 2002). Reduções na pressão arterial, que normalmente não alterariam a perfusão cerebral normal, podem levar a isquemia na presença de $\mathrm{A} \beta$. Isquemia relacionada à hipoperfusão é mais marcante na substância branca periventricular, que é uma região irrigada por arteríolas com circulação colateral limitada (Finch, 2005). Além disso, a isquemia cerebral aumenta a expressão de PPA e o acúmulo de A $\beta$, amplificando a citotoxicidade. $O$ peptídeo $A \beta$ promove a liberação de mediadores inflamatórios que pioram o processo após isquemia e contribuem para a disfunção cerebrovascular (Iadecola e Gorelick, 2003).

\subsection{Interação entre FRCV e demência: evidências clínicas}

Evidências do impacto vascular sobre a DA também vêm de estudos clínicos independentes. Resultados dos estudos de coorte de Rotterdam (Breteler et al., 2000), Kungsholmen (Aguero-Torres et al., 2006), EURODEM (Ruitenberg et al., 2005), Framingham (Ivan et al., 2004) e Honolulu-Asia (White and Launer, 2006) apontam vários FRCV relacionados à demência.

FRCV parecem estar ligados à DV e também à DA. HAS, dislipidemia, diabetes mellitus (DM), tabagismo, fibrilação atrial, homocisteinemia estão associados à maior risco de desenvolver demência (Gorelick, 2004). FRCV estão relacionados à atrofia cerebral global, atrofia hipocampal e lesões de substância branca periventricular (Strassburger et al., 1997; Breteler et al., 1994). A presença destas lesões cerebrais e sua extensão estão associadas à aterosclerose sistêmica, como doença coronariana, doença 
Introdução

arterial periférica e espessamento das camadas íntima-média de artérias carótidas (Hofman et al., 1997).

Em estudo longitudinal, com mais de 8.000 indivíduos seguidos por cerca de 30 anos, a presença de tabagismo (HR=1,26, IC 95\% 1,08-1,47), HAS (HR=1,20, IC 95\% 1,04-1,48), dislipidemia (HR=1,42, IC 95\% 1,22-1,66) e DM (HR=1,46, IC 95\% 1,191,79) na meia idade foram fatores de risco associados à demência em idades avançadas. A associação destes fatores conferiu um risco de déficit cognitivo ainda maior. O risco de demência subia de 1,27 nos que apresentavam um fator de risco para 2,37 quando quatro FRCV estavam presentes (Whitmer et al., 2005).

A obesidade está associada a pior desempenho cognitivo, particularmente em obesos com HAS. Obesidade na meia idade é fator de risco para demência e DA em idades avançadas (Kivipelto et al., 2005). Atividade física parece diminuir o risco de declínio cognitivo em idosos e evitar progressão do déficit naqueles com demência (Yaffe et al., 2001; Rovio et al., 2005).

A relação entre tabagismo e demência ainda necessita ser completamente esclarecida, já que estudos que examinaram esta questão apresentaram resultados contraditórios (Swan e Lessov-Schlaggar, 2007). Em meta-análise recente, incluindo mais de 13.000 participantes, tabagistas atuais apresentam maior risco de demência (40\%) e declínio cognitivo (80\%) em relação àqueles que nunca fumaram. Não foi encontrado aumento de risco quando se agruparam os que já fumaram (ex-tabagistas e atuais) em relação a quem nunca fumou. Da mesma forma, não houve diferença estatística entre aqueles que nunca fumaram e os que já fumaram no passado. Neste estudo, não foi possível avaliar a quantidade consumida e sua relação com o risco de demência, assim como a relação entre o tempo de exposição e o desenvolvimento de déficit cognitivo (Anstey et al., 2007). O efeito do álcool na cognição depende da 
Introdução

quantidade usada ao longo da vida. Estudos sugerem que o consumo moderado de álcool (7 a 106 gramas de álcool por semana) pode proteger contra declínio cognitivo, enquanto que o uso abusivo pode levar à demência e AVC (Galanis et al., 2000; Elias et al., 1999).

A prevalência de síndrome metabólica em idosos é de 45\% (Ford et al., 2002). Considera-se portador desta síndrome, portadores de três ou mais dos seguintes critérios: (1) obesidade abdominal (circunferência abdominal $>88 \mathrm{~cm}$ em mulheres e $>102 \mathrm{~cm}$ em homens); (2) hipertrigliceridemia ( $\geq 150 \mathrm{mg} / \mathrm{dL}$ ); (3) HDL-colesterol baixo ( $<40 \mathrm{mg} / \mathrm{dL}$ em homens e $<50 \mathrm{mg} / \mathrm{dL}$ em mulheres); (4) pressão arterial elevada (sistólica $\geq 130 \mathrm{mmHg}$ e diastólica $\geq 85 \mathrm{mmmHg}$ ) ou uso de anti-hipertensivos; (5) glicemia de jejum alta ( $\geq 110 \mathrm{mg} / \mathrm{dL})$ ou uso de medicação hipoglicemiante. Muitos dos critérios definidores de síndrome metabólica também estão associados ao desenvolvimento de demência. HAS, DM, obesidade e dislipidemia são exemplos desta ligação. Três estudos avaliaram o impacto desta síndrome na função cognitiva: Health ABC (Health Aging and Body Composition Study) (Yaffe et al., 2004), SALSA (Sacramento Area Latino Study of Aging) (Yaffe et al., 2007) e LASA (Longitudinal Aging Study Amsterdam) (Dik et al., 2007). Nestes três estudos, envolvendo idosos de diferentes etnias, a síndrome metabólica esteve associada a declínio cognitivo, principalmente nos indivíduos que apresentavam níveis séricos elevados de indicadores de inflamação (proteína $\mathrm{C}$ reativa, interleucina-6 e $\alpha 1$-antitripsina). Além disso, a soma total dos fatores componentes da síndrome metabólica apresentou maior risco para declínio cognitivo do que os fatores de risco considerados isoladamente.

A presença da apolipoproteína Eع4 parece aumentar o risco de DA e também modular o efeito da doença vascular cerebral e a extensão do dano neuronal associado à isquemia, sendo considerada fator de risco para DA esporádica (Mahley et al., 2006). 
Introdução

Apolipoproteína Eع4 está associada à dislipidemia, fato que pode explicar seu efeito sobre as complicações cerebrovasculares. Xu et al. (2004) e Hofman et al. (1997) constataram que a associação entre DA e FRCV é maior na presença da apolipoproteína alelo $\varepsilon 4$. Outros estudos mostram que os riscos dos FRCV e da apolipoproteína alelo $\varepsilon 4$ são independentes (Newman et al., 2005 e Kivipelto et al., 2005).

\subsection{Interação entre doenças cardíacas e demência}

A presença de doenças cardiovasculares está associada à maior incidência de demência em estudos longitudinais. No estudo CHS (Cardiovascular Health Study), o risco de DA foi $30 \%$ maior em indivíduos com história de doença cardiovascular $(\mathrm{HR}=1,3$, IC 95\% 1,0-1,7), principalmente em portadores de doença arterial periférica (HR=2,4, IC95\% 1,4-4,2) (Newman et al., 2005). Em estudo britânico similar, a presença de angina pectoris, infarto do miocárdio e claudicação intermitente esteve associada à pior função cognitiva (Singh-Manoux et al., 2003). Na avaliação de idosos de 85 anos de idade ou mais, pior desempenho em testes cognitivos foi mais freqüente entre os portadores de duas ou mais doenças cardiovasculares (van Exel et al., 2002).

Entre os participantes do estudo de Rotterdam, a presença de fibrilação atrial foi fator de risco para o aparecimento de demência (OR=2,3, IC95\% 1,4-3,7). Este efeito não pode ser explicado apenas pela presença de AVC (Ott et al., 1997). Pacientes com insuficiência cardíaca congestiva grave apresentam mais déficits cognitivos em relação a controles. Acredita-se que sejam devido à hipofluxo sanguíneo cerebral. Estudos de neuroimagem funcional mostram padrões semelhantes de fluxo sanguíneo cerebral em 
Introdução

indivíduos com insuficiência cardíaca congestiva e portadores de DA leve (Ferraz-Alves e Bussatto, 2006).

\subsection{Associação entre os principais FRCV e demência}

\subsubsection{HAS}

Evidências mostram que a presença de HAS ao longo da vida aumenta o risco de desenvolvimento de lesões cerebrais associadas à demência. Em um estudo de coorte, demonstrou-se associação entre o aumento da pressão arterial sistólica e diastólica e a presença de lesões de substância branca periventricular e subcortical (Van Dijk et al., 2004). Estas lesões estão associadas à maior risco de AVC e demência. Neste estudo, indivíduos com HAS não controlada apresentaram maior risco de lesões do que aqueles sem HAS ou com HAS controlada. Dados derivados da coorte de Rotterdam mostram que a presença de HAS foi associada à atrofia hipocampal na ressonância magnética (RM), um marcador potencial de DA (Den Heijer et al., 2005). O estudo EVA (Epidemiology of Vascular Aging) mostrou associação de pressão arterial $\geq 160$ x 95 mmHg e a presença de hiperintensidade de substância branca na RM após 4 anos de seguimento (Dufoil et al., 2001). Esta associação foi mais significativa em indivíduos, que mesmo fazendo uso de anti-hipertensivos, estavam com a pressão arterial não controlada, quando comparados com aqueles com pressão arterial controlada.

Mesmo em idosos não hipertensos, a presença de aumento da pressão arterial induzida por estresse está associada a pior desempenho em testes de memória verbal e função executiva (Waldstein e Katzel, 2005). Outro estudo em indivíduos hipertensos não tratados submetidos a testes neuropsicológicos demonstrou menor fluxo sanguíneo 
Introdução

em área parietal posterior, tálamo e no território de fronteira médio-posterior, demonstrando menor ativação de áreas importantes para o processamento da memória (Jennings et al., 2005).

HAS na meia idade é preditora de déficit cognitivo 25 a 30 anos mais tarde. Kivipelto et al. (2001 e 2002) mostraram que hipertensão sistólica na meia idade está associada à maior prevalência de DA em idades avançadas. Yamada et al. (2003) demonstraram que a cada $10 \mathrm{mmHg}$ de aumento da pressão arterial sistólica na meia idade aumenta a prevalência de DA em idades avançadas em cerca de $3 \%$. No estudo Honolulu-Asia (Freitag et al., 2006), demonstrou-se que os indivíduos que apresentaram pressão arterial sistólica maior que $140 \mathrm{mmHg}$ tinham duas vezes mais chance de demência anos depois, independente de outros fatores demográficos e cardiovasculares. $\mathrm{O}$ risco era maior em indivíduos sem tratamento (HR=2,7, IC95\% 1,5-4,7), do que naqueles que relatavam tratamento prévio ( $\mathrm{HR}=1,8$, IC 95\% 1,2-2,8). A associação entre pressão diastólica maior que $90 \mathrm{mmHg}$ e demência mostra resultados contraditórios. Enquanto Kivipelto et al. (2002) foram incapazes de demonstrar associação, Freitag et al. (2006) encontraram aumento de incidência e prevalência de demência entre homens que não foram tratados para hipertensão diastólica.

Estudos que mostram associação entre HAS e demência têm períodos longos de seguimento (Freitag et al, 2006; Skoog et al., 1996 e Launer et al., 2000), de pelo menos 5 a 10 anos, enquanto os que não mostraram associação apresentam menor tempo de seguimento (Kivipelto et al., 2002; Posner et al., 2002 e Shah et al., 2006). Uma explicação para falta de associação entre HAS e demência em estudos de curta duração, pode ser devido à queda da pressão arterial três a quatro anos antes do diagnóstico de DA. Esta diminuição da pressão arterial pode dificultar a avaliação da importância da 
Introdução

HAS quando a avaliação da exposição é feita poucos anos antes do diagnóstico de demência. No estudo de Kungsholmen, uma diminuição da pressão arterial sistólica maior do que $15 \mathrm{mmHg}$, próxima ao diagnóstico de demência, esteve associada a uma incidência de DA três vezes maior ao longo de três anos de seguimento (Qiu et al., 2004). Skoog et al. (1996) também demonstraram uma diminuição da pressão arterial sistólica ao longo de 15 anos a partir da idade de 70 anos e maior risco de DA entre os 79 a 88 anos de idade. Isto pode ocorrer porque algumas das regiões cerebrais afetadas precocemente na DA (hipotálamo, amígdala, córtex insular, córtex pré-frontal medial, locus ceruleus e ponte) estão envolvidos na regulação central da pressão arterial (Skoog e Gustafson, 2006). Este mecanismo pode explicar a associação inversa entre HAS e DA em hipertensos tratados na coorte de Rotterdam, onde foi encontrado um risco 7\% menor para cada $10 \mathrm{mmHg}$ de aumento na pressão arterial sistólica basal no período de 2,1 anos de seguimento (Ruitenberg et al., 2001).

Resumidamente, HAS na meia idade está associada à maior prevalência de DA em idades avançadas, sendo o risco, particularmente maior em indivíduos sem tratamento. Hipertensão sistólica em idosos tende a representar um maior risco para incidência de DA em mais de cinco anos de seguimento. Queda de pressão arterial parece ocorrer na fase prodrômica da demência.

Além dessas evidências de associação entre HAS e alteração da cognição, foi demonstrado que o tratamento da hipertensão diminui a incidência de déficit cognitivo. O estudo Syst-Eur (Systolic Hypertension in Europe) demonstrou que o tratamento com bloqueador de canal de cálcio de longa duração (nitrendipina) diminuiu a incidência de demência em idosos com hipertensão arterial sistólica. Comparado com o grupo controle, o uso do antihipertensivo diminuiu a incidência de demência em 55\%, de 7,4 para 3,3 casos por 1000 pacientes-ano. Após ajustes para sexo, idade, educação e 
Introdução

pressão arterial inicial, o risco relativo associado ao uso da nitrendipina foi de 0,38 (IC 95\%, 0,23-0,64; $\mathrm{p}<0,001)$. Segundo dados desse estudo, seria necessário tratar 1000 pacientes por cinco anos para prevenir 20 novos casos de demência (Forette et al., 2002).

O estudo SCOPE (Study on Cognition and Prognosis in the Elderly) contou com a participação de 4.964 idosos (idade média de 76,4 anos) que foram randomizados a receber placebo ou bloqueador de receptor da angiotensina II (candersartan). Os resultados confirmaram que o tratamento da HAS em idosos previne novos casos de AVC e demência (Lithell et al., 2003). O estudo PROGRESS (The Perindopril Protection Against Recurrent Stroke Study) demonstrou os benefícios da prevenção secundária em pacientes que já tiveram AVC (Tzourio et al., 2003). O uso de perindopril, um inibidor da enzima de conversão da angiotensina, e o diurético indapamida foram usados em 6.105 pacientes por 3,9 anos. Foi demonstrado diminuição do risco de AVC e outros eventos vasculares. Houve redução de risco de $19 \%$ na presença de declínio cognitivo, quando foram comparados os grupos com e sem tratamento. Demência diminuiu em 12\%, demonstrando os benefícios do tratamento da HAS na prevenção secundária de AVC e demência.

Entretanto, meta-análise recente, realizada por McGuiness et al. (2008), não encontrou benefício significativo no tratamento da HAS em relação à cognição. Reuniu o resultado de três estudos, SHEP (SHEP Cooperative Research Group, 1991), SCOPE (Lithell et al., 2003) e Syst-Eur (Forrette et al., 2002) com a avaliação de mais de 12.000 participantes hipertensos, sem história de doença cerebrovascular prévia. O resultado combinado dos três ensaios clínicos mostrou uma redução no risco relativo de 11\%, porém sem significância estatística. Houve heterogeneidade importante entre os 
Introdução

estudos, devido ao grande número de participantes que perderam seguimento e à grande quantidade de participantes do grupo placebo que receberam tratamento ativo.

Finalmente, em estudo de autópsia, os hipertensos que usaram medicação antihipertensiva tiveram menos lesões neuropatológicas características de DA (placas neuríticas e emaranhados neurofibrilares) do que os hipertensos sem tratamento e do que os normotensos (Hoffman et al., 2009), sugerindo um efeito protetor da medicação contra alterações neuropatológicas de DA.

\subsubsection{Hipertrofia miocárdica como medida de HAS sem controle adequado}

A hipertrofia miocárdica tornou-se mais facilmente analisada após a padronização do ecocardiograma para sua avaliação. A prevalência de fatores de risco associados à hipertrofia ventricular esquerda (HVE) foi estudada em quase 5.000 participantes da coorte de Framingham (Levy et al., 1988). A prevalência de HVE foi de $16 \%$ em homens e $10 \%$ em mulheres. A idade foi fator de risco importante, sendo que $33 \%$ dos homens e $49 \%$ das mulheres com 70 anos ou mais foram acometidos. Houve associação significativa entre pressão arterial sistêmica e HVE, mesmo em medidas de PA menores do que $140 \mathrm{mmHg}$ (Figura 8). Obesidade também esteve relacionada à HVE, em ambos os sexos (Figura 9). 
Introdução

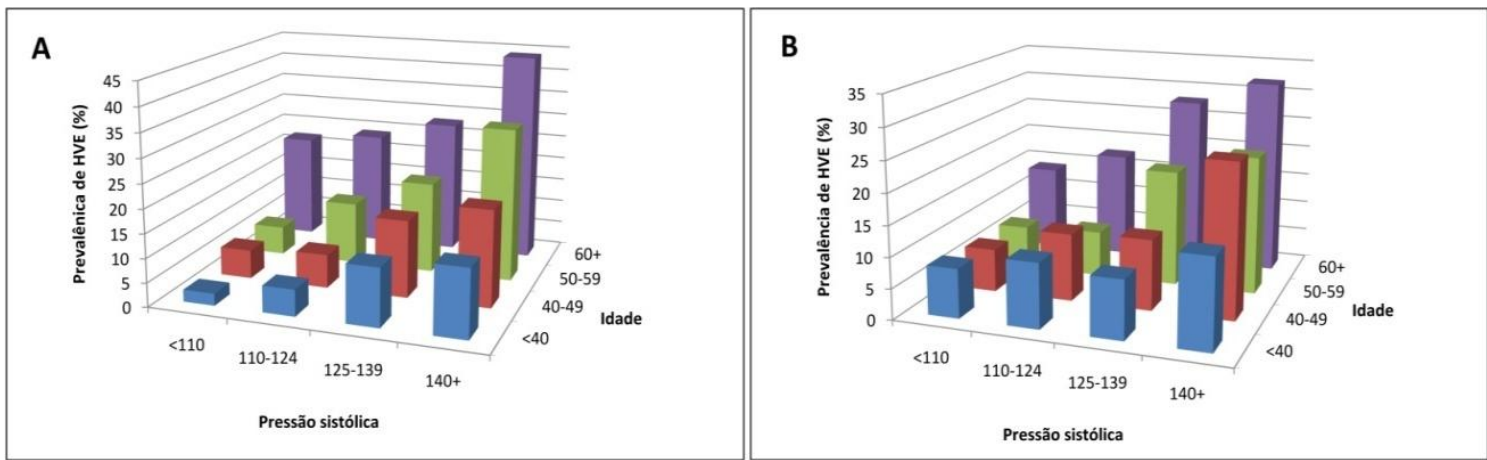

Figura 8. A. Prevalência de hipertrofia ventricular esquerda (\%) de acordo com a pressão arterial sistólica e idade em mulheres. Pressão arterial sistólica em mmHg. B. Prevalência de hipertrofia ventricular esquerda (\%) de acordo com a pressão arterial sistólica e idade em homens. Fonte: Levy et al., 1988
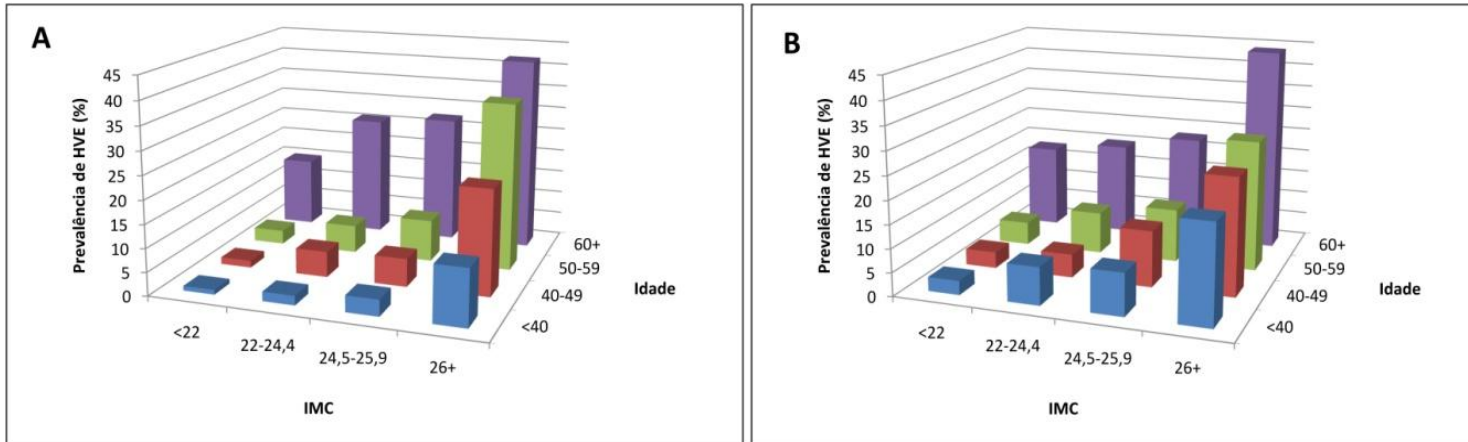

Figura 9. A. Prevalência (\%) de hipertrofia ventricular esquerda de acordo com índice de massa corpórea (IMC) e idade em mulheres. IMC expresso em $\mathrm{kg} / \mathrm{m}^{2}$. B. Prevalência (\%) de hipertrofia ventricular esquerda de acordo com índice de massa corpórea (IMC) e idade em homens. Fonte: Levy et al., 1988

Tanto a duração, como a magnitude da HAS estão inversamente relacionada ao desempenho cognitivo. Entretanto, é difícil estimar com exatidão o início da hipertensão e, portanto sua duração, em estudos epidemiológicos. A hipertrofia miocárdica de ventrículo esquerdo está fortemente associada à HAS de longa data e prediz o risco de hipertensão futura em indivíduos normotensos (Lauer et al., 1991; Devereux et al., 1991). Além disso, a hipertrofia miocárdica tem relação com a incidência de outras doenças cardiovasculares e lesão de órgão-alvo em outros sítios em estudos prospectivos (Levy et al., 1990; Bikkina et al., 1994; Casale et al., 1986; Selvetella et 
Introdução

al., 2003). Estes achados sugerem que a hipertrofia miocárdica de ventrículo esquerdo pode relacionar-se com a função cognitiva de maneira similar à HAS.

Como foi anteriormente descrito, a HAS tem comportamento distinto no decorrer da vida de um indivíduo que irá desenvolver demência. Pode estar elevada durante sua vida adulta e ter uma queda próxima ao período de desenvolvimento do déficit cognitivo. Como a hipertrofia miocárdica pode estar relacionada ao tempo de exposição e à gravidade da HAS e a outros fatores cardiovasculares, pode servir como um marcador da cronicidade e da gravidade da pressão arterial ao longo da vida.

Desta forma, alguns estudos procuraram investigar a associação entre hipertrofia miocárdica e demência. Hipertrofia miocárdica de ventrículo esquerdo medida por ecocardiograma foi inversamente associada ao desempenho cognitivo em indivíduos de meia idade sem demência e história de doença cerebrovascular. Entretanto, após ajuste para a presença de fatores de risco (colesterol total, tabagismo, etilismo, homocisteinemia, diabetes mellitus) e doenças cardiovasculares (doença coronariana, claudicação intermitente e insuficiência cardíaca), esta associação desapareceu, sugerindo a importância destes fatores como mediadores na relação entre hipertrofia miocárdica e cognição (Elias et al., 2007). Em estudo envolvendo idosos maiores de 75 anos de idade, a avaliação inicial demonstrou que indivíduos com déficit cognitivo tinham pressão arterial mais baixa, embora apresentassem mais hipertrofia miocárdica do que aqueles que eram cognitivamente normais. A hipertrofia de ventrículo esquerdo foi preditora de declínio cognitivo durante o seguimento de cinco anos. Entretanto, após seguimento de 10 anos, a associação entre hipertrofia miocárdica e demência foi perdida, sugerindo que embora a hipertrofia miocárdica seja fator de risco para declínio cognitivo, ela perde seu valor preditivo com o avançar da idade (Kähönen-Väre et al., 
Introdução

2004). Em outro estudo, com material de autópsia, Irina et al. (1999) aplicaram um índice cardiovascular que incluía entre outros fatores, o peso do coração. Encontraram associação inversa entre o índice cardiovascular e a presença de placas senis e emaranhados neurofibrilares, sugerindo que quanto maior o peso cardíaco menor a carga de lesões neuropatológicas associadas à DA.

Beeri et al. (2006) não encontraram associação entre peso do coração e DA. Houve correlação negativa entre espessura de ventrículo esquerdo e quantidade de emaranhado neurofibrilares no córtex cerebral, sugerindo que quanto menor o peso cardíaco maior relação com as alterações neuropatológicas da DA. Segundo os autores, este resultado pode ser devido à inclusão de casos com demência avançada e, consequente, perda ponderal acentuada, observada nestes estágios da doença.

\subsubsection{Dislipidemia}

Hipercolesterolemia parece contribuir para a patogênese da síndrome demencial. Experimentos com culturas de células e animais transgênicos mostraram que concentrações aumentadas de colesterol causam uma maior produção de $\beta$-amilóide. Além disso, a depleção de colesterol inibe a formação da mesma proteína in vivo e in vitro (Refolo et al., 2000; Fassbender et al., 2001).

A associação entre a presença de dislipidemia e demência é controversa. Alguns estudos indicam que a presença aumentada de colesterol na meia idade está associada a um risco duas vezes maior de DA em idades avançadas (Pappolla et al., 2003; Whitmer et al., 2005). Esta associação parece ser independente da idade, presença da apolipoproteína Eع4, sexo, nível educacional e outros FRCV. Além disso, o declínio 
Introdução

cognitivo nos pacientes dislipidêmicos parece ocorrer mais rapidamente (Kivipelto et al., 2002). Entretanto, Kalminjin et al. (2000) mostrou que não há associação entre os níveis de colesterol total e triglicérides na meia idade e a prevalência de DA em idades avançadas. Outros dois estudos longitudinais com 2,1 e 5,5 anos de seguimento não mostraram associação entre os níveis de lípides e o risco de DA durante a terceira idade (Moroney et al., 1999; Luchsinger et al., 2005). Em estudo de autópsia, a presença de colesterol elevado esteve associada à presença de placas senis em pacientes com DA (Pappolla et al, 2003).

O uso de hipolipemiantes, particularmente a classe das estatinas, foi avaliado para a prevenção de demência. As estatinas possuem uma série de propriedades in vitro que justificam pesquisas nesta área (DeKosky, 2005). Aumentam o fluxo sanguíneo local através da ação do óxido nítrico, diminuem a adesão plaquetária e, em culturas de neurônios, inibem a formação de $\beta$-amilóide e facilitam sua remoção. Até o presente momento, algumas evidências sugerem que o uso de hipolipemiantes possa reduzir o risco de demência. Entretanto, os dados disponíveis baseiam-se, principalmente, em estudos de caso-controle. Jick et al. (2000) mostraram em um estudo caso-controle derivado de um banco de dados de 368 médicos no Reino Unido, que o risco relativo de demência naqueles que fizeram o uso de estatinas foi de 0,29 (IC 95\% 0,13-0,63). Porém, os dados não foram controlados para possíveis variáveis, como nível educacional, condição sócio-econômica e níveis de colesterol. Outro estudo semelhante mostrou efeito benéfico dos hipolipemiantes mesmo quando associado a FRCV, como HAS e tabagismo (Rockwood et al., 2002). Entretanto, houve benefício apenas em indivíduos menores de 80 anos (OR 0,26, IC 95\% 0,08-0,88). Em estudo transversal com mais de 57 mil participantes, o uso de estatina esteve associado a uma diminuição de risco para DA de 60\% (Wolozin et al., 2000). Alguns estudos sugerem que o 
Introdução

benefício não seja exclusivo da classe das estatinas, mas sim do efeito do controle da dislipidemia. Estudo prospectivo francês com 9.294 idosos mostrou uma diminuição do risco de demência em pacientes em uso de hipolipemiantes, sem benefício adicional para o uso de estatinas (OR=0,61, IC95\% 0,41-0,91) (Dufoil et al., 2005). Outro estudo mostrou resultado semelhante em indivíduos com menos de 80 anos de idade, sem distinção para a classe de medicamentos utilizada no tratamento da dislipidemia e tipo de demência (Rockwood et al., 2004).

Entretanto, alguns trabalhos não encontraram diminuição do risco com o tratamento da dislipidemia. Estudo prospectivo de seguimento de 2.356 idosos não foi capaz de provar efeito protetor das estatinas para a diminuição da incidência de DA (Li et al., 2004). No estudo CHS (Cardiovascular Health Study), o uso de estatina não mostrou benefício na redução do risco de demência em geral, DA, DV e DA associada à DCV (Rea et al., 2005).

Ensaios clínicos que avaliam o impacto do tratamento da dislipidemia na cognição ainda são escassos. Estudos com sinvastatina e pravastatina encontraram efeitos benéficos em eventos cardiovasculares, mas não na cognição. Entretanto, melhora cognitiva fazia parte dos desfechos secundários e há certas ressalvas à qualidade dos instrumentos de avaliação utilizados (Heart Protection Study (HPS) Collaborative Group, 2002; PROSPER Study Group, 2002). Em meta-análise recente, McGuiness et al. (2009), analisando resultados do estudo PROSPER (2002) e HPS (2002), concluíram que não há evidências para indicar o uso das estatinas na prevenção de demência e da DA. Em ensaio clínico, randomizado, controlado por placebo, 44 pacientes com DA leve a moderada foram avaliados quanto ao uso de sinvastatina em altas doses. Houve declínio mais lento no mini-exame do estado mental, mas nenhuma 
Introdução

mudança numa escala cognitiva padronizada e em biomarcadores no líquor (Simons et al., 2002).

\subsubsection{Aterosclerose de artérias carótidas}

A presença de aterosclerose em artérias carótidas está relacionada a lesões cerebrais, como hiperintensidades de substância branca, infartos lacunares e atrofia cortical (Shepherd et al., 2002; Leeuw et al., 2000). A atrofia cortical, por sua vez, está associada ao desenvolvimento de DA, enquanto as hiperintensidades de substância branca e infartos estão relacionados a maior risco de DV e AVC em estudos longitudinais (Manolio et al., 1999). Espessamento da camada íntima e média destas artérias também está ligado à maior risco de lesões cerebrais (Manolio et al., 1999), sendo considerado sinalizador da presença de doença cardiovascular sistêmica (Ali e tal., 2006; Mukherjee e Yadav, 2002). Aumento da espessura da camada íntima-média de artérias carótidas comum e interna está associado a maior risco de DA, principalmente no grupo com maior espessamento da artéria carótida comum $(\mathrm{HR}=1,4$. IC 95\% 1,0-2,0) (Newman et al., 2005).

O estudo norueguês chamado Tromso avaliou 189 indivíduos com estenose carotídea e 201 controles (Mathiesen et al., 2004). Os portadores de lesão aterosclerótica em carótidas apresentaram pior desempenho em testes de atenção, velocidade psicomotora e memória, mesmo sem história prévia de AVC. No grupo com estenose carotídea, foi encontrado maior número de infartos lacunares na RM, o que levou Mathiesen et al. a sugerirem que lesões ateroscleróticas em carótidas são marcadores de aterosclerose em pequenos vasos cerebrais. Jonhston et al. (2004) procuraram correlacionar a presença de estenose carotídea e alterações em testes 
Introdução

cognitivos em 4.000 indivíduos sem história prévia de AVC ou endarterectomia. Estenoses carotídeas maiores que $75 \%$ foram associadas a déficit e declínio cognitivo no decorrer de cinco anos de seguimento, mesmo na ausência de infartos cerebrais na RM.

Hofman et al. (1997) descreve associação entre doença carotídea e demência em estudo transversal. Placas ateroscleróticas e espessamento da parede em artéria carótida comum estiveram associados à maior risco de demência, incluindo DA e DV. As placas carotídeas e o espessamento íntima-média descritos conferiram um risco $80 \%$ e 30\% maior de DA, respectivamente. Para DV, o risco associado a essas placas ateroscleróticas e espessamento foi ainda maior ( $220 \%$ e $90 \%$, respectivamente). A continuação do estudo longitudinal de Rotterdam, realizado com 6.647 participantes, demonstrou persistência da associação entre aterosclerose carotídea e incidência de demência, particularmente DA (Van Oijen et al., 2007). A ligação encontrada entre aterosclerose e demência foi maior no início do estudo, atenuando-se com o transcorrer do mesmo, provavelmente devido ao impacto da aterosclerose na mortalidade. $\mathrm{O}$ espessamento da camada íntima-média aumentou o risco de demência em 50\%, quando comparados os indivíduos no maior grupo de espessamento em relação ao grupo com menor espessamento.

Entretanto, Newman et al. (2005) não encontraram associação entre demência e estenose de artéria carótida no estudo CHS (Cardiovascular Health Study). O espessamento da parede de artéria carótida interna esteve associado a um aumento de $50 \%$ na incidência de demência. 
Introdução

\subsubsection{Aterosclerose do polígono de Willis (PW)}

Evidências ligam a presença de aterosclerose em vasos cerebrais com declínio cognitivo. Em estudos de autópsia, comparando indivíduos com DA e controles, aterosclerose de artérias do PW foi mais freqüente e grave em indivíduos com demência (Roher et al., 2003 e 2004). Foi encontrada correlação entre o índice de estenose das artérias cerebrais e lesões anatomopatológicas sugestivas de DA, tais como emaranhados neurofibrilares, placas neuríticas e rarefação de substância branca. Há também relatos de que a gravidade da aterosclerose está associada à amiloidose vascular, que por sua vez, correlaciona-se com rarefação da substância branca (Kalback et al., 2004). Recentemente, o mesmo grupo de pesquisadores analisou dados de 397 autópsias (92 controles, 215 indivíduos com DA, 30 com DV e 60 portadores de outras demências) (Beach et al., 2007). Aterosclerose do PW foi mais grave em indivíduos com DA e DV do que nos controles, sendo que não houve diferença entre estes e os portadores de outras demências. O grupo com aterosclerose grave apresentou risco de DA $130 \%$ maior em relação ao grupo sem aterosclerose. A maior gravidade da lesão aterosclerótica do PW no grupo com DA também se relacionou à presença maior de lesões neurodegenerativas, como placas neuríticas e emaranhados neurofibrilares. Este achados foram significativos $\mathrm{e}$ independentes da idade, sexo e presença de apolipoproteína Eع4. Outro estudo com dados de autópsia mostrou que aterosclerose cerebral é frequente entre indivíduos com demência (45,5\%), independente da etiologia da síndrome demencial (Fu et al., 2003). Nesta casuística, 32,2\% dos casos apresentaram aterosclerose moderada a grave.

Dados de 1.054 autópsias, sendo 921 casos de DA, mostraram correlação entre aterosclerose do PW, medida qualitativamente, e a presença de placas neuríticas em 
Introdução

cérebros de indivíduos com DA, independente da presença de infartos cerebrais, sexo e idade (Honig et al., 2005).

Roher et al. (2006) compararam as artérias do PW de pacientes com DA com controles por ultrassonografia transcraniana. A artéria carótida interna esquerda e a artéria cerebral posterior esquerda apresentaram associação com o diagnóstico clínico de DA, diferentemente das demais artérias do PW. Em outro estudo usando ultrassonografia transcraniana e volumetria de hipocampo por RM, baixo fluxo sanguíneo cerebral esteve associado à maior incidência de demência e a lesões precursoras de demência, como menor volume de hipocampo e amígdalas, sugerindo que a hipoperfusão cerebral precedeu e, possivelmente, contribuiu para o aparecimento clínico do déficit cognitivo (Ruitenberg et al., 2005).

\subsubsection{Diabetes mellitus}

Pacientes com DM apresentam risco aumentado de cardiopatia isquêmica, semelhante aos indivíduos que já são portadores de doença coronariana (NCEP, 2002). Frequentemente apresentam outros fatores de risco associados, como hipertensão arterial e dislipidemia.

Episódios de hipoglicemia e hiperglicemia estão relacionados à alteração cognitiva (Sheetz e King, 2002). Hipoglicemia leva à neurotoxicidade devido ao fato das células neuronais dependerem de glicose, particularmente na região do hipocampo. Hiperglicemia crônica pode causar disfunção neuronal, através dos produtos finais avançados da glicosilação, levando à formação de $\beta$ amilóide.

Evidências clínicas sugerem a ligação entre DM e demência. Estudos populacionais mostram esta associação, particularmente para DV. A relação entre DA e 
Introdução

DM ainda não está clara (Yaffe et al., 2004; Crooks et al., 2003; Grodstein et al., 2001; MacKnight et al., 2002; Schnaider et al., 2004; Hassing et al., 2002). Em estudo de coorte com 824 religiosos seguidos por nove anos, portadores de DM tiveram um risco de $65 \%$ de desenvolver demência quando comparados a controles (Arvanitakis et al., 2004). Os diabéticos apresentaram comprometimento cognitivo global, incluindo memória episódica, memória semântica, memória de trabalho e habilidades vísuoespaciais. Outro estudo que acompanhou 599 idosos com 85 anos ou mais por cinco anos não encontrou associação entre a presença de DM e o aparecimento de demência. Entretanto, os diabéticos apresentaram pior desempenho em testes de velocidade de processamento e atenção (Van den Berg et al., 2006). Beeri et al. (2004), em um estudo de coorte de longo seguimento, demonstrou que pacientes com DM na meia idade apresentaram um risco significativo de desenvolver demência após 30 anos $(\mathrm{OR}=2,83$, IC 95\%1,4-5,71). O nível de alteração glicêmica também contribui para o risco de declínio cognitivo. Dessa forma, pacientes com intolerância a glicose apresentam risco aumentado em relação a indivíduos normais e, os diabéticos, chance ainda maior do que os dois grupos descritos. Yaffe et al. (2004) demonstraram que os diabéticos têm $79 \%$ mais risco de demência em relação aos controles e os indivíduos com intolerância à glicose, $64 \%$. Além disso, o risco de declínio cognitivo parece ser maior em pacientes com doença de longa data ou em uso de insulina, sinalizando maior tempo de exposição aos efeitos deletérios do DM.

Poucos ensaios clínicos estudaram se os hipoglicemiantes reduzem o risco de demência ou estabilizam a função cognitiva. Há poucas informações disponíveis sobre o tempo de tratamento e o nível de controle glicêmico ideal em relação à cognição (Logroscino et al., 2004; Hewer et al., 2003; Areosa e Grimley et al., 2002), não 
Introdução

permitindo conclusões sobre a eficácia do tratamento na prevenção ou controle dos sintomas cognitivos.

\subsection{Interação entre fatores de risco cardiovascular, doença cardiovascular e demência: importância dos estudos clinicopatológicos}

Na última década, surgiram muitos estudos clínicos associando os FRCV e as doenças cardiovasculares ao maior risco de desenvolver demência, seja ela DV ou DA. Embora, a quantidade de informação existente permita formular hipóteses que associem as alterações vasculares e demência, não existem ainda conclusões definitivas sobre este assunto. Um dos fatores limitantes dos estudos clínicos reside na imprecisão de se definir a causa da demência estudada. Como descrito anteriormente, os critérios clínicos existentes para a classificação nosológica da demência ainda são falhos. Muitos casos classificados clinicamente como DA, apresentam coexistência de lesões vasculares significativas (Fernando e Ince, 2004 e Snowdon et al., 1997). Além disso, a heterogeneidade da DV limita a aplicabilidade dos critérios clínicos estabelecidos para essa forma de demência (Jellinger, 2008). Outro ponto vulnerável dos estudos clínicos reside na definição dos indivíduos considerados cognitivamente normais. É sabido que embora muitos idosos não apresentem sintomas cognitivos, seu parênquima cerebral pode ter grande quantidade de lesões anatomopatológicas características de DA e DV (Price et al., 2009; Chen et al; 2009). O que faz com que estes indivíduos tenham diagnóstico neuropatológico de demência, mas não apresentem déficit cognitivo?

Para responder esta questão, estudos de autópsia podem contribuir para a resolução das imprecisões sobre a classificação nosológica de demência e também para mostrar esta população de pessoas sem sintomas cognitivos, mas portadores de 
Introdução

significativa quantidade de lesões associadas a doenças neurodegenerativas. Entretanto, a maioria dos estudos de autópsia existentes baseia-se principalmente em portadores de demência avançada (Honig et al., 2005) ou limitam-se a populações específicas (membros da Igreja Católica (Schneider et al. 2004), caucasianos (Troncoso e tal., 2008), sexo feminino (Snowdon, 1997), ou portadores de alta escolaridade (Sonnen et al., 2007), limitando a generalização dos resultados encontrados. Estudos de autópsia que possam responder a estas limitações são necessários para o maior entendimento do envelhecimento cerebral normal e patológico. 
2. OBJETIVOS 


\section{Objetivo primário}

- Avaliar a associação entre doença cardiovascular (hipertrofia miocárdica, aterosclerose de artérias carótidas e do polígono de Willis) com demência, definida por critérios clínicos, neuropatológicos e clinicopatológicos.

\section{Objetivos secundários}

- Avaliar o perfil demográfico e fatores de risco cardiovascular da amostra estudada e sua relação com demência, definida por critérios clínicos, neuropatológicos e clinicopatológicos.

- Avaliar se existe associação entre a presença de alterações neuropatológicas sugestivas de doença de Alzheimer (placas neuríticas e emaranhados neurofibrilares) e demência vascular (infarto lacunar e arteriosclerose hialina) com doença cardiovascular comprovada por análise anatomopatológica. 
3.MÉTODOS 


\subsection{Grupo de Estudos em Envelhecimento Cerebral}

O presente trabalho constitui-se num dos projetos do Grupo de Estudos em Envelhecimento Cerebral (GEEC) da Faculdade de Medicina da Universidade de São Paulo (FMUSP) (Grinberg et al., 2006). O GEEC foi criado em 2003 e é composto por um grupo multidisciplinar de pesquisadores (medicina, enfermagem, fisioterapia, biologia). Entre as especialidades médicas, tem participação especial a geriatria, a patologia e neurologia. O GEEC tem como finalidade coletar e estudar um grande número de encéfalos de idosos cognitivamente normais e também de portadores de diversas doenças neurodegenerativas.

Desde 2004, são coletados os encéfalos que compõem o acervo do Banco de Encéfalos Humanos (BEH) do GEEC. Estes são provenientes do Serviço de Verificação de Óbitos da Capital da Universidade de São Paulo (SVOC-USP). O SVOC-USP tem por finalidade esclarecer a causa de óbito por moléstia mal definida ou sem assistência médica, decorridos de morte natural. É responsável pela realização de autópsias de indivíduos que faleceram na região metropolitana da Grande São Paulo. Realiza cerca de 13.000 autópsias anualmente (SVOC-USP, 2008).

Para a realização do presente estudo, foi colhido material cardiovascular (artérias carótidas, PW e coração) de abril de 2005 a dezembro de 2008. O projeto de pesquisa proposto foi aprovado pela Comissão de Ética para Análise de Projetos de Pesquisa do Hospital das Clínicas da FMUSP, sob o número 219/07. 


\subsection{Casuística}

\subsubsection{Seleção dos casos}

No momento em que os familiares se dirigiam ao SVOC-USP para solicitar a liberação do corpo, eles eram convidados a participar do estudo. Obtinha-se, inicialmente, o consentimento dos familiares e, durante o período de espera para que a autópsia fosse executada, era realizada a entrevista para a aquisição das informações referentes ao histórico de saúde do falecido.

Foram eleitos como informantes (familiar, cuidador ou responsável legal) aqueles que tiveram contato próximo com o sujeito a ser estudado por pelo menos seis meses anteriores ao óbito, a fim de que as informações coletadas fossem confiáveis.

\subsubsection{Critérios de inclusão}

- Idade maior que 50 anos na data do óbito

- Consentimento livre e esclarecido assinado pelo informante. Este documento foi aprovado pela Comissão de Ética para Análise de Projetos de Pesquisa do Hospital das Clínicas da FMUSP, sob o número 285/04 (Anexo I).

- Os casos coletados durante o período do estudo que apresentassem material cardiovascular completo, composto por coração, artérias carótidas e PW. 


\subsubsection{Critérios de exclusão}

- Indivíduos que morreram por causas cerebrais primárias (acidente vascular encefálico de origem isquêmica ou hemorrágica, traumatismo craniano, meningite, tumores), devido à necessidade de exame imediato durante a autópsia para preenchimento da declaração de óbito;

- Pacientes submetidos à condições mórbidas que, potencialmente, pudessem causar lesões isquêmicas secundárias como, por exemplo, a encefalopatia anóxica de longa duração;

- Portadores de comorbidades que pudessem, potencialmente, prejudicar a função cognitiva, como aqueles portadores de doenças crônicas em fase avançada (por exemplo, insuficiência cardíaca grave, doença pulmonar obstrutiva crônica grave), no período de seis meses anteriores ao óbito;

- Inexistência de informante capaz de fornecer dados adequados relacionados à história pregressa, antecedentes pessoais e funcionalidade do indivíduo;

- Sujeitos com sinais de acidose devido a estado agônico grave (pH do líquor menor que 6,5), o que tornaria o tecido cerebral incompatível para análises químicas e moleculares (Ravid et al., 1992)

- Incompatibilidade entre as escalas de avaliação cognitiva (CDR- Clinical Dementia Rating/Escore Clínico de Demência e IQCODE - Informant Questionnaire on Cognitive Decline in the Elderly), conforme será descrito no item 2.4;

- Portadores de demência questionável $(\mathrm{CDR}=0,5)$; 


\subsection{Avaliação do perfil demográfico e do perfil de risco cardiovascular}

Enquanto a autópsia era realizada, um membro da equipe do BEH-GEEC abordava o cuidador do indivíduo autopsiado e aplicava um questionário padronizado (Anexo II), após a assinatura do termo de consentimento livre e esclarecido. Foram coletadas informações sobre dados demográficos, perfil de risco cardiovascular, funções cognitivas e capacidade funcional do falecido. Durante a entrevista, outras escalas foram aplicadas aos cuidadores, sendo investigada a presença de sintomas comportamentais, de depressão e de parkinsonismo. Entretanto, estas informações não foram utilizadas neste projeto por não terem relação direta com o tema abordado.

Os dados demográficos colhidos durante a entrevista foram: idade, sexo, raça, estado civil, escolaridade e lateralização (destro ou canhoto). A condição sócioeconômica foi acessada através da classificação criada pela Associação Brasileira de Institutos de Pesquisa de Mercado (ABIPEME), que classifica os indivíduos em cinco diferentes classes sócio-econômicas, sendo a classe social A, aquela com maior poder aquisitivo e a classe E, aquela com menor poder aquisitivo.

A causa de óbito foi obtida no laudo de autópsia do SVOC-USP e, posteriormente, classificada em cinco grupos: cardiovascular, infecciosa, oncológica, outras causas e indefinida.

Para avaliar os FRCV presentes na amostra, foram utilizadas duas fontes de informação: 
1. Menção pelo informante durante a entrevista, de antecedente de HAS, DM, doença arterial coronariana (DAC), insuficiência cardíaca, arritmia, insuficiência arterial periférica, dislipidemia, AVC, sedentarismo, tabagismo e etilismo.

2. Informações obtidas, através do laudo de autópsia, sugestivas de DAC, com intuito de aumentar a acurácia do diagnóstico desta doença, uma vez que a DAC é frequentemente assintomática em idosos. Termos como infarto do miocárdio, miocardiopatia isquêmica, aterosclerose de artérias coronárias definiram a presença de DAC. Da mesma forma, a presença de repercussões observadas durante autópsia sugestivas de insuficiência cardíaca também foi utilizada para o diagnóstico desta síndrome.

\subsection{Avaliação funcional}

A avaliação funcional foi realizada através da aplicação do índice de Katz e da escala IADL (Instrumental Activities of Daily Life). O índice de Katz avalia as atividades básicas de vida diária (ABVD) (Katz et al., 1970): banhar-se, vestir-se, locomover-se, ter continência urinária e fecal e alimentar-se. A pontuação varia de 0 a 6, sendo que os indivíduos totalmente dependentes nestas atividades recebem pontuação 0 e os totalmente independentes têm pontuação 6. Já a escala IADL, desenvolvida por Lawton e Brody, em 1969, foi utilizada para a avaliação de atividades instrumentais de vida diária (AIVD) (Lawton e Brody, 1969): habilidade para o uso do telefone, fazer compras, preparar alimentos, executar tarefas domésticas, lavar roupas, utilizar meios de transporte, cuidar da própria medicação e controlar as finanças. A pontuação varia de 0 a 8, sendo que valores mais elevados sinalizam maior independência para as atividades instrumentais avaliadas. 


\subsection{Avaliação da função cognitiva}

A avaliação das funções cognitivas foi realizada através da aplicação da escala CDR, que foi desenvolvida por Hughes et al. (1982) e adaptada por Morris (1993). É amplamente utilizada em estudos longitudinais e ensaios clínicos para classificar a gravidade dos casos de DA. Trata-se de uma entrevista semi-estruturada feita com o paciente e com um informante. Em nosso estudo, entretanto, foi aplicada apenas no informante. Esta abordagem foi anteriormente realizada em outros estudos com material de autópsia (Haroutunian et al., 1998 e 1999). Esta escala detecta alterações em seis categorias cognitivas diferentes (memória, orientação, julgamento e resolução de problemas, relações comunitárias, lar e passatempos e cuidados pessoais). Através da análise das categorias individuais é estabelecido um escore clínico, que aponta a ausência ou presença de demência e sua gravidade $(\mathrm{CDR} 0=$ sem demência, $\mathrm{CDR}$ 0,5 = demência questionável, CDR 1 = demência leve, CDR 2 = demência moderada, CDR 3 = demência grave). Recentemente, foi publicada a validação da versão em português da escala CDR (Montãno e Ramos, 2005).

Para dar suporte ao diagnóstico de demência utilizou-se a escala IQCODE (Jorm e Jacomb, 1989). Foi desenvolvida visando medir o declínio cognitivo comparado a um nível pré-mórbido. Baseia-se nas informações fornecidas por um informante e compara o estado cognitivo atual do indivíduo avaliado em relação ao apresentado há dez anos. É composta de 26 itens que cobrem aspectos da memória (aquisição de novas informações e recuperação de conhecimentos prévios) e da inteligência (verbal e performance). Para cada um dos itens, o informante deve classificar o desempenho atual do paciente de maneira qualitativa em: "muito melhor", “melhor", "não muito alterado", “um pouco pior" ou "muito pior". 
Métodos

Sobre a melhor nota de corte a se utilizar, Jorm (2004) recomenda o valor de 3,44, devido ao melhor ajuste entre sensibilidade especificidade. No Brasil, foram utilizadas as notas de corte de 3,4 (Nunes et al., 2007) e 3,41 (Bustamante et al., 2001) com boa acurácia em estudos de comunidade, diferenciando os casos de demência daqueles cognitivamente normais. Desta forma, neste estudo, a nota de corte 3,4 foi escolhida para discriminar participantes sem (IQCODE <3,4) e com comprometimento cognitivo (IQCODE $\geq 3,4$ ).

Portanto, para definição clínica de indivíduos sem demência foi necessário CDR igual a 0 e IQCODE menor que 3,4, enquanto para classificá-los como portadores de demência, os indivíduos tinham que apresentar CDR maior ou igual a 1 e IQCODE maior ou igual a 3,4. Em caso de discordância entre os critérios apresentados de CDR e IQCODE, o caso foi excluído. Os portadores de demência questionável $(\mathrm{CDR}=0,5)$ foram excluídos do estudo, devido à dificuldade de classificá-los, considerando os resultados obtidos nas escalas de avaliação cognitiva CDR e IQCODE. A Tabela 1 mostra as escalas utilizadas para as avaliações funcional, cognitiva e sócio-econômica, conforme descritas previamente.

Tabela 1 - Domínios avaliados na entrevista clínica e as respectivas escalas utilizadas. BEH-GEEC-FMUSP, 2005 a 2008

\begin{tabular}{lll}
\hline Domínio & Escala \\
\hline Avaliação sócio-econômica & - ABIPEME (Associação Brasileira de Institutos de \\
& Pesquisa de Mercado) \\
Avaliação funcional & - Índice de Katz (Atividades básicas de vida diária) \\
& - IADL - Instrumental Activities of Daily Life \\
& (Atividades instrumentais de vida diária) & \\
Avaliação cognitiva & - CDR - Clinical Dementia Ratins Scale \\
& - IQCODE - Informant Questionnaire on \\
& Cognitive Decline & \\
\hline
\end{tabular}


Métodos

\subsection{Avaliação cardiovascular}

Durante a realização da autópsia, além do encéfalo que é obtido de rotina para compor o acervo do BEH-GEEC, foram coletados coração, artérias carótidas e do PW. A avaliação cardiovascular foi integralmente realizada pela autora desta tese, de forma independente da avaliação clínica e da avaliação neuropatológica, que será descrita mais adiante.

\subsubsection{Análise do coração}

Os corações foram retirados, lavados em água corrente para eliminar os coágulos e fixados com paraformaldeído 10\%. Posteriormente, os corações foram pesados em balança eletrônica (Automarte ${ }^{\circledR}$ AM 5500) e seu peso expresso em gramas. Com o auxílio de uma régua, mediu-se a parede livre do ventrículo esquerdo a um centímetro abaixo da valva aórtica. Além disso, foi realizada a classificação qualitativa da presença de hipertrofia miocárdica de ventrículo esquerdo. Para tanto, levou-se em consideração o peso do coração, a espessura da parede livre de ventrículo esquerdo, sexo e idade do indivíduo.

\subsubsection{Análise das artérias carótidas}

As artérias carótidas foram dissecadas da base do arco aórtico e armazenadas em álcool 70\%. Posteriormente, injetou-se ágar no interior da luz dos vasos para evitar que os mesmos colabassem (Figura 10). Neste momento, a peça foi colocada em paraformaldeído $10 \%$ por 24 horas para melhor fixação. 


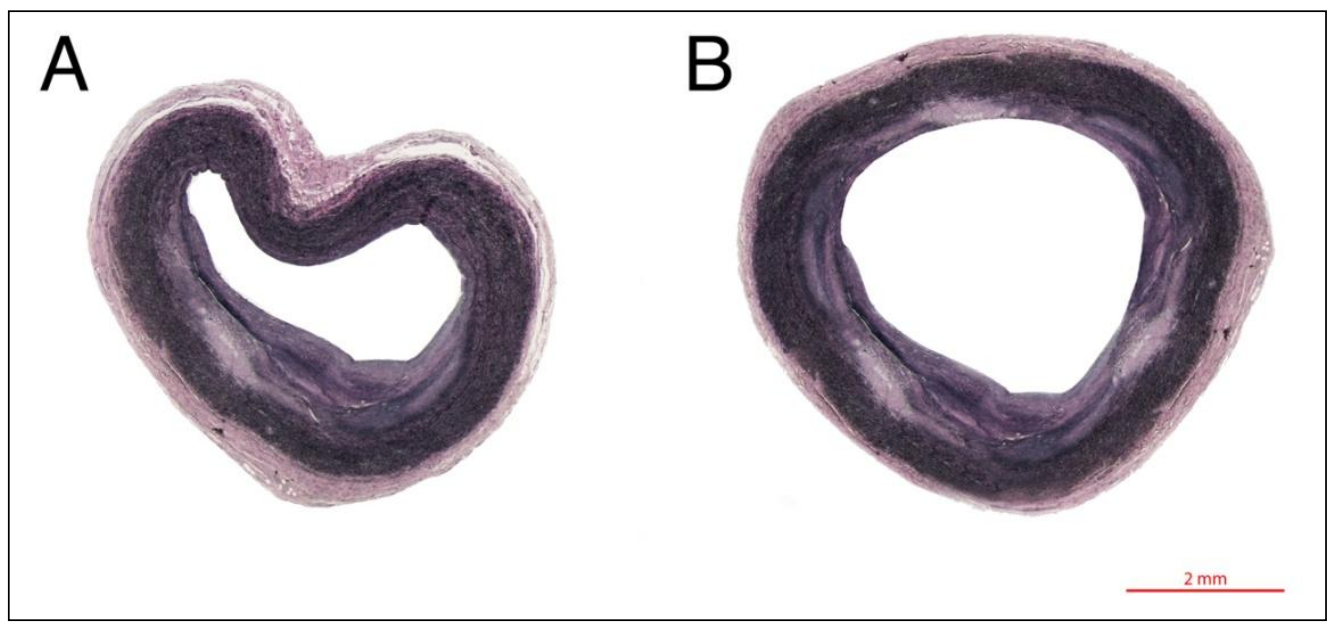

Figura 10. A. Representação histológica de artéria carótida comum sem a injeção de ágar, parcialmente colapsada. B. Representação histológica de artéria carótida comum após a injeção de ágar. Coloração de Verhoeff. Barra de calibração=2 mm. Fonte: BEHGEEC-FMUSP, 2009.

Após esta etapa, com o auxílio de uma lâmina, as artérias carótidas comum e interna foram cortadas transversalmente em intervalos de cerca de $5 \mathrm{~mm}$. Foram representados quatro segmentos de cada lado (direito e esquerdo) do sistema carotídeo (Figura 11A):

1. corte com maior obstrução da luz por aterosclerose da artéria carótida comum;

2. corte da artéria carótida comum a $1 \mathrm{~cm}$ da bifurcação carotídea;

3. corte da artéria carótida interna $1 \mathrm{~cm}$ após a bifurcação carotídea;

4. corte com maior obstrução da luz por aterosclerose da artéria carótida interna; 


\section{Métodos}

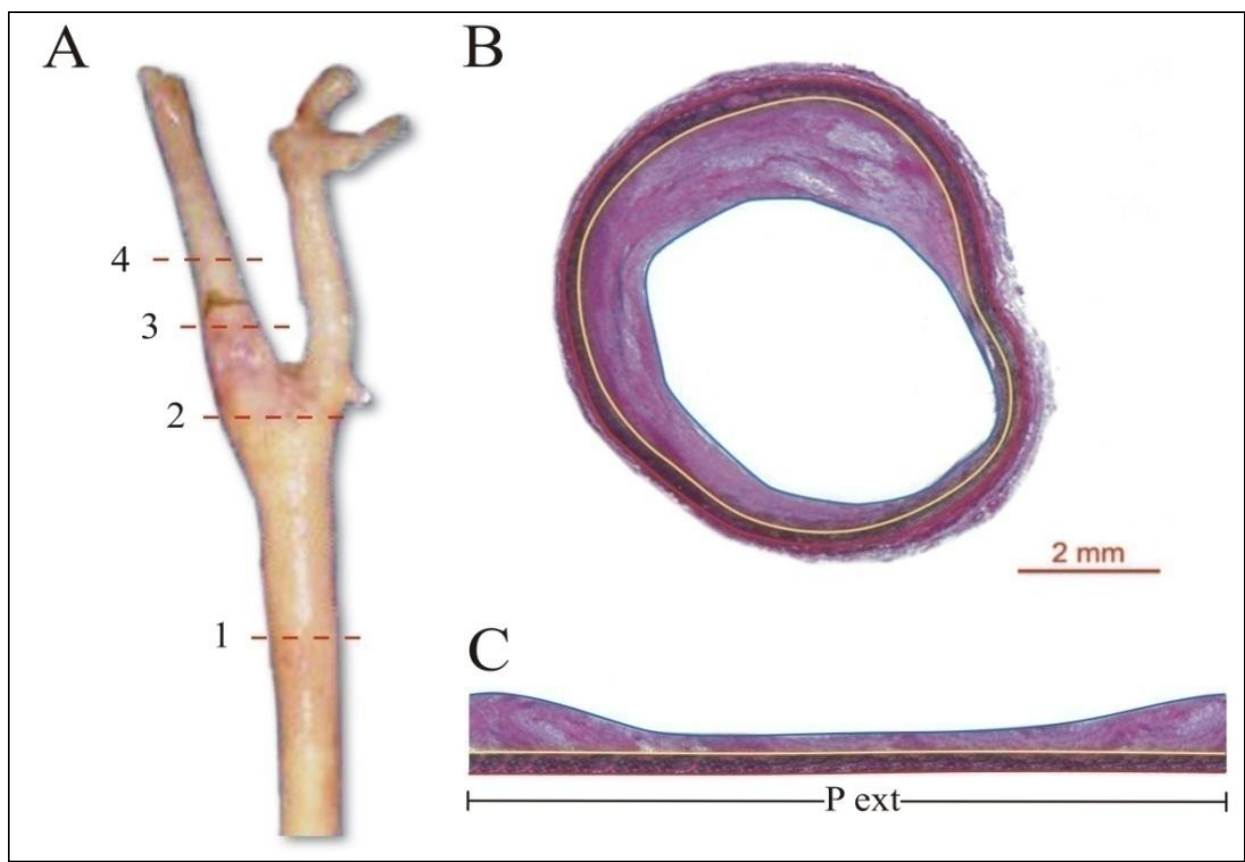

Figura 11. A. Artéria carótida direita e os quatro cortes representados: 1. corte com maior obstrução da luz por aterosclerose da artéria carótida comum; 2. corte da artéria carótida comum a $1 \mathrm{~cm}$ da bifurcação carotídea; 3. corte da artéria carótida interna $1 \mathrm{~cm}$ após bifurcação; 4. corte com maior obstrução da luz por aterosclerose da artéria carótida interna; B. Representação histológica da artéria carótida comum (coloração de Verhoeff). Vermelho: lâmina limitante elástica externa; amarelo: lâmina limitante elástica interna; azul: lúmen. C: Representação da artéria carótida comum (B) após ser aberta. Para o cálculo da espessura íntima-média, foi utilizado a área íntima-média, compreendida entre as linhas vermelha e amarela, e o perímetro delimitado pela lâmina elástica externa (vermelho). Pext=perímetro da lâmina elástica interna. Barra de calibração=2 mm. Fonte: BEH-GEEC-FMUSP, 2009.

Foram feitas lâminas histológicas de cada um dos oito cortes representados, com a utilização da coloração de Verhoeff. Cada lâmina foi fotografada com o auxílio de um estereomicroscópio (Nikon ${ }^{\circledR}$ SMZ 1000). Posteriormente, foram medidas a área do lúmen e a área delimitada pela lâmina elástica interna com o uso do analisador de imagens Image $\mathrm{J} \circledast$ (Abramoff et al., 2004) (Figura 11B). Para cada segmento representado foi calculada a porcentagem de obstrução arterial, que corresponde a placa de ateroma localizada na camada íntima, de acordo com a fórmula: 
Porcentagem de obstrução arterial = Área interna à LEI - área do lúmen x 100 Área interna à LEI

Outra medida de interesse envolvendo as artérias carótidas foi o cálculo do espessamento íntima-média (EIM). Optou-se por realizar esta medida nos cortes realizados na artéria carótida comum à $1 \mathrm{~cm}$ da bifurcação carotídea e na artéria carótida interna $1 \mathrm{~cm}$ após a mesma bifurcação. Estas localizações coincidem com estudos clínicos que realizaram a medida do EIM, utilizando ultrassonografia (Fathi e Marwick, 2001) e, portanto, os mesmos locais foram escolhidos para facilitar futuras comparações. Para o cálculo do EIM foram utilizados os seguintes dados: a) área da camada média e da íntima, definida como a área interna à lâmina elástica externa até o limite interno do vaso; b) área do lúmen; c) perímetro da camada média, delimitado pela lâmina elástica externa (Figura 11C). O EIM, em milímetros, foi calculado de acordo com a fórmula descrita a seguir:

Espessamento íntima-média $(\mathrm{mm})=\underline{\text { (Área da média }+ \text { área da íntima }) \text { - área do lúmen }}$ Perímetro da média

\subsubsection{Análise das artérias do PW}

O PW foi removido da base do encéfalo, lavado em água corrente para retirada de coágulos e conservado em álcool etílico $70 \%$ até o momento do processamento. Similarmente ao protocolo adotado para as artérias carótidas, injetou-se ágar no interior dos vasos para evitar o colabamento arterial (Figura 12). O material ficava 24 horas no paraformaldeído $10 \%$ para fixação. 
Métodos

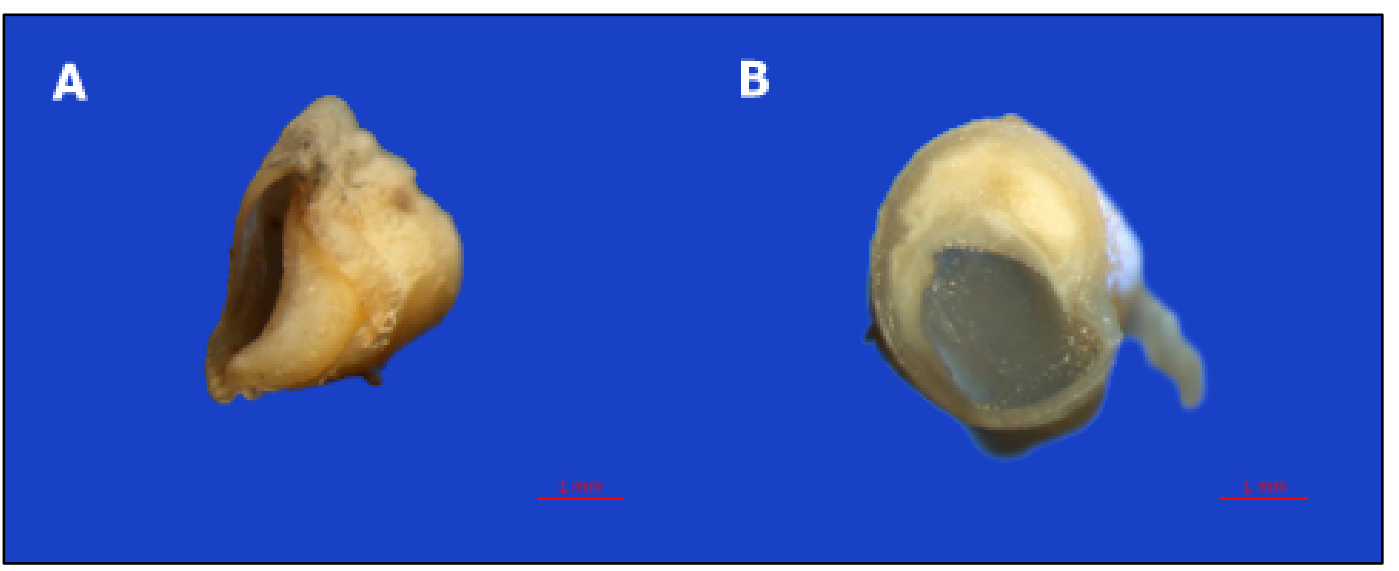

Figura 12. A. Corte transversal de artéria cerebral posterior sem a injeção de ágar, parcialmente colapsada. B. Corte transversal de artéria cerebral posterior após a injeção de ágar. Barra de calibração=1 mm. Fonte: BEH-GEEC-FMUSP, 2009.

Após esta etapa, cortes transversais de cerca de três milímetros foram realizados nas seguintes artérias do polígono: artérias cerebrais anteriores, artéria comunicante anterior, artérias cerebrais médias, artérias carótidas internas (segmento destas artérias junto ao PW), artérias comunicantes posteriores, artérias cerebrais posteriores e artéria basilar (Figura 13). O segmento com maior obstrução da luz de cada artéria foi fotografado com o auxílio do estereomicróscopio (Nikon ${ }^{\circledR}$ SMZ 1000). 
Métodos

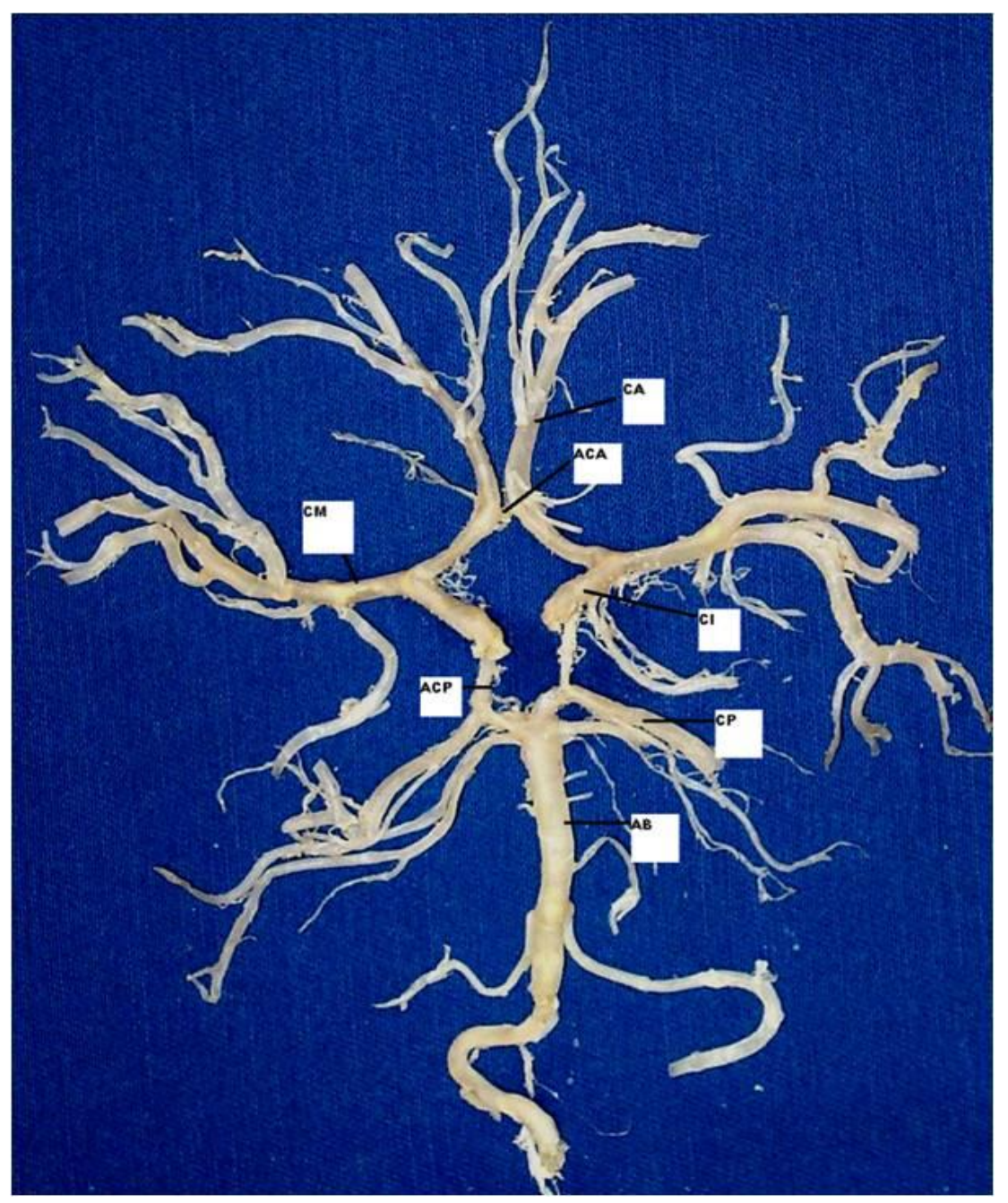

Figura 11. Polígono de Willis. $\mathrm{CA}=$ artéria cerebral anterior, $\mathrm{ACA}=$ artéria comunicante anterior, $\mathrm{CM}=$ artéria cerebral média, $\mathrm{CI}=$ artéria carótida interna, $\mathrm{ACP}=$ artéria comunicante posterior, $\mathrm{CP}=$ artéria cerebral posterior; $\mathrm{AB}=$ artéria basilar. Fonte: $\mathrm{BEH}$ GEEC-FMUSP, 2009

Segundo descrito por Roher et al. (2003), diretamente no segmento arterial cortado transversalmente foram medidas a área delimitada pela parede externa do vaso e a área do lúmen, com o uso do processador de imagens Image J® (Figura 14). A porcentagem de obstrução arterial foi calculada através da fórmula:

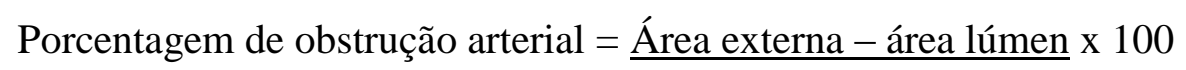
Área externa 
Métodos

Além da porcentagem de obstrução arterial, para cada caso, foi contado o número de artérias do PW com placas de ateroma, representando a extensão da doença aterosclerótica. Outra medida utilizada foi a contagem do número de artérias em cada PW, com obstrução arterial maior do que $50 \%$, a fim de mostrar os casos com aterosclerose grave e difusa.

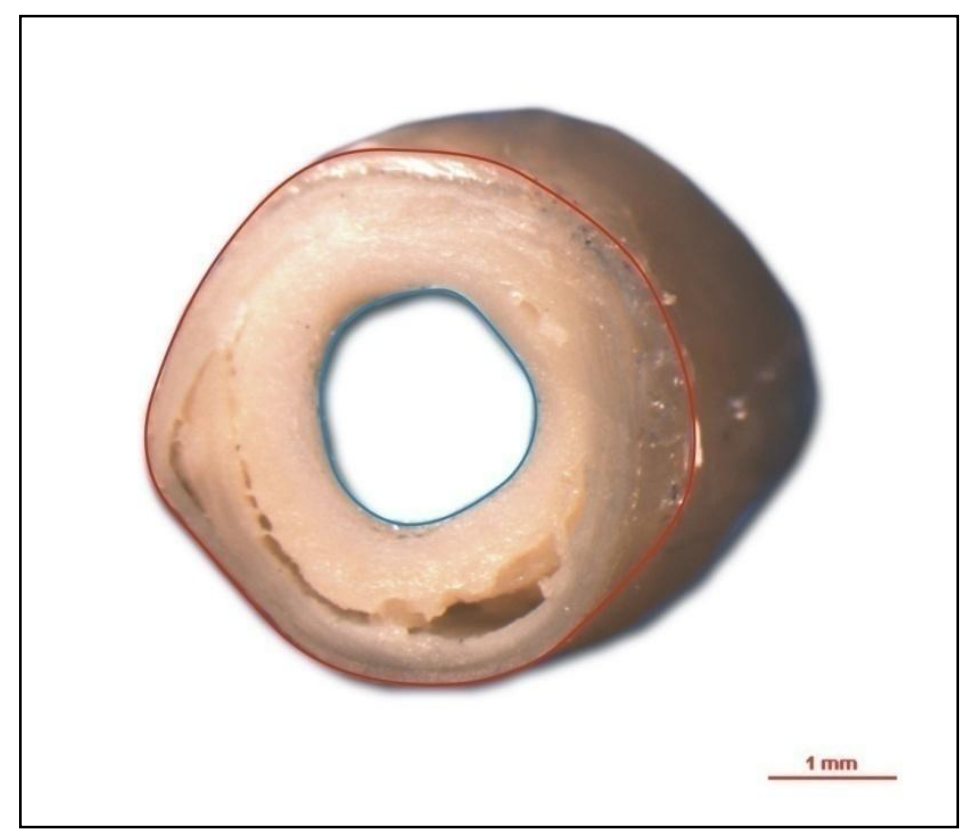

Figura 14. Corte transversal de artéria basilar, componente do polígono de Willis. Linha vermelha delimita a área interna à parede externa do vaso e a linha azul, a área do lúmen. Observação macroscópica. Barra de calibração=1mm. Fonte: BEH-GEECFMUSP, 2009.

\subsection{Avaliação neuropatológica}

Num subgrupo da amostra, além da avaliação clínica e cardiovascular, foi realizado um estudo neuropatológico. Este estudo foi executado segundo critérios aceitos internacionalmente para o diagnóstico de doenças neurodegenerativas associadas 
ao envelhecimento (Grinberg et al., 2007). Os cérebros foram retirados, medidos (peso e volume) e fixados em paraformaldeído tamponado a 4\% por 14 a 21 dias. Após esta etapa, 13 áreas cerebrais foram representadas e incluídas em parafina:

- Giro frontal superior e médio

- Giro parietal superior e inferior

- Giro temporal superior e médio

- Giro do cíngulo anterior

- Lobo occipital

- Hipocampo, no nível do corpo geniculado lateral (córtex entorrinal)

- Amígdala

- Tálamo

- Gânglios da base, incluindo o núcleo basal de Meynert, na altura da comissura anterior

- Mesencéfalo, incluindo a substância negra

- Ponte, incluindo locus ceruleus

- Bulbo

- Cerebelo

Todos os blocos de parafina foram seccionados com espessura de oito micrometros e corados com hematoxilina e eosina. Imunoistoquímica de rotina foi realizada em áreas selecionadas (Tabela 2), utilizando anticorpos contra as seguintes proteínas: $\beta$-amilóide, tau fosforilada e $\alpha$-sinucleína (Tabela 3). Quando houve suspeita de alterações em áreas relacionadas às demências frontotemporais (perda neuronal, gliose e vacuolização da camada cortical II), imunocolorações adicionais com ubiquitina foram realizadas nestes cortes. 
Métodos

Tabela 2 - Protocolo de imunoistoquímica utilizado, mostrando as áreas cerebrais analisadas e os respectivos anticorpos utilizados. BEH-GEEC-FMUSP, 2005 a 2008

\begin{tabular}{lccc}
\hline Área cerebral & $\boldsymbol{B}$-amilóide & Tau fosforilada & $\boldsymbol{\alpha}$-sinucleína \\
\hline Giro frontal superior e médio & $\mathrm{X}$ & $\mathrm{X}$ & \\
Giro parietal superior e inferior & $\mathrm{X}$ & $\mathrm{X}$ & \\
Giro temporal superior e médio & $\mathrm{X}$ & $\mathrm{X}$ & $\mathrm{X}$ \\
Giro do cíngulo anterior & $\mathrm{X}$ & $\mathrm{X}$ & $\mathrm{X}$ \\
Lobo occipital & $\mathrm{X}$ & $\mathrm{X}$ & $\mathrm{X}$ \\
Hipocampo & $\mathrm{X}$ & $\mathrm{X}$ & $\mathrm{X}$ \\
Amígdala & $\mathrm{X}$ & $\mathrm{X}$ & $\mathrm{X}$ \\
Tálamo & $\mathrm{X}$ & $\mathrm{X}$ & \\
Gânglios da base & & $\mathrm{X}$ & $\mathrm{X}$ \\
Mesencéfalo & & $\mathrm{X}$ & $\mathrm{X}$ \\
Ponte & & $\mathrm{X}$ & $\mathrm{X}$ \\
Bulbo & & $\mathrm{X}$ & $\mathrm{X}$ \\
Cerebelo & $\mathrm{X}$ & & \\
\hline
\end{tabular}

Tabela 3 - Método imunoistoquímico utilizado. BEH-GEEC-FMUSP, 2005 a 2008

\begin{tabular}{|c|c|c|c|c|c|}
\hline Proteína & $\begin{array}{l}\text { Alteração } \\
\text { cerebral }\end{array}$ & Anticorpo & Fonte & Diluição & $\begin{array}{l}\text { Sistema de } \\
\text { detecção }\end{array}$ \\
\hline B-amilóide & $\begin{array}{l}\text { Placas } \\
\text { neuríticas }\end{array}$ & $4 \mathrm{G} 8$ & $\begin{array}{l}\text { Signet } \\
\text { Pathology } \\
\text { System }\end{array}$ & $1: 5000$ & $\begin{array}{l}\text { Avidina- } \\
\text { biotina }\end{array}$ \\
\hline $\begin{array}{l}\text { Tau } \\
\text { fosforilada }\end{array}$ & $\begin{array}{l}\text { Emaranhados } \\
\text { neurofibrilares }\end{array}$ & PHF-1 & $\begin{array}{l}\text { Cedido por } \\
\text { Peter Davies }\end{array}$ & 1: 1000 & $\begin{array}{l}\text { Avidina- } \\
\text { biotina }\end{array}$ \\
\hline$\alpha$-sinucleína & $\begin{array}{l}\text { Corpúsculos } \\
\text { de Lewy }\end{array}$ & EQV-1 & Chemicon & $1: 1000$ & $\begin{array}{l}\text { Avidina- } \\
\text { biotina }\end{array}$ \\
\hline Ubiquitina & $\begin{array}{l}\text { Inclusões com } \\
\text { ubiquitina }\end{array}$ & $\begin{array}{l}\text { Anti- } \\
\text { ubiquitina }\end{array}$ & DAKO & $1: 500$ & $\begin{array}{l}\text { Avidina- } \\
\text { biotina }\end{array}$ \\
\hline
\end{tabular}

A avaliação neuropatológica foi realizada pelas patologistas do BEH-GEECFMUSP, de forma cega quanto aos resultados das análises clínicas e cardiovasculares anteriormente descritas. 
Métodos

\subsubsection{Diagnóstico neuropatológico das doenças neurodegenerativas}

\subsubsection{Doença de Alzheimer}

Como o diagnóstico neuropatológico de DA baseia-se na detecção e quantificação de placas neuríticas e emaranhados neurofibrilares, utilizou-se as seguintes classificações:

1. CERAD (Consortium to Establish a Registry for Alzheimer's Disease), descrita por Mirra et al. (1991), que consiste num método semiquantitativo para caracterização do número de placas neuríticas:

- CERAD 0 - ausência de placas neuríticas no tecido cerebral analisado;

- CERAD A - leve (1-5 placas neuríticas por campo, aumento 100X)

- CERAD B - moderado (6-15 placas neuríticas por campo, aumento 100X)

- CERAD C - freqüente (>15 placas neuríticas por campo, aumento 100X)

2. Classificação dos emaranhados neurofibrilares quanto à quantidade e distribuição, segundo os critérios de Braak e Braak (1991), em seis estágios:

I - número reduzido de emaranhados neurofibrilares restritos ao córtex transentorrinal;

II - moderado número de emaranhados neurofibrilares no córtex transentorrinal e poucos no hipocampo;

III - emaranhados neurofibrilares freqüentes no córtex transentorrinal e moderado no hipocampo;

IV - acometimento grave do hipocampo e discreto no isocórtex temporal;

V - emaranhados neurofibrilares no isocórtex temporal, frontal e parietal; 
Métodos

VI - emaranhados neurofibrilares no córtex sensorial primário ou em neurônios piramidais da fáscia dentata no hipocampo.

Neste estudo, foram classificados como portadores de DA através de critério neuropatológico, os portadores de CERAD B ou C e estágio de Braak e Braak $\geq$ IV, baseado no consenso do National Insitute of Aging - Reagan Institute (1997), que associa as classificações do CERAD e de Braak e Braak para o diagnóstico de DA, sendo critério amplamente utilizado para este fim. Classifica a probabilidade de DA em:

- Baixa probabilidade para DA - CERAD A e Braak e Braak estágio I ou II;

- Moderada probabilidade para DA - CERAD B e Braak e Braak estágio III ou IV;

- Alta probabilidade para DA - CERAD C e Braak e Braak estágio V ou VI.

\subsubsection{Demência vascular}

Foram utilizados os critérios adotados pelo BEH-GEEC-FMUSP para diagnosticar DV do ponto de vista neuropatológico. Esses critérios são definidos pela presença de:

1. Infarto lacunar em área estratégica como tálamo, hipocampo ou gânglios da base ou;

2. Alterações microvasculares, tais como arterioloesclerose hialina, infarto lacunar e angiopatia amilóide, em pelo menos três regiões corticais diferentes. 


\subsubsection{Outras demências}

O diagnóstico de demência por corpúsculos de Lewy foi feito de acordo com os critérios descritos por McKeith (2006) e o diagnóstico de demência secundária à doença de Parkinson, segundo descrito por Braak et al (2004). As taupatias, incluindo a degeneração lobar frontotemporal (Cairns et al., 2007) e a doença com grãos argirofílicos (Saito et al., 2004) foram classificadas de acordo com os critérios amplamente aceitos. Entretanto, as sinucleopatias, a degeneração lobar frontotemporal e a doença com grãos argirofílicos foram denominadas "outras demências" e excluídas das análises deste estudo, por representarem um grupo pequeno e que, até o momento, não apresentam evidência de estarem relacionados aos FRCV.

\subsection{Tipo de estudo}

Trata-se de estudo observacional e transversal em material de autópsia.

\subsection{Determinação dos grupos de estudo de acordo com critérios clínicos e neuropatológicos}

Os participantes do estudo foram agrupados de acordo com três critérios: clínico, neuropatológico e clinicopatológico. Foram estudadas as diferenças entre os grupos quanto à presença de FRCV e doença cardiovascular (hipertrofia miocárdica, aterosclerose carotídea e do PW). 
Métodos

\subsubsection{Critério clínico}

Como mencionado anteriormente, os indivíduos foram classificados em dois grupos de acordo com a escala CDR e IQCODE.

- Indivíduos sem demência: $\mathrm{CDR}=0$ e IQCODE <3,4;

- Indivíduos com demência: $\mathrm{CDR} \geq 1$ e IQCODE $\geq 3,4$.

Os portadores de demência questionável $(\mathrm{CDR}=0,5)$ foram excluídos do estudo, como anteriormente descrito.

\subsubsection{Critério neuropatológico}

Os participantes foram avaliados quanto à presença de doença cerebral e classificados em três grupos:

- Grupo controle: indivíduos com exame neuropatológico sem evidências de doença cerebral associada ao diagnóstico de demência

- Portadores de DA

- Portadores de DV

Os indivíduos que apresentaram diagnóstico neuropatológico compatível tanto com DA como com DV, foram incluídos no grupo de DV. Isto foi feito para assegurar que o grupo DA estivesse livre de lesões cerebrais vasculares que pudessem contribuir para o diagnóstico neuropatológico de doença cerebral.

Os portadores de outras demências foram excluídos da análise deste estudo neuropatológico, como informado anteriormente. 
Métodos

As lesões neuropatológicas sugestivas de DA (emaranhados neurofibrilares e placas neuríticas) foram correlacionadas às variáveis quantitativas medidas no coração, nas artérias carótidas e nas artérias do PW. Foi pesquisada a associação de lesões vasculares cerebrais (infarto lacunar, arterioloesclerose hialina e angiopatia amilóide) com as medidas de doença cardiovascular em coração, artérias carótidas e cerebrais.

\subsubsection{Critério clinicopatológico}

Os indivíduos foram classificados em três grupos quando foram agrupados os critérios clínico e neuropatológico:

- Sem demência: $\mathrm{CDR}=0$, IQCODE<3,4 e sem diagnóstico anatomopatológico de doença cerebral;

- Doença cerebral assintomática: $\mathrm{CDR}=0$, IQCODE $<3,4$ e com diagnóstico anatomopatológico de doença cerebral (DA ou DV);

- Demência: $\mathrm{CDR} \geq 1$, IQCODE $\geq 3,4$ e com diagnóstico anatomopatológico de doença cerebral (DA ou DV).

\subsection{Análise estatística}

No estudo clínico, a presença de demência definida por critérios clínicos foi considerada a variável desfecho. Para o estudo neuropatológico, a presença de DA e DV foram as variáveis de desfecho. No estudo clinicopatológico, as variáveis de desfecho foram doença cerebral assintomática e demência. As variáveis de exposição avaliadas foram: dados demográficos (idade, sexo, raça, estado civil, lateralização, causa de óbito e classe social); FRCV (HAS, DM, DAC, insuficiência cardíaca, arritmia, insuficiência 
arterial periférica, dislipidemia, AVC, sedentarismo, tabagismo, etilismo e IMC); variáveis cardíacas (peso cardíaco, espessura miocárdica e hipertrofia miocárdica), variáveis carotídeas (porcentagem de obstrução da luz por aterosclerose e EIM de artérias carótidas); variáveis relacionadas ao PW (porcentagem de obstrução da luz por aterosclerose, número de artérias com ateroma por $\mathrm{PW}$ e número de artérias com obstrução $>50 \%$ por $\mathrm{PW})$.

Primeiramente, uma análise descritiva das variáveis analisadas foi realizada para a caracterização da amostra. Na análise univariada, o teste de Qui-quadrado foi utilizado para variáveis categóricas, sendo que o teste exato de Fisher foi usado quando necessário. Para as variáveis contínuas, os dados foram examinados para verificar pressupostos de normalidade, utilizando o teste de Kolgomorov-Smirnov. Como esta suposição foi rejeitada na grande maioria dos casos, optou-se por utilizar teste nãoparamétrico de Kruskall-Wallis nos casos de comparação entre três grupos independentes e o teste de Mann-Whitney para a comparação entre dois grupos independentes. Testes de correlações bivariadas de Spearman foram utilizados para investigar as associações entre variáveis ordinais (como por exemplo, as escalas de Braak e Braak e CERAD) com as variáveis contínuas cardiovasculares. As associações significantes encontradas na análise univariada foram testadas em modelo de regressão logística para investigar os efeitos de possíveis variáveis de confusão. Para a construção do modelo de regressão logística, optou-se por incluir as variáveis demográficas e FRCV que mostraram associação estatística significante com a variável de desfecho através do método stepwise forward. Este consiste na introdução progressiva de variáveis no modelo, iniciando pela variável de maior significância estatística. Em relação às variáveis cardíacas, carotídeas e relacionadas ao PW, optou-se por ajustar os 
Métodos

resultados significantes na análise univariada por possíveis fatores de confusão conhecidos, tais como idade, sexo e escolaridade. Foram mantidas no modelo final as variáveis com $\mathrm{p}<0,05$ de acordo com o teste da verossimilhança, comparando os modelos com e sem a variável estudada. Os programas SPSS versão 14.0 (Statistical Package for the Social Sciences, Inc., Chicago, IL) e STATA 10.0 (Stata Corporation, 2007) foram utilizados para realizar as análises. 
4. RESULTADOS 


\subsection{Casuística}

De abril de 2005 a dezembro de 2008, foram coletados órgãos de 1054 indivíduos. Destes casos, foi possível obter 1037 corações, 743 pares de artérias carótidas e 910 PW. Foi obtido material cardiovascular completo (coração, artérias carótidas e PW) de 649 indivíduos, representando 61,6\% da amostra inicial. A distribuição da coleta destes órgãos durante o período citado pode ser vista na figura 15 .

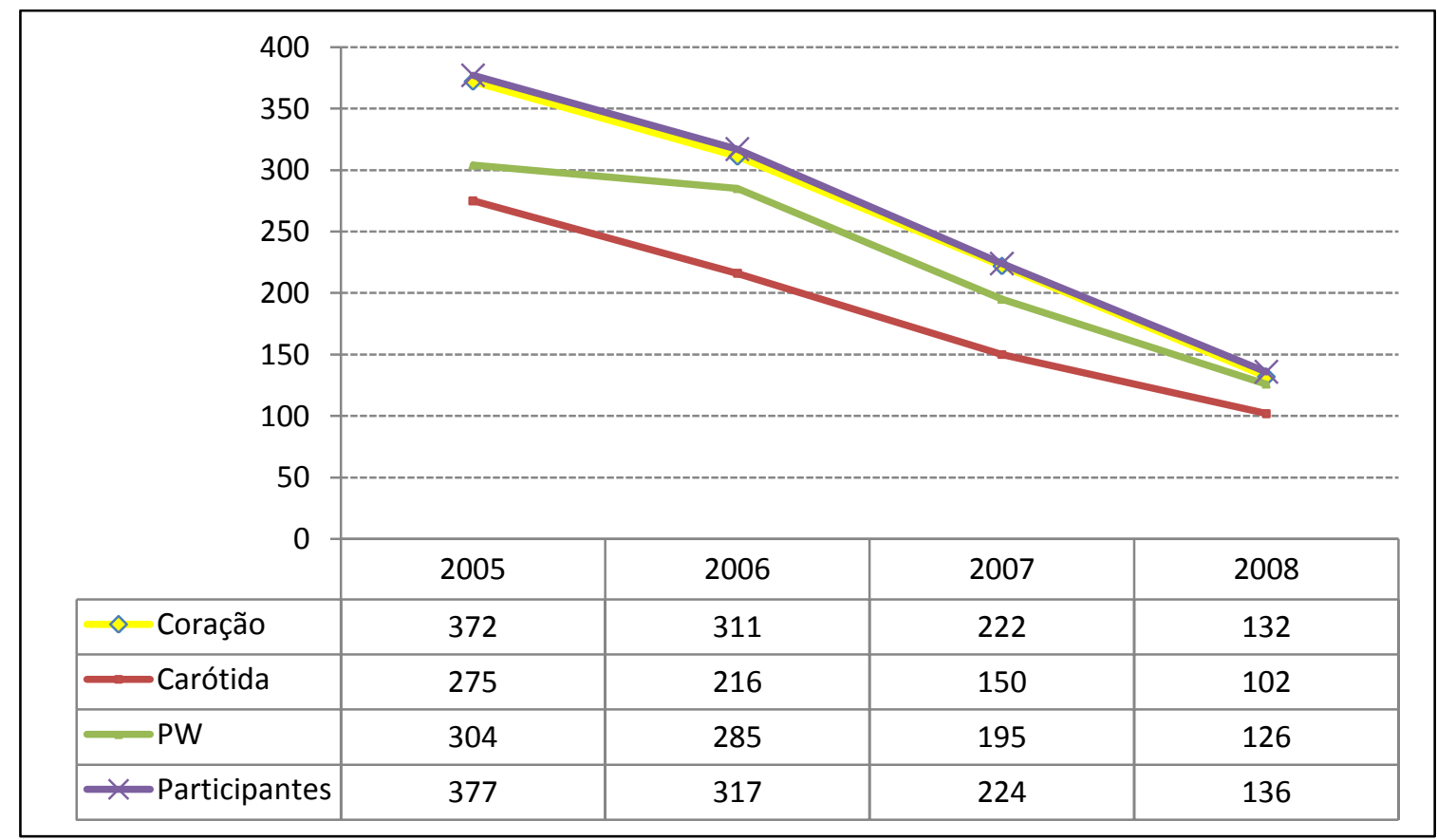

Figura 15. Números de participantes (total), corações, artérias carótidas e PW coletados durante o período de 2005 a 2008.

Conforme descrito no capítulo Métodos, foram excluídos os casos em que ocorreu incompatibilidade entre as duas escalas de avaliação cognitiva (CDR e IQCODE). Também foram excluídos os portadores de demência questionável (CDR = 0,5), resultando no fluxograma mostrado na figura 16. 
Resultados

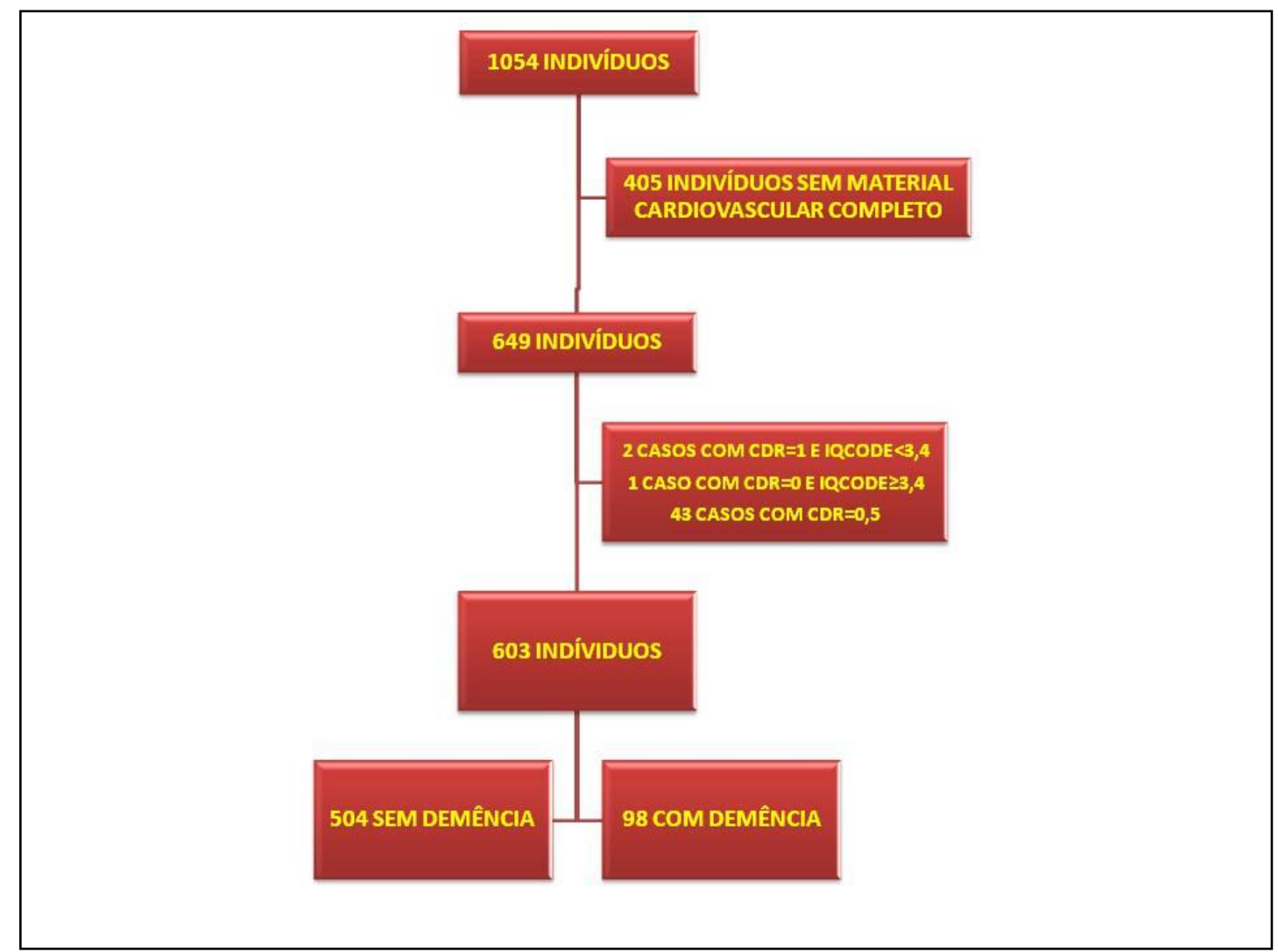

Figura 16. Fluxograma dos participantes do estudo clínico.

Foram comparados os alguns dados dos 603 indivíduos do estudo clínico com os dos outros 451 indivíduos que foram excluídos do estudo (405 indivíduos sem material cardiovascular completo e 46 pessoas com critérios de exclusão). A comparação entre estes dois grupos pode ser vista na tabela 4.

Sobre a confiabilidade dos dados fornecidos durante a entrevista clínica, é importante salientar que $78,6 \%$ dos informantes conviviam diariamente com o indivíduo falecido, sendo a maioria deles cônjuge ou filho do mesmo $(77,5 \%)$. 
Resultados

Tabela 4 - Comparação entre os indivíduos incluídos e excluídos do estudo clínico em relação a variáveis demográficas. BEH-GEEC-FMUSP, 2005 a 2008

\begin{tabular}{lll}
\hline Variável & Incluídos & Excluídos \\
\hline $\begin{array}{l}\text { Idade, média (DP) } \\
\text { Sexo }\end{array}$ & $70,8(11,8)$ & $69,2(1,8)$ \\
$\quad$ Masculino, n (\%) & $309(51,2)$ & $245(54,3)$ \\
$\quad$ Feminino, n (\%) & $294(48,8)$ & $206(45,7)$ \\
Escolaridade, média (DP) & $4,3(3,6)$ & $4,7(3,8)$ \\
CDR, n (\%)* & & \\
$\quad \mathbf{0}$ & $505(83,7)$ & $330(85,9)^{*}$ \\
$\quad \geq \mathbf{1}$ & $98(16,3)$ & $54(14,1)^{*}$ \\
IQCode, média (DP) & $3,2(0,6)$ & $3,2(0,4)$ \\
\hline Total (n) & 603 & 451 \\
\hline
\end{tabular}

*Excluídos os portadores de CDR 0,5

$\mathrm{DP}=$ desvio padrão

\subsection{Estudo clínico}

\subsubsection{Análise descritiva}

Foram analisados dados de 603 indivíduos. A média de idade da amostra foi de 70,8 anos (desvio padrão=11,8 anos). Foi observado predomínio do sexo masculino $(51,2 \%)$, da raça branca $(67,3 \%)$, de indivíduos casados $(43,1 \%)$ e de destros $(88,6 \%)$. A média de escolaridade foi de 4,3 anos (desvio padrão=3,6 anos). A principal causa de óbito foi cardiovascular $(63,5 \%)$. Quanto à classe social, houve predomínio de indivíduos da classe social C (47,3\%). A análise descritiva destes dados encontra-se na Tabela 5. 
Resultados

Tabela 5 - Dados demográficos dos participantes do estudo clínico (n=603). BEHGEEC-FMUSP, 2005 a 2008

\begin{tabular}{llll}
\hline Variável & Categoria & n & \% \\
\hline Sexo & Masculino & 309 & 51,2 \\
Raça* & Feminino & 294 & 48,8 \\
& Branca & 406 & 67,3 \\
& Negra & 66 & 10,9 \\
Estado civil* & Parda & 112 & 18,6 \\
& Amarela & 14 & 2,3 \\
& Solteiro & 87 & 14,4 \\
& Casado & 260 & 43,1 \\
Lateralização* & Viúvo & 218 & 36,2 \\
& Divorciado & 36 & 6 \\
Causa de óbito & Destro & 533 & 88,6 \\
& Canhoto & 20 & 3,3 \\
& Cardiovascular & 383 & 63,5 \\
& Infecciosa & 78 & 12,9 \\
& Oncológica & 39 & 6,5 \\
Classe social & Outras & 98 & 16,3 \\
& Indeterminada & 5 & 0,8 \\
& A & 27 & 4,5 \\
& B & 144 & 23,9 \\
& C & 285 & 47,3 \\
& D & 135 & 22,4 \\
\hline Total & E & 12 & 2 \\
\hline$*$ Os totaing & - & 603 & 100 \\
\hline
\end{tabular}

* Os totais não coincidem devido à falta de informações para as variáveis assinaladas

Os participantes foram avaliados quanto à função cognitiva através das escalas CDR e IQCODE. Foi encontrada uma forte correlação entre estas duas escalas na amostra estudada. Se for considerado o total de indivíduos com material cardiovascular completo ( $n=649$, vide Figura 16), de forma que fossem incluídos os portadores de demência questionável $(\mathrm{CDR}=0,5)$ e os casos em que foram encontradas discordâncias entre CDR e IQCODE, encontrou-se uma correlação forte e significante entre as escalas $\left(\mathrm{r}_{\mathrm{s}}=0,875, \mathrm{p}<0,001\right)$. A Figura 17 mostra os valores de IQCODE de acordo com a classificação de CDR nesta situação. Se forem considerados os 603 participantes do estudo clínico, a correlação entre CDR e IQCODE foi semelhante $\left(\mathrm{r}_{\mathrm{s}}=0,831, \mathrm{p}<\right.$ $0,001)$. 


\section{Resultados}

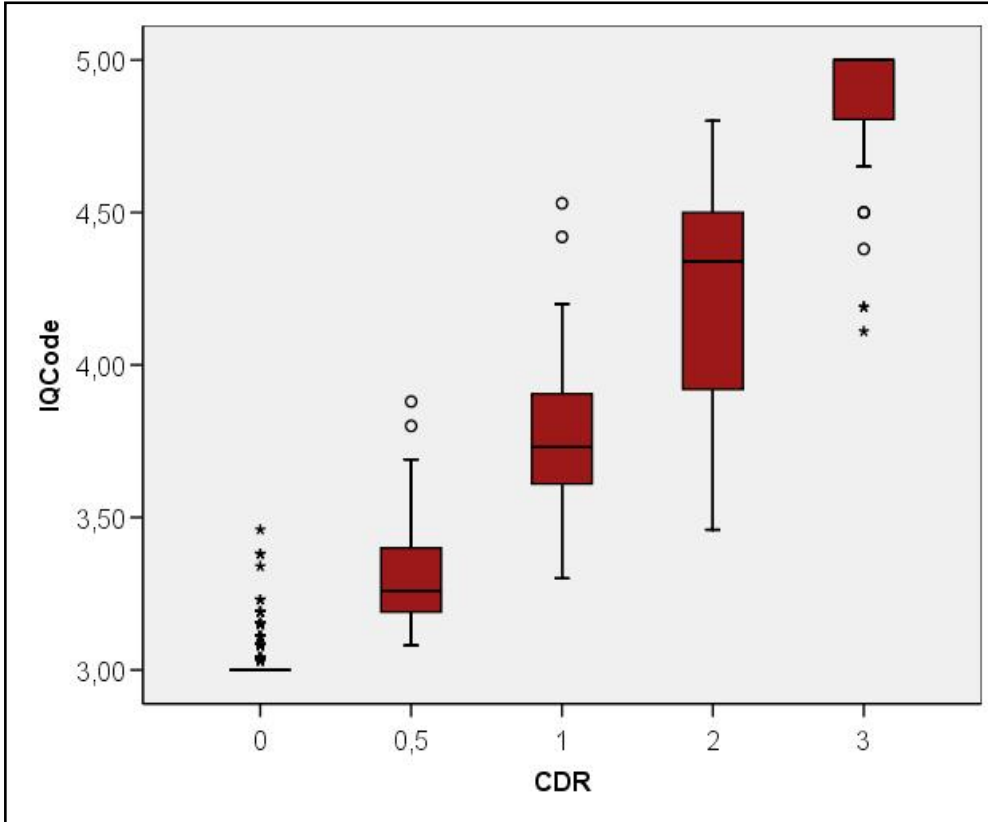

Figura 17. Distribuição dos valores de IQCODE de acordo com a classificação pela escala CDR nos indivíduos que apresentaram material cardiovascular completo.

No estudo clínico, tanto com a escala CDR como com a escala IQCODE, observou-se um predomínio de indivíduos cognitivamente normais $(83,7 \%)$. Indivíduos com demência representaram 16,3\% da amostra, de acordo com a distribuição mostrada na Figura 18. A escala IQCODE apresentou uma média de 3,2, (desvio padrão=0,5).

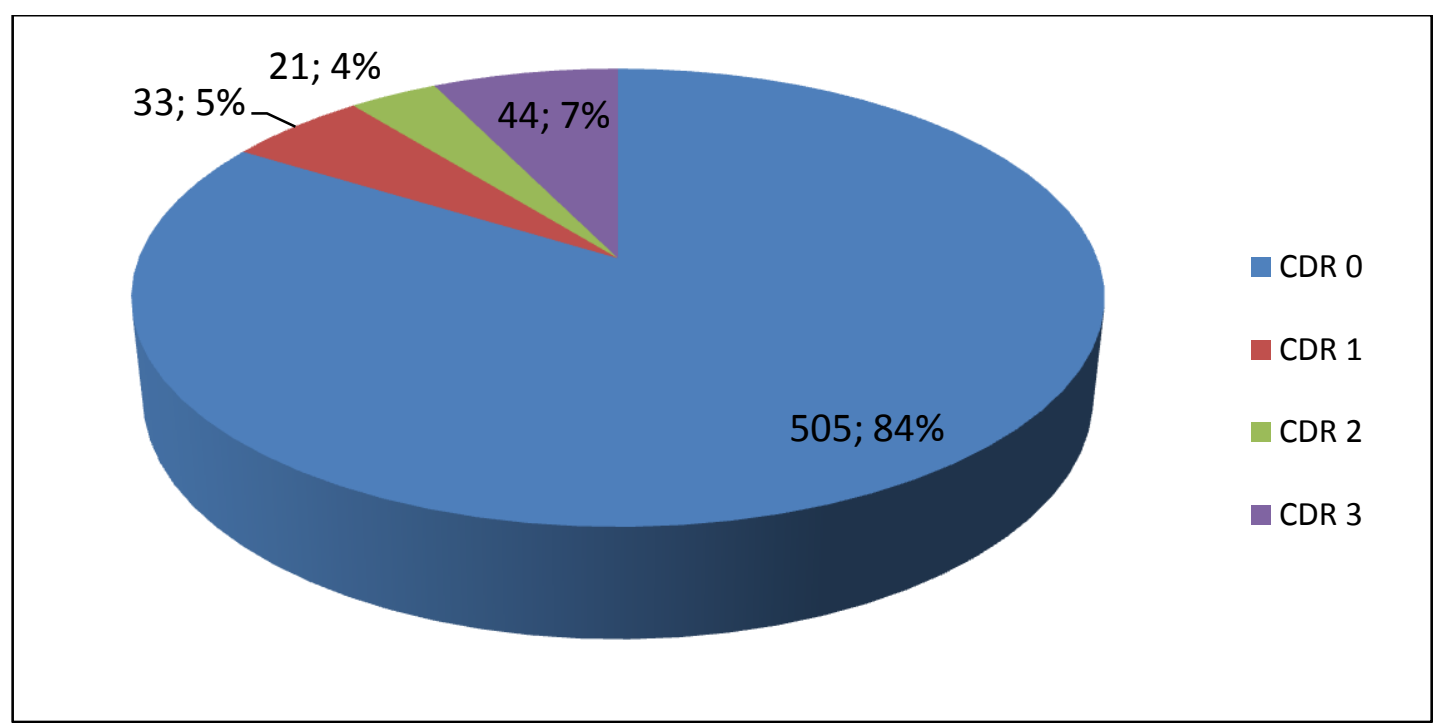

Figura 18. Frequência absoluta (n) e relativa (\%) dos 603 participantes do estudo clínico, distribuídos de acordo com a escala CDR. 
Resultados

Quanto à avaliação funcional, a maioria dos participantes apresentava pouco comprometimento tanto em atividades básicas quanto em atividades instrumentais de vida diária. A média obtida foi de 5,1 (desvio padrão=1,8) para a escala de atividades básicas de vida diária e de 6,1 (desvio padrão=2,9) para escala de atividades instrumentais.

Foi observada uma concordância entre a avaliação funcional e cognitiva. $\mathrm{O}$ grupo sem demência apresentava menor comprometimento em ABVD e AIVD, enquanto os dementados apresentavam maior comprometimento funcional como esperado (correlação entre CDR e ABVD: $r_{s}=-0,662$; CDR e AIVD: $r_{s}=-0,664$; IQCODE e ABVD: $r_{s}=-0,594$; IQCODE e AIVD: $r_{s}=-0,603 ; p<0,01$ para todas as correlações) (Figura 19).

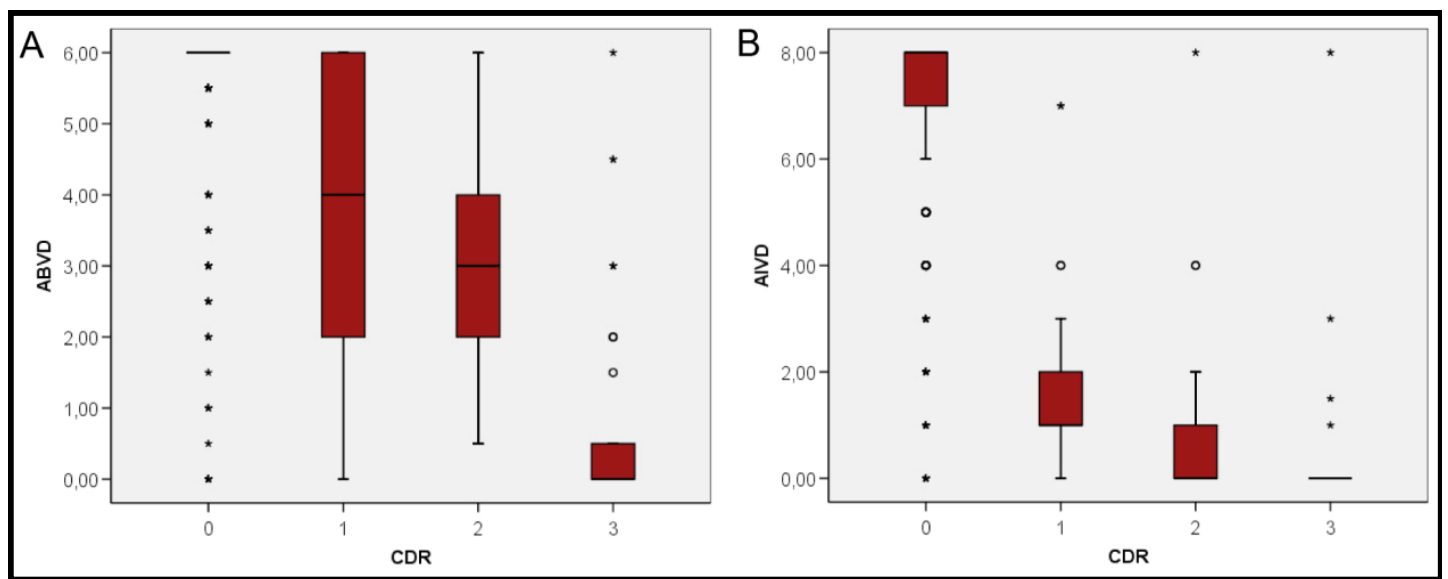

Figura 19. Atividades básicas (A) e instrumentais (B) de vida diária em portadores de CDR 0, 1,2 e 3.

Em relação aos FRCV, a Tabela 6 mostra a frequência dos fatores analisados na amostra. Quanto ao índice de massa corpórea, encontrou-se uma média de 23,2 kg/m² (desvio padrão $=4,4 \mathrm{~kg} / \mathrm{m}^{2}$ ).

Quanto à presença de doença cardiovascular, foram analisadas variáveis cardíacas, carotídeas e do PW. Em relação aos parâmetros cardíacos avaliados, o peso 
Resultados

cardíaco médio foi de 384,8 g (desvio padrão = 129,0 g). A espessura da parede livre do ventrículo esquerdo foi de 12,6 cm (desvio padrão $=2,6 \mathrm{~cm}$ ). Verificou-se hipertrofia miocárdica em 262 indivíduos (43,4\%), segundo avaliação qualitativa, considerando a idade e o sexo do paciente. A Tabela 7 mostra dados de peso, espessura de ventrículo esquerdo (VE) e hipertrofia miocárdica, de acordo com o sexo do indivíduo.

Tabela 6 - Fatores de risco cardiovascular nos participantes do estudo clínico (n=603). BEH-GEEC-FMUSP, 2005 a 2008

\begin{tabular}{lll}
\hline Variável & $\mathbf{n}$ & $\mathbf{\%}$ \\
\hline HAS & 386 & 64,0 \\
DM & 167 & 27,7 \\
DAC entrevista & 160 & 26,5 \\
DAC autópsia & 390 & 64,7 \\
ICC entrevista & 115 & 19,1 \\
ICC autópsia & 256 & 42,5 \\
Arritmia & 55 & 9,1 \\
Insuficiência arterial periférica & 14 & 2,3 \\
Dislipidemia & 57 & 9,5 \\
AVC referido & 67 & 11,1 \\
Sedentarismo & 374 & 62,0 \\
Tabagismo & & \\
$\quad$ Nunca & 289 & 47,8 \\
$\quad$ Atual & Prévio & 25,1 \\
Etilismo & 151 & 27,1 \\
$\quad$ Nunca & 163 & 59,0 \\
$\quad$ Atual & & 24,6 \\
$\quad$ Prévio & 356 & 16,4 \\
\hline Total & 148 & $\mathbf{1 0 0}$ \\
\hline
\end{tabular}

HAS = hipertensão arterial sistêmica; DM = diabetes mellitus; DAC = doença arterial coronariana; ICC = insuficiência cardíaca congestiva; AVC=acidente vascular cerebral. 
Resultados

Tabela 7 - Peso cardíaco, espessura de ventrículo esquerdo e hipertrofia miocárdica, de acordo com sexo, entre os participantes do estudo clínico (n=603). BEH-GEECFMUSP, 2009

\begin{tabular}{lll}
\hline Variável cardíaca & Sexo feminino & Sexo masculino \\
\hline Peso cardíaco $(\mathbf{g})$, média (DP) & $350,4(114,9)$ & $417,6(133,2)$ \\
Espessura VE (mm), média (DP) & $12,3(2,5)$ & $12,9(2,7)$ \\
Hipertrofia miocárdica, n (\%) & $116(39,5)$ & $146(47,2)$ \\
\hline Total (n) & 294 & 309 \\
\hline
\end{tabular}

$\mathrm{DP}=$ desvio padrão; $\mathrm{VE}=$ ventrículo esquerdo

Os dados apresentados na Tabela 8 mostram as médias de obstrução arterial nas oito regiões das artérias carótidas previamente indicadas na Figura 11. A análise dos resultados das regiões estudadas mostra uma aterosclerose maior próxima à região da bifurcação carotídea. Na Figura 20, podem ser observados diferentes graus de obstrução por aterosclerose em artérias carótidas.

Tabela 8 - Porcentagem de obstrução arterial por aterosclerose em artérias carótidas, segundo região representada, dos participantes do estudo clínico (n=603). BEH-GEECFMUSP, 2005 a 2008

\begin{tabular}{lll}
\hline Obstrução arterial (\%) & Média & Desvio padrão \\
\hline D1 & 30,2 & 18,6 \\
D2 & 34,6 & 15,5 \\
D3 & 32,2 & 20,9 \\
D4 & 23,6 & 24,8 \\
E1 & 32,8 & 19,2 \\
E2 & 34,4 & 16,3 \\
E3 & 31,9 & 20,3 \\
E4 & 22,4 & 24,2 \\
\hline D1=Carótida comum direita, região de maior obstrução; D2=Carótida comum direita, 1 \\
cm antes da bifurcação; D3= Carótida interna direita, região de maior obstrução; D4= \\
Carótida interna direita, 1 cm após bifurcação; E1= Carótida comum esquerda, região \\
de maior obstrução; E2= Carótida comum esquerda, 1 cm antes da bifurcação; E3= \\
Carótida interna esquerda, região de maior obstrução; E4= Carótida interna esquerda, 1 \\
cm após bifurcação.
\end{tabular}




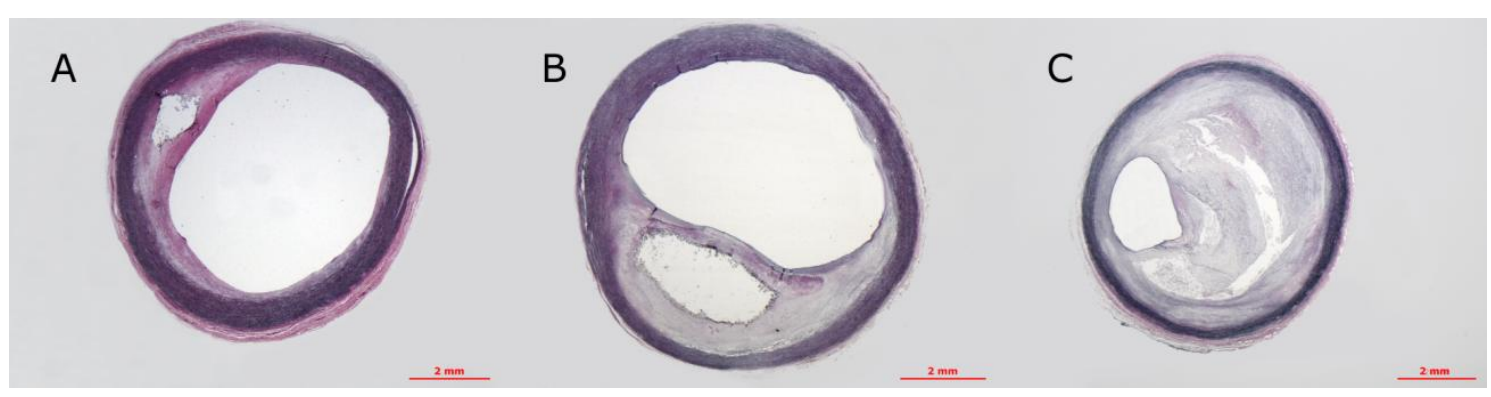

Figura 20. Graus progressivos de obstrução da luz por aterosclerose em artérias carótidas. Artéria carótida comum esquerda com 29,2\% (A); 43,2\% (B) e 91\% (C) de obstrução da luz. Barra de calibração=2mm. Fonte: BEH-GEEC-FMUSP, 2005 a 2008.

A espessura íntima-média foi medida a um centímetro antes da bifurcação carotídea em artéria carótida comum e um centímetro após a bifurcação em artéria carótida interna. Os valores encontrados encontram-se na Tabela 9. A espessura íntimamédia foi maior em artéria carótida comum do que na carótida interna.

Tabela 9 - Espessura íntima-média em milímetros de artérias carótidas comum e interna dos participantes do estudo clínico (n=603). BEH-GEEC-FMUSP, 2005 a 2008

\begin{tabular}{lll}
\hline Espessura íntima-média $(\mathbf{m m})$ & Média & Desvio padrão \\
\hline Carótida comum & 1,0 & 0,3 \\
Carótida interna & 0,8 & 0,3 \\
\hline
\end{tabular}

Em cada artéria do PW foi medida a porcentagem de obstrução arterial no nível de maior comprometimento por aterosclerose. Maior gravidade das lesões ateroscleróticas foi observada em artéria basilar, seguida por artérias cerebrais médias e cerebrais posteriores. Menor comprometimento por aterosclerose foi visto em artérias comunicante anterior e comunicantes posteriores (Tabela 10). Graus progressivos de aterosclerose de artérias do PW estão representados na Figura 21. 
Resultados

Tabela 10 - Porcentagem de obstrução da luz das artérias que compõem o PW dos participantes do estudo clínico (n=603). BEH-GEEC-FMUSP, 2005 a 2008

\begin{tabular}{lll}
\hline Obstrução arterial (\%) & Média & Desvio padrão \\
\hline Basilar & 31,3 & 29,0 \\
Cerebral posterior direita & 22,2 & 31,3 \\
Cerebral posterior esquerda & 24,8 & 32,3 \\
Comunicante posterior direita & 2,8 & 14,2 \\
Comunicante posterior esquerda & 3,0 & 14,3 \\
Carótida interna direita & 19,5 & 26,8 \\
Carótida interna esquerda & 19,4 & 27,0 \\
Comunicante anterior & 0,2 & 4,3 \\
Cerebral média direita & 25,9 & 30,5 \\
Cerebral média esquerda & 26,2 & 30,5 \\
Cerebral anterior direita & 9,3 & 22,7 \\
Cerebral anterior esquerda & 8,3 & 21,7 \\
\hline
\end{tabular}

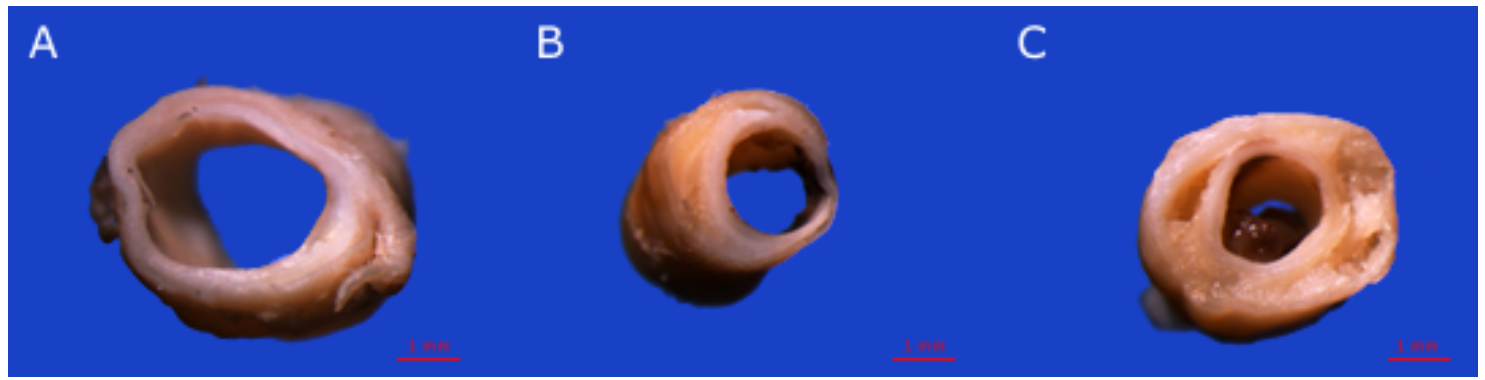

Figura 21. Graus progressivos de obstrução da luz por aterosclerose de artérias do PW. A. Artéria carótida interna esquerda com $25,6 \%$ de obstrução; B. Artéria cerebral posterior direita com 47,2\% de obstrução; C. artéria basilar com 80,3\% de obstrução. Barra de calibração=1 mm. Fonte: BEH-GEEC-FMUSP, 2009.

Foi calculada a média de obstrução arterial do PW, considerando as médias obtidas nas 12 artérias do polígono, e o número de artérias com placas de aterosclerose por caso. A segunda medida mostra a extensão da doença aterosclerótica. Na tentativa de sinalizar a extensão e gravidade da doença aterosclerótica foram contadas quantas artérias por PW apresentavam obstrução arterial maior do que 50\%. Os resultados são mostrados na Tabela 11. 
Tabela 11 - Porcentagem de obstrução arterial do PW, número de artérias com ateroma por caso e número de artérias com obstrução arterial maior do que $50 \%$ por $\mathrm{PW}$ dos participantes do estudo clínico (n=603). BEH-GEEC-FMUSP, 2005 a 2008

\begin{tabular}{lll}
\hline Polígono de Willis & Média & Desvio padrão \\
\hline Obstrução arterial (\%) & 17,5 & 17,3 \\
Número de artérias com ateroma/PW & 3,5 & 3,0 \\
Número de artérias com obstrução $>\mathbf{5 0 \%} / \mathbf{P W}$ & 2,1 & 2,5 \\
\hline
\end{tabular}

\subsubsection{Análise univariada}

Foram classificados 505 indivíduos $(83,7 \%)$ como sendo cognitivamente normais, de acordo com as escalas cognitivas CDR e IQCODE. Desta forma, 98 pacientes $(16,3 \%)$ foram considerados portadores de demência. Estes dois grupos foram comparados quanto aos dados demográficos, FRCV e doença cardiovascular.

\section{Dados demográficos}

Os grupos foram diferentes quanto à idade, ao sexo e ao estado civil. Os portadores de demência eram mais velhos $(\mathrm{p}<0,001)$ e predominantemente do sexo feminino $(\mathrm{p}<0,001)$. Quanto ao estado civil, entre os indivíduos sem demência era mais comum a presença de pessoas casadas e, entre os dementados, os viúvos eram mais prevalentes $(\mathrm{p}=0,001)$. Na tentativa de melhor compreender este resultado, foram agrupados os indivíduos não casados (solteiros, viúvos e divorciados) e foi feita a comparação contra o grupo de casados. A análise revelou que os casados tinham menos demência do que os outros indivíduos que não eram casados $(\mathrm{p}=0,001)$. A escolaridade de portadores de demência era significativamente menor do que indivíduos sem demência $(\mathrm{p}<0,001)$.

Em relação à causa de óbito determinada pela autópsia, entre os indivíduos cognitivamente normais predominou a causa cardiovascular. Entre os dementados, ainda houve predomínio desta causa, mas com menor intensidade e proporcional aumento da prevalência de causas infecciosas e outras causas, sendo estas 
Resultados

predominantemente respiratórias $(\mathrm{p}<0,001)$. Por tratar-se de um estudo com enfoque na importância do risco cardiovascular em relação à demência, foram comparados os indivíduos que morreram de causa cardiovascular contra as pessoas que faleceram por causas não cardiovasculares (infecção, câncer, outras causas e indeterminada). A causa de óbito cardiovascular foi mais prevalente entre os indivíduos sem demência em comparação aos portadores de demência $(\mathrm{p}=0,02)$ (Tabela 12).

Tabela 12 - Dados demográficos de indivíduos sem demência (controle) e com demência. Estudo clínico (n=603), BEH-GEEC-FMUSP, 2005 a 2008

\begin{tabular}{|c|c|c|c|}
\hline Variável & Controle & Demência & $\mathbf{p}$ \\
\hline Idade, média (DP) & $69,2(11,42)$ & $79,4(9,58)$ & $<0,001$ \\
\hline Sexo, n $(\%)$ & & & $<0,001$ \\
\hline Feminino & $229(45,3)$ & $65(66,3)$ & \\
\hline Masculino & $276(54,7)$ & $33(33,7)$ & \\
\hline Raça, n $(\%)^{*}$ & & & 0,69 \\
\hline Branca & $336(67,2)$ & $70(71,4)$ & \\
\hline Negra & $55(11,0)$ & $11(11,2)$ & \\
\hline Parda & $96(19,2)$ & $16(16,3)$ & \\
\hline Amarela & $13(2,6)$ & $1(1,0)$ & \\
\hline Estado civil, $\mathbf{n}(\%) *$ & & & 0,001 \\
\hline Solteiro & $74(14,7)$ & $13(13,3)$ & \\
\hline Casado & $232(46,1)$ & $28(28,6)$ & \\
\hline Viúvo & $165(32,8)$ & $23(54,1)$ & \\
\hline Divorciado & $32(6,4)$ & $4(4,1)$ & \\
\hline Escolaridade,média(DP) & $4,51(3,70)$ & $3,14(3,09)$ & $<0,001$ \\
\hline Lateralização, n (\%)* & & & 0,35 \\
\hline Destro & $450(96,8)$ & $84(94,4)$ & \\
\hline Canhoto & $15(3,2)$ & $5(5,6)$ & \\
\hline Causa de óbito, n (\%) & & & $<0,001$ \\
\hline Cardiovascular & $331(65,5)$ & $52(53,1)$ & \\
\hline Infecciosa & $56(11,1)$ & $22(22,4)$ & \\
\hline Oncológica & $38(7,5)$ & $1(1,0)$ & \\
\hline Outras & $78(15,4)$ & $20(20,4)$ & \\
\hline Indeterminada & $2(0,4)$ & $3(3,1)$ & \\
\hline Classe social, n (\%) & & & 0,16 \\
\hline A & $18(3,6)$ & $9(9,2)$ & \\
\hline B & $121(24)$ & $23(23,5)$ & \\
\hline $\mathrm{C}$ & $241(47,7)$ & $44(44,9)$ & \\
\hline $\mathrm{D}$ & $114(22,6)$ & $21(21,4)$ & \\
\hline $\mathrm{E}$ & $11(2,2)$ & $1(1,0)$ & \\
\hline Total, $\mathbf{n}$ & 504 & 98 & \\
\hline
\end{tabular}




\section{Fatores de risco cardiovascular}

Dados referentes à comparação de indivíduos com e sem demência em relação aos FRCV encontram-se na Tabela 13. Os dementados apresentaram menos doença coronariana relatada pelo familiar durante a entrevista do que os indivíduos sem demência $(\mathrm{p}=0,05)$. Esta variável avalia a doença coronariana diagnosticada em vida, sendo provavelmente insuficiência coronariana sintomática. Quando foi usada a variável doença coronariana diagnosticada através da autópsia, não foi encontrada diferença entre os grupos com e sem demência $(\mathrm{p}=0,21)$. Esta variável inclui muitos casos de insuficiência coronariana não diagnosticada, sendo frequentemente assintomática.

A insuficiência cardíaca foi mais comum no grupo sem demência do que nos dementados. O resultado foi o mesmo independente da fonte de informação usada, seja ela a entrevista clínica $(\mathrm{p}=0,03)$ ou a autópsia $(\mathrm{p}=0,01)$. O grupo com demência apresentou mais AVC referido pelo informante do que os indivíduos cognitivamente normais $(p<0,001)$. Os indivíduos com demência eram mais sedentários $(p<0,001)$ do que os sem demência. Em relação ao tabagismo e ao etilismo, os dementados apresentaram menor exposição a estas substâncias do que as pessoas sem demência $(\mathrm{p}=0,001)$. O índice de massa corpórea foi menor em indivíduos com demência $(\mathrm{p}<0,001)$. 
Resultados

Tabela 13 - Fatores de risco cardiovascular nos grupos sem demência (controle) e com demência. Estudo clínico (n=603), BEH-GEEC-FMUSP, 2005 a 2008.

\begin{tabular}{llll}
\hline FRCV & Controle & Demência & p \\
\hline HAS, n (\%) & $331(65,5)$ & $55(56,1)$ & 0,08 \\
DM, n (\%) & $139(27,5)$ & $28(28,6)$ & 0,83 \\
DAC entrevista, n (\%) & $142(28,1)$ & $18(18,4)$ & 0,05 \\
DAC autópsia, n (\%) & $332(65,7)$ & $58(59,2)$ & 0,21 \\
ICC entrevista, n (\%) & $104(20,6)$ & $11(11,2)$ & 0,03 \\
ICC autópsia, n (\%) & $226(44,8)$ & $30(30,6)$ & 0,01 \\
Arritmia, n (\%) & $49(9,7)$ & $6(6,1)$ & 0,26 \\
IAP, n (\%) & $10(2,0)$ & $4(4,1)$ & 0,21 \\
Dislipidemia, n (\%) & $52(10,3)$ & $5(5,1)$ & 0,11 \\
AVC referido, n (\%) & $43(8,5)$ & $24(24,5)$ & $<0,001$ \\
Sedentarismo, n (\%) & $291(57,6)$ & $83(84,7)$ & $<0,001$ \\
Tabagismo, n (\%) & & & 0,001 \\
$\quad$ Nunca & $226(44,8)$ & $63(64,3)$ & \\
$\quad$ Atual & $138(27,3)$ & $13(13,3)$ & \\
$\quad$ Prévio & $141(27,9)$ & $22(22,4)$ & \\
Etilismo, n (\%) & & & 0,001 \\
$\quad$ Nunca & $282(55,8)$ & $74(75,5)$ & \\
$\quad$ Atual & Prévio & $15(15,3)$ & \\
IMC, média (DP) & $90(17,8)$ & $9(9,2)$ & \\
\hline Total & $23,6(4,5)$ & $21,4(3,9)$ & $<0,001$ \\
\hline
\end{tabular}

HAS=hipertensão arterial sistêmica; DM=diabetes mellitus; DAC=doença arterial coronariana; ICC=insuficiência cardíaca congestiva; IAP=insuficiência arterial periférica; $A V C=$ acidente vascular cerebral; IMC=índice de massa corpórea

\section{Avaliação cardíaca}

Os grupos foram diferentes quanto às variáveis cardíacas medidas durante o estudo. Os dementados apresentaram menor peso cardíaco, menor espessura da parede ventricular e menos hipertrofia miocárdica do que os indivíduos sem demência (Tabela 14).

Tabela 14 - Variáveis cardíacas nos grupos sem demência (controle) e com demência. Estudo clínico (n=603), BEH-GEEC-FMUSP, 2005 a 2008

\begin{tabular}{llll}
\hline Variável cardíaca & Controle & Demência & p \\
\hline Peso cardíaco $(\mathbf{g})$, média (DP) & $397,1(131,4)$ & $321,8(93,5)$ & $<0,001$ \\
Espessura VE $\mathbf{( m m ) , ~ m e ́ d i a ~ ( D P ) ~}$ & $12,7(2,6)$ & $11,79(2,4)$ & 0,002 \\
Hipertrofia miocárdica, n(\%) & $231(45,7)$ & $31(31,6)$ & 0,01 \\
\hline
\end{tabular}

$\mathrm{VE}=$ ventrículo esquerdo 
Resultados

\section{Avaliação de artérias carótidas}

Para a comparação entre os grupos, foi utilizada a região com maior estenose em artéria carótida comum, interna, direita e esquerda (Tabela 15). Nesta análise, os grupos controle e com demência foram semelhantes em relação à obstrução em artérias carótidas.

Tabela 15 - Obstrução por aterosclerose em artérias carótidas nos grupos sem demência (controle) e com demência. Estudo clínico (n=603), BEH-GEEC-FMUSP, 2005 a 2008

\begin{tabular}{llll}
\hline Obstrução arterial (\%) & Controle & Demência & p \\
\hline ACC, média (DP) & $46,5(16,1)$ & $45,0(17,1)$ & 0,29 \\
ACI, média (DP) & $44,4(22,1)$ & $43,4(27,1)$ & 0,23 \\
ACD, média (DP) & $45,7(18,7)$ & $43,8(21,4)$ & 0,14 \\
ACE, média (DP) & $46,1(18,8)$ & $46,7(22,0)$ & 0,80 \\
\hline
\end{tabular}

$\mathrm{DP}=$ desvio padrão; $\mathrm{ACC}=$ artéria carótida comum; $\mathrm{ACI}=$ artéria carótida interna; $\mathrm{ACD}$ $=$ artéria carótida direita; $\mathrm{ACE}=$ artéria carótida esquerda.

Optou-se por estratificar a porcentagem de obstrução arterial em dois grupos: porcentagem de estenose arterial menor do que $75 \%$ e outro grupo com porcentagem de obstrução $\geq 75 \%$. A escolha deste valor baseou-se em estudos prévios que mostraram que este valor está associado ao maior risco de AVC e demência (Barnett et al., 2002 e Johnston et al., 2004). Os portadores de obstrução arterial $\geq 75 \%$ em artéria carótida interna tiveram 2,05 vezes mais chance de demência do que os indivíduos com estenose arterial menor do que $75 \%$. Lesões obstrutivas $\geq 75 \%$ em artéria carótida esquerda conferiram 2,21 vezes mais chance de demência do que obstruções arteriais $<75 \%$ (Tabela 16). 
Resultados

Tabela 16 - Odds ratio para demência, de acordo com obstrução arterial por aterosclerose em artérias carótidas. Estudo clínico (n=603), BEH-GEEC-FMUSP, 2005 a 2008

\begin{tabular}{|c|c|c|c|c|c|}
\hline Variável & $\begin{array}{l}\text { Com } \\
\text { demência }\end{array}$ & $\begin{array}{l}\text { Sem } \\
\text { demência }\end{array}$ & OR & IC $95 \%$ & $\mathbf{p}$ \\
\hline \multicolumn{6}{|l|}{$\mathbf{A C C}$} \\
\hline$<75 \%$ & 92 & 480 & 1 & & 0,63 \\
\hline$\geq 75 \%$ & 6 & 25 & 1,25 & $0,50-3,14$ & \\
\hline \multicolumn{6}{|l|}{ ACI } \\
\hline$<75 \%$ & 80 & 455 & 1 & & 0,02 \\
\hline$\geq 75 \%$ & 18 & 50 & 2,05 & $1,14-3,69$ & \\
\hline \multicolumn{6}{|l|}{$\bar{A} \mathbf{C D}$} \\
\hline$<75 \%$ & 88 & 474 & 1 & & 0,14 \\
\hline$\geq 75 \%$ & 10 & 31 & 1,74 & $0,82-3,67$ & \\
\hline \multicolumn{6}{|l|}{$\overline{\mathbf{A}} \mathbf{C E}$} \\
\hline$<75 \%$ & 82 & 464 & 1 & & 0,01 \\
\hline$\geq 75 \%$ & 16 & 41 & 2,21 & $1,18-4,12$ & \\
\hline
\end{tabular}

Os grupos sem e com demência se comportaram de maneira similar em relação à espessura íntima-média de artérias carótidas comum e interna (Tabela 17).

Tabela 17 - Espessura íntima-média de artérias carótidas nos grupos sem demência (controle) e com demência. Estudo clínico (n=603), BEH-GEEC-FMUSP, 2005 a 2008

\begin{tabular}{llll}
\hline Espessura íntima-média (mm) & Controle & Demência & p \\
\hline Carótida comum, média (DP) & $1,01(0,25)$ & $0,98(0,25)$ & 0,30 \\
Carótida interna, média (DP) & $0,75(0,25)$ & $0,74(0,30)$ & 0,18 \\
\hline
\end{tabular}

$\mathrm{DP}=$ desvio padrão

\section{Avaliação das artérias do PW}

A obstrução arterial por aterosclerose do PW foi mais prevalente entre portadores de demência $(\mathrm{p}=0,02)$. O número de artérias com placas de aterosclerose por PW estudado, revelando a extensão da doença aterosclerótica cerebral, mostrou ser maior no grupo com demência $(\mathrm{p}=0,01)$. Quando se avaliaram quantas destas artérias apresentavam placas ateroscleróticas maiores do que 50\% foi possível mostrar que os dementados apresentavam aterosclerose cerebral mais extensa e grave $(p=0,01)$. A 
Resultados

comparação entre os grupos sem e com demência em relação à aterosclerose do PW pode ser vista na Tabela 18 e Figura 22.

Tabela 18 - Aterosclerose do polígono de Willis (PW) nos grupos sem demência (controle) e com demência. Estudo clínico (n=603), BEH-GEEC-FMUSP, 2005 a 2008

\begin{tabular}{llll}
\hline Aterosclerose do PW & Controle & Demência & p \\
\hline $\begin{array}{l}\text { Obstrução arterial (\%), média (DP) } \\
\text { No de artérias com ateroma/PW, }\end{array}$ & $16,8(17,0)$ & $21,3(18,3)$ & 0,02 \\
$\begin{array}{l}\text { média (DP) } \\
\begin{array}{l}\text { No de artérias com obstrução>50\%/PW, } \\
\text { média (DP) }\end{array}\end{array}$ & $4,1(3,0)$ & 0,01 \\
\hline
\end{tabular}

$\mathrm{No}=$ número; $\mathrm{DP}=$ desvio padrão

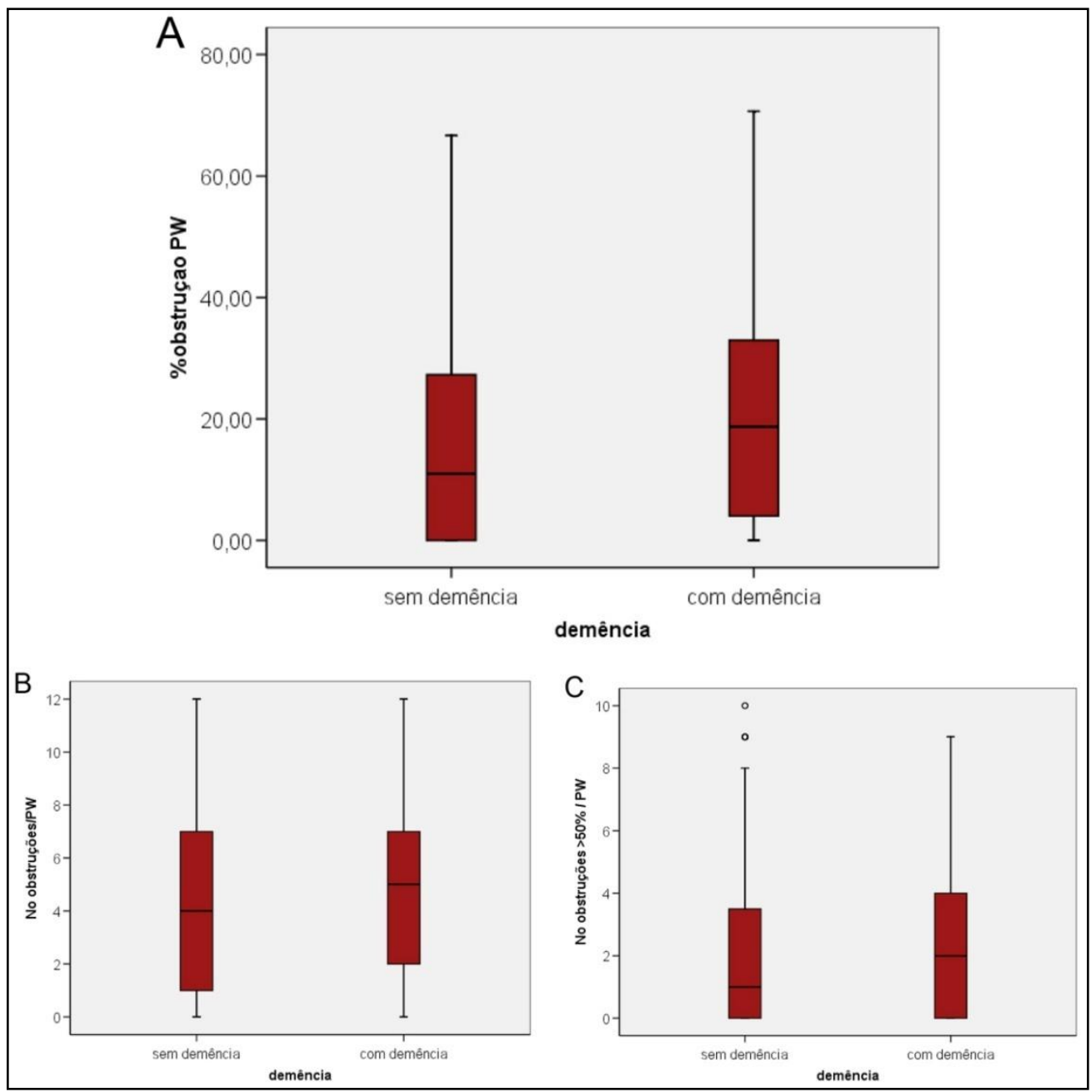

Figura 22. (A) Porcentagem de obstrução arterial nos grupos sem e com demência. (B) Número de artérias com ateroma por PW nos grupos sem e com demência. (C) Número de artérias com obstrução maior do que $50 \%$ por PW nos grupos sem e com demência. 
Além disso, foi possível detectar diferenças na gravidade da doença aterosclerótica cerebral entre os grupos sem e com demência em algumas artérias do PW: artéria cerebral posterior direita, artérias cerebrais médias direita e esquerda e artérias cerebrais anteriores direita e esquerda (Tabela 19).

Tabela 19 - Média (desvio padrão) da porcentagem de obstrução arterial nas artérias do polígono de Willis (PW) nos grupos sem demência (controle) e com demência. Estudo clínico (n=603), BEH-GEEC-FMUSP, 2005 a 2008

\begin{tabular}{llll}
\hline Artéria do PW & Controle & Demência & p \\
\hline Basilar & $28,5(27,9)$ & $34,5(28,9)$ & 0,06 \\
Cerebral posterior direita & $18,4(29,2)$ & $28,3(33,1)$ & 0,02 \\
Cerebral posterior esquerda & $22,7(31,2)$ & $24,6(33,6)$ & 0,54 \\
Comunicante posterior direita & $2,5(13,3)$ & $2,4(12,4)$ & 0,42 \\
Comunicante posterior esquerda & $2,7(13,5)$ & $2,5(11,9)$ & 0,31 \\
Carótida interna direita & $17,6(25,8)$ & $19,9(27,5)$ & 0,32 \\
Carótida interna esquerda & $18,9(26,7)$ & $19,7(25,9)$ & 0,62 \\
Comunicante anterior & $0,3(5,1)$ & $0(0)$ & 0,53 \\
Cerebral média direita & $22,5(29,2)$ & $31,3(30,7)$ & 0,03 \\
Cerebral média esquerda & $24,5(29,8)$ & $31,3(32,4)$ & 0,01 \\
Cerebral anterior direita & $8,1(21,5)$ & $14,6(27,1)$ & 0,01 \\
Cerebral anterior esquerda & $7,3(21,1)$ & $12,1(25,6)$ & 0,02 \\
\hline
\end{tabular}

\subsubsection{Análise multivariada}

\section{Dados demográficos e FRCV}

As variáveis demográficas e FRCV que mostraram associação significativa com demência definida por critérios clínicos foram avaliadas em modelo de regressão logística. Conforme descrito anteriormente, a variável estado civil foi agrupada em dois grupos (casados e não casados). O mesmo foi feito com a variável causa de óbito (cardiovascular e não cardiovascular). Os resultados obtidos encontram-se na Tabela 20. 
Resultados

Tabela 20 - Odds ratio para demência, segundo características demográficas e fatores de risco cardiovascular, de acordo com modelo de regressão multivariável. Estudo clínico (n=603), BEH-GEEC-FMUSP, 2005 a 2008

\begin{tabular}{llll}
\hline Variável & OR* $^{*}$ & IC 95\% & p \\
\hline Idade & 1,07 & $1,04-1,10$ & $<0,001$ \\
Sexo masculino & 0,86 & $0,45-1,63$ & 0,64 \\
Estado civil (não casado) & 1,11 & $0,60-2,06$ & 0,75 \\
Escolaridade & 0,94 & $0,87-1,03$ & 0,17 \\
Causa de óbito cardiovascular & 0,95 & $0,55-1,64$ & 0,86 \\
DAC & 0,89 & $0,48-1,66$ & 0,71 \\
ICC & 0,45 & $0,21-0,97$ & 0,04 \\
AVC referido & 3,36 & $1,67-6,76$ & $<0,001$ \\
Sedentarismo & 3,81 & $2,03-7,15$ & $<0,001$ \\
Tabagismo & 0,83 & $0,58-1,19$ & 0,32 \\
Etilismo & 0,72 & $0,47-1,11$ & 0,14 \\
IMC & 0,92 & $0,86-0,98$ & 0,01 \\
\hline
\end{tabular}

*ajustado para as demais variáveis da tabela

$\mathrm{OR}=$ odds ratio; IC 95\%=intervalo de confiança $95 \% \mathrm{DAC}=$ doença arterial coronariana; ICC=insuficiência cardíaca congestiva; $\mathrm{AVC}=$ acidente vascular cerebral

Portanto, idade, AVC e sedentarismo foram considerados fatores de risco independentes para o desenvolvimento de demência. Insuficiência cardíaca e IMC mais elevado, por outro lado, foram considerados fatores protetores independentes para demência.

\section{Variáveis cardíacas, carotídeas e relacionadas ao $\mathrm{PW}$}

A análise de regressão logística também foi feita para investigar a associação entre as variáveis cardíacas (peso, espessura de VE e hipertrofia miocárdica), com demência, ajustado para idade, sexo e escolaridade. As mesmas análises foram feitas para pesquisar a associação entre artérias carótidas (obstrução $\geq 75 \%$ em artéria carótida interna e artéria carótida esquerda) com demência e entre as artérias do PW (porcentagem de obstrução arterial, número de artérias com ateroma/PW e número de 
Resultados

artérias com obstrução>50\%) com demência, ajustado para idade, sexo e escolaridade (Tabela 21).

Tabela 21 - Odds ratio para demência, segundo variáveis cardíacas, carotídeas e do polígono de Willis (PW), ajustado para idade, sexo e escolaridade, de acordo com modelo de regressão multivariável. Estudo clínico (n=603), BEH-GEEC-FMUSP, 2005 a 2008

\begin{tabular}{llll}
\hline Variável & OR & IC95\% & p \\
\hline Peso cardíaco & 0,995 & $0,993-0,998$ & $<0,001$ \\
Espessura de VE & 0,88 & $0,80-0,97$ & 0,005 \\
Hipertrofia miocárdica & 0,69 & $0,42-1,12$ & 0,09 \\
Artéria carótida interna & 1,93 & $1,01-3,71$ & 0,05 \\
Artéria carótida esquerda & 2,47 & $1,24-4,95$ & 0,01 \\
Obstrução arterial PW & 1,00 & $0,99-1,02$ & 0,82 \\
No de artérias com ateroma/PW & 1,00 & $0,92-1,09$ & 0,96 \\
No de artérias com obstrução & 1,01 & $0,92-1,10$ & 0,86 \\
>50\%/PW & & & \\
\hline VE=ventrículo esquerdo; OR=odds & ratio; IC & 95\%=intervalo de confiança 95\%; \\
No=número & & &
\end{tabular}

Considerando os resultados da regressão logística, maior peso cardíaco e maior espessura de VE foram fatores de proteção para demência. Aterosclerose de artérias carótidas interna e esquerda mantiveram associação com demência após ajuste para idade, sexo e escolaridade. Por outro lado, as variáveis do PW perderam associação significativa após a regressão logística.

\subsection{Estudo neuropatológico}

Dos 603 participantes do estudo clínico, 199 apresentavam avaliação neuropatológica. Entretanto, seis destes indivíduos apresentavam incompatibilidade entre os exames clínico e neuropatológico. Embora fossem portadores de demência 
pelas escalas CDR e IQCODE, apresentavam exame neuropatológico normal. Estes casos foram excluídos do estudo neuropatológico e também do estudo clinicopatológico que será descrito a seguir. Também foram excluídos os indivíduos que não preencheram critérios neuropatológicos para DA e DV, mas eram portadores de outras demências segundo critérios anteriormente descritos. O grupo "outras demências" era constituído por poucos indivíduos distribuídos por diversas doenças cerebrais (4 portadores de demência secundária a doença de Parkinson, 2 indivíduos com demência por corpúsculos de Lewy, 3 portadores de demência por degeneração lobar frontotemporal e 1 indivíduo com doença por grãos argirofílicos), dificultando as análises estatísticas. Além disso, até o momento, não foi descrita interação destas doenças com FRCV. Desta forma, o fluxograma dos participantes do estudo neuropatológico encontra-se na Figura 23. Os 183 participantes do estudo neuropatológico foram classificados em controles, portadores de DA e indivíduos com DV (Figura 24).

Foram considerados apenas critérios anatomopatológicos para a classificação deste estudo. Assim, o grupo DA incluía 10 indivíduos (32,3\%) com lesões neurodegenerativas sugestivas de DA, mas sem sintomas cognitivos. Da mesma forma, quatro indivíduos $(14,3 \%)$ classificados como DV por critérios neuropatológicos não apresentavam quadro clínico de demência. 
Resultados

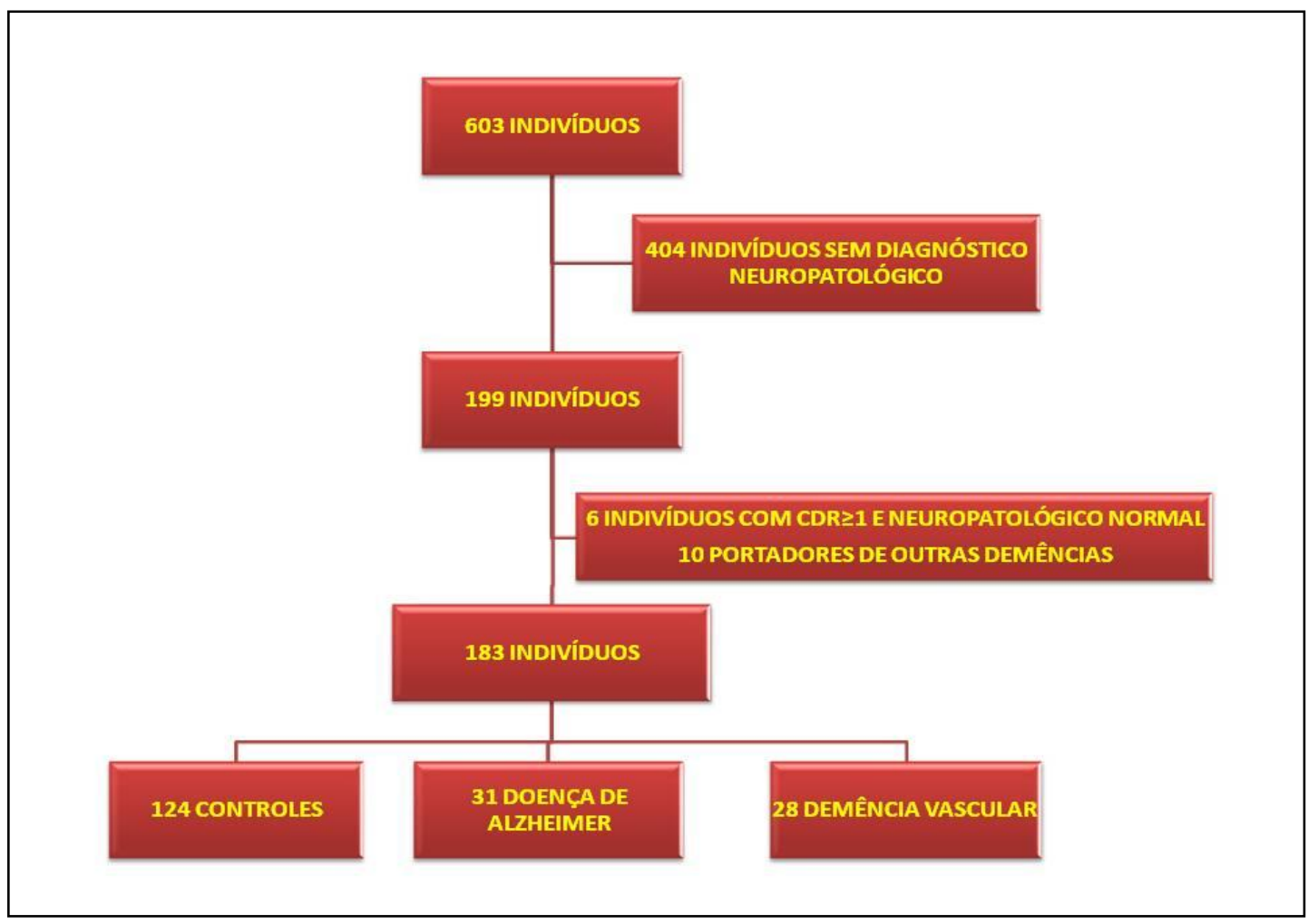

Figura 23. Fluxograma dos participantes do estudo neuropatológico.

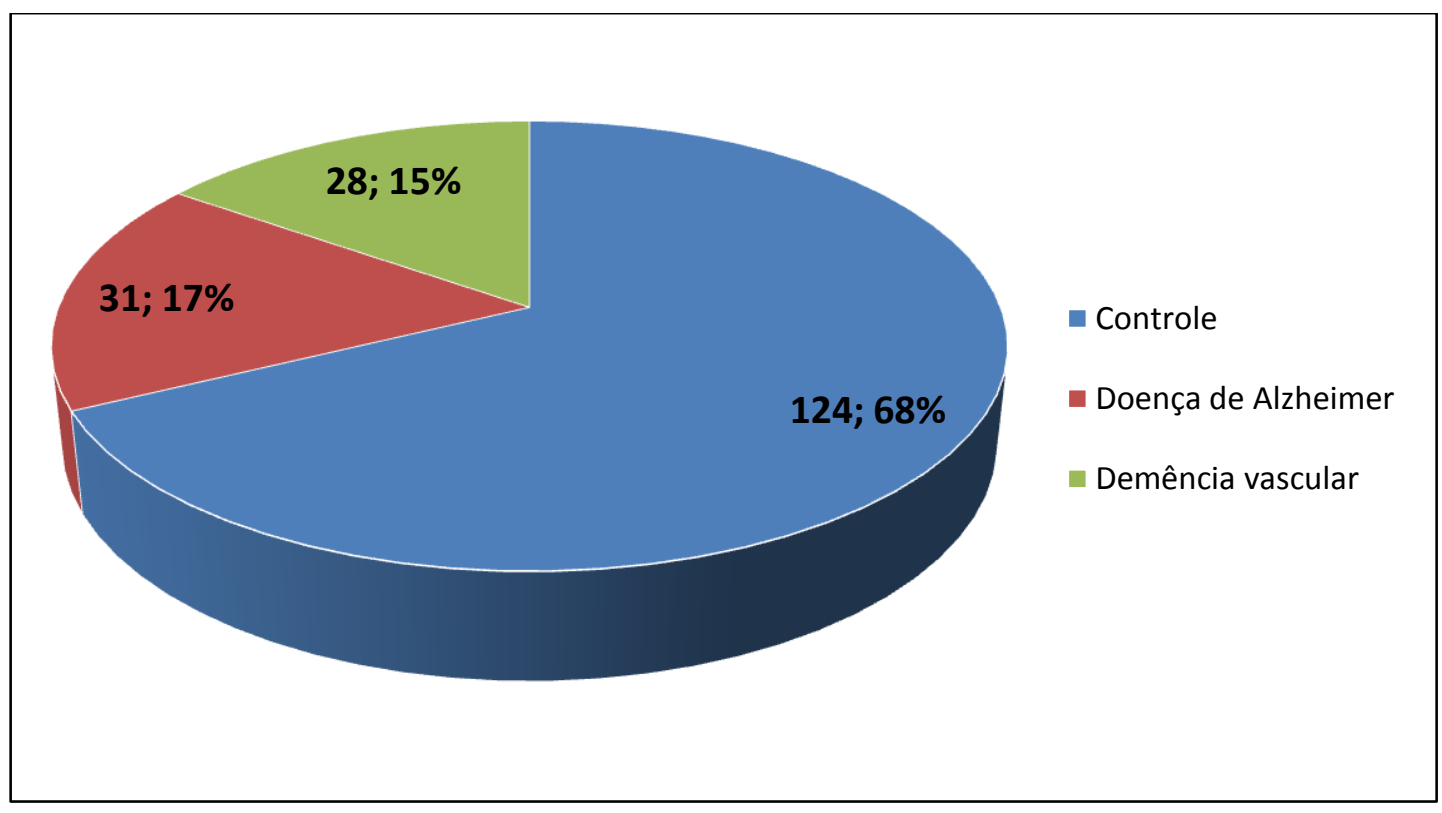

Figura 24. Frequência absoluta (n) e relativa (\%) dos 183 participantes do estudo neuropatológico. 
Resultados

Alguns dados dos participantes do estudo neuropatológico foram comparados com os 420 indivíduos que foram excluídos deste estudo, como mostra a Tabela 22. Os participantes do estudo neuropatológico eram mais velhos do que os que foram excluídos. Além disso, foram observadas maiores proporções de mulheres e portadores de demência, segundo a escala CDR.

Tabela 22 - Comparação entre participantes incluídos e excluídos do estudo neuropatológico em relação a variáveis demográficas BEH-GEEC-FMUSP, 2005 a 2008

\begin{tabular}{lll}
\hline & Incluído & Excluído \\
\hline Idade, média (DP) & $73,2(11,4)$ & $69,8(11,7)$ \\
Sexo, n (\%) & & \\
Feminino & $96(52,5)$ & $198(47,1)$ \\
Masculino & $87(47,5)$ & $222(52,9)$ \\
Escolaridade, média (DP) & $4,3(3,6)$ & $4,3(3,7)$ \\
CDR, n (\%) & & \\
0 & $136(74,3)$ & $367(87,4)$ \\
$\geq 1$ & $47(25,7)$ & $53(12,6)$ \\
\hline Total & 183 & 420 \\
\hline
\end{tabular}

\subsubsection{Análise descritiva}

A análise dos dados dos 183 participantes do estudo neuropatológico mostrou média de idade de 73,2 anos com desvio padrão de 11,4 anos, predomínio do sexo feminino $(52,5 \%)$, da raça branca $(65,6 \%)$, de indivíduos casados $(41,5 \%)$ e de destros (91,8\%). A média de escolaridade foi de 4,3 anos e desvio padrão de 3,6 anos. A principal causa de óbito foi cardiovascular (66,7\%). Quanto à classe social, houve predomínio de indivíduos da classe social C (46,4\%). A análise descritiva destes dados encontra-se na Tabela 23. 
Resultados

Tabela 23 - Dados demográficos dos participantes do estudo neuropatológico $(n=183)$. BEH-GEEC-FMUSP, 2005 a 2008

\begin{tabular}{llll}
\hline Variável & Categoria & n & \% \\
\hline Sexo & Masculino & 87 & 47,5 \\
& Feminino & 96 & 52,5 \\
Raça* & Branca & 120 & 65,6 \\
& Negra & 20 & 10,9 \\
& Parda & 35 & 19,1 \\
Estado civil* & Amarela & 6 & 3,3 \\
& Solteiro & 22 & 12,0 \\
& Casado & 76 & 41,5 \\
& Viúvo & 73 & 39,9 \\
Lateralização* & Divorciado & 12 & 16,6 \\
& Destro & 168 & 91,8 \\
Causa de óbito & Canhoto & 7 & 3,8 \\
& Cardiovascular & 122 & 66,7 \\
& Infecciosa & 19 & 10,4 \\
& Oncológica & 11 & 6,0 \\
& Outras & 29 & 15,8 \\
Classe social & Indeterminada & 2 & 1,1 \\
& A & 10 & 5,5 \\
& B & 47 & 25,7 \\
& C & 85 & 46,4 \\
& D & 39 & 21,3 \\
& E & 2 & 1,1 \\
\hline & & 183 & 100 \\
\hline
\end{tabular}

*Os totais não coincidem devido à falta de informações para as variáveis assinaladas

A Tabela 24 mostra a frequência absoluta e relativa dos FRCV na amostra. Quanto ao índice de massa corpórea, encontrou-se uma média de 23,4 e desvio padrão de 4,5 .

Quanto à doença cardiovascular avaliada anatomicamente, os dados referentes ao coração, artérias carótidas e PW dos participantes do estudo neuropatológico encontram-se na Tabela 25. 
Resultados

Tabela 24 - Fatores de risco cardiovascular nos participantes do estudo neuropatológico ( $\mathrm{n}=183)$. BEH-GEEC-FMUSP, 2005 a 2008

\begin{tabular}{lll}
\hline Variável & $\mathbf{n}$ & $\mathbf{\%}$ \\
\hline HAS & 124 & 67,8 \\
DM & 50 & 27,3 \\
DAC entrevista & 58 & 31,7 \\
DAC autópsia & 119 & 65,0 \\
ICC entrevsta & 39 & 21,3 \\
ICC autópsia & 78 & 42,6 \\
Arritmia & 18 & 9,8 \\
Insuficiência arterial periférica & 6 & 3,3 \\
Dislipidemia & 14 & 7,7 \\
AVC referido & 23 & 12,6 \\
Sedentarismo & 125 & 68,3 \\
Tabagismo & & \\
$\quad$ Nunca & 90 & 49,2 \\
$\quad$ Atual & Prévio & 26,2 \\
Etilismo & 48 & 24,6 \\
$\quad$ Nunca & 49 & 63,4 \\
$\quad$ Atual & & 20,8 \\
$\quad$ Prévio & 116 & 15,8 \\
\hline Total & 38 & $\mathbf{1 0 0}$ \\
\hline
\end{tabular}

HAS = hipertensão arterial sistêmica; DM = diabetes mellitus; DAC $=$ doença arterial coronariana; $\mathrm{ICC}=$ insuficiência cardíaca congestiva; $\mathrm{AVC}=$ acidente vascular cerebral

Tabela 25 - Variáveis cardíacas, carotídeas e relacionadas ao polígono de Willis dos participantes do estudo neuropatológico $(\mathrm{n}=183)$. BEH-GEEC-FMUSP, 2005 a 2008

\begin{tabular}{lll}
\hline Variável & Média & Desvio padrão \\
\hline Peso cardíaco $(\mathrm{g})$ & 383,5 & 119,2 \\
Espessura VE $(\mathrm{mm})$ & 12,3 & 2,6 \\
Obstrução ACCD $(\%)$ & 33,5 & 28,6 \\
Obstrução ACID $(\%)$ & 28,6 & 18,0 \\
Obstrução ACCE $(\%)$ & 31,1 & 14,2 \\
Obstrução ACIE (\%) & 28,2 & 21,8 \\
EIM carótida comum (mm) & 1,0 & 0,2 \\
EIM carótida interna (mm) & 0,76 & 0,26 \\
Obstrução arterial PW (\%) & 18,6 & 16,4 \\
No de artérias com ateroma/PW & 3,5 & 2,8 \\
No de artérias com obstrução>50\%/PW & 2,3 & 2,4 \\
\hline VE = ventrículo esquerdo, ACCD=artéria carótida comum direita; ACID=artéria \\
carótida interna direita; ACCE=artéria carótida comum esquerda; ACIE=artéria carótida \\
interna esquerda; EIM=espessura íntima-média, PW=polígono de Willis; No=número.
\end{tabular}




\subsubsection{Análise univariada}

\section{Dados demográficos}

Após classificação neuropatológica, os participantes foram comparados quanto aos dados demográficos (Tabela 26). Os portadores de DA e DV eram mais velhos que os controles $(\mathrm{p}<0,001)$. Os grupos também foram diferentes quanto ao estado civil. A maioria dos controles era composta por indivíduos casados, enquanto nos portadores de DA e DV predominavam os viúvos $(\mathrm{p}=0,05)$. Quanto à causa de óbito, entre todos os grupos predominava a morte por doença cardiovascular. Entretanto, nos grupos com demência diminuiu relativamente a importância desta e aumentou relativamente a participação de causas infecciosas e "outras causas de óbito" $(\mathrm{p}=0,002)$. Os grupos também foram diferentes quanto à classificação sócio-econômica. Entre os controles e os portadores de DV, predominou a classe social $\mathrm{C}$, enquanto que a maioria dos indivíduos com DA eram da classe B. 
Resultados

Tabela 26 - Perfil demográfico de indivíduos controle, portadores de doença de Alzheimer (DA) e demência vascular (DV). Estudo neuropatológico ( $\mathrm{n}=183)$, BEHGEEC-FMUSP, 2005 a 2008

\begin{tabular}{|c|c|c|c|c|}
\hline Variável & Controle & DA & DV & $\mathbf{p}$ \\
\hline Idade, média (DP) & $70,3(11,5)$ & $80,1(7,6) \#$ & $78,7(9,8) \#$ & $<0,001$ \\
\hline Sexo, n $(\%)$ & $60(48,4)$ & $21(67,7)$ & $15(53,6)$ & 0,15 \\
\hline Feminino & $64(51,6)$ & $10(32,3)$ & $13(46,4)$ & \\
\hline \multicolumn{5}{|l|}{ Masculino } \\
\hline Raça, n (\%)* & $78(63,9)$ & $23(74,2)$ & $19(67,9)$ & 0,42 \\
\hline Branca & $13(10,7)$ & $5(16,1)$ & $2(7,1)$ & \\
\hline Negra & $26(21,3)$ & $2(6,50)$ & $7(25,0)$ & \\
\hline Parda & $5(4,1)$ & $1(3,2)$ & $0(0)$ & \\
\hline \multicolumn{5}{|l|}{ Amarela } \\
\hline Estado civil, $\mathbf{n}(\%) *$ & $16(12,9)$ & $4(12,9)$ & $1(3,7)$ & 0,05 \\
\hline Solteiro & $58(46,8)$ & $9(29,0)$ & $9(33,3)$ & \\
\hline Casado & $40(32,3)$ & $18(58,1)$ & $15(55,6)$ & \\
\hline Viúvo & $10(8,1)$ & $0(0)$ & $2(7,4)$ & \\
\hline \multicolumn{5}{|l|}{ Divorciado } \\
\hline Escolaridade,média (DP) & $4,6(3,7)$ & $3,5(3,3)$ & $3,9(3,7)$ & 0,31 \\
\hline Lateralização, n $(\%) *$ & $117(97,5)$ & $27(90,0)$ & $24(96,0)$ & 0,17 \\
\hline Destro & $3(2,5)$ & $3(10,0)$ & $1(4,0)$ & \\
\hline \multicolumn{5}{|l|}{ Canhoto } \\
\hline Causa de óbito, n (\%) & $89(71,8)$ & $17(54,8)$ & $16(57,1)$ & $<0,01$ \\
\hline Cardiovascular & $8(6,5)$ & $4(12,9)$ & $7(25,0)$ & \\
\hline Infecciosa & $10(8,1)$ & $0(0)$ & $1(3,6)$ & \\
\hline Oncológica & $17(13,7)$ & $8(25,8)$ & $4(14,3)$ & \\
\hline Outras & $0(0)$ & $2(6,5)$ & $0(0)$ & \\
\hline \multicolumn{5}{|l|}{ Indeterminada } \\
\hline Classe social, n (\%) & $5(4,0)$ & $4(12,9)$ & $1(3,6)$ & 0,05 \\
\hline A & $26(21,0)$ & $13(41,9)$ & $8(28,6)$ & \\
\hline B & $67(54,0)$ & $7(22,6)$ & $11(39,3)$ & \\
\hline $\mathrm{C}$ & $24(19,4)$ & $7(22,6)$ & $7(28,6)$ & \\
\hline $\mathrm{D}$ & $2(1,6)$ & $0(0)$ & $0(0)$ & \\
\hline $\mathrm{E}$ & & & & \\
\hline Total, $\mathbf{n}$ & 124 & 31 & 28 & \\
\hline
\end{tabular}

\section{Fatores de risco cardiovascular}

Em relação ao FRCV, os grupos foram diferentes quanto às presenças de AVC $(\mathrm{p}=0,002)$, sedentarismo $(\mathrm{p}=0,05)$ e IMC $(\mathrm{p}=0,02)($ Tabela 27). 
Resultados

Tabela 27 - Fatores de risco cardiovascular dos indivíduos controle, portadores de doença de Alzheimer (DA) e demência vascular (DV). Estudo neuropatológico ( $n=183)$, BEH-GEEC-FMUSP, 2005 a 2008

\begin{tabular}{lllll}
\hline Variável & Controle & DA & DV & p \\
\hline HAS, n (\%) & $86(69,4)$ & $20(64,5)$ & $18(64,3)$ & 0,80 \\
DM, n (\%) & $35(28,2)$ & $6(19,4)$ & $9(32,1)$ & 0,50 \\
DAC entrevista, n (\%) & $43(34,7)$ & $6(19,4)$ & $9(32,1)$ & 0,26 \\
DAC autópsia, n (\%) & $82(66,1)$ & $17(54,8)$ & $20(71,4)$ & 0,37 \\
ICC entrevista, n (\%) & $30(24,2)$ & $6(19,4)$ & $3(10,7)$ & 0,28 \\
ICC autópsia, n (\%) & $60(48,4)$ & $8(25,8)$ & $10(35,7)$ & 0,06 \\
Arritmia, n (\%) & $14(11,3)$ & $1(3,2)$ & $3(10,7)$ & 0,40 \\
IAP, n (\%) & $4(3,2)$ & $0(0)$ & $2(7,1)$ & 0,31 \\
Dislipidemia, n (\%) & $10(8,1)$ & $3(9,7)$ & $1(3,6)$ & 0,65 \\
AVC referido, n (\%) & $10(8,1)$ & $4(12,9)$ & $9(32,1)$ & 0,002 \\
Sedentarismo, n (\%) & $78(62,9)$ & $23(74,2)$ & $24(85,7)$ & 0,05 \\
Tabagismo, n (\%) & & & & 0,24 \\
Nunca & $56(45,2)$ & $19(61,3)$ & $15(53,6)$ & \\
Atual & $38(30,6)$ & $6(19,4)$ & $4(14,3)$ & \\
Prévio & $30(24,2)$ & $6(19,4)$ & $9(32,1)$ & \\
Etilismo, n (\%) & & & & 0,56 \\
Nunca & $74(59,7)$ & $23(74,2)$ & $19(67,9)$ & \\
Atual & $28(22,6)$ & $4(12,9)$ & $6(21,4)$ & \\
Prévio & $22(17,7)$ & $4(12,9)$ & $3(10,7)$ & \\
IMC, média (DP) & $24,0(4,8)$ & $22,3(3,7)$ & $21,9(3,2) \#$ & 0,02 \\
\hline Total & 124 & 31 & 28 & \\
\hline
\end{tabular}

HAS=hipertensão arterial sistêmica; DM=diabetes mellitus; DAC=doença arterial coronariana; ICC=insuficiência cardíaca congestiva; IAP=insuficiência arterial periférica; $A V C=$ acidente vascular cerebral; IMC=índice de massa corpórea; $\mathrm{DP}=$ desvio padrão.

\# Diferente do controle, $\mathrm{p}<0,05$.

\section{Avaliação cardíaca}

Não foram encontradas diferenças na amostra estudada em relação às variáveis

cardíacas (Tabela 28).

Tabela 28 - Variáveis cardíacas do grupo controle, portadores de doença de Alzheimer (DA) e demência vascular (DV). Estudo neuropatológico $(n=183)$, BEH-GEECFMUSP, 2005 a 2008

\begin{tabular}{lllll}
\hline Variável & Controle & DA & DV & p \\
\hline Peso cardíaco, $(\mathbf{g})^{*}$ & $397,3(121,0)$ & $354,5(120,7)$ & $354,6(101,5)$ & 0,07 \\
Espessura VE $(\mathbf{m m}) *$ & $12,4(2,6)$ & $12,5(2,3)$ & $12,0(3,1)$ & 0,70 \\
Hipertrofia miocárdica, & $55(44,4)$ & $14(45,2)$ & $8(28,6)$ & 0,29 \\
n $(\%)$ & & & & \\
\hline
\end{tabular}

\footnotetext{
*média (desvio padrão); VE=ventrículo esquerdo
} 


\section{Avaliação de artérias carótidas}

Os grupos controle, DA e DV foram comparados quanto à região de maior obstrução arterial por aterosclerose em artéria carótida comum, artéria carótida interna, artéria carótida direita e artéria carótida esquerda. Não foi encontrada diferença significante entre os grupos (Tabela 29).

Tabela 29 - Média (desvio padrão) da porcentagem de obstrução em artérias carótidas no grupo controle, doença de Alzheimer (DA) e demência vascular (DV). Estudo neuropatológico ( $\mathrm{n}=183)$, BEH-GEEC-FMUSP, 2005 a 2008

\begin{tabular}{lllll}
\hline Variável & Controle & DA & DV & p \\
\hline Carótida comum & $45,3(17,1)$ & $45,1(15,5)$ & $50,4(16,7)$ & 0,42 \\
Carótida interna & $43,5(22,5)$ & $46,3(28,3)$ & $53,8(27,7)$ & 0,28 \\
Carótida direita & $44,9(19,5)$ & $43,8(16,9)$ & $54,5(22,5)$ & 0,10 \\
Carótida esquerda & $44,7(19,0)$ & $50,0(24,6)$ & $54,3(21,8)$ & 0,12 \\
\hline
\end{tabular}

Os valores de maior obstrução em artérias carótidas foram divididos em dois grupos: porcentagem de obstrução arterial menor do que $75 \%$ e porcentagem de estenose arterial $\geq 75 \%$. Os grupos controle, DA e DV foram comparados em relação a esta classificação de obstrução de artérias carótidas. Foram observadas freqüências relativas crescentes de obstruções $\geq 75 \%$ em artérias carótidas interna e esquerda, quando foram avaliados os grupos controle, DA e DV (Tabela 30).

Tabela 30 - Frequência de obstrução arterial $\geq 75 \%$ em artérias carótidas comum, interna, direita e esquerda entre o grupo controle, portadores de DA e DV. Estudo neuropatológico ( $\mathrm{n}=183$ ), BEH-GEEC-FMUSP, 2005 a 2008

\begin{tabular}{lllll}
\hline Variável & Controle & DA & DV & p \\
\hline ACC, $\mathbf{n}(\%)$ & $9(7,3)$ & $1(3,2)$ & $2(7,1)$ & 0,71 \\
ACI, $\mathbf{n}(\%)$ & $11(8,9)$ & $6(19,4)$ & $10(35,7)$ & 0,001 \\
ACD, $\mathbf{n}(\%)$ & $9(7,3)$ & $2(6,5)$ & $5(17,9)$ & 0,18 \\
ACE, $\mathbf{n}(\%)$ & $9(7,3)$ & $6(19,4)$ & $8(28,6)$ & 0,004 \\
\hline ACC
\end{tabular}

$\mathrm{ACC}=$ artéria carótida comum; $\mathrm{ACI}=$ artéria carótida interna; $\mathrm{ACD}=$ artéria carótida direita; $\mathrm{ACE}=$ artéria carótida esquerda. 
Resultados

Foram analisados separadamente os dados de indivíduos com DA e do grupo controle em relação à porcentagem de obstrução de artérias carótidas e calculados os odds ratio dos portadores de obstrução arterial $\geq 75 \%$ em relação àqueles com estenoses arteriais < 75\% (Tabela 31). Os portadores de alguma obstrução arterial $\geq 75 \% \mathrm{em}$ artéria carótida esquerda tiveram uma chance de DA três vezes maior do que aqueles com obstruções arteriais $<75 \%$.

Tabela 31 - Odds ratio para doença de Alzheimer (DA), de acordo com porcentagem de obstrução arterial de artérias carótidas. Estudo neuropatológico $(n=155)$, BEH-GEECFMUSP, 2005 a 2008

\begin{tabular}{|c|c|c|c|c|c|}
\hline Obstrução arterial & Com DA & Sem DA & OR & IC 95\% & $\mathbf{p}$ \\
\hline \multicolumn{6}{|l|}{$\mathrm{ACC}$} \\
\hline$<75 \%$ & 30 & 115 & 1,0 & & \multirow[t]{2}{*}{0,69} \\
\hline$\geq 75 \%$ & 1 & 9 & 0,43 & $0,05-3,50$ & \\
\hline \multicolumn{6}{|l|}{$\bar{A} \mathbf{C I}$} \\
\hline$<75 \%$ & 25 & 113 & 1,0 & & \multirow[t]{2}{*}{0,09} \\
\hline$\geq 75 \%$ & 6 & 11 & 2,47 & $0,83-7,30$ & \\
\hline \multicolumn{6}{|l|}{ ACD } \\
\hline$<75 \%$ & 29 & 115 & 1,0 & & \multirow[t]{2}{*}{1,0} \\
\hline$\geq 75 \%$ & 2 & 9 & 0,88 & $0,18-4,30$ & \\
\hline \multicolumn{6}{|l|}{$\mathbf{A C E}$} \\
\hline$<75 \%$ & 25 & 115 & 1,0 & & \multirow[t]{2}{*}{0,04} \\
\hline$\geq 75 \%$ & 6 & 9 & 3,07 & $1,001-9,40$ & \\
\hline
\end{tabular}

$\mathrm{OR}=$ odds ratio; IC 95\%=intervalo de confiança 95\%; ACC=artéria carótida comum; $\mathrm{ACI}=$ artéria carótida interna; $\mathrm{ACD}=$ artéria carótida direita; $\mathrm{ACE}=$ artéria carótida esquerda.

Os mesmos procedimentos foram feitos na comparação do grupo DV e controle (Tabela 32). Os indivíduos com alguma obstrução arterial $\geq 75 \%$ em artéria carótida interna tiveram uma chance de DV 5,7 vezes maior do que aqueles com obstruções arteriais $<75 \%$. Obstrução $\geq 75 \%$ em artéria carótida esquerda associou-se a uma chance de DV 5,1 vezes maior. 
Resultados

Tabela 32 - Odds ratio para demência vascular (DV), de acordo com porcentagem de obstrução arterial de artérias carótidas. Estudo neuropatológico $(\mathrm{n}=152), \mathrm{BEH}-\mathrm{GEEC}$ FMUSP, 2005 a 2008

\begin{tabular}{|c|c|c|c|c|c|}
\hline Obstrução Arterial & Com DV & Sem DV & OR & IC $95 \%$ & $\mathbf{p}$ \\
\hline \multicolumn{6}{|l|}{$\mathrm{ACC}$} \\
\hline$<75 \%$ & 26 & 115 & 1,0 & & \multirow[t]{3}{*}{1,00} \\
\hline$\geq 75 \%$ & 2 & 9 & 0,98 & $0,20-4,82$ & \\
\hline \multicolumn{5}{|l|}{$\overline{A C I}$} & \\
\hline$<75 \%$ & 18 & 113 & 1,0 & & \multirow[t]{2}{*}{$<0,001$} \\
\hline$\geq 75 \%$ & 10 & 11 & 5,71 & $2,12-15,36$ & \\
\hline \multicolumn{6}{|l|}{$\overline{A C D}$} \\
\hline$<75 \%$ & 23 & 115 & 1,0 & & \multirow[t]{2}{*}{0,14} \\
\hline$\geq 75 \%$ & 5 & 9 & 2,78 & $0,85-9,05$ & \\
\hline \multicolumn{6}{|l|}{$\mathbf{A C E}$} \\
\hline$<75 \%$ & 20 & 115 & 1,0 & & \multirow[t]{2}{*}{0,001} \\
\hline$\geq 75 \%$ & 8 & 9 & 5,11 & $1,76-14,81$ & \\
\hline
\end{tabular}

$\mathrm{OR}=$ odds ratio; IC 95\%=intervalo de confiança 95\%; $\mathrm{ACC}=$ artéria carótida comum; $\mathrm{ACI}=$ artéria carótida interna; $\mathrm{ACD}=$ artéria carótida direita; $\mathrm{ACE}=$ artéria carótida esquerda.

O EIM em artérias carótidas comum e interna foi semelhante entre o grupo controle, portadores de DA e DV (Tabela 33).

Tabela 33 - Média (desvio padrão) da espessura íntima-média (EIM) de artérias carótidas nos grupos controle, doença de Alzheimer (DA) e demência vascular (DV). Estudo neuropatológico ( $\mathrm{n}=183$ ), BEH-GEEC-FMUSP, 2005 a 2008

\begin{tabular}{lllll}
\hline EIM $(\mathbf{m m})$ & Controle & DA & DV & p \\
\hline Carótida comum & $1,03(0,25)$ & $1,03(0,17)$ & $1,09(0,27)$ & 0,46 \\
Carótida interna & $0,74(0,25)$ & $0,76(0,30)$ & $0,84(0,29)$ & 0,38 \\
\hline
\end{tabular}

\section{Avaliação das artérias do $P W$}

A porcentagem de obstrução arterial do polígono de Willis, o número de artérias com ateroma por PW e o número de artérias com obstrução > 50\% por PW apresentaram valores progressivamente maiores quando analisados controles, portadores de DA e DV.

Posteriormente, foi realizada a comparação dos grupos dois a dois (controle $\mathrm{x}$ DA, controle x DV e DA x DV). Foi encontrada diferença significante entre controles e 
Resultados

DV em relação às três variáveis analisadas no PW. A porcentagem de obstrução arterial do polígono de Willis, o número de artérias com ateroma por PW e o número de artérias com obstrução $>50 \%$ por $\mathrm{PW}$ foram maiores em portadores de $\mathrm{DV}$ do que em controles. Na comparação entre controles e DA, observou-se maior número de artérias com aterosclerose por PW em portadores de DA do que em controles (Tabela 34 e Figura 25). Não foram encontradas diferenças entre os grupos DA e DV quantos às variáveis analisadas.

Tabela 34 - Aterosclerose do polígono de Willis (PW) nos indivíduos controle, portadores de doença de Alzheimer (DA) e demência vascular (DV). Estudo neuropatológico (n=183), BEH-GEEC-FMUSP, 2005 a 2008

\begin{tabular}{lllll}
\hline Aterosclerose do PW & Controle & DA & DV & p \\
\hline $\begin{array}{l}\text { Obstrução arterial, média (DP) } \\
\begin{array}{l}\text { No de artérias com ateroma/PW, } \\
\text { média (DP) }\end{array}\end{array}$ & $3,0(2,7)$ & $4,29(2,3) \#$ & $4,90(3,0) \#$ & 0,001 \\
$\begin{array}{l}\text { No de artérias com } \\
\text { obstrução }>\mathbf{5 0 \% / P W , ~ m e ́ d i a ~ ( D P ) ~}\end{array}$ & $2,0(2,3)$ & $2,6(2,1)$ & $3,4(3,0) \#$ & 0,01 \\
\hline $\begin{array}{l}\text { DP=desvio padrão } \\
\text { \# diferente do controle, } \mathrm{p}<0,05\end{array}$ & & & & \\
\hline
\end{tabular}

As artérias basilar, comunicante posterior direita, cerebral média direita e esquerda e cerebral anterior direita e esquerda mostraram diferenças entre os grupos quanto à porcentagem de obstrução arterial $(\mathrm{p}<0,05)$. Nestas artérias a porcentagem de obstrução foi maior em portadores de DV em relação a controles (Tabela 35). A artéria cerebral média esquerda apresentou maior porcentagem de obstrução arterial em portadores de DA do que em controles. Em relação à comparação entre indivíduos com DA e DV, não foram encontradas diferenças nas porcentagens de obstrução arterial em cada uma destas artérias do PW. 


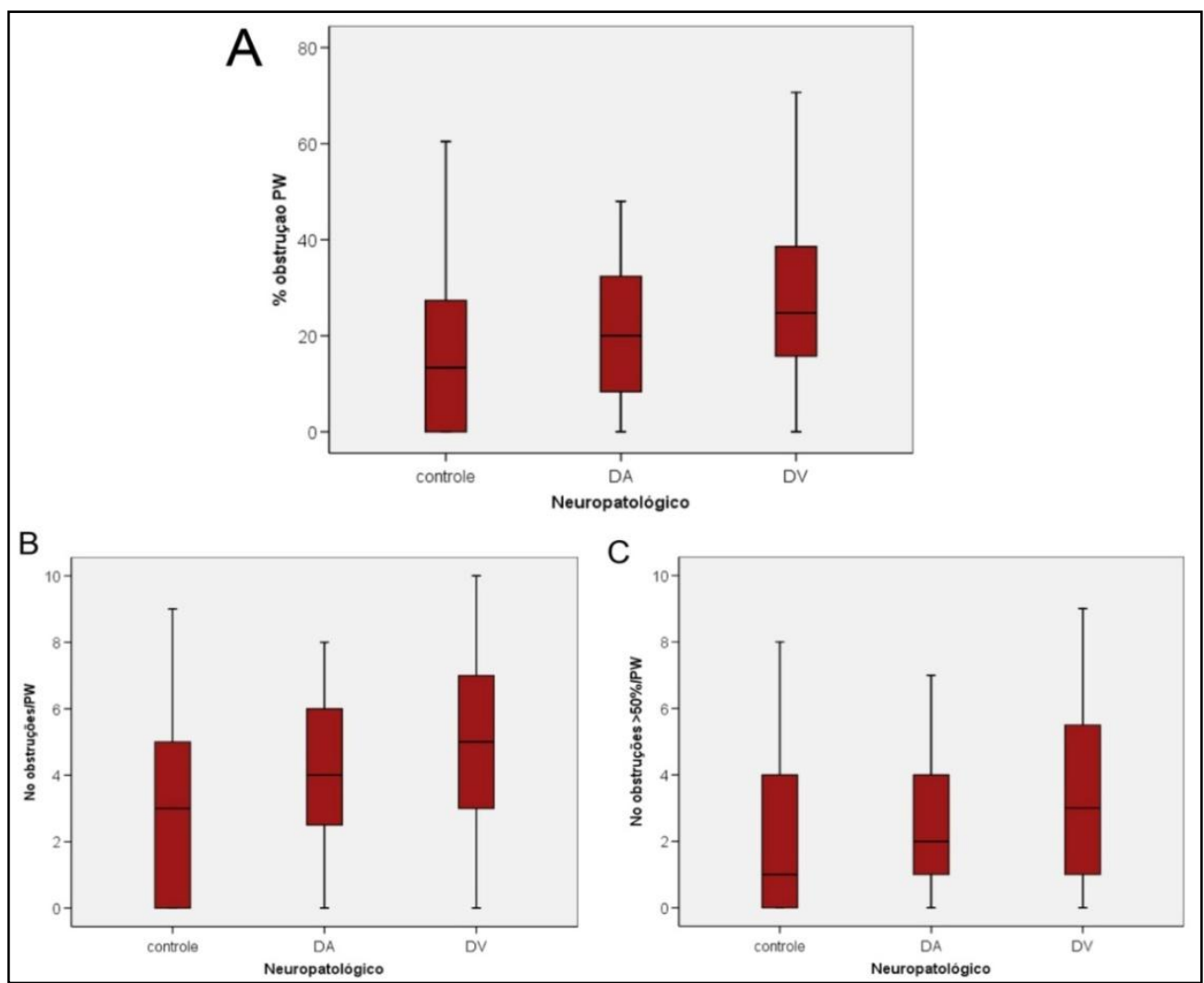

Figura 25. (A) Porcentagem de obstrução arterial nos grupos controle, doença de Alzheimer (DA) e demência vascular (DV). (B) Número de artérias com ateroma/PW nos três grupos. (C) Número de artérias com obstrução maior do que 50\%/PW nos três grupos

Tabela 35 - Média (desvio padrão) da porcentagem de obstrução arterial nas artérias do polígono de Willis nos indivíduos controle, portadores de doença de Alzheimer (DA) e demência vascular (DV). Estudo neuropatológico ( $n=183$ ), BEH-GEEC-FMUSP, 2005 a 2008

\begin{tabular}{|c|c|c|c|c|}
\hline Artéria & Controle & $\mathbf{D A}$ & DV & $\mathbf{p}$ \\
\hline Basilar & $29,4(28,4)$ & $41,7(25,6)$ & $38,6(30,1) \#$ & 0,04 \\
\hline Cerebral posterior direita & $23,0(33,4)$ & $34,5(35,0)$ & $36,6(35,9)$ & 0,08 \\
\hline $\begin{array}{l}\text { Cerebral posterior } \\
\text { esquerda }\end{array}$ & $24,6(33,5)$ & $25,1(30,4)$ & $32,6(38,1)$ & 0,40 \\
\hline $\begin{array}{l}\text { Comunicante posterior } \\
\text { direita }\end{array}$ & $0,5(5,2)$ & $0(0)$ & $3,1(14,1) \#$ & 0,001 \\
\hline $\begin{array}{l}\text { Comunicante posterior } \\
\text { esquerda }\end{array}$ & $3,5(15,7)$ & $0(0)$ & $0(0)$ & 0,49 \\
\hline Carótida direita & $17,0(24,9)$ & $20,1(25,8)$ & $26,5(31,7)$ & 0,23 \\
\hline Carótida esquerda & $15,8(24,6)$ & $18,2(24,0)$ & $28,1(28,9)$ & 0,24 \\
\hline Comunicante anterior & $0(0)$ & $0(0)$ & $0(0)$ & 1,0 \\
\hline Cerebral média direita & $21,3(29,0)$ & $36,7(29,6)$ & $40,7(30,0) \#$ & 0,02 \\
\hline Cerebral média esquerda & $23,4(29,9)$ & $38,4(29,7) \#$ & $47,9(30,8) \#$ & $<0,001$ \\
\hline Cerebral anterior direita & $5,3(17,4)$ & $9,4(23,2)$ & $24,7(33,5) \#$ & $<0,01$ \\
\hline Cerebral anterior esquerda & $5,20(16,7)$ & $16,3(31,7)$ & $17,5(29,6) \#$ & 0,02 \\
\hline
\end{tabular}

\# diferente do controle, $\mathrm{p}<0,05$ 


\subsubsection{Análise multivariada}

\section{Variáveis demográficas e FRCV}

As variáveis demográficas e FRCV que mostraram associação significante com DA e DV foram selecionadas para avaliação em modelo de regressão logística. Foi analisado o odds ratio para cada variável em relação à DA e em relação à DV, como mostra a Tabela 36.

Tabela 36 - Odds ratio para doença de Alzheimer (DA) em relação a controles e para demência vascular (DV) em relação a controles, segundo características demográficas e fatores de risco cardiovascular, de acordo com modelo de regressão multivariável. Estudo neuropatológico ( $\mathrm{n}=183)$, BEH-GEEC-FMUSP, 2005 a 2008

\begin{tabular}{lll}
\hline Variável & DA - OR* $(\mathbf{I C ~ 9 5 \% )}$ & $\mathbf{D V}-\mathbf{O R}^{*}(\mathbf{I C ~ 9 5 \% )}$ \\
\hline Idade & $1,09(1,04-1,14)^{\mathrm{a}}$ & $1,07(1,02-1,11)^{\mathrm{b}}$ \\
AVC & $1,38(0,36-5,32)$ & $4,72(1,50-14,85)^{\mathrm{b}}$ \\
Sedentarismo & $1,28(0,49-3,32)$ & $2,78(0,86-8,99)$ \\
IMC & $0,96(0,87-1,05)$ & $0,96(0,86-1,06)$ \\
\hline
\end{tabular}

*ajustado para as demais variáveis da tabela ${ }^{\mathrm{a}} \mathrm{p}<0,001 ;{ }^{\mathrm{p}}<0,01$

$\mathrm{OR}=$ odds ratio; IC 95\%=intervalo de confiança 95\%; $\mathrm{AVC}=$ acidente vascular cerebral; $\mathrm{IMC}=$ índice de massa corpórea

Após esta análise, idade foi fator de risco para DA e DV. AVC referido pelo informante continuou associado a DV, conferindo um risco 4,8 vezes maior.

\section{Variáveis carotídeas e relacionadas ao $P W$}

Modelo de regressão logística foi aplicado para investigar a associação entre variáveis carotídeas e relacionadas ao PW com DA, ajustando-se os resultados para idade, sexo e escolaridade. Obstrução $\geq 75 \%$ em artéria carótida interna e carótida esquerda permaneceram associadas à DA. Com os ajustes efetuados para idade, sexo e 
Resultados

escolaridade, foi encontrado um valor de odds ratio maior, mas com um aumento considerável do intervalo de confiança (Tabela 37). As variáveis relacionadas ao PW perderam associação significante com DA, após ajuste para idade, sexo e escolaridade.

Outro modelo foi feito para analisar a associação entre as variáveis carotídeas e do PW com DV, considerando-se também idade, sexo e escolaridade como variáveis de confusão. Aterosclerose carotídea e do PW permaneceram associadas à DV após ajuste (Tabela 38).

Tabela 37 - Odds ratio para doença de Alzheimer (DA) em relação a controles, segundo aterosclerose carotídea e do polígono de Willis (PW), ajustado para idade, sexo e escolaridade, de acordo com modelo de regressão multivariável. Estudo neuropatológico ( $\mathrm{n}=155)$, BEH-GEEC-FMUSP, 2005 a 2008

\begin{tabular}{lll}
\hline Variável & OR $(\mathbf{I C ~ 9 5 \% )}$ & $\mathbf{p}$ \\
\hline Artéria carótida interna & $3,96(1,10-14,22)$ & 0,04 \\
Artéria carótida esquerda & $5,73(1,51-21,73)$ & 0,01 \\
Obstrução arterial & $1,01(0,98-1,04)$ & 0,56 \\
No de artérias com ateroma/PW & $1,10(0,93-1,31)$ & 0,27 \\
No de artérias com obstrução $>\mathbf{5 0 \%} / \mathbf{P W}$ & $1,02(0,84-1,24)$ & 0,85 \\
\hline
\end{tabular}

$\mathrm{OR}=$ odds ratio; IC 95\%=intervalo de confiança 95\%; $\mathrm{No}=$ número

Tabela 38 - Odds ratio para demência vascular (DV) em relação a controles, segundo aterosclerose carotídea e do polígono de Willis (PW), ajustado para idade, sexo e escolaridade, de acordo com modelo de regressão multivariável. Estudo neuropatológico ( $\mathrm{n}=152)$, BEH-GEEC-FMUSP, 2005 a 2008

\begin{tabular}{lll}
\hline Variável & OR $(\mathbf{I C ~ 9 5 \% )}$ & $\mathbf{p}$ \\
\hline Artéria carótida interna & $5,47(1,86-16,05)$ & 0,002 \\
Artéria carótida esquerda & $5,17(1,66-16,09)$ & 0,006 \\
Obstrução arterial & $1,04(1,01-1,07)$ & 0,006 \\
No de artérias com ateroma/PW & $1,24(1,05-1,47)$ & 0,009 \\
No de artérias com obstrução>50\%/PW & $1,21(1,01-1,43)$ & 0,03 \\
\hline
\end{tabular}

$\mathrm{OR}=$ odds ratio; IC $95 \%=$ intervalo de confiança 95\%; No=número

Considerando que as associações que permaneceram significantes após a análise multivariada descrita previamente pudessem ser intermediadas pela presença de lesões isquêmicas cerebrais, foi optado por investigar, em um novo modelo de regressão 
logística, o papel dos infartos lacunares nas associações descritas entre aterosclerose carotídea e do PW com DA e DV.

Em relação à associação entre obstrução $\geq 75 \%$ em artérias carótidas interna e esquerda com DA, a adição da variável "infarto lacunar" ao modelo não alterou a associação encontrada (artéria carótida interna com demência: OR=3,68, IC 95\% 1,0512,90, $\mathrm{p}=0,04)$; artéria carótida esquerda com demência: OR=5,17, IC 95\% 1,33-20,04, $\mathrm{p}=0,02)$.

O mesmo foi verificado em relação à associação entre artéria carótida interna e DV, onde a adição da variável "infarto lacunar" não alterou o valor de odds ratio encontrado no modelo de regressão prévio (OR 3,68, IC 95\% 1,05-12,90, p=0,04). Em relação à associação entre artéria carótida esquerda e DV, a presença de infarto lacunar também não alterou o resultado $(\mathrm{OR}=5,17$, IC 95\% 1,33-20,04, $\mathrm{p}=0,02)$.

Quanto à associação entre as variáveis do PW e DV, a adição de infarto lacunar ao modelo de regressão não alterou a significância da relação entre porcentagem de obstrução arterial do PW e número de artérias com ateroma por PW com DV (Porcentagem de obstrução arterial - OR=1,04, IC 95\%=1,005-1,07, p=0,02; Número de artérias com ateroma por $\mathrm{PW}$ - $\mathrm{OR}=1,21$, IC 95\% 1,003-1,47, p=0,04). Por outro lado, o ajuste para a presença de infarto lacunar, fez com que a associação entre número de artérias com obstrução >50\% e DV perde-se significância (OR=1,20, IC 95\% 0,98$1,46, \mathrm{p}=0,08)$. 
Resultados

\subsection{Correlação entre a presença de lesões neuropatológicas e doença cardiovascular}

Os 183 casos submetidos ao exame neuropatológico foram classificados quanto à presença de placas neuríticas através da escala semiquantitativa do CERAD. Da mesma forma, a presença de emaranhados neurofibrilares foi quantificada pela escala de Braak e Braak. O número de participantes em cada estágio das escalas do CERAD e de Braak e Braak estão representados na Figura 26.

Os indivíduos também foram classificados de forma qualitativa quanto à presença de infarto lacunar, arteriosclerose hialina e angiopatia amilóide, segundo dados descritos na Tabela 39.
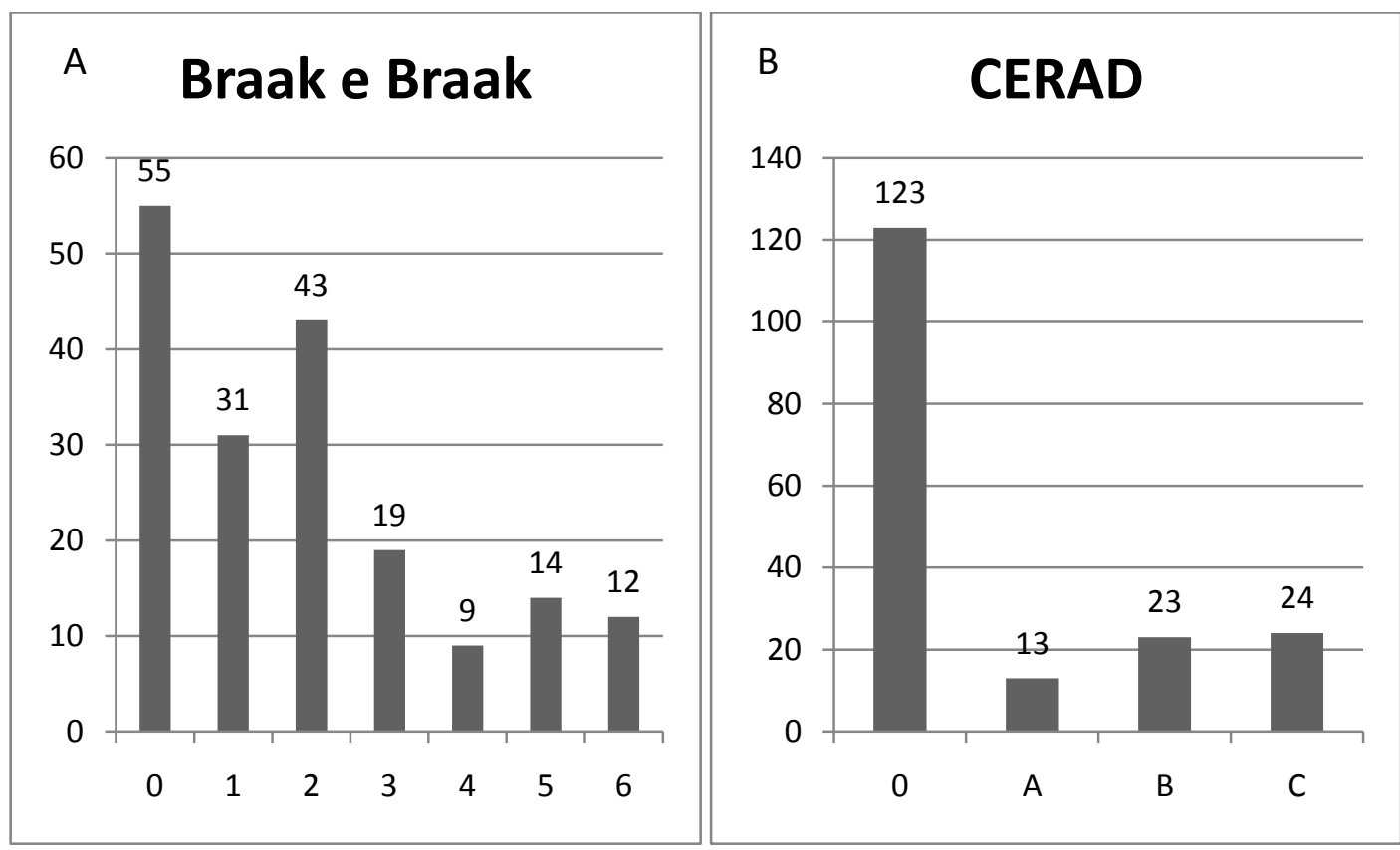

Figura 26. A - Frequência absoluta dos participantes em cada estágio da classificação de Braak e Braak. B - Frequência absoluta dos participantes em cada estágio da classificação do CERAD 
Resultados

Tabela 39 - Presença de infarto lacunar, arteriosclerose hialina e angiopatia amilóide entre os participantes do estudo neuropatológico $(n=183)$, BEH-GEEC-FMUSP, 2005 a 2008

\begin{tabular}{lcc}
\hline Variável & $\mathbf{n}$ & \% \\
\hline Infarto lacunar & 27 & 14,8 \\
Arteriosclerose hialina & 47 & 25,7 \\
Angiopatia amilóide & 15 & 8,2 \\
\hline
\end{tabular}

Estes dados foram correlacionados com as variáveis cardíacas, carotídeas e do PW. Quanto à presença de emaranhados neurofibrilares, foi encontrada correlação negativa com o peso cardíaco $\left(r_{s}=-0,272, p<0,001\right)$ e espessura de VE $\left(r_{s}=-0,144\right.$, $\mathrm{p}=0,05)$. Não foi encontrada associação entre hipertrofia miocárdica e presença de emaranhados neurofibrilares. A escala de Braak não se correlacionou às variáveis carotídeas. Em relação ao PW, houve correlação entre quantidade de emaranhados neurofibrilares e porcentagem de obstrução arterial $\left(r_{s}=0,258, p<0,001\right)$, número de artérias com aterosclerose por PW $\left(\mathrm{r}_{\mathrm{s}}=0,270, \mathrm{p}<0,001\right)$ e número de artérias com obstrução maior do que 50\% por PW ( $\left.\mathrm{r}_{\mathrm{s}}=0,211, \mathrm{p}=0,004\right)$.

Quanto à escala do CERAD, o peso cardíaco $\left(\mathrm{r}_{\mathrm{s}}=-0,213, \mathrm{p}=0,004\right)$ correlacionou-se negativamente com a presença de placas neuríticas, mas não foi encontrada correlação significante com a espessura de VE $\left(r_{s}=-0,096, p=0,20\right)$. Também não houve associação entre placas neuríticas e hipertrofia miocárdica $(\mathrm{p}=0,15)$. A escala do CERAD não se correlacionou às variáveis carotídeas. Em relação ao PW, foram verificadas correlações entre porcentagem de obstrução do arterial $\left(\mathrm{r}_{\mathrm{s}}=0,187, \mathrm{p}=0,01\right)$ e número de artérias com aterosclerose por $\mathrm{PW}\left(\mathrm{r}_{\mathrm{s}}=0,213, \mathrm{p}=0,004\right)$ com placas neuríticas. Porém, não houve correlação entre número de artérias com obstrução maior do que $50 \%$ por PW e placas neuríticas $\left(\mathrm{r}_{\mathrm{s}}=0,137, \mathrm{p}=0,06\right)$.

Quanto à presença de infarto lacunar, não foram encontradas associações com as variáveis cardíacas. Entretanto, verificou-e uma associação entre infarto lacunar e 
Resultados

presença de obstrução $\geq 75 \%$ em artéria carótida interna. O grupo com infarto lacunar apresentou maior porcentagem de obstrução do PW e maior número de artérias com aterosclerose por PW do que o grupo sem infarto (Tabela 40).

Tabela 40 - Variáveis cardíacas, carotídeas e do polígono de Willis, segundo presença de infarto cerebral lacunar, entre os participantes do estudo neuropatológico $(n=183)$. BEH-GEEC-FMUSP, 2005 a 2008

\begin{tabular}{llll}
\hline Variável & Sem infarto & Com infarto & p \\
\hline Peso cardíaco (g), média (DP) & $383,8(117,6)$ & $382,1(130,6)$ & 0,85 \\
Espessura VE (mm), média (DP) & $12,38(2,56)$ & $12,04(2,93)$ & 0,52 \\
$\begin{array}{l}\text { Hipertrofia miocárdica, n(\%) } \\
\text { Obstrução carotídea } \geq \mathbf{7 5 \%}, \mathbf{n}(\%)\end{array}$ & $70(44,9)$ & $7(25,9)$ & 0,07 \\
Carótida comum & $10(6,4)$ & $2(7,4)$ & 0,70 \\
Carótida interna & $19(12,2)$ & $8(29,6)$ & 0,02 \\
EIM carotídea, média (DP) & $0,88(0,22)$ & $0,97(0,24)$ & 0,07 \\
Obstrução PW, média (DP) & $17,69(16,56)$ & $23,75(14,81)$ & 0,04 \\
$\begin{array}{l}\text { Artérias com ateroma/PW, } \\
\text { média (DP) }\end{array}$ & $3,38(2,79)$ & $4,48(2,49)$ & 0,05 \\
$\begin{array}{l}\text { Artérias com obstrução>50\%/PW, } \\
\text { média (DP) }\end{array}$ & $2,17(2,42)$ & $2,96(2,26)$ & 0,06 \\
\hline DP=desvio padrão; EIM=espessura íntima média & & \\
\hline
\end{tabular}

Em relação à presença de arterioloesclerose hialina, os grupos foram homogêneos quanto ao peso cardíaco $(\mathrm{p}=0,54)$, espessura de $\mathrm{VE}(\mathrm{p}=0,30)$, hipertrofia miocárdica $(\mathrm{p}=0,54)$, obstrução carotídea $(\mathrm{p}=0,43)$ e espessura íntima-média de artérias carótidas $(\mathrm{p}=0,67)$. Por outro lado, entre os portadores de arterioloesclerose hialina, a porcentagem de obstrução do PW foi maior $(17,08 \pm 15,99$ vs $22,82 \pm 17,02 ; \mathrm{p}=0,04)$. Entre indivíduos com arterioloesclerose hialina, foi encontrada tendência de maior número de artérias com aterosclerose por PW $(3,31 \pm 2,75$ vs $4,19 \pm 2,73 ; \mathrm{p}=0,06)$.

Não foram encontradas associações entre angiopatia amilóide cerebral e peso cardíaco $(\mathrm{p}=0,32)$, espessura de $\operatorname{VE}(\mathrm{p}=0,47)$, hipertrofia miocárdica $(\mathrm{p}=0,47)$, obstrução carotídea $(\mathrm{p}=0,26)$, espessura íntima-média carotídea $(\mathrm{p}=0,73)$, obstrução do 
Resultados

PW (0,96), número de artérias com aterosclerose por PW $(\mathrm{p}=0,81)$ e número de artérias do PW com obstrução maior do que $50 \%$ por $\mathrm{PW}(\mathrm{p}=0,76)$.

\subsection{Estudo clinicopatológico}

Os 183 indivíduos, que tinham diagnóstico neuropatológico, foram analisados levando em consideração seu desempenho cognitivo. Os 124 controles descritos no estudo neuropatológico continuaram sob a mesma classificação, pois não apresentavam sintomas cognitivos e também não tinham lesões cerebrais suficientes para um diagnóstico neuropatológico. Os 59 indivíduos que tinham critérios neuropatológicos para doenças cerebrais e que anteriormente foram classificados em 31 casos de DA e 28 portadores de DV foram reclassificados usando agora critérios clinicopatológicos. Estes 59 casos foram divididos em 12 portadores de doença cerebral assintomática - DCA $(\mathrm{CDR}=0, \mathrm{IQCODE}<3,4$ e lesões anatomopatológicas suficientes para o diagnóstico de DA ou DV) e 47 indivíduos com demência (CDR $\geq 1, \quad$ IQCODE $\geq 3,4$ e lesões anatomopatológicas suficientes para o diagnóstico de DA ou DV) (Figura 27). 
Resultados

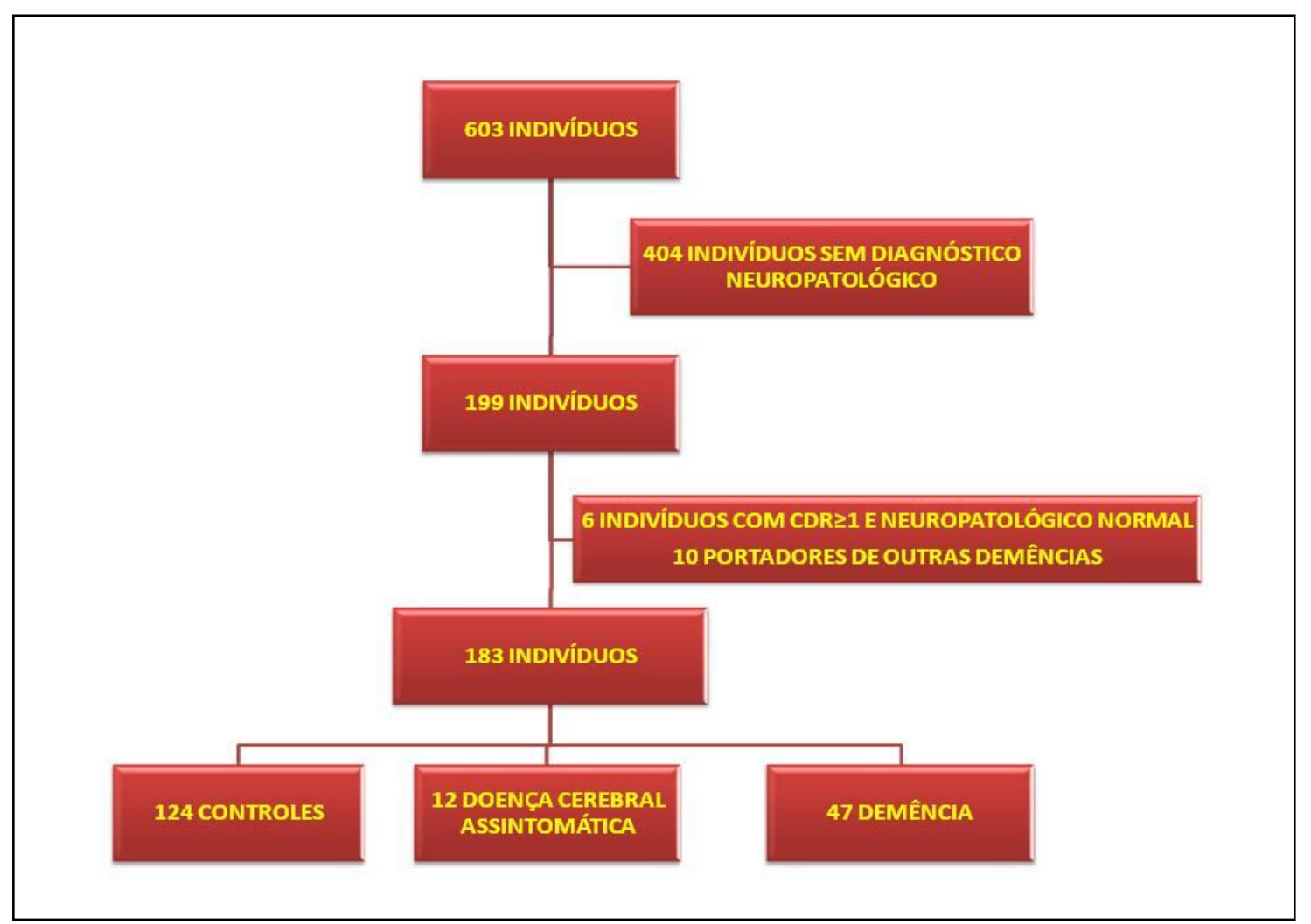

Figura 27. Fluxograma dos participantes do estudo clinicopatológico.

A distribuição dos participantes do estudo clinicopatológico encontra-se na Figura 28.

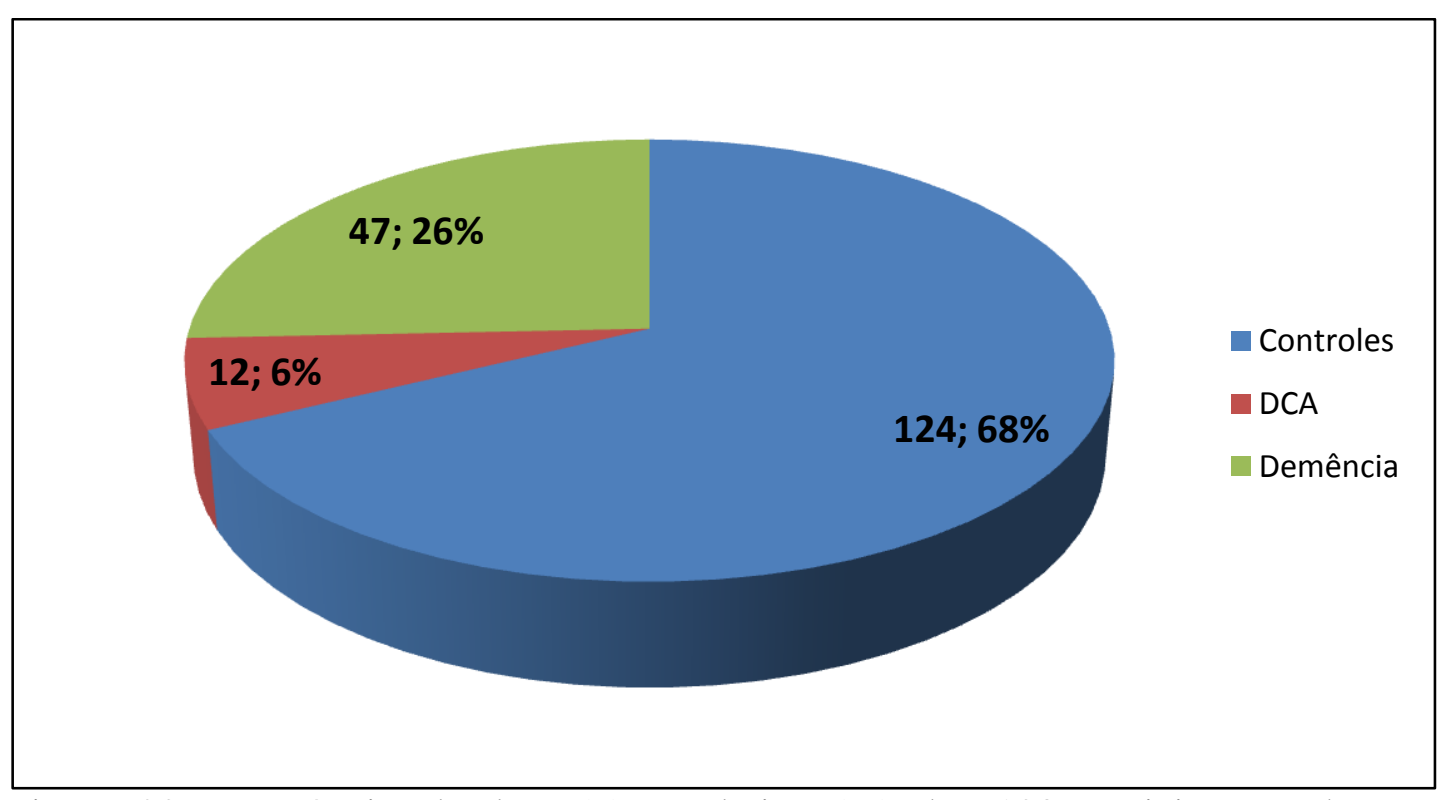

Figura 28. Frequência absoluta (n) e relativa (\%) dos 183 participantes do estudo clinicopatológico. $\mathrm{DCA}=$ doença cerebral assintomática 


\subsubsection{Análise descritiva}

Como os estudos neuropatológico e clinicopatológico contam com os mesmos participantes, a análise descritiva feita na seção 4.3.1., referente ao estudo neuropatológico, também é válida para este estudo clinicopatológico.

\subsubsection{Análise univariada}

\section{Dados demográficos}

Os grupos do estudo clinicopatológico foram diferentes quanto à idade $(\mathrm{p}<0,001)$ e escolaridade $(\mathrm{p}=0,003)$. Os portadores de DCA $(\mathrm{p}=0,03)$ e de demência $(p<0,001)$ foram significativamente mais velhos do que os controles. Não foi encontrada diferença de idade entre os grupos DCA e demência ( $\mathrm{p}=1)$. Quanto à escolaridade, esta foi menor no grupo demência tanto em relação aos controles $(p=0,03)$ quanto em relação ao grupo DCA $(\mathrm{p}=0,01)$. Embora a escolaridade dos portadores de DCA tenha sido maior do que nos controles, esta diferença não atingiu significância estatística $(\mathrm{p}=0,18)$.

Os grupos diferiram quanto à causa de óbito $(\mathrm{p}=0,03)$. Em todos os grupos predominou a causa cardiovascular, mas esta foi relativamente menor em portadores de DCA e demência, com aumento relativo de causas infecciosas e "outras causas" nestes grupos. Também ocorreu diferença entre os grupos quanto à classificação socioeconômica $(\mathrm{p}=0,01)$. Entre os portadores de DCA predominou a classe social $\mathrm{B}$, enquanto entre controles e dementados preponderou a classe C (Tabela 41). 
Tabela 41 - Perfil demográfico de indivíduos controle, portadores de doença cerebral assintomática (DCA) e de demência. Estudo clinicopatológico (n=183), BEH-GEECFMUSP, 2005 a 2008

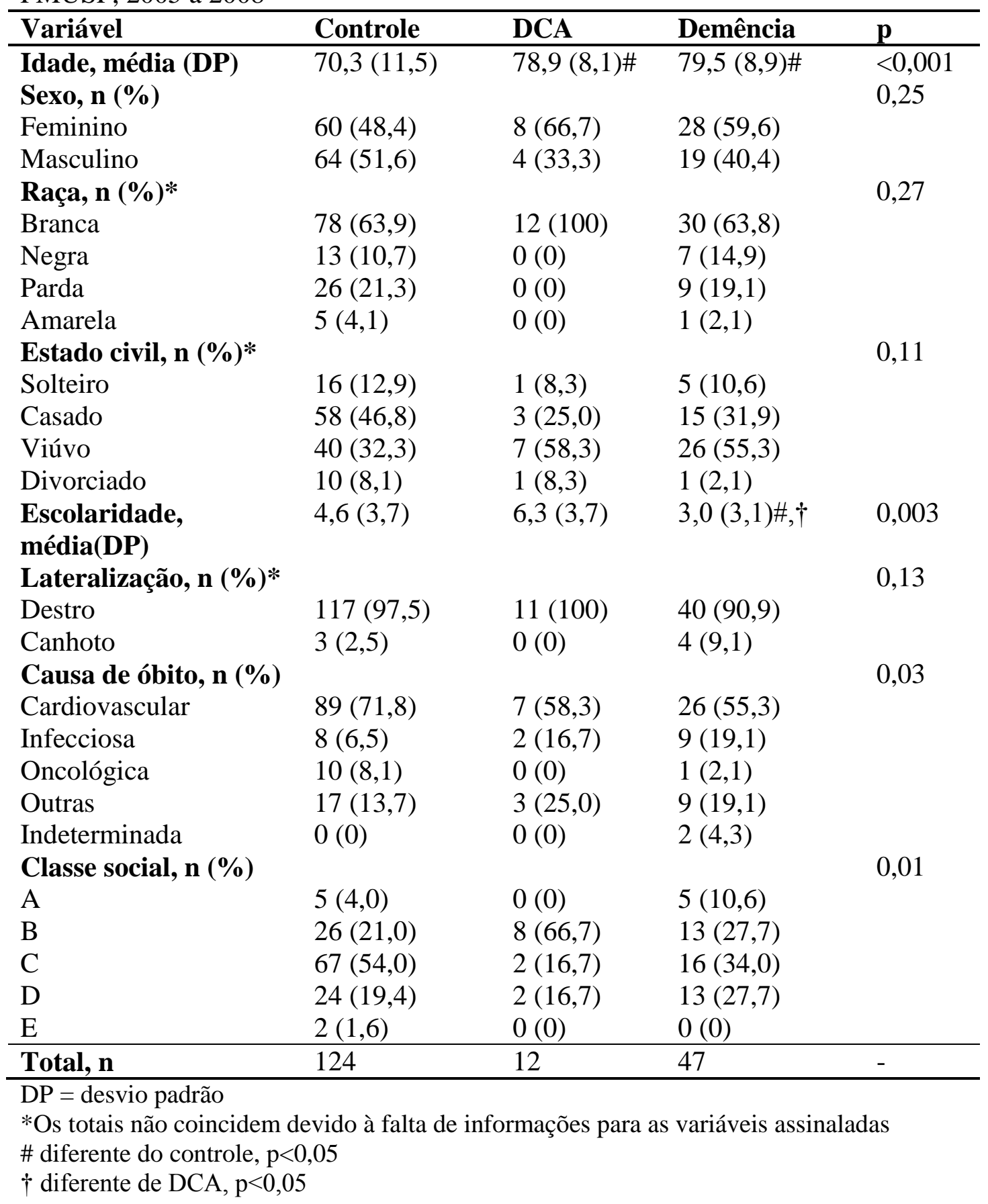

\section{Fatores de risco cardiovascular}

Em relação aos FRCV, a porcentagem de insuficiência cardíaca detectada pela autópsia foi progressivamente menor entre controles $(48,4 \%)$, portadores de DCA $(41,7 \%)$ e dementados $(27,7 \%)(\mathrm{p}=0,05)$. Os indivíduos com demência apresentavam 
Resultados

frequência relativa de AVC referido pelo informante maior do que controles e dementados $(\mathrm{p}=0,001)$. A proporção de sedentarismo também foi maior entre os indivíduos com demência $(\mathrm{p}=0,04)$. Quanto ao IMC, foi encontrada diferença entre os grupos $(\mathrm{p}=0,02)$, sendo significativamente menor em dementados em relação a controles $(\mathrm{p}=0,02)($ Tabela 42$)$.

Tabela 42 - Fatores de risco cardiovascular dos indivíduos controle, portadores de doença cerebral assintomática (DCA) e de demência. Estudo clinicopatológico $(n=183)$, BEH-GEEC-FMUSP, 2005 a 2008.

\begin{tabular}{lllll}
\hline FRCV & Controle & DCA & Demência & p \\
\hline HAS, n (\%) & $86(69,4)$ & $7(58,3)$ & $31(65,2)$ & 0,70 \\
DM, n (\%) & $35(28,2)$ & $2(16,7)$ & $13(27,7)$ & 0,69 \\
DAC entrevista, n (\%) & $43(34,7)$ & $4(33,3)$ & $11(23,4)$ & 0,37 \\
DAC autópsia, n (\%) & $82(66,1)$ & $8(66,7)$ & $29(61,7)$ & 0,86 \\
ICC entrevista, n (\%) & $30(24,2)$ & $2(16,7)$ & $7(14,9)$ & 0,38 \\
ICC autópsia, n (\%) & $60(48,4)$ & $5(41,7)$ & $13(27,7)$ & 0,05 \\
Arritmia, n (\%) & $14(11,3)$ & $1(8,3)$ & $3(6,4)$ & 0,62 \\
IAP, n (\%) & $4(3,2)$ & $0(0)$ & $2(4,3)$ & 0,76 \\
Dislipidemia, n (\%) & $10(8,1)$ & $1(8,3)$ & $3(6,4)$ & 0,93 \\
AVC referido, n (\%) & $10(8,1)$ & $0(0)$ & $13(27,7)$ & 0,001 \\
Sedentarismo, n (\%) & $78(62,9)$ & $8(66,7)$ & $39(83,0)$ & 0,04 \\
Tabagismo, n (\%) & & & & 0,29 \\
$\quad$ Nunca & $56(45,2)$ & $7(58,3)$ & $27(57,4)$ & \\
$\quad$ Atual & $38(30,6)$ & $3(25,0)$ & $7(14,9)$ & \\
$\quad$ Prévio & $30(24,2)$ & $3(16,7)$ & $13(27,7)$ & \\
Etilismo, n (\%) & & & & 0,41 \\
$\quad$ Nunca & $74(59,7)$ & $10(83,3)$ & $32(68,1)$ & \\
$\quad$ Atual & $28(22,6)$ & $2(16,7)$ & $8(17,0)$ & \\
$\quad$ Prévio & $22(17,7)$ & $0(0)$ & $7(14,9)$ & \\
IMC, média (DP) & $24,0(4,8)$ & $22,4(2,7)$ & $22,1(3,6) \#$ & 0,02 \\
\hline Total & 124 & 12 & 47 & \\
\hline
\end{tabular}

HAS=hipertensão arterial sistêmica; $\mathrm{DM}=$ diabetes mellitus; $\mathrm{DAC}=$ doença arterial coronariana; ICC=insuficiência cardíaca congestiva; IAP=insuficiência arterial periférica; AVC=acidente vascular cerebral; IMC=índice de massa corpórea

\# Diferente do controle, $\mathrm{p}<0,05$. 


\section{Avaliação cardíaca}

Não foram encontradas diferenças entre os grupos quanto ao peso cardíaco $(\mathrm{p}=0,06)$, espessura de $\operatorname{VE}(\mathrm{p}=0,79)$ e presença de hipertrofia miocárdica $(\mathrm{p}=0,63)$ (Tabela 43).

Tabela 43 - Variáveis cardíacas dos indivíduos controle, portadores de doença cerebral assintomática (DCA) e de demência. Estudo clinicopatológico $(n=183)$, BEH-GEECFMUSP, 2005 a 2008

\begin{tabular}{|c|c|c|c|c|}
\hline Variável & Controle & DCA & Demência & $\mathbf{p}$ \\
\hline $\begin{array}{l}\text { Peso cardíaco }(\mathrm{g}), \\
\text { média }(\mathrm{DP})\end{array}$ & $397,3(121,0)$ & $389,0(171,0)$ & $345,8(90,4)$ & 0,06 \\
\hline $\begin{array}{l}\text { Espessura VE }(\mathrm{mm}) \text {, } \\
\text { média }(\mathrm{DP})\end{array}$ & $12,4(2,6)$ & $12,9(3,4)$ & $12,1(2,5)$ & 0,79 \\
\hline $\begin{array}{l}\text { Hipertrofia miocárdica, } \\
\text { n (\%) }\end{array}$ & $55(44,4)$ & $5(41,7)$ & $17(36,2)$ & 0,63 \\
\hline
\end{tabular}

\section{Avaliação das artérias carótidas}

Os grupos foram homogêneos quanto à aterosclerose carotídea $(\mathrm{p}=0,19)$ quando foram comparadas as médias da porcentagem de obstrução arterial entre os grupos controle, DCA e demência (Tabela 44).

Tabela 44 - Média (desvio padrão) da porcentagem de obstrução em artérias carótidas no grupo controle, doença cerebral assintomática (DCA) e de demência. Estudo clinicopatológico ( $\mathrm{n}=183)$, BEH-GEEC-FMUSP, 2005 a 2008

\begin{tabular}{lllll}
\hline Variável & Controle & DCA & Demência & p \\
\hline ACC & $45,3(17,1)$ & $43,0(12,5)$ & $48,8(16,9)$ & 0,48 \\
ACI & $43,5(22,5)$ & $42,8(23,9)$ & $51,6(28,9)$ & 0,31 \\
ACD & $44,9(19,5)$ & $39,2(15,6)$ & $51,4(20,7)$ & 0,09 \\
ACE & $44,7(19,0)$ & $48,5(20,9)$ & $52,9(23,9)$ & 0,19 \\
\hline
\end{tabular}

$\mathrm{ACC}=$ artéria carótida comum; $\mathrm{ACI}=$ artéria carótida interna; $\mathrm{ACD}=$ artéria carótida direita; $\mathrm{ACE}=$ artéria carótida esquerda

Ao analisar os segmentos de artérias carótidas, foi excluído o grupo DCA porque ele só tem 11 indivíduos, dificultando a análise. Levando-se em conta só os indivíduos 
Resultados

sem demência e com demência, segundo critérios clinicopatológicos, os portadores de estenose arterial $\geq 75 \%$ em artéria carótida interna tiveram uma chance 4,8 vezes maior de demência do que aqueles com lesões obstrutivas $<75 \%$. Para artéria carótida esquerda, a chance de demência foi 4,9 vezes maior naqueles com lesões $\geq 75 \%$ (Tabela 45).

Tabela 45 - Odds ratio para demência, de acordo com porcentagem de obstrução arterial de artérias carótidas. Estudo clinicopatológico (n=171), BEH-GEEC-FMUSP, 2005 a 2008

\begin{tabular}{|c|c|c|c|c|c|}
\hline Variável & $\begin{array}{l}\text { Com } \\
\text { demência }\end{array}$ & $\begin{array}{l}\text { Sem } \\
\text { demência }\end{array}$ & OR & IC 95\% & $\mathbf{p}$ \\
\hline \multicolumn{6}{|l|}{$\overline{A C C}$} \\
\hline$<75 \%$ & 44 & 115 & 1,0 & & 1,00 \\
\hline$\geq 75 \%$ & 3 & 9 & 0,87 & $0,23-3,37$ & \\
\hline \multicolumn{6}{|l|}{$\overline{A C I}$} \\
\hline$<75 \%$ & 32 & 113 & 1,0 & & $<0,001$ \\
\hline$\geq 75 \%$ & 15 & 11 & 4,82 & $2,02-11,51$ & \\
\hline \multicolumn{6}{|l|}{$\overline{A C D}$} \\
\hline$<75 \%$ & 40 & 115 & 1,0 & & 0,13 \\
\hline$\geq 75 \%$ & 7 & 9 & 2,24 & $0,78-6,40$ & \\
\hline \multicolumn{6}{|l|}{$\overline{A C E}$} \\
\hline$<75 \%$ & 34 & 115 & 1,0 & & $<0,001$ \\
\hline$\geq 75 \%$ & 13 & 9 & 4,89 & $1,92-12,41$ & \\
\hline
\end{tabular}

$\mathrm{OR}=$ odds ratio; IC 95\%=intervalo de confiança $95 \%$

$\mathrm{ACC}=$ artéria carótida comum; $\mathrm{ACI}=$ artéria carótida interna; $\mathrm{ACD}=$ artéria carótida direita; $\mathrm{ACE}=$ artéria carótida esquerda

Não foi encontrada diferença entre os grupos em relação à EIM de artérias carótidas (Tabela 46).

Tabela 46 - Média (desvio padrão) da espessura íntima-média (EIM) de artérias carótidas nos grupos controle, doença cerebral assintomática (DCA) e demência. Estudo clinicopatológico ( $\mathrm{n}=183)$, BEH-GEEC-FMUSP, 2005 a 2008

\begin{tabular}{lllll}
\hline EIM $(\mathbf{m m})$ & Controle & DCA & Demência & p \\
\hline ACC & $1,03(0,25)$ & $1,04(0,13)$ & $1,06(0,24)$ & 0,37 \\
ACI & $0,74(0,25)$ & $0,70(0,23)$ & $0,82(0,31)$ & 0,19 \\
\hline
\end{tabular}




\section{Avaliação das artérias do PW}

Os grupos foram diferentes em relação à porcentagem de obstrução arterial por aterosclerose do PW $(\mathrm{p}=0,001)$, número de artérias com aterosclerose por $\mathrm{PW}(\mathrm{p}<0,001)$ e número de artérias com obstruções maiores do que 50\% por PW ( $\mathrm{p}=0,004)$ (Tabela 47e Figura 29).

Quando os grupos foram comparados dois a dois (controle X DCA, controle $\mathrm{x}$ demência e DCA x demência), foram encontradas diferenças apenas entre os grupos controle e demência. Portadores de demência tiveram porcentagem de obstrução do PW $(\mathrm{p}<0,01)$, número de artérias com aterosclerose por $\mathrm{PW}(\mathrm{p}<0,001)$ e número de artérias com obstruções maiores do que 50\% maior do que controles ( $\mathrm{p}=0,003)$.

Tabela 47 - Aterosclerose do polígono de Willis (PW) dos indivíduos controle, portadores de doença cerebral assintomática (DCA) e de demência. Estudo clinicopatológico ( $\mathrm{n}=183)$, BEH-GEEC-FMUSP, 2005 a 2008

\begin{tabular}{lllll} 
Aterosclerose do PW & Controle & DCA & Demência & p \\
\hline $\begin{array}{l}\text { Obstrução arterial (\%), } \\
\text { média (DP) }\end{array}$ & $15,9(15,8)$ & $16,3(14,3)$ & $26,3(16,4) \#$ & 0,001 \\
$\begin{array}{l}\text { No de artérias com } \\
\text { ateroma/PW, média (DP) }\end{array}$ & $3,0(2,7)$ & $3,1(2,1)$ & $5,0(2,6) \#$ & $<0,001$ \\
$\begin{array}{l}\text { No de artérias com } \\
\text { obstrução>50\%/PW, } \\
\text { média (DP) }\end{array}$ & $2,0(2,3)$ & $1,9(2,1)$ & $3,2(2,6) \#$ & 0,004 \\
\hline
\end{tabular}

No=número; \# diferente do controle, $\mathrm{P}<0,05$ 


\section{Resultados}

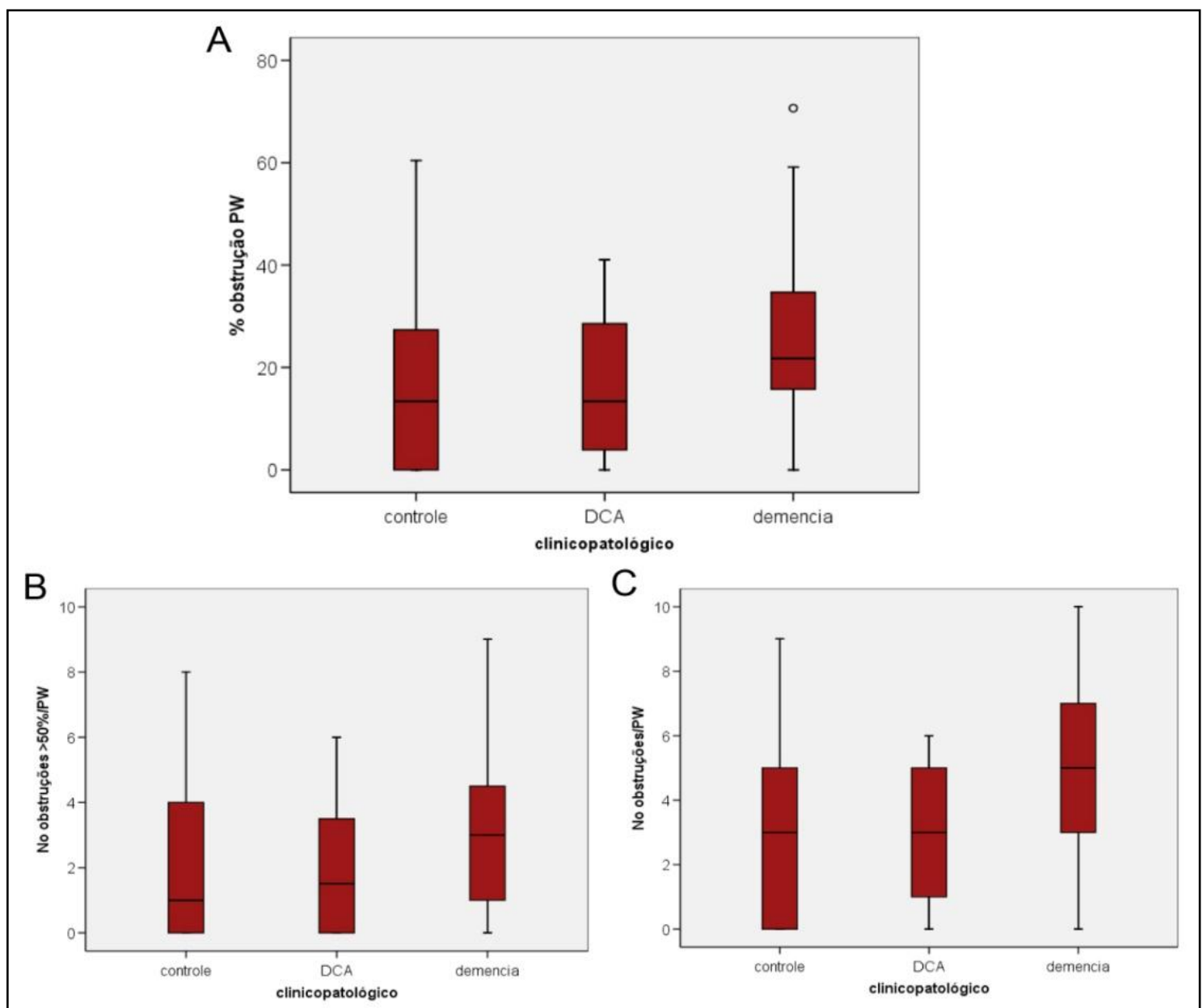

Figura 29. (A) Porcentagem de obstrução arterial nos grupos controle, doença cerebral assintomática (DCA) e demência. (B) Número de artérias com placas de ateroma nos 3 grupos. (C) Número de artérias com porcentagem de obstrução arterial maior do que $50 \%$ nos 3 grupos

As artérias basilar, cerebral posterior direita, carótida interna esquerda, cerebral média direita e esquerda, cerebral anterior direita e esquerda apresentaram maior obstrução em dementados do que em controles $(p<0,05)$ (Tabela 48). Não foram encontradas diferenças na porcentagem de obstrução destas artérias entre controles e indivíduos com DCA e entre os grupos DCA e demência. 
Tabela 48 - Média (desvio padrão) da porcentagem de obstrução arterial nas artérias do polígono de Willis (PW) dos indivíduos controle, portadores de doença cerebral assintomática (DCA) e de demência. Estudo clinicopatológico (n=183), BEH-GEECFMUSP, 2005 a 2008

\begin{tabular}{|c|c|c|c|c|}
\hline $\begin{array}{l}\text { Obstrução arterial } \\
(\%)\end{array}$ & Controle & $\overline{\text { DCA }}$ & Demência & $\mathbf{p}$ \\
\hline Basilar & $29,4(28,4)$ & $34,1(26,9)$ & $41,3(27,7)$ & 0,04 \\
\hline $\begin{array}{l}\text { Cerebral posterior } \\
\text { direita }\end{array}$ & $23,1(33,4)$ & $23,5(39,1)$ & $38,1(33,4)$ & 0,05 \\
\hline $\begin{array}{l}\text { Cerebral posterior } \\
\text { esquerda }\end{array}$ & $24,6(33,5)$ & $23,7(32,7)$ & $33,5(34,1)$ & 0,17 \\
\hline $\begin{array}{l}\text { Comunicante } \\
\text { posterior direita }\end{array}$ & $0,5(5,3)$ & $0(0)$ & $1,7(10,2)$ & 0,08 \\
\hline $\begin{array}{l}\text { Comunicante } \\
\text { posterior esquerda }\end{array}$ & $3,5(15,7)$ & $0(0)$ & $0(0)$ & 0,63 \\
\hline $\begin{array}{l}\text { Carótida interna } \\
\text { direita }\end{array}$ & $17,0(24,9)$ & $8,0(18,1)$ & $26,1(29,3)$ & 0,06 \\
\hline $\begin{array}{l}\text { Carótida interna } \\
\text { esquerda }\end{array}$ & $15,8(24,6)$ & $9,8(21,9)$ & $26,4(26,8)$ & 0,06 \\
\hline $\begin{array}{l}\text { Comunicante } \\
\text { anterior }\end{array}$ & $0(0)$ & $0(0)$ & $0(0)$ & 1,0 \\
\hline $\begin{array}{l}\text { Cerebral média } \\
\text { direita }\end{array}$ & $21,3(29,0)$ & $30,1(28,8)$ & 40,3 (28,7)\# & 0,02 \\
\hline $\begin{array}{l}\text { Cerebral média } \\
\text { esquerda }\end{array}$ & $23,4(29,9)$ & $35,8(29,5)$ & 45,2 (29,8)\# & $<0,001$ \\
\hline $\begin{array}{l}\text { Cerebral anterior } \\
\text { direita }\end{array}$ & $5,3(17,4)$ & $5,6(17,7)$ & $19,64(30,8) \#$ & 0,002 \\
\hline $\begin{array}{l}\text { Cerebral anterior } \\
\text { esquerda }\end{array}$ & $5,2(16,7)$ & $9,1(30,2)$ & $18,2(30,1) \#$ & 0,01 \\
\hline
\end{tabular}

$\mathrm{DP}=$ desvio-padrão

\# diferente do controle, $\mathrm{p}<0,05$

\subsubsection{Análise multivariada}

\section{Dados demográficos e FRCV}

As variáveis demográficas e FRCV que mostraram associação significante com DCA e demência (idade, escolaridade, insuficiência cardíaca, AVC, sedentarismo e IMC) foram selecionadas para serem analisadas conjuntamente em modelo de regressão logística. Os resultados obtidos com cálculo de odds ratio para DCA e demência encontram-se na Tabela 49. 
Resultados

Tabela 49 - Odds ratio para doença cerebral assintomática (DCA) em relação a controles e odds ratio para demência em relação a controles, segundo dados demográficos e fatores de risco cardiovascular, de acordo com modelo de regressão multivariável. Estudo clinicopatológico (n=183), BEH-GEEC-FMUSP, 2005 a 2008

\begin{tabular}{lll}
\hline Variável & DCA - OR $($ IC 95\%)* & Demência - OR $($ IC 95\%)* \\
\hline Idade & $1,08(1,01-1,15)^{\mathrm{a}}$ & $1,07(1,03-1,12)^{\mathrm{c}}$ \\
Escolaridade & $1,19(1,01-1,39)^{\mathrm{b}}$ & $0,94(0,83-1,07)$ \\
ICC & $0,76(0,14-4,20)$ & $0,51(0,18-1,45)$ \\
AVC referido & - & $3,88(1,34-11,24)^{\mathrm{a}}$ \\
Sedentarismo & $0,82(0,21-3,25)$ & $2,24(0,88-5,65)$ \\
IMC & $0,95(0,86-1,04)$ & $0,93(0,85-1,02)$ \\
\hline
\end{tabular}

*ajustado para as demais variáveis da tabela

${ }^{\mathrm{a}} \mathrm{p}=0,01 ;{ }^{\mathrm{b}} \mathrm{p}<0,05 ;{ }^{\mathrm{c}} \mathrm{p}<0,001$

$\mathrm{OR}=$ odds ratio; IC 95\%=intervalo de confiança 95\%; ICC=insuficiência cardíaca congestiva, $\mathrm{AVC}=$ acidente vascular cerebral; IMC=índice de massa corpórea

Idade foi fator de risco para DCA. A escolaridade mais elevada manteve associação com DCA em relação a controles, mostrando que indivíduos com maior escolaridade não apresentaram sintomas cognitivos, embora tivessem lesões neuropatológicas suficientes para tanto. Idade também foi fator de risco para demência. Além disso, quem teve AVC referido pelo informante teve um risco 3,7 vezes maior de demência.

\section{Variáveis carotídeas e relacionadas ao $P W$}

Pesquisou-se se as associações encontradas entre aterosclerose carotídea e do PW com demência, vistas na análise univariada, persistiam após ajuste para idade, sexo e escolaridade.

Após ajuste pela regressão logística, a associação entre artéria carótida interna e demência permaneceu significativa $(\mathrm{p}=0,001)$ e pouco alterada. Ajuste adicional para a presença de infarto lacunar também não alterou a associação encontrada $(p=0,004)$ (Tabela 50). 
Resultados

A associação entre artéria carótida esquerda e demência permaneceu após ajuste para idade, sexo e escolaridade $(\mathrm{p}<0,001)$. Embora o valor do odds ratio ajustado tenha aumentado em relação ao odds ratio bruto, o intervalo de confiança referente a esta associação alargou-se consideravelmente, o que enfraquece a importância deste aumento. Assim como observado para artéria carótida interna, o ajuste para infarto lacunar, alterou pouco a associação observada entre artéria carótida esquerda e demência, ajustada para idade, sexo e escolaridade $(p<0,001)$ (Tabela 50).

Tabela 50 - Odds ratio bruto e ajustado para demência, segundo aterosclerose de artérias carótidas interna e esquerda. Estudo clinicopatológico $(n=171)$, BEH-GEECFMUSP, 2005 a 2008

\begin{tabular}{llll}
\hline Variável & OR bruto (IC 95\%) & $\begin{array}{l}\text { OR ajustado (IC 95\%) } \\
\text { Modelo 1* }\end{array}$ & $\begin{array}{l}\text { OR ajustado (IC 95\%) } \\
\text { Modelo 2** }\end{array}$ \\
\hline ACI & $4,82(2,02-11,51)$ & $5,47(2,03-14,70)$ & $4,52(1,62-12,61)$ \\
ACE & $4,89(1,92-12,41)$ & $7,55(2,49-22,89)$ & $7,12(2,26-22,43)$ \\
\hline OR=odds ratio; IC 95\%=intervalo de confiança 95\%; ACI=artéria carótida interna; \\
ACE=artéria carótida esquerda \\
*ajustado para idade, sexo e escolaridade (Modelo de regressão multivariável) \\
**ajustado para idade, sexo, escolaridade e infarto lacunar (Modelo de regressão \\
multivariável)
\end{tabular}

As variáveis de PW foram analisadas em modelo de regressão logística para pesquisa da associação com demência, ajustado para idade, sexo e escolaridade. Após esta análise, houve persistência da associação entre porcentagem de obstrução arterial do PW e demência $(\mathrm{p}=0,01)$ e número de artérias com ateroma por PW e demência $(\mathrm{p}=0,005)$. A relação entre o número de artérias com obstrução $>50 \%$ por PW perdeu significância após ajuste para idade, sexo e escolaridade $(\mathrm{p}=0,07)$ (Tabela 51).

As associações entre porcentagem de obstrução arterial do PW e número de artérias com ateroma por PW com demência ficaram semelhantes mesmo após ajuste adicional do modelo anterior pela variável "infarto lacunar", sugerindo que a relação entre aterosclerose do PW e demência é independente da presença deste tipo de infarto 
Resultados

cerebral (porcentagem de obstrução arterial do PW e demência: $p=0,04$; número de artérias com ateroma por PW e demência: $\mathrm{p}=0,02$ ).

Tabela 51 - Odds ratio para demência, segundo aterosclerose do polígono de Willis (PW), ajustado para idade, sexo e escolaridade. Estudo clinicopatológico $(\mathrm{n}=171)$, BEH-GEEC-FMUSP, 2005 a 2008

\begin{tabular}{|c|c|c|}
\hline Variável & $\begin{array}{l}\text { OR ajustado (IC 95\%) } \\
\text { Modelo 1* }\end{array}$ & $\begin{array}{l}\text { OR ajustado (IC 95\%) } \\
\text { Modelo 2** }\end{array}$ \\
\hline \% Obstrução arterial & $1,03(1,01-1,05)$ & $1,03(1,001-1,05)$ \\
\hline $\begin{array}{l}\text { No de artérias com } \\
\text { ateroma/PW }\end{array}$ & $1,23(1,06-1,42)$ & $1,20(1,04-1,13)$ \\
\hline $\begin{array}{l}\text { No de artérias com } \\
\text { obstrução>50\%/PW }\end{array}$ & $1,15(0,99-1,34)$ & $1,12(0,96-1,31)$ \\
\hline
\end{tabular}

$\mathrm{OR}=$ odds ratio; $\mathrm{IC}$ 95\%=intervalo de confiança 95\%; $\mathrm{PW}=$ polígono de Willis *ajustado para idade, sexo e escolaridade

**ajustado para idade, sexo, escolaridade e infarto lacunar 
5. DISCUSSÃO 


\subsection{Amostra}

O estudo clínico analisou 61,6\% dos casos coletados durante o ano de 2005 a 2008. A comparação de alguns dados demográficos e cognitivos mostrou que a amostra do estudo clínico era semelhante aos outros casos que foram coletados e excluídos de acordo com os critérios já descritos. Outro ponto relevante foi a confiabilidade das informações coletadas através da entrevista com informantes. Cerca de $78 \%$ destes conviviam diariamente com o falecido e foram capazes de fornecer informações consistentes. De forma que os resultados das escalas cognitivas, que foram preenchidas com as informações dos familiares, mostraram alta correlação entre si (CDR e IQCODE) e com as escalas funcionais (ABVD e AIVD).

Outra questão interessante foi o grande número de indivíduos sem demência nos três estudos analisados (clínico, neuropatológico e clinicopatológico), um diferencial em relação a outros $\mathrm{BEH}$ que contam, essencialmente, com grande número de dementados e poucos controles (Honig et al, 2005 e Beach et al., 2007). Além disso, no nosso estudo, houve participação de portadores de demência leve, moderada e grave. A maior parte dos estudos de autópsia conta com a doação espontânea de cérebros, o que ocasiona que boa parte da amostra seja composta por portadores de demência avançada (Honig et al., 2005).

Os participantes dos estudos neuropatológico e clinicopatológico foram mais velhos, predominantemente do sexo feminino e com maior proporção de portadores de demência $(\mathrm{CDR} \geq 1)$, quando comparados aos indivíduos que não tinham exame neuropatológico e que foram excluídos destes estudos. As diferenças observadas podem ser explicadas pela maneira como foram incluídos os casos. A produção científica prévia do GEEC-FMUSP investigou a neuropatologia em indivíduos acima de 80 anos 
(Farfel, 2008) e o diagnóstico nosológico das demências (Grinberg et al., 2009) o que levou à realização de exame neuropatológico em indivíduos mais velhos e com CDR $\geq 1$. Esta tese utilizou parte destas avaliações neuropatológicas já realizadas previamente.

\subsection{Perfil demográfico e FRCV}

Idade foi um fator associado ao risco de demência, independente da abordagem metodológica utilizada. Esteve associada à demência nos estudos clínico, neuropatológico e clinicopatológico e manteve associação após análise multivariada. Aumento da idade é um dos fatores de risco mais consistentes para o desenvolvimento de demência (Nitrini et al., 2005 e Swerdlow, 2007). O envelhecimento populacional observado principalmente no último século transformou a demência em um problema de saúde publica e levou a DA a ser considerada a principal causa de demência nos dias atuais (Ferri et al., 2008).

O sexo feminino foi mais prevalente em dementados no estudo clínico, porém esta associação perdeu significância após análise multivariada. Sexo feminino é considerado fator de risco para demência, particularmente DA (Kalaria et al., 2008). Quanto ao estado civil, observamos no estudo clínico e neuropatológico, uma maior proporção de viúvos nos grupos com demência e uma maior porcentagem de casados entre os controles. É descrito que fatores psicossociais também estão ligados à expressão de demência. Fatores preditores de demência incluem morar sozinho e ausência de laços sociais (Wilson et al., 2007), o que poderia em parte explicar os resultados encontrados no nosso trabalho. Vale ressaltar que após a análise de regressão 
logística esta associação entre estado civil e demência perdeu associação frente a outros fatores de risco mais fortes, como por exemplo, a idade e AVC referido.

A escolaridade mostrou associação com demência nos estudos clínico e clinicopatológico. Manifestar sintomas cognitivos esteve associado à menor escolaridade. Além disso, no estudo clinicopatológico, a escolaridade foi mais elevada entre os portadores de DCA. Apesar de ter a mesma carga de lesões neurodegenerativas dos dementados, os indivíduos com DCA não apresentaram sintomas cognitivos. A escolaridade mais alta observada entre estes indivíduos pode ter exercido um papel protetor contra a manifestação de demência. De acordo com estudos prévios, pessoas com alta escolaridade teriam maior reserva cognitiva e, portanto, necessitariam de alterações patológicas mais abundantes para expressar clinicamente o déficit cognitivo (Ngandu et al., 2007 e Roe et al., 2007).

A causa de óbito mais prevalente foi cardiovascular em todos os grupos analisados. Porém entre os portadores de demência, independente do estudo analisado, aumentou proporcionalmente a importância de causas infecciosas e "outras causas", compostas principalmente por doenças pulmonares. Este dado é compatível com estudos prévios que relatam que a principal causa de óbito em dementados é infecção e complicações pulmonares (Fu et al., 2003 e Brunnstrom e Englund, 2009).

Quanto à classe social, notou-se diferença entre os grupos no estudo neuropatológico e clinicopatológico. No estudo neuropatológico, os portadores de DA apresentaram maior proporção de indivíduos em classe social mais elevada (classe social B) do que controles e portadores de DV, que tinham maior proporção de indivíduos na classe social C. A associação entre poder aquisitivo e demência em nossa amostra perdeu significância após análise multivariada envolvendo outros fatores de 
risco. Classe social provavelmente está relacionada a outros fatores de risco, como escolaridade e mau controle de FRCV.

A maior prevalência de DAC e insuficiência cardíaca entre controles em relação aos portadores de demência vista em nosso estudo foi inesperada. É descrito na literatura que a presença destas doenças está associada à maior risco de demência (De la Torre, 2006). Entretanto, nos estudos clínico (DAC e insuficiência cardíaca) e clinicopatológico (insuficiência cardíaca), estas doenças foram mais prevalentes em controles do que nos dementados. Este resultado pode ser fruto de viés de seleção. Analisando estes resultados e os resultados obtidos em relação a variáveis cardíacas (peso, espessura de VE e hipertrofia miocárdica), foi observado que parte do grupo controle era composta por pessoas com doença cardíaca. Possivelmente, os controles morreram de doença cardiovascular antes de ter tido tempo de desenvolver demência, resultando na impressão de que doença cardíaca é fator protetor para demência, explicando os resultados contraditórios encontrados neste estudo em relação aos divulgados por outros estudos longitudionais (Qiu et al., 2006 e Román, 2005).

AVC referido pelo informante durante a entrevista clínica foi um dos fatores de risco mais consistente para demência em nosso estudo, assim como a idade. AVC associou-se ao risco de demência clínica e clinicopatológica e à demência vascular avaliada por critérios neuropatológicos e manteve associação após análise multivariada. AVC referido durante a entrevista foi frequentemente associado à seqüela motora aparente, o que facilitou o seu reconhecimento pelo familiar. É importante ressaltar que devido aos critérios de exclusão o AVC agudo e extenso foi excluído e, portanto, a associação encontrada entre esta doença e demência pode ser ainda mais forte. Estes 
resultados estão de acordo com a literatura que associa a presença de infartos cerebrais com o risco de demência, incluindo DA e DV (Romàn, 2003 e Snowdon et al., 1997).

Sedentarismo também esteve associado ao risco de demência. Devido à natureza transversal do estudo, a presença de inatividade física foi avaliada perto do momento do óbito. A associação com demência observada pode ser devido à baixa atividade física observada entre os portadores de déficit cognitivo e não pode ser avaliada como fator causal. Embora haja uma plausibilidade biológica para a associação encontrada, esta pode ser fruto não só de um viés de informação, mas também de fator de confusão. Inatividade física é mais comum em indivíduos mais velhos e portadores de AVC com seqüela motora, fatores fortemente associados à demência em nosso estudo. Estudos longitudinais prévios mostraram com maior propriedade, o efeito protetor da atividade física na demência (Verghese et al., 2003 e Friedland et al., 2001).

Tabagismo e etilismo foram associados à proteção contra demência, definida por critérios clínicos. Estas associações perderam significância após análise multivariada. A associação entre tabagismo e demência é controversa. Pode ser considerado fator de proteção ou de risco, dependendo do estudo analisado (Anstey et al., 2007). Considerase que as diferenças encontradas possam ser devido à potencial viés de seleção, que falsamente mostra que o tabagismo é protetor para demência quando avaliado em idades avançadas (Hernán et al., 2008). Em relação ao etilismo, concordando com os nossos resultados, é descrito que o etilismo leve a moderado possa ser fator protetor contra demência, assumindo caráter deletério quando associado ao etilismo grave (Galanis et al., 2000 e Elias et al., 1999). Em nosso estudo, não foi possível quantificar o consumo de tabaco e álcool durante a vida, prejudicando este tipo de análise. 
IMC baixo esteve associado à maior chance de demência. Estudos prévios mostram resultados diferentes. Obesidade está associada ao maior risco de demência (Ford et al., 2002 e Kivipelto et al., 2005). Novamente, a natureza transversal do nosso estudo prejudica a análise desta associação. É sabido que a demência leva à desnutrição (Salerno-Kennedy e Cashman, 2005) e a associação entre IMC baixo e demência pode ser explicada desta forma.

Não foi encontrada associação entre HAS e demência em nossa amostra. No estudo clínico, foi observada uma tendência de ter mais hipertensos entre os indivíduos sem demência. Os resultados encontrados podem ter duas explicações: a pesquisa da relação entre HAS e demência em um estudo transversal e a maior mortalidade cardiovascular entre controles. Quanto à primeira explicação, HAS foi definida pela resposta dada pelos informantes durante a entrevista clínica, já que não dispúnhamos de medidas de pressão arterial prévias ao óbito. É sabido que quando HAS é pesquisada perto do início dos sintomas cognitivos frequentemente não se encontra a associação entre este fator de risco e demência (Kivipelto et al., 2002; Posner et al., 2002 e Shah et al., 2006). Além disso, cerca de três anos antes do desenvolvimento da demência, particularmente em DA, há uma queda da pressão arterial, provavelmente devido a alterações neurodegenerativas em regiões responsáveis pela regulação central da pressão arterial (Skoog e Gustafson, 2006). Outra explicação para os nossos resultados seria a elevada mortalidade cardiovascular entre os controles. É sabido que HAS está associada ao maior risco de óbito cardiovascular. De acordo com as informações coletadas pela entrevista clínica, a prevalência de HAS em nossa amostra foi alta (64\% no estudo clínico e $67,8 \%$ nos estudos neuropatológico e clinicopatológico). Estudos populacionais, que avaliaram a prevalência de HAS em países da América Latina e no 
Brasil, relatam que 50,6\% a $65 \%$ dos maiores de 60 anos teriam HAS (Kearney et al., 2005, Pereira et al., 2008 e Lebrão e Laurenti, 2005). Uma explicação para a maior prevalência de HAS em nosso estudo é o local onde nossos casos são coletados. O SVOC-USP é responsável por elucidar óbitos de causa natural não definida, que em sua maioria são secundários às causas cardiovasculares. Desta forma, a amostra estudada apresenta elevada prevalência de FRCV e doença cardíaca, explicando parte das associações encontradas.

DM não mostrou associação com demência em nosso estudo. Alguns estudos clínicos prévios mostraram associação entre DM e demência, seja ela DA ou DV (Yaffe et al., 2004 e Arvanitakis et al., 2004), enquanto outros não conseguiram evidenciar esta associação (Sanz et al., 2009 e Xu et al., 2004). A prevalência de DM em nossa amostra foi alta (27\%), quando comparada a de outros estudos populacionais em idosos brasileiros (cerca de 18\%) (Pereira et al., 2008 e Lebrão e Laurenti, 2005), novamente indicando uma amostra com maior risco cardiovascular. Além disso, em nosso estudo, não foi possível obter níveis glicêmicos prévios que poderiam refinar a qualidade das informações obtidas. Yaffe et al. (2004) demostraram que o risco de demência é tanto maior quanto maior o nível glicêmico.

Não foi demonstrada associação entre dislipidemia e demência em nosso estudo. Ao contrário dos outros FRCV já discutidos, a prevalência de dislipidemia em nossa amostra foi baixa $(9,5 \%$ no estudo clínico e 7,7\% nos estudos neuropatológico e clinicopatológico). Estudo populacional brasileiro mostra uma prevalência mais alta de dislipidemia em idosos $(33,1 \%)$ (Pereira et al., 2008). A dislipidemia é doença assintomática e necessita de exames laboratoriais para seu diagnóstico, o que pode explicar a baixa prevalência desta doença em nossa amostra, já que muitos informantes 
Discussão

poderiam desconhecer se o falecido tinha dislipidemia. Existe controvérsia sobre a associação entre dislipidemia e demência. Alguns estudos mostram que dislipidemia é fator de risco para demência (Pappola et al., 2003 e Whitmer et al., 2005), enquanto outros não encontraram associação (Kalminjin et al., 2000 e Luchsinger et al., 2005).

Insuficiência arterial periférica não mostrou associação com demência. Esta doença apresentou prevalência mais baixa em nossa amostra do que em estudos populacionais. A prevalência de insuficiência arterial periférica em nosso estudo foi em torno de $3 \%$, enquanto em que em estudo populacional prévio em idosos americanos foi de 12\% (Ostchega et al., 2007). A baixa freqüência de insuficiência arterial periférica dificultou a detecção da associação desta doença e demência. Estudo transversal da coorte de Rotterdam mostrou associação entre insuficiência arterial periférica com DV, mas não foi capaz de detectar relação entre esta doença arterial e DA (Hofman et al., 1997). Já Newman et al. (2005) encontraram associação entre insuficiência arterial periférica e DA.

Em relação a arritmias, nossa prevalência foi de 9\%. Entretanto, devido a limitações de nossa metodologia, não foi possível identificar se a arritmia era ventricular ou supraventricular. Não encontramos associação entre a variável arritmia referida na entrevista clínica e demência. Entre as arritmias, destaca-se a fibrilação atrial, cuja prevalência é de 3,8\% em idosos americanos (Go et al., 2001). Esta arritmia está associada ao maior risco de AVC, DA e DV (Ott et al., 1997). 
Discussão

\subsection{Doença cardiovascular anatomicamente comprovada}

Quanto às variáveis cardíacas, peso cardíaco e espessura de VE foram maiores em controles do que em dementados no estudo clínico. Nos estudos neuropatológicos e clinicopatológicos, estas medidas não foram associadas ao risco de demência, principalmente após ajuste para idade, sexo e escolaridade. Quando comparado à lesões anatomopatológicas, o peso cardíaco correlacionou-se negativamente com placas neuríticas e emaranhados neurofibrilares, lesões associadas à DA.

Estudos prévios de autópsia mostram resultados semelhantes. Beeri et al. (2006) mostraram que quanto maior espessura de VE, menor a quantidade de emaranhados neurofibrilares. Estes autores consideraram que os resultados encontrados foram fruto da inclusão de casos com demência avançada. O estado nutricional ruim destes pacientes estaria associado à atrofia miocárdica, o que explicaria os resultados encontrados. Irina et al. (1999), avaliando o peso cardíaco de portadores de demência avançada, encontrou maior quantidade de lesões neuropatológicas de DA associada a baixo peso cardíaco. Novamente, a explicação do status nutricional ruim de portadores de demência avançada foi utilizada. Entretanto, nossa amostra incluía dementados de grau leve e moderado e foram encontrados resultados semelhantes: associação de emaranhados neurofibrilares e placas neuríticas com menor peso cardíaco e espessura de VE. Uma explicação alternativa foi proposta para explicar estes resultados. Conforme discutido anteriormente, os indivíduos sem demência eram constituídos por uma população mais jovem e portadora de mais doenças cardíacas (DAC e insuficiência cardíaca) do que os indivíduos com demência. Provavelmente, os controles faleceram de doença cardiovascular antes de manifestar a síndrome demencial. 
Foi encontrada associação entre aterosclerose de artérias carótidas e demência quando foi analisado o impacto de lesões obstrutivas críticas ( $\geq 75 \%$ ). Nossos resultados mostraram um risco maior para demência em portadores de lesões críticas proximais (artéria carótida interna) e localizadas do lado esquerdo. Ter alguma obstrução $\geq 75 \%$ em artéria carótida interna ou carótida esquerda esteve associado à maior chance de demência no estudo clínico e clinicopatológico. Obstruções $\geq 75 \%$ em artéria carótida esquerda associaram-se à maior chance de DA e DV. Lesões obstrutivas $\geq 75 \%$ em artéria carótida interna estiveram associadas também a maior risco de DV. Estas associações foram significativas mesmo após ajuste para idade, sexo e escolaridade. Ajuste adicional para a presença de infarto lacunar não alterou as associações encontradas. A ausência de impacto significativo de lesões isquêmicas cerebrais nos nossos resultados sugere que a associação entre aterosclerose carotídea e demência deva envolver outros mecanismos causais que não envolvam diretamente o papel destes infartos cerebrais na cognição. Evidências experimentais mostram a importância do hipofluxo sanguíneo no acúmulo de proteína $\mathrm{A} \beta$ no cérebro de modelos animais na ausência de infartos cerebrais (Iadecola e Gorelick, 2003).

As primeira evidências que ligaram a aterosclerose de artérias carótidas à demência partiram de Hofman et al. (1997), que descreveu a associação entre doença carotídea (aterosclerose e espessamento íntima-média) e demência no estudo transversal de Rotterdam. Durante o seguimento deste estudo, foi demonstrada a persistência da associação entre aterosclerose carotídea e espessamento íntima-média com a incidência de demência, particularmente DA (Van Oijen et al., 2007). Entretanto, as associações só foram significativas quando foram comparados os indivíduos com síndrome demencial e controles. A extensão da aterosclerose carotídea não conferiu maior risco de DA ou 
DV. Nos estudos de Rotterdam (Hofman et al., 1997 e van Oijen et al., 2007), foram medidas apenas o número de placas por artérias e não foram avaliadas medidas quantitativas da porcentagem de obstrução arterial. Jonhston et al. (2004) demonstraram que portadores de estenoses $\geq 75 \%$ em artéria carótida interna esquerda foram associadas a déficit e declínio cognitivo no decorrer de cinco anos de seguimento, mesmo na ausência de infartos cerebrais na RNM. Os portadores de lesões $\geq 75 \%$ correspondiam à pequena parcela da amostra acompanhada (61 indivíduos de uma coorte de 4006 participantes). Não foi encontrada associação entre lesão crítica em artéria carótida direita e déficit cognitivo, confirmando a importância da lateralidade da obstrução carotídea no risco de demência.

Diferentemente dos resultados obtidos em nosso estudo, Newman et al. (2005) não encontraram associação entre demência e estenose de artéria carótida no estudo CHS (Cardiovascular Health Study). A porcentagem de obstrução carotídea foi dividida em quatro grupos: zero; $1-24 \% ; 25-49 \%$ e $\geq 50 \%$. Nesta abordagem, estenose carotídea não conferiu maior risco de demência, DA ou DV.

Em nosso estudo, espessamento íntima-média de artérias carótidas, tanto comum quanto interna, não se associou à demência em nenhuma das abordagens propostas. Johnston et al. (2004) encontraram resultado semelhante ao analisar a espessamento íntima-média em artéria carótida interna. Van Oijen et al. (2007) mostraram que espessamento íntima-média em artéria carótida comum esteve associada a maior risco de demência e DA, quando comparados os grupos com menor espessamento (primeiro quintil) e com maior espessamento (quinto quintil). Newman et al. (2005) encontraram resultado semelhante na análise de espessamento íntima-média em artéria carótida interna. O EIM de artéria carótida interna esteve associado a um aumento de $50 \%$ na 
incidência de demência. Novamente, só houve diferença significativa quando foram comparados os portadores de EIM mais grave em relação àqueles que não tinham espessamento

Os resultados diferentes encontrados em nosso estudo podem ser devido às diferenças na metodologia. Nosso estudo avaliou espessamento íntima-média em material de autópsia. Não foram encontrados na literatura estudos deste tipo. Os estudos descritos utilizaram a ultrassonografia para determinação do espessamento íntimamédia. Neste método, avalia-se a espessura íntima-média em apenas duas incidências, enquanto na nossa avaliação morfométrica, tivemos a oportunidade de calcular um valor médio de espessura íntima-média de todo o segmento arterial avaliado. Além disso, nos estudos disponíveis na literatura, a presença de demência e suas diferentes etiologias foram classificadas de acordo apenas com critérios clínicos.

Quanto à presença de lesões neuropatológicas, lesões críticas $\geq 75 \%$ em artéria carótida interna associaram-se a maior chance de infarto lacunar. Aterosclerose de artérias carótidas, classicamente relacionadas às lesões cerebrais isquêmicas de grandes vasos, já foram associadas previamente à presença de lesões cerebrais de pequenos vasos, vistas por RM (hiperintensidade de substância branca) (Pico et al., 2002). Quanto à presença de lesões neuropatológicas associadas à DA, não foram encontradas correlações entre a presença de emaranhados neurofibrilares e placas neuríticas com aterosclerose de artérias carótidas.

A análise univariada inicial mostrou que a aterosclerose do PW associou-se à demência, definida por critérios clínicos e clinicopatológicos. No estudo neuropatológico, esteve relacionada à DA e à DV. Após análise multivariada, ajustada para idade, sexo e escolaridade, a associação entre aterosclerose do PW manteve-se com 
demência no estudo clinicopatológico e com DV definida por critérios neuropatológicos.

Lesões anatomopatológicas associadas à DA (placas neuríticas e emaranhados neurofibrilares) correlacionaram-se com medidas de aterosclerose do PW. Além disso, infarto lacunar e arterioloesclerose hialina associaram-se ao grau de obstrução arterial do PW.

A relação entre aterosclerose de PW e demência observada em nossa pesquisa está de acordo com estudos recentes. Roher et al. (2003) demonstrou a associação entre a gravidade da aterosclerose do PW, medida quantitativamente, e DA. A amostra estudada era composta por 54 indivíduos (32 portadores de DA e 22 controles), com média de idade de 85,3 anos e portadores de lesões ateroscleróticas graves (porcentagem média de obstrução arterial em portadores de DA 66,9\% e 53,8\% em controles). Neste estudo, foram demonstradas maior gravidade e extensão da doença aterosclerótica em portadores de DA em relação a controles. Todas as artérias do PW analisadas separadamente apresentaram maior obstrução em indivíduos com DA do que em controles. Aterosclerose do PW correlacionou-se com emaranhados neurofibrilares e placas neurítcas. Os mesmo autores (Roher et al, 2004), selecionaram uma subamostra do estudo anterior composta por apenas 10 portadores de DA e 10 controles. A média etária foi ainda mais alta (87,5 anos) e a porcentagem de obstrução arterial também foi mais grave (74\% em indivíduos com DA e 55\% em controles) do que no nosso estudo. Novamente, foi encontrada maior gravidade da aterosclerose cerebral em portadores de DA do que em controles, com forte correlação entre a porcentagem de estenose arterial do PW com placas neuríticas $(\mathrm{r}=0,82)$ e emaranhados neurofibrilares $(\mathrm{r}=0,70)$. 
Honig et al. (2005), usando o banco de dados do "United States National Alzheimer's Coordinating Center" de 1985 a 2003, foram capazes de reunir informações de 1054 indivíduos com exame neuropatológico e avaliação qualitativa da aterosclerose cerebral. A gravidade da aterosclerose do PW foi associada apenas à presença de placas neuríticas. Os dados apresentados foram ajustados para idade, sexo e presença de infarto cerebral. Outro estudo de Beach et al. (2007) avaliou a relação entre aterosclerose cerebral e diagnóstico neuropatológico de demência em 397 indivíduos (92 controles, 215 portadores de DA, 30 com DV e 60 portadores de outras demências). A amostra estudada é oriunda de um programa de doação espontânea de cérebros e apresenta média etária elevada (82,3 anos) e grande prevalência de portadores de demência avançada. A aterosclerose cerebral foi medida qualitativamente e classificada em ausente, leve, moderada e grave. Foi encontrada associação entre aterosclerose grave do PW com DA e DV. Usando o grupo controle como referência, a chance de DA aumentava 1,3 vezes a cada aumento de uma unidade na gravidade da aterosclerose do PW. Para DV, a chance aumentou 2,5 vezes a cada aumento na gravidade da aterosclerose cerebral. Estas medidas foram ajustadas para idade, sexo e presença de apolipoproteína Eع4.

As amostras avaliadas em estudos prévios eram mais idosas do que em nosso estudo. Os trabalhos que fizeram medidas quantitativas de obstrução arterial do PW apresentaram maior gravidade das lesões ateroscleróticas do que aquelas que foram encontradas neste estudo (porcentagem média de obstrução arterial encontrada por Roher et al. $(2004)=64,5 \%$ VS este estudo neuropatológico e clinicopatológico=18,6\%). Considerando estas diferenças, demonstramos associação entre aterosclerose do PW e demência definida por critérios clinicopatológicos numa amostra mais jovem e com 
lesões ateroscleróticas menos graves. No estudo neuropatológico, foi mostrada associação entre DV e aterosclerose cerebral. A associação inicialmente encontrada, no estudo neuropatológico, entre DA e aterosclerose do PW foi perdida após ajuste para idade.

Neste estudo, foram analisadas diferenças entre os grupos com e sem demência em relação ao comprometimento por aterosclerose de cada artéria que compõem o PW nos estudos clínico, neuropatológico e clinicopatológico. Entretanto, é de particular interesse analisar as diferenças encontradas no estudo neuropatológico. Desta forma, é possível sinalizar quais artérias foram mais comprometidas em determinado grupo nosológico de demência. No nosso estudo neuropatológico, encontramos maior comprometimento aterosclerótico nas artérias cerebrais médias, artérias cerebrais anteriores e artéria comunicante posterior direita em portadores de DV em relação a controles. Um dos critérios utilizados para definição de DV foi a presença de lesões microvasculares em pelo menos três áreas corticais. Doença vascular extensa pode explicar o comprometimento vascular envolvendo grande parte da circulação cerebral como o encontrado. Outro critério que definiu a presença de DV foi a presença de infarto lacunar em área estratégica (tálamo, gânglios da base e hipotálamo). Estas áreas são irrigadas principalmente pela artéria cerebral posterior, que não apresentou maior comprometimento em portadores de DV em relação a controles e não explica as diferenças encontradas.

No estudo neuropatológico, os portadores de DA apresentaram maior comprometimento de artéria cerebral média esquerda do que controles. Trabalhos prévios com RM avaliaram diferenças de fluxo sanguíneo cerebral em portadores de DA e controles (Johnson et al., 2005 e Dai et al., 2009). Nestes estudos, os indivíduos com 
DA apresentavam menor fluxo sanguíneo cerebral em região parietal inferior e giro frontal médio. Estas áreas são irrigadas pela artéria cerebral média. Resultados similares foram encontrados em estudos com PET (positron emission tomography) e SPECT (single photon emission computed tomography), que demonstraram maior comprometimento destas áreas e também da região temporoparietal em indivíduos com DA, envolvendo a circulação média e posterior (Nobili et al., 2005 e Mielke e Heiss, 1998). Da mesma forma, Roher et al. (2006), em estudo com ultrassonografia transcraniana, encontraram maior envolvimento de artéria cerebral média em portadores de DA do que em controles.

Em relação à presença de infarto lacunar, foi encontrada associação entre aterosclerose do PW e este tipo de lesão microvascular. Este resultado pode sugerir um papel etiológico da aterosclerose dos grandes vasos cerebrais e infartos lacunares. Já a associação entre aterosclerose cerebral do PW e arterioloesclerose hialina sugere uma ligação entre a doença arterial de grandes e pequenas artérias cerebrais.

\subsection{Considerações finais}

As vantagens do nosso estudo residem na abrangência das informações clínicas, na heterogeneidade da amostra e na acurácia do diagnóstico neuropatológico para determinar a classificação etiológica de demência. Quanto à avaliação cardiovascular, foram obtidas informações quantitativas medidas em peças anatômicas, tornando a avaliação menos sujeita à subjetividade do avaliador. Além disso, a medida quantitativa da estenose arterial em material de autópsia, não havia ainda sido feita em larga escala, 
particularmente em estudos que investigam a associação entre artérias carótidas e demência.

As desvantagens residem na natureza transversal inerente aos estudos de autópsia que podem dificultar o estabelecimento de relações de causalidade. Além disso, a pesquisa de FRCV foi falha. O ideal seria ter medidas dos FRCV obtidas em vida, como por exemplo, medidas de pressão arterial, glicemia e colesterol sérico. Entretanto, a estrutura do BEH-GEEC-FMUSP não permite a obtenção destes dados. É importante ressaltar que a avaliação cognitiva foi feita a partir das informações fornecidas por um cuidador, sendo que a escala CDR foi desenvolvida para ser aplicada tanto no paciente como em seu informante. Mesmo não sendo ideal, esta abordagem já foi validada (Isella et al., 2006) e aplicada em estudos prévios (Haroutunian et al., 1998 e 1999). Outra desvantagem é que, embora a associação entre apolipoproteína E\&4, demência e FRCV seja conhecida, ainda não dispomos do perfil da apolipoproteína E4 de nossa amostra.

Apesar das limitações descritas, as informações obtidas juntam-se às evidências que ligam os fatores de risco cardiovascular, particularmente a aterosclerose de polígono de Willis e de artérias carótidas, ao maior risco de demência. Medidas preventivas que visem o controle dos fatores de risco associados à aterosclerose e a conseqüente diminuição da progressão de lesões ateroscleróticas já instaladas podem ser um meio eficaz de postergar o desenvolvimento das demências. 


\section{CONCLUSÕES}


1. A porcentagem de obstrução arterial por aterosclerose no PW e a extensão da doença aterosclerótica estiveram associados à demência definida por critérios clinicopatológicos. Além disso, a extensão da doença aterosclerótica do PW associou-se com demência vascular definida por critérios neuropatológicos.

2. Foi encontrada correlação entre a aterosclerose do PW e a quantidade de placas neuríticas e emaranhados neurofibrilares, lesões associadas ao diagnóstico neuropatológico de DA.

3. Aterosclerose do PW esteve associada à presença de infarto lacunar e arterioloesclerose hialina, sinalizando uma ligação entre a doença aterosclerótica de pequenos e grandes vasos cerebrais.

4. Obstruções arteriais críticas, maiores ou iguais a 75\%, em artéria carótida interna ou em artéria carótida esquerda estiveram associadas à maior chance de demência.

5. Estenose crítica em artéria carótida interna associou-se à DA. Obstruções maiores ou iguais a $75 \%$ em artéria carótida interna ou em artéria carótida esquerda foram mais comuns em DV.

6. Obstruções críticas em artéria carótida interna associaram-se à presença de infarto lacunar, sugerindo a participação das lesões carotídeas na etiologia deste tipo de infarto cerebral. 
Conclusões

7. O peso cardíaco e a espessura da parede livre de VE foram maiores em controles do que em portadores de demência, definida por critérios clínicos.

8. Os dementados eram mais velhos, tinham menos escolaridade e menor proporção de óbitos de etiologia cardiovascular do que os controles.

9. Além de terem morrido mais jovens e de terem maior proporção de óbitos de etiologia cardiovascular, os controles tiveram maior prevalência de doença arterial coronariana e insuficiência cardíaca do que os dementados, sugerindo que os controles compunham um grupo com maior mortalidade cardiovascular que os impediu de ter vivido tempo suficiente para desenvolver demência.

10. AVC informado durante a entrevista clínica foi mais prevalente entre os dementados, sinalizando a importância de eventos isquêmicos para a manifestação de sintomas cognitivos. 
7. ANEXOS 


\title{
ANEXO I
}

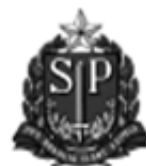

\author{
HOSPITAL DAS CLINICAS \\ da Faculdade de Medicina da Universidade de Sáo Paulo \\ CAIXA Postal, 8091 - SÃo PaUlo - BRAsIL
}

TERMO DE CONSENTIMENTO LIVRE E ESCLARECIDO

I - DADOS DE IDENTIFICAÇÄO DO SUJEITO DA PESQUISA OU RESPONSÁVEL LEGAL

1. NOME DO PACIENTE
DOCUMENTO DE IDENTIDADE No :
DATA NASCIMENTO:
ENDEREC
BAIRRO:
CEP:

2RESPONSÁVEL LEGAL

NATUREZA (grau de parentesco, tutor, curador etc.)

DOCUMENTO DE IDENTIDADE

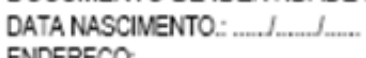

ENDERECO:

BAIRRO:

CEP:

CIDADE: SEXO:M F $\mathrm{N}^{\circ}$ APTO: TELEFONE DOD (

\section{II - DADOS SOBRE A PESQUISA CIENTIFICA}

1. TITULO DO PROTOCOLO DE PESQTTSA: CORRELACุÃO ANÁTOMO - FUNCIONAL DAS ALTERAÇÒES CEREBRAIS NO ENVELHECIMENTO:Um estudo quantitativo em material de necropsia

PESQUISADOR:-_Lea Tenenholz Grinberg

CARGOFIUNÇAO: ..Médica- pesquisadora.... INSCRIÇÄO CONSELHO REGIONAL N N..... 105280

UN DADE DO HCFMUSP: Departamento de Patclogis

3. AVALIAÇARO DO RISCO DA PESQUISA:

SEM RISCOX RISCO MINMO RISCO MEDIO

RISCOBAIXO RISCO MAIOR

4.DURAÇAO DA PESQUISA : 3 anos 


\section{III - REGISTRO DAS EXPLICAÇÕES DO PESQUISADOR AO PACIENTE OU SEU REPRESENTANTE LEGAL SOBRE A PESQUISA CONSIGNANDO:}

Muito obrigada por sua atencão. Estamos realizando um estudo para identficar como o envelhecimento ocorre no cérebro. Este estudo é muito importante porque ainda não sabemos direito porque as pessoas tềm demência ou ficam mais esquecidas ou tremendo. Tratamentos novos para as doenças só são descorbertos fazendo estudos como este. Esta pesquisa determinará as condições cerebrais de seu familiar no momento de sua morte.

O(a) Senhor(a) será entrevistado por um enfeirmeiro à respeito de seu parente que faleceu. As perguntas sảo simples, porém é importante que o(a) senhor(a) pense por dois minutos antes de responder e que seja o mais exato possivel. Caso não saiba a resposta, diga "não sei".

Durante a autópsia serão retirados o cérebro e pedaços de órgãos cujo comprometimento podem afetar a funç̃̃o cerebral, incluindo coração, rim e carótidas. De acordo com sua autorização, esses órgãos seräo analisados com bastante cuidado para verificar alteracões que possam prejudicar o funcionamento do cérebro. Os resultados serão comparados com as respostas que o(a) senhor(a) respondeu. Não será feito nada a mais que o procedimento nomal da autópsia e o corpo não será mutilado.

Com sua colaboração, poderemos saber se existiam alterações no cérebro de seu familiar que pudessem ser responsáveis por provocar doenças. Desta forma, outras pessoas poderáo ser beneficiadas por conhecermos melhor doenças como Alzheimer e mal de Parkinson. Algumas das doenças passam de pai para filho e, além disso, podem afetar grande parte da populaçăo. Entäo, os resultados que conseguiremos poderão ajudar muitas pessoas a não ficarem doentes.

O estudo não lhe causará nenhum transtorno. $O$ (a) senhor(a) não precisará voltar aqui novamente e este estudo não atrasará a realizaçäo da autópsia.

\section{IV - ESCLARECIMENTOS DADOS PELO PESQUISADOR SOBRE GARANTIAS DO SUJEITO DA PESQUISA CONSIGNANDO:}

Qualquer dúvida que o(a) senhor(a) tenha será esclarecida pela própria médica responsável pelo trabalho, os resultados estarão disponiveis somente para o(a) senhor(a). A qualquer momento, se for sua vontade, o seu familiar pode ser retirado da pesquisa e todas as informaçōes obtidas serão sigilosas. Caso não queira participar deste estudo, não haverá prejuizo nem para o(a) senhor(a), nem para seu parente .

Uma cópia deste documente será entregue para o(a) senhor(a).

\section{INFORMAÇÖES DE NOMES, ENDEREÇOS E TELEFONES DOS RESPONSÁVEIS PELO ACOMPANHAMENTO DA PESQUISA, PARA CONTATO}

A responsável pela pesquisa em caso de dúvidas é,

Dra. Lea Tenenholz Grinberg

CRM-SP: 105280

Telefone: (011) 30867322

\section{VI - CONSENTIMENTO LIVRE E ESCLARECIDO}

Declaro que, após convenientemente esclarecido pelo pesquisador e ter entendido o que me foi explicado, consinto em participar do presente Protocolo de Pesquisa
Săo Paulo,
de
de 200 
Anexos

\section{ANEXO II}

ENTREVISTA CLÍNICA

NSVO

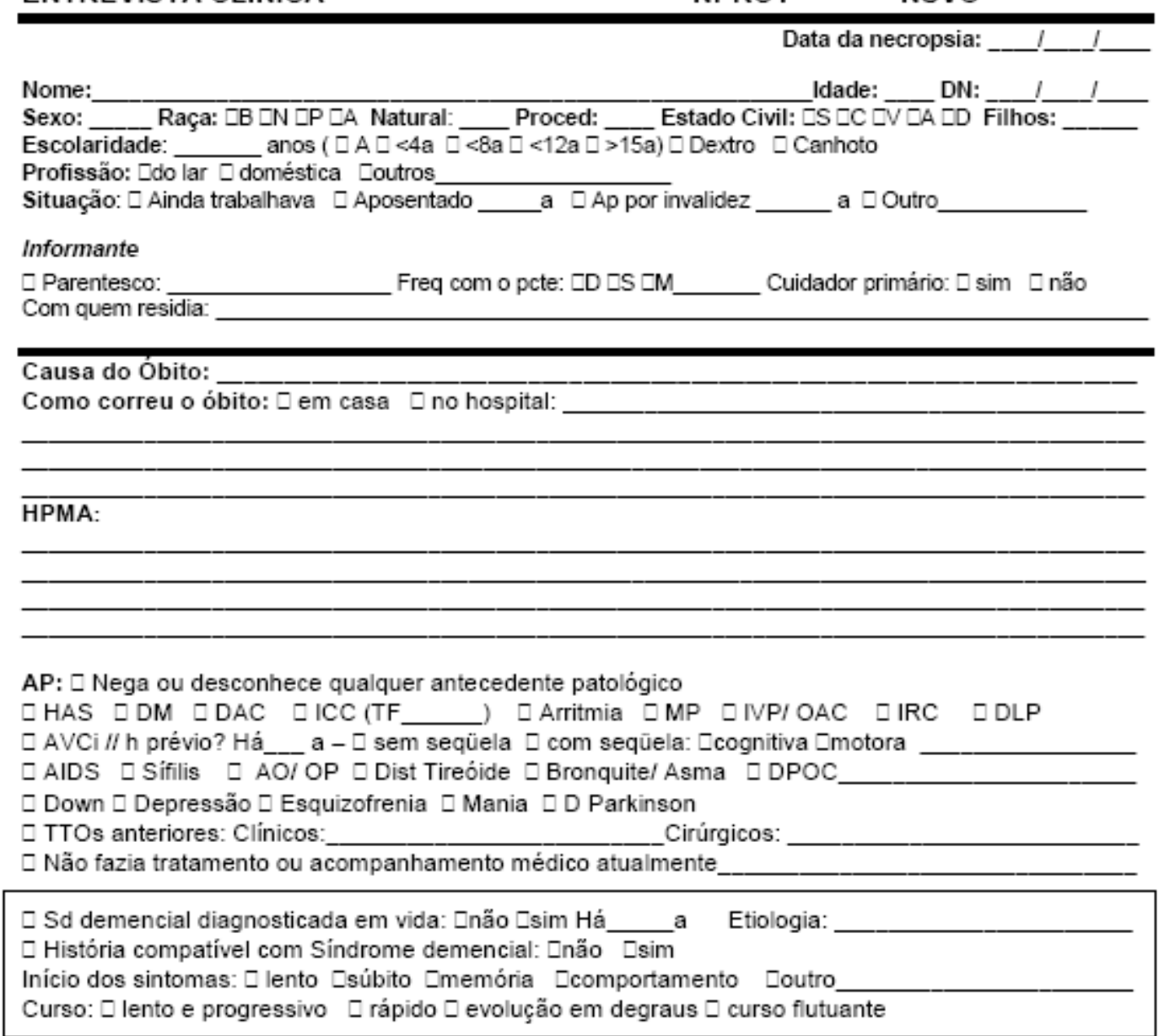

Função anterior à morte

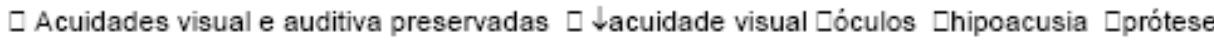

- Dentição preservada Zuso de prótese dentária \ disfagia [ SNG/SNE

口 Sedentário \ Atividade física: $\square$ caminhada $\square$ doméstica $\square$ outra Freq_____sem-ano

口 Andava: $\square$ sem auxílio $\square$ com auxílio: Zpessoas Zparede/ móveis 口 Lesões cutâneas (úlceras)

uxiliares

c Amputações $\square$ Acamado

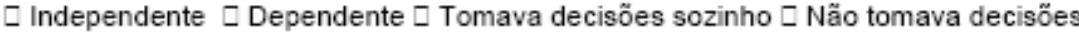

口 Em que situações convivia com muitas pessoas

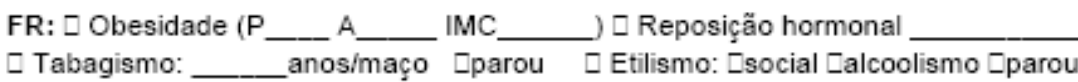


Anexos

¿ Tabagismo: anos/maço Zparou a Etilismo: Zsocial Zalcoolismo Zparou

Medicações que usava: ¿Não usa: Znão foi prescrito पcontrole inadequado Medicações:

Psicotrópicos:

Automedicação:

AF: $\square$ IAM__ $\square$ _ HAS $\square D M$

[ Epilepsia ou convulsőes:

口- Surdez: đDemência: 口 Retardo mental ou autismo:

- Episodios de euforia/mania:

- Tentativa de Suicidio: D Diabetes: $\square$ Desequilibrio:

- Fraqueza muscular -Parou de andar sem acidente प Derrame

\section{Pai:}

Data ou Ano de Nascimento:

Data ou Idade Falecimento:

Cidade Nascimento:

Data ou Ano de Nascimento:

Data ou Idade Falecimento:

Cidade Nascimento:

O pai e a mãe era parentes entre si? \ Não $\square$ Sim

Irmãos/Irmãs: (sexo e idade) 1.

2 .

3.

4.

5.

6.
Filhos/Filhas: (sexo e idade)

1.

2 .

3.

4.

5.

6.

Outras Informações relevantes: 


\section{Informant questionnaire on cognitive decline in the elderly}

\section{(IQCODE - Versão retrospectiva)}

Gostariamos que você se lembrasse de como era seu amigo ou familiar há 10 anos atrás e compare com o estado em que ele estava há 3 meses antes de sua morte.

Comparada com há 10 anos atrás, como estava a pessoa antes de sua morte

\begin{tabular}{|c|c|c|c|c|c|}
\hline & \begin{tabular}{|c|}
$\begin{array}{c}\text { Muito } \\
\text { melhor }\end{array}$ \\
(1) \\
\end{tabular} & $\begin{array}{l}\text { Um } \\
\text { pouco } \\
\text { melhor } \\
(2)\end{array}$ & $\begin{array}{c}\text { Não } \\
\text { muito } \\
\text { alterado } \\
(3)\end{array}$ & $\begin{array}{l}\text { Um } \\
\text { pouco } \\
\text { pior } \\
(4)\end{array}$ & \begin{tabular}{|c|}
$\begin{array}{c}\text { Muito } \\
\text { pior }\end{array}$ \\
$(5)$ \\
\end{tabular} \\
\hline 1. Reconhecer a face das pessoas amigas e da familia & & & & & \\
\hline 2. Lembrar do nome de parentes e amigos & & & & & \\
\hline $\begin{array}{l}\text { 3. Lembrar de coisas sobre a familia e amigos (aniversários, } \\
\text { ocupações, endereços...) }\end{array}$ & & & & & \\
\hline 4. Lembrar de coisas que aconteceram recentemente & & & & & \\
\hline 5. Lembrar de conversas que teve nos últimos dias & & & & & \\
\hline 6. Esquecia o que queria dizer no meio de uma conversa & & & & & \\
\hline 7. lembrar-se de seu próprio endereço e telefone & & & & & \\
\hline 8. lembrar (saber) que dia e mês era & & & & & \\
\hline 9. Lembrar onde as coisas são usualmente guardadas & & & & & \\
\hline $\begin{array}{l}\text { 10. Lembrar-se de onde encontrar as coisas que foram } \\
\text { colocadas em lugares fora do comum }\end{array}$ & & & & & \\
\hline 11. Adaptar-se a qualquer mudança na sua rotina diária & & & & & \\
\hline 12. Saber como funcionam os eletrodomésticos & & & & & \\
\hline $\begin{array}{l}\text { 13. Aprender a usar novos eletrodomésticos/ utensilios } \\
\text { domésticos }\end{array}$ & & & & & \\
\hline 14. Aprender coisas novas em geral & & & & & \\
\hline $\begin{array}{l}\text { 15. Lembrar-se de coisas que aconteceram em sua vida quando } \\
\text { era jovem }\end{array}$ & & & & & \\
\hline 16. Lembrar-se de coisas que aprendeu quando era jovem & & & & & \\
\hline 17. Entender o significado de palavras não comuns & & & & & \\
\hline $\begin{array}{l}\text { 18. Entender o significado do que está escrito em jornais e } \\
\text { revistas }\end{array}$ & & & & & \\
\hline 19. Acompanhar uma estória em um livro ou pela TV & & & & & \\
\hline 20. Escrever uma carta para um amigo ou com fins de trabalho & & & & & \\
\hline 21. Saber sobre eventos históricos importantes do passado & & & & & \\
\hline 22. Tomar decisões com problemas do dia a dia & & & & & \\
\hline 23. Manusear dinheiro para compras & & & & & \\
\hline $\begin{array}{l}\text { 24. Lidar com problemas financeiros (ex: pensào, conta } \\
\text { bancária) }\end{array}$ & & & & & \\
\hline $\begin{array}{l}\text { 25. Lidar com outros problemas matemáticos, por exemplo: } \\
\text { saber quanto comprar de comida, saber quanto tempo se } \\
\text { passou entre as visitas dos familiares/ amigos. }\end{array}$ & & & & & \\
\hline $\begin{array}{l}\text { 26. Usar sua inteligência para entender o que está acontecendo } \\
\text { e o motivo pelo qual está acontecendo. }\end{array}$ & & & & & \\
\hline
\end{tabular}

Total: 


\section{ESCORE CLÍNICO DE DEMÊNCIA - FOLHA DE REGISTRO}

Esta é uma entrevista semi-estruturada. Por favor, faça todas estas perguntas. Faça quaisquer questões adicionais que sejam necessárias para determinar o CDR do sujeito. Por favor, tome nota das informaçóes das perguntas adicionas.

\section{QUESTÕES SOBRE MEMÓRIA PARA O INFORMANTE}

1. Elelela tem algum problema com sua memónia ou seu pensamento (raciocínio)?
口 SIM 口 NAOO
口 SIM ¿ NAPO

1a - Se sim, é um problema constante? (em oposiçăo a eventual, raro)

2. Elefela pode se lembrar de eventos recentes?

$\square$ Freqüentemente $\square$ As vezes $\square$ Raramente

3. Elelela pode se lembrar de uma lista curta de itens (compras)?

$\square$ Freqüentemente $\square$ As vezes $\square$ Raramente

4. Houve algum declínio na memória durante o úlimo ano?

5. Sua memória está comprometida a tal ponto que teria interferido em suas atividades de vida diária de alguns anos atrás? (ou atividades pré-aposentadoria) (opiniấo de outros informantes)

- SIM \ NAOO

6. Elelela se esquece completamente de um evento importante (ex. viagem, festa, casamento em família) algumas semanas depois do evento?

$\square$ Freqüentemente $\square$ As vezes $\square$ Raramente

7. Ele/ela se esquece de detalhes pertinentes de um evento importante?

$\square$ Freqüentemente $\square$ As vezes $\square$ Raramente

8. Ele/ela se esquece completamente de informacoies importantes do passado distante (ex data de nascimento. data de casamento, local do emprego)?

9. OBS - Questão removida por năo ser aplicável.

\section{QUESTÕES SOBRE ORIENTAÇÃO PARA O INFORMANTE}

Com que freqüencia elelela sabe 0 exato:

1. Dia do MÈs?

$\square$ Freqüentemente $\quad \square$ As vezes $\quad$ Raramente $\quad \square$ Năo sabe

2. Mês?

$\square$ Freqūentemente $\quad \square A_{5}$ vezes $\quad \square$ Raramente $\quad \square N$ Näo sabe

3. Ano?

$\square$ Freqūentemente $\quad \square$ As vezes $\quad \square$ Raramente $\quad \square$ Năo sabe

4. Dia da semana?

$\square$ Freqūentemente $\quad \square A_{s}$ vezes $\quad \square$ Raramente $\quad \square$ Näo sabe

5. Elelela tem dificuldades com relaçêes temperais (quande os eventos cocrreram em relaçâe uns com os outros)?

$\square$ Frequèntemente $\quad \square$ As vezes $\quad \square$ Raramente $\quad \square$ Năo sabe 
6. Ele/ ela pode achar seu caminho em ruas conhecidas?

$\square$ Freqūentemente $\quad \square$ As vezes $\quad$ Raramente $\quad$ Năosabe

7. Com que frequéncia eleelela sabe como ir de um lugar para o outro fora de sua vizinhança?

$\square$ Freqūentemente $\quad \square$ As vezes $\quad$ Raramente $\quad$ aNăo sabe

8. Com que frecuiencia elefela code encontrar sev caminho dentro de casa?

$\square$ Freqüentemente $\quad \square$ As vezes $\quad$ Raramente $\quad$ Nö̆o sabe

\section{QUESTÕES SOBRE JULGAMENTO E RESOLUÇÃO DE PROBLEMAS PARA O INFORMANTE}

1. Em geral, se você tivesse que avaliar as habiidades deleidela para resolver problemas atualmente, você consideraria que elas săo:

- Tằ boas quanto sempre foram.

- Boas, mas nấ tão boas quanto antes.

a Regulares.

a Ruins.

[ Não há nenhuma habīidade.

2. Avale sua habilidade em lidar com pequenas quantias de dinheiro (ex: trocar dinheiro, dar gorjeta):

๑ Nâo há perda. $\quad$ Alguma perda. $\quad$ Perda grave

3. Avalie sua habi-idade em lidar com transaçôes financeiras complicadas (ex.: pagar contas, controle de conta bancária):

๑ Nâo há perda. \ Alguma perda. \ Perda grave.

4. Ele/ela pode lidar com uma emergência doméstica (ex. vazamento nos encanamentos, pequenos incêndios):

๑ Tăo bem quanto antes.

- Pior do que antes por causa da dficuldade de pensamento (raciocínio).

a Pior do que antes, por outra razão. (qual)

5. Ele/ela pode entender situacoōes ou explicapöes?

- Frecüentemente $\quad \square A_{5}$ vezes $\quad$ Raramente Nằ sabe

6. Elefela se comporta de modo apropriado* [isto é, em sua maneira usual (pré-doença)]em situaçöes sociais e em interaçăo com outras pessoas?

$\square$ Freqüentemente $\square$ As vezes $\quad$ Raramente $\quad$ Nă̈o sabe

- Este Item avalla comportamento, nğo aparencla. 


\section{QUESTÕES SOBRE ASSUNTOS COMUNITÁRIOS PARA O INFORMANTE}

\section{Ocupacional}

1. O sujeito ainda está trabalhando?

$\square$ SIM $\square$ NÅO $\square N / A$

Se não aplicável - vá parạ o item número 4

Se sim - vá para o item número 3

Se nâo - vá para o item número 2

2. Os problemas de memória ou de pensamento (raciocínio) contribuiram para a decisấo do suje to de se aposentar? (A questâo 4 é a proxima)

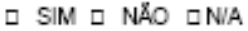

3. O sujeito tem dificuldade significante en seu trabalho por causa de problemas com memória ou pensamento (raciocínio)? 口 Raramente ou nunca $\square$ As vezes $\square$ Freqüentemente $\square$ Nấo sabe

$\underline{\text { Social }}$

4. Elelela alguma vez dirigiu carto?

5. Elelela dirige carros atualmente?

6. Se năo, é devido a problemas de memónia ou pensamento (raciocínio)?

7. Se elelela ainda está dirigindo, há problemas ou riscos devido ao pensamento (raciocinio) pobre?
๑ SIM $\square \mathrm{NAOO}$

- SIM \ NAOO

๑ SIM $\square \mathrm{NARO}$

- SIM $\square$ NAOO

8. Elelela é capaz de fazer compras para suas próprias necessidades independentemente?

8. Raramente ou nunca
$\square$ RAs vezes $\quad \square$ Freqüentemente Sabe

(precisa ser acompanhado (Pode comprar um número

$\begin{array}{ll}\text { em qualquer compra) } & \text { imliado de itens, compra ltens duplicados } \\ \text { ou esquece tens necessarios) }\end{array}$

9. Elelela é capaz de fazer atividades independentemente fora de sua casa?

प Raramente ounuca

a As vezes

व Freqüentemente

ם Não sabe

(Frequentemente incapaz de
realzar attvidades sem aluda)

(At:Mdades Imtadas ou de rotina,

por exemplo, patic paçào superficia na Igreja ou reunibes, Jdas a

(Partlcipaçăo slonifcattva saláo de beleza).

10. Elelela é levado a eventos sociais fora da casa de familiares?

a SIM I NAO Se năo, por que năo?

11. Um observador casual do comportamento do sujeito pensaria que ele está doente?

¿ SIM $\square \mathrm{NAO}$

12. Se institucionalizado, ele/ela participa bem de atividades sociais?

口 SIM ¿ NAOO

IMPORTANTE:

As informaçōes coletadas são suficientes para classificar o nivel de comprometimento do sujeito em assuntos comunitários?

Se não, por favor, investigue mais.

Atividades na comunidade: tais como ir à igreja, vistar amigos ou familia, atividades políticas, organizaçôes profissionais tais oomo associaçóes, outros grupos profissionais, clubes sociais, organizaçăo de servio̧os, programas educacionais).

* Por favor, adicione notas se necessário para esclarecer o nivel de funcionamento do sujeito nesta área. 
QUESTÕES SOBRE O LAR E ATIVIDADES DE LAZER PARA O INFORMANTE

1a) Que mudanças ocorreram em suas habilidades de realizar tarefas domésticas?

1b) $O$ que ele/ela ainda pode fazer bem?

2a) Que mudanças ocorreram em suas habilidades para realizar seus passatempos (hobbies)?

2b) O que ele/ela ainda pode fazer bem?

3) Se institucionalizado, o que elelela năo pode mais fazer bem (Casa e Hobbies)

Atividades da vida diária (Blessed):

Nenhuma perda

0

4. Habì dade para realizar tarefas domésticas

Por favor, descreva

5. Ele/ela é capaz de realizar tarefas domésticas até o nivel de: (Escolha uma, o informante nâo precisa ser perguntado diretamente)

․ Sem função significativa

(Realiza atividades simples, tais como fazer a cama, somente com muita supervisäo)

D. Funciona somente em atividades limitadas

(Com alguma supervisăo, lava a louça com limpeza aceitável, coloca a mesa)

I. Funciona indegendentemente em algumas atividades

(Opera equipamentos, tal como aspirador de pó, prepara refeições simples)

I. Funciona em atividades usuas mas näe ne nivel usual.

I. Funciona nomalmente em atividades usuais

IMPORTANTE:

As informações coletadas são suficientes para classificar o nivel de comprometimento do sujeito en CASA \& HOBBIES?

Se não, por favor investique mais.

Tarefas Domésticas: Tais como cozinhar, lavar, limpar, fazer compras, levar o lixo para fora, limpar o quintal, manutençâo de cuidados básicos e reparos básicos na casa

Hobbies: Costurar, pirtar, artesanato, leitura, entretenimento, fotografia, jardinagem, ir ao teatro ou concerto, trabalho em madeira, participaçäo em esportes. 


\section{QUESTÖES SOBRE 0 AUTOCUIDADO PARA O INFORMANIE}

"Qual sua estimativa da habilidade mental dele (a) nas seguintes áreas:"

\begin{tabular}{|c|c|c|c|c|}
\hline $\begin{array}{l}\text { Vestir-se } \\
\text { (Blessed) }\end{array}$ & $\begin{array}{l}\text { Sem ajuda } \\
\text { (0) }\end{array}$ & $\begin{array}{c}\text { Às vezes näo abotoa os } \\
\text { botôes cometamente,... } \\
\text { (1) }\end{array}$ & $\begin{array}{l}\text { Sequência errada - } \\
\text { esquece itens } \\
\text { comumente. } \\
\text { (2) }\end{array}$ & $\begin{array}{c}\text { Incapaz de se vestir } \\
\text { (3) }\end{array}$ \\
\hline $\begin{array}{l}\text { Lavar-se } \\
\text { (Arrumar- } \\
\text { se) }\end{array}$ & $\begin{array}{l}\text { Sem ajuda } \\
\text { (0) }\end{array}$ & $\begin{array}{l}\text { Necessita de estimulo } \\
\text { (1) }\end{array}$ & $\begin{array}{l}\text { Algumas vezes } \\
\text { precisa de ajuda } \\
\text { (2) }\end{array}$ & $\begin{array}{l}\text { Sempre - ou quase } \\
\text { sempre - precisa de } \\
\text { ajuda } \\
\text { (3) }\end{array}$ \\
\hline $\begin{array}{l}\text { Hábitos } \\
\text { À mesa }\end{array}$ & $\begin{array}{l}\text { De modo limpo; utiliza os } \\
\text { talheres adequados. } \\
\text { (0) }\end{array}$ & $\begin{array}{l}\text { De modo desorgan zado; } \\
\text { utiliza apenas colher. } \\
\text { (1) }\end{array}$ & $\begin{array}{l}\text { Apenas sólidos } \\
\text { simples } \\
\text { (2) }\end{array}$ & $\begin{array}{l}\text { Tem que ser } \\
\text { alimentado } \\
\text { (3) }\end{array}$ \\
\hline $\begin{array}{l}\text { Controle } \\
\text { de } \\
\text { esfincter }\end{array}$ & $\begin{array}{l}\text { Controle completo } \\
\text { nomal } \\
\text { (0) }\end{array}$ & $\begin{array}{c}\text { Ocasionalmente molha a } \\
\text { cama } \\
\text { (1) }\end{array}$ & $\begin{array}{l}\text { Freqũentemente } \\
\text { molha a cama } \\
\text { (2) }\end{array}$ & $\begin{array}{c}\text { Duplamente } \\
\text { incontinente } \\
\text { (3) }\end{array}$ \\
\hline
\end{tabular}

"Escore 1 pode ser considerado ge o auto-cuidado estiver comprometido quando comparado a um estado anterior, mesno que nào receba estinnulo 
ESCORE CLÍNICO DE DEMÊNCIA (CDR)

\begin{tabular}{|l|l|l|l|l|l|}
\hline Escore Clínico de Demència (CDR) & 0 & 0,5 & 1 & 2 & 3 \\
\hline
\end{tabular}

\begin{tabular}{|c|c|c|c|c|c|}
\hline & \multicolumn{5}{|c|}{ Comprometimento } \\
\hline & $\begin{array}{c}\text { Normal } \\
0\end{array}$ & $\begin{array}{c}\text { Questionável } \\
0,5\end{array}$ & \begin{tabular}{|c|} 
Leve \\
1
\end{tabular} & $\begin{array}{c}\text { Moderada } \\
2\end{array}$ & $\begin{array}{c}\text { Grave } \\
3\end{array}$ \\
\hline Memória & $\begin{array}{l}\text { Sem perda de } \\
\text { memória ou } \\
\text { esquecimento leve e } \\
\text { inconstante. }\end{array}$ & $\begin{array}{c}\text { Esquecimento leve e } \\
\text { constante (em } \\
\text { oposiçăo a eventual); } \\
\text { recordaçăo parcial de } \\
\text { eventos; } \\
\text { esquecimento } \\
\text { "benigno". }\end{array}$ & $\begin{array}{c}\text { Moderada perda de } \\
\text { memória; mais marcada } \\
\text { para eventos recentes; } \\
\text { déficit interfere nas } \\
\text { atividades cotidianas. }\end{array}$ & $\begin{array}{c}\text { Perda de memória } \\
\text { grave; somente retém } \\
\text { material intensamente } \\
\text { aprendido; material } \\
\text { novo rapidamente } \\
\text { perdido. } \\
\end{array}$ & $\begin{array}{l}\text { Perda de memória } \\
\text { grave; restam } \\
\text { apenas fragmentos. }\end{array}$ \\
\hline Orientação & $\begin{array}{l}\text { Plenamente } \\
\text { crientado. }\end{array}$ & $\begin{array}{l}\text { Plenamente orientado, } \\
\text { exceto por leve } \\
\text { dificuldade nas } \\
\text { relaçóes temporais. }\end{array}$ & $\begin{array}{c}\text { Dficuldade moderada } \\
\text { com relaçóes } \\
\text { temporais; orientado } \\
\text { para lugar do exame; } \\
\text { pode ter desorientaçăo } \\
\text { gecgráfica em outros } \\
\text { lugares. }\end{array}$ & $\begin{array}{c}\text { Dificuildade grave com } \\
\text { relaçóes temporais; } \\
\text { usualmente } \\
\text { desorientado para o } \\
\text { tempo, } \\
\text { freqūentemente para o } \\
\text { espaço. } \\
\end{array}$ & $\begin{array}{l}\text { Orientado apenas } \\
\text { para pessoa. }\end{array}$ \\
\hline $\begin{array}{l}\text { Julgamento } \\
\text { e resolução } \\
\text { de } \\
\text { problemas }\end{array}$ & $\begin{array}{l}\text { Resolve bem } \\
\text { problemas diários e } \\
\text { administra bem } \\
\text { negócios e finanças; } \\
\text { bom julgamento em } \\
\text { relaçà̃o ao } \\
\text { desempenho prévio. }\end{array}$ & $\begin{array}{l}\text { Leve dificuldade em } \\
\text { resolver problemas, } \\
\text { similaridades e } \\
\text { diferenças. }\end{array}$ & $\begin{array}{c}\text { Dificuldade moderada } \\
\text { para administrar } \\
\text { problemas, } \\
\text { similaridades e } \\
\text { diferenças; julgamento } \\
\text { social usualmente } \\
\text { mantida. }\end{array}$ & $\begin{array}{c}\text { Grave dificuldade em } \\
\text { administrar problemas, } \\
\text { simi laridades e } \\
\text { diferenças; julgamento } \\
\text { social usualmente } \\
\text { comprometido. }\end{array}$ & $\begin{array}{l}\text { Incapaz de fazer } \\
\text { julgamentos ou de } \\
\text { resolver problemas. }\end{array}$ \\
\hline $\begin{array}{l}\text { Assuntos } \\
\text { Comunitários }\end{array}$ & $\begin{array}{c}\text { Funcão } \\
\text { independente no } \\
\text { nivel usual no } \\
\text { trabalho, em } \\
\text { compras, grupos } \\
\text { scciais ou de } \\
\text { woluntários. }\end{array}$ & $\begin{array}{l}\text { Leve dificuldade } \\
\text { nessas atividades }\end{array}$ & \begin{tabular}{|l|} 
Incapaz de funcionar \\
independentemente \\
nessas atividades, \\
embora ainda possa \\
engajar-se em algumas; \\
parece nommal à \\
inspeçào casual.
\end{tabular} & $\begin{array}{c}\text { Nenhuma referéncia a } \\
\text { funcionamento } \\
\text { independente fora de } \\
\text { casa. Parece estar } \\
\text { bem para ser levado a } \\
\text { atividades fora de } \\
\text { ambiente familiar. }\end{array}$ & $\begin{array}{l}\text { Nenhuma referéncia } \\
\text { a funcionamento } \\
\text { independente fora } \\
\text { de casa. Parece } \\
\text { estar muito doente } \\
\text { para ser levado a } \\
\text { atividades fora de } \\
\text { ambiente familiar }\end{array}$ \\
\hline $\begin{array}{l}\text { Tarefas do } \\
\text { Lar e } \\
\text { Atividades } \\
\text { de Lazer }\end{array}$ & $\begin{array}{l}\text { Vida no lar, } \\
\text { passatempos e } \\
\text { interesses } \\
\text { intelectuais bem } \\
\text { mantidos. }\end{array}$ & $\begin{array}{c}\text { Vida no lar, } \\
\text { passatempos e } \\
\text { atividades intelectuais } \\
\text { levemente } \\
\text { comprometidos. }\end{array}$ & $\begin{array}{c}\text { Dficuldade leve mas } \\
\text { evidente nas funçöes } \\
\text { do lar, tarefas mais } \\
\text { dificeis abandonadas; } \\
\text { passatempos e } \\
\text { interesses mais } \\
\text { complexos } \\
\text { abandonados. } \\
\end{array}$ & $\begin{array}{l}\text { Somente tarefas } \\
\text { simples preservadas, } \\
\text { interesses muito } \\
\text { restritos e mal } \\
\text { sustentados. }\end{array}$ & $\begin{array}{c}\text { Sem funçâo } \\
\text { significativa em } \\
\text { casa. }\end{array}$ \\
\hline Autocuidado & Plenamente capaz & para o autocuidado. & Necessita estimulo. & $\begin{array}{c}\text { Requer ajuda para } \\
\text { vestir-se, higiene e } \\
\text { cuidado com objetos } \\
\text { pessoais. }\end{array}$ & $\begin{array}{c}\text { Requer muita ajuda } \\
\text { para o cuidado } \\
\text { pessoal, } \\
\text { incontinéncia } \\
\text { freqüente. }\end{array}$ \\
\hline
\end{tabular}


Inventário Neuropsiquiátrico

(Cummungs et al - 1994)

- Responder baseando-se nas mudanças que ocorreram desde que o paciente começou a ter problemas de memória

- Marcar sim apenas quando o sintoma estiver presente no último mês. Do contrário, marcar não.

- Responda honestamente e meticulosamente às questöes

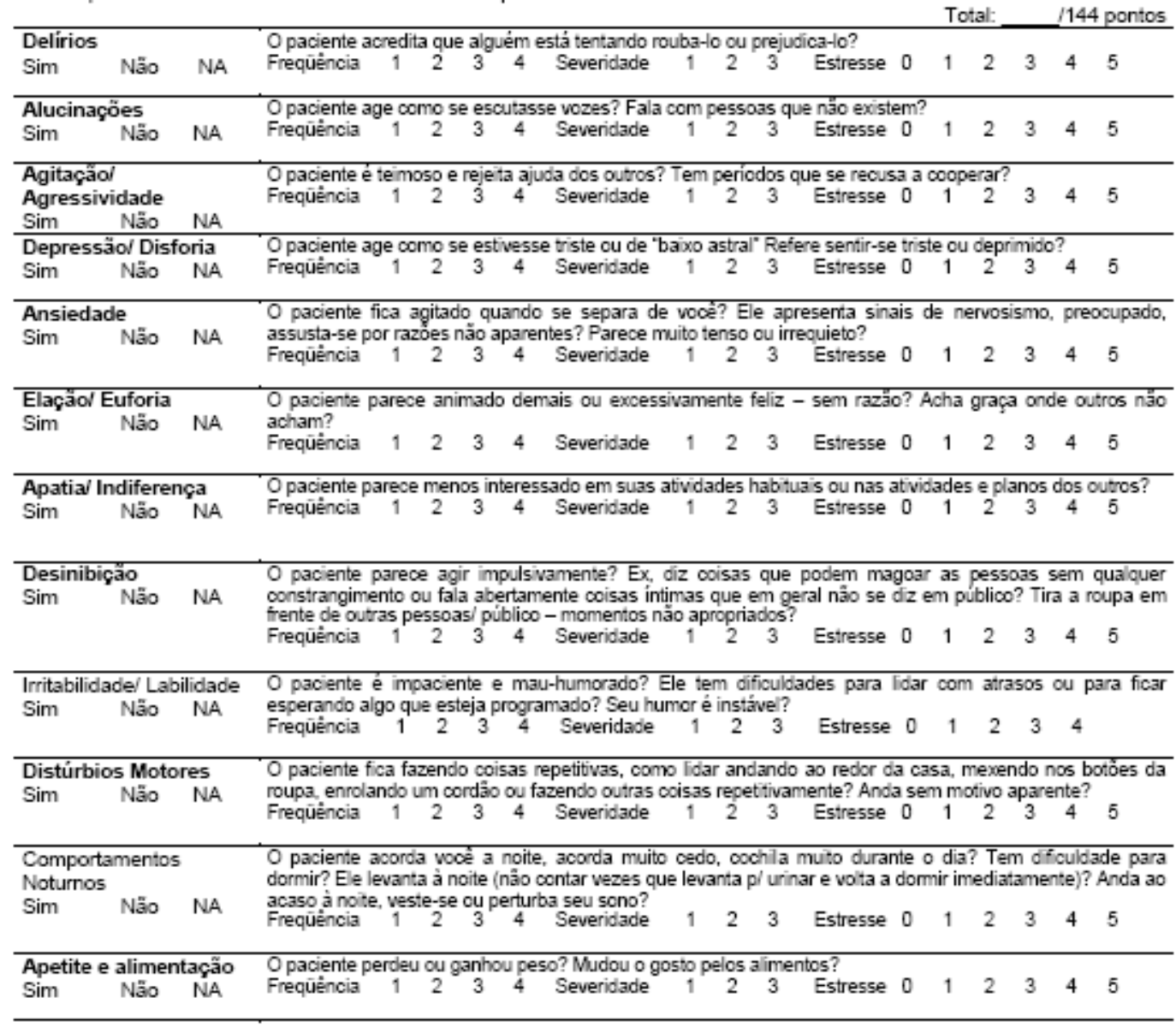

\section{FREQUENCIA}

1 - ocasionalmente - menos que $1 \mathrm{X} / \mathrm{sem}$

2 - Algumas vezes - cerca de $1 \mathrm{X} / \mathrm{sem}$

3 - Freqüentemente - várias vezes, menos que todos os dias

4 - Muito freqūentemente -1 ou + vezes/ dia

SEVERIDADE

1 - Leve - presente, mas produzindo pouca aflição no paciente

2 - Moderada - aflitiva e perturbadora

3 - Marcada - muito perturbadora

\section{ESTRESSE DO CUIDADOR}

$0=$ Nenhum

1 = Mínimo (levemente estressante, lidar com a situaçäo

não chega a ser um problema

2 = Leve (não muito estressante, geralmente fácil de lidar com a situaçăo)

$3=$ Moderado (razoavelmente estressante, nem sempre fácil de lidar com a situação

4 = Importante (muito estressante, dificil de lidar com a situação)

5 = Muito importante (extremamente estressante, incapaz de lidar com a situaçäo) 


\section{Índice de Katz para Atividades de Vida Diária}

(Kaz, S; Down, TD; Cash, HR et al - 1970)

\begin{tabular}{|c|c|}
\hline Banho & $\begin{array}{l}\text { I - Independente - não necessita de auxílio } \\
\text { A - Auxílio - recebe assistência para banhar uma parte do corpo (dorso/pernas) } \\
\text { D - Dependente - necessita que alguém o banhe }\end{array}$ \\
\hline Vestuário & $\begin{array}{l}\text { I - Alcança as roupas e se veste sem auxílio } \\
\text { A - Necessita de auxílio apenas para amarrar sapatos } \\
\text { D - Necessita de auxílio para alcançar as roupas, para se vestir - do contrário não se } \\
\text { veste completamente ou pemanece totalmente despido }\end{array}$ \\
\hline $\begin{array}{l}\text { Uso de } \\
\text { sanitário }\end{array}$ & $\begin{array}{l}\text { I - Consegue chegar ao banheiro, usa o sanitário, e recoloca o vestuário sem auxílio (pode } \\
\text { usar equipamento auxiliar como bengala, cadeira de roda, usar comadre e esvaziar pela } \\
\text { manhã) } \\
\text { A - Necessita de auxílio para ir até o banheiro, ou para sua higienização/ recomposição do } \\
\text { vestuário após uso do sanitário/ ou no uso de comadre } \\
\text { D - Não usa o banheiro para eliminações }\end{array}$ \\
\hline Transferência & $\begin{array}{l}\text { I - Independente (cama/ cadeira)- pode necessitar de bengala, andador. } \\
\text { A - Necessita de ajuda para sentar-se/ deitar-se/ levantar-se } \\
\text { D - Não sai da cama }\end{array}$ \\
\hline Continência & $\begin{array}{l}\text { I - Tem controle de esfíncter vésico - intestinal } \\
\text { A - Apresenta "acidentes ocasionais" - perder urina/ conteúdo fecal ocasionalmente } \\
\text { D - Necessita de auxílio para o controle urinário/intestinal; uso de SVD; incontinência }\end{array}$ \\
\hline Alimentação & $\begin{array}{l}\text { I- Se alimenta sem auxílio } \\
\text { A - Se alimenta sozinho, mas necessita de assistência para cortar os alimentos ou passar } \\
\text { manteiga no pão. } \\
\text { D - Necessita de auxílio para alimentar-se; usa SNG/SNE; Soroterapia/ Nutrição } \\
\text { parenteral. }\end{array}$ \\
\hline
\end{tabular}

$\mathrm{I}=1$ ponto $\mathrm{e}=0$ ponto

TOTAL: 18

Avaliação de Parkinsonismo (Adaptado de Tanner et al, 1990)

\begin{tabular}{|l|c|c|}
\hline & SIM & NÃO \\
\hline 1. Tinha dificuldade para se levantar de uma cadeira? & & \\
\hline 2. Notou se a letra (escrita) ficou pequena, se reduziu de tamanho? & & \\
\hline $\begin{array}{l}\text { 3. Notou ou alguém comentou se a sua voz estava mais baixa ou mais fraca } \\
\text { que era antes? }\end{array}$ & & \\
\hline 4. Tinha alterações do equilíbrio ao caminhar? & & \\
\hline 5. Os pés ficavam presos ou agarrados no chão ao atravessar portas? & & \\
\hline 6. Acha o seu rosto ficou mais "paradon, menos expressivo do que era antes? & & \\
\hline 7. Tinha tremores nos braços ou nas pernas? & & \\
\hline 8. Tinha dificuldades de abotoar as roupas? & & \\
\hline 9. Arrastava os pés ou dava passos curtos ao caminhar? & & \\
\hline
\end{tabular}




\section{ESCALA DE ATIVIDADES INSTRUMENTAIS DA VIDA DIÁRIA (IADL)} (Lawton \& Brody)

\section{A - Habilidade para usa o telefone \\ 1. Utiliza o telefone por iniciativa própria \\ 2. Disca alquns números conhecidos \\ 3. Atende mas näo faz ligaçöes \\ 4. Năo usa o telefone de modo algum \\ B - Compras \\ 1. Faz compras independentele \\ 2. Faz pequenas compras independente/e \\ 3. Precisa ser acompanhado nas compras \\ 4. Incapaz de fazer compras \\ C - Preparo de alimentos \\ 1. Planeia, prepara e serve adequadamente as refeicões independentemente \\ 2. Prepara adequadamente as refeicões se alquém Ihe fornecer os inqredientes \\ 3. Aquece, serve e prepara refeicōes, mas não garante uma dieta adequada \\ 4. Necessita que alquém prepare e sirva a refeição}

\section{D - Tarefas domésticas}

1. Matem a casa sozinho ou com auxilio ocasional (p.ex: auxílio para tarefas pesadas)

2. Realiza tarefas diárias leves, como lavar louca, fazer a cama

3. Realiza tarefas diárias leves, mas näo conseque fazé-las dentro dos padröes de limpeza

4. Necessita de auxilio com todas as tarefas domésticas

5. Näo faz/ participa de nenhuma tarefa doméstica

\section{E - Lavanderia}

1. Lava completamente as roupas

2. Lava pequenas peças: meias, etc

3. Toda a roupa deve ser lavada por terceiros

\section{F - Transporte}

1. Usa independentemente transportes públicos ou dirige seu próprio carro

2. Chama de táxi, mas não usa transporte público

3. Usa transporte público se acompanhado

4. Locomove-se limitadamente de táxi ou carro com auxílio de outros

5. Não sai de casa/ Não usa nenhum transporte

G - Medicação

1. É responsável por tomar sua medicacäo em dose e horários corretos

2. Assume responsabilidade por tomar sua medicacäo se separada anteriormente por outros

3. Não é capaz de tomar sua medicação

\section{$\mathrm{H}$ - Finanças}

1. Controla suas financas independentemente (conta de banco, talão de cheque, preenche cheques, paga contas)

2. Controla contas no dia a dia, mas necessita de auxilio com banco, compras maiores,..

3. Incapaz de controlar finanças

Lawton,MP: Brody, EM - The instrumental activities of Daily Living Scale. Gerontologist, 1969, 8: 179 - 188

Perguntas adicionais:

Total: 8 pontos

Ele(a) esquece panela no fogo, torneira aberta ou ferro ligado?

Ele(a) pode ser deixado(a) em casa sozinho(a) de forma segura? 


\section{Episódio Maior Depressivo no Passado - SCID}

Critérios para classificar como depressão maior: Cinco (ou mais) dos seguintes critérios presentes durante período maior ou igual a duas semanas, sendo que um dos cinco deve ser ou (1) humor deprimido, ou (2) perda do interesse ou prazer.

1) Já houve, pelo menos uma vez na vida dele(a), algum momento em que se sentiu deprimido(a), ou na pior na maior parte do dia, quase todos os dias? (Como é que foi isso?) SE SIM: Durou mais que duas semanas? SIM () NÃO( )

Critério: $\begin{array}{llll}1 & 2 & 3\end{array}$

2) Naquele tempo ou em outro momento, ele(a) perdeu o interesse ou o prazer pelas coisas que costumava gostar? (Como é que foi isso?) Isso acontecia quase todos os dias?

SE SIM: Durou mais que duas semanas? SIM ( ) NÄO ( )

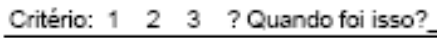

3) Naguele período ele(a) perdeu ou ganhou peso? Ele(a) estava tentando perder peso?

SE NAO: Como estava o apetite dele(a)? (Tinha que forçar para comer? Comia menos/mais que o habitual? Isso acontecia quase todos os dias?)

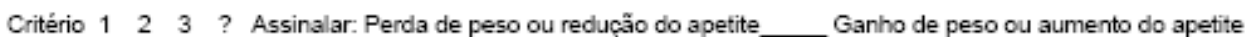

4) Como estava o sono dele(a)? (Dificuldade para dormir, acordando freqüentemente, dificuldades em ficar acordado, acordando muito cedo, ou, dormindo demais? Quantas horas por noite comparado com o habitual? Isso acontecia quase todas as noites?

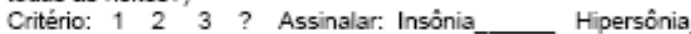

5) Ele(a) estava tăo inquieto(a) ou agitado(a) que nåo era capaz de ficar parado(a)? (Isso acontecia todos os dias?)

SE NAO: E o contrário: falando e se movendo mais devagar do que o normal dele(a)? (lsso acontecia todos os dias?)

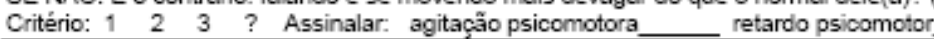

6) Como estava a energia dele(a)? (Cansado(a) o tempo inteiro? Quase todos os dias?)

Critério: 123 ?

7) Como ele se sentia em relação a si mesmo? (Inútil, sem valor?) Quase todos os dias?

SE NẪO: Ele se sentia culpado por coisas que fazia ou deixava de fazer? Quase todos os dias?

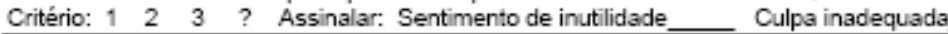

8) Ele(a) tinha dificuldade para se concentrar ou pensar? (Com que tipo de coisas isso interferia?) Quase todos os dias?

SE NAOO: Era dificil para ele(a) tomar decisóes sobre coisas do dia a dia? Quase todos os dias?

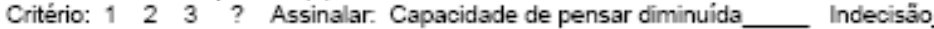

9) As coisas estavam tăo ruins que ele(a) pensava muito em morte ou que estaria em melhor situaçắo se estivesse morto(a)? E quanto a se ferir?

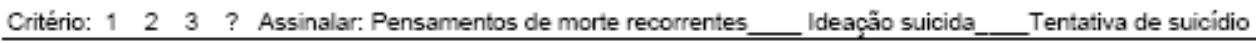

10) Durante aquele tempo ficou difícil para ele(a) trabalhar, cuidar das coisas em casa, ou se relacionar com as pessoas? $\operatorname{SIM}() \mathrm{NÃO}()$

11) Pouco antes de tudo isso começar ele estava bebendo em excesso ou usando drogas? SIM ( ) NÃO ( )

12) Pouco antes disso comecar ele estava fisicamente doente? $\operatorname{SIM}($ ) NÄO ( )

13) Isso começou logo depois de alguém próximo a ele(a) morrer? SIM ( ) NÃO ( )

Durou mais que 2 meses? SIM( ) NÃO( )

OBS: Houve algum outro episódio de depressão na vida do paciente? ( ) SIM （ ) NÃO Quando ocorreu (eram)?

CONSIDERAR:

1 -ausente ou falso $\quad 2$-subliminar (duvidoso) $\quad 3$-limiar ou verdadeiro ?-informaçäo inadequada 
Episódio Maníaco no Passado - SCID

Critérios para classificar como mania no passado: Humor elevado e mais três dos outros sintomas, ou humor irritável e mais quatro dos outros sintomas.

HUMOR ELEVADO: Já houve algum período de tempo em ele(a) estava se sentindo tão bem, agitado(a) ou excitado(a) que vocês perceberam que ele(a) năo estava no seu normal? Ou ficava tão excitado(a) que se envolvia em problemas? $\begin{array}{lllll}\text { Critério } & 1 & 2 & 3 & \text { ? }\end{array}$

Durou pelo menos 1 semana? Ou ele(a) teve que procurar um hospital? $\operatorname{Sim}($ ) Não ( )

Quando foi isso?

HUMOR IRRITAVEL: Houve algum período em que ele(a) estava tão irritado(a), que era pego(a) gritando com as pessoas ou começando brigas ou discussöes?

Durou mais que 1 semana? Ou ele(a) teve que procurar um hospital? Sim ( ) Não ( )

Critério: \begin{tabular}{lllll}
1 & 2 & 3 & ? Quando foi isso? \\
\hline 3) Naquele periodo como ele(a) se sentia em relaçåo a si mesmo? (Mais confiante do que o habitual? Com algum poder ou
\end{tabular} habilidade especial?)

Critério 123 ?

4) Naquele tempo ele(a) tinha que dormir menos que o habitual? (Mesmo assim se sentia descansado?)

Critério: $\begin{array}{llll}1 & 2 & 3 & \text { ? }\end{array}$

5) Naquele tempo ele(a) estava muito mais falante que o habitual? (Vocés tinham dificuldade para interromper ou entender 0 que ele(a) estava falando?)

Critério: $1 \begin{array}{llll} & 2 & 3 & ?\end{array}$

6) Naquele tempo os pensamentos passavam rapidamente pela cabeça dele(a)?

Critério: $1 \quad 2 \quad 3$ ?

7) Naquele tempo ele(a) era tão facilmente distraído(a) por coisas a sua volta que tinha dificuldades para se concentrar ou continuar o que estava fazendo?

Critério: $\begin{array}{lllll} & 2 & 3 & \text { ? }\end{array}$

8) Naquele período, como ele(a) passava o tempo? (Ele(a) se envolvia em tantas atividades a ponto de vocés ficarem preocupados?

SE NÂO: Ele(a) estava fisicamente inquieto(a)? (Qual a intensidade disso?)

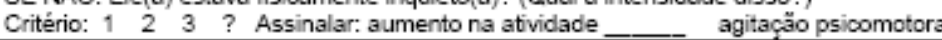

9) Naquele tempo, ele(a) fez alguma coisa que pudesse trazer problemas para ele(a) mesmo(a) ou para vocês

(Comprando coisas que näo precisava?) (Tendo comportamento sexual inadequado?)

Critério: $1 \begin{array}{llll} & 2 & 3 & \text { ? }\end{array}$

10) Durante aquele tempo ficou dificil para ele(a) trabalhar, cuidar das coisas em casa, ou se relacionar com as pessoas?

SIM ( ) NÄO( )

11) Pouco antes de tudo isso começar ele(a) estava bebendo em excesso ou usando drogas?

SIM ( ) NÄO ( )

12) Pouco antes disso começar, ele(a) estava fisicamente doente?

SIM ( ) NÃO ( )

CONSIDERAR:

1 - ausente ou falso $\quad 2$-subliminar (duvidoso) $\quad 3$-limiar ou verdadeiro $\quad$ ?-informaçäo inadequada 


\section{CLASSIFICAÇÃO SÓCIO ECONÔMICA}

Associação Brasileira dos Institutos de Pesquisa de Mercado

(ABIPEME)

A- Em sua casa tem?

\begin{tabular}{|l|c|c|c|c|c|c|c|c|}
\hline & \multirow{2}{*}{} & \multirow{2}{*}{ NÃO } & \multirow{2}{*}{ SIM } & \multicolumn{6}{|c|}{ QUANTIDADE } \\
\cline { 4 - 9 } & & & $\mathbf{1}$ & $\mathbf{2}$ & $\mathbf{3}$ & $\mathbf{4}$ & $\mathbf{5}$ & $\mathbf{6}$ ou + \\
\hline Televisão & & & 2 & 4 & 6 & 8 & 10 & 12 \\
\hline Empregada mensalista & & & 6 & 12 & 18 & 24 & 24 & 24 \\
\hline Rádio & & & 1 & 2 & 3 & 4 & 5 & 6 \\
\hline Banheiro & & & 2 & 4 & 6 & 8 & 10 & 12 \\
\hline Aspirador de pó & & & 5 & 5 & 5 & 5 & 5 & 5 \\
\hline Máquina de lavar & & & 2 & 2 & 2 & 2 & 2 & 2 \\
\hline Automóvel de passeio & & & 4 & 8 & 16 & 16 & 16 & 16 \\
\hline
\end{tabular}

TOTAL:

B- Qual a instrução do chefe de família?

\begin{tabular}{|l|c|}
\hline Sem Instrução/ primário incompleto & 0 \\
\hline Primário completo/ ginásio incompleto & 1 \\
\hline Ginásio completo/ colegial incompleto & 3 \\
\hline Colegial completo/superior incompleto & 5 \\
\hline Superior completo & 10 \\
\hline
\end{tabular}

TOTAL:

\begin{tabular}{|c|c|}
\hline \multicolumn{2}{|c|}{ CLASSE ABIPEME } \\
\hline CLASSE & PONTOS \\
\hline A & 35 OU + \\
\hline B & 21 a 34 \\
\hline C & 10 a 20 \\
\hline D & 05 a 09 \\
\hline E & 00 a 04 \\
\hline
\end{tabular}




\section{REFERÊNCIAS}


Abramoff MD, Magalhaes PJ, Ram SJ. Image Processing with ImageJ. Biophotonics International 2004; 11: 36-42.

Adelman AM, Daly MP. Initial evaluation of the patient with suspected dementia. Am Fam Physician 2005; 71: 1745-50.

Aguero-Torres H, Kivipelto M, von Strauss E. Rethinking the dementia diagnoses in a population-based study: what is Alzheimer's disease and what is vascular dementia? A study from the Kungsholmen project. Dement Geriatr Cogn Disord 2006; 22: 244-9.

Ali YS, Rembold KE, Weaver B, Wills MB, Tatar S, Ayers CR, Rembold CM. Prediction of major adverse cardiovascular events by age-normalized carotid intimal medial thickness. Atherosclerosis 2006; 187: 186-90.

Alzheimer A. Die arteriosklerotische Atrophie des Gehirns. Neurol Zentrabl 1894; 13: 765-8.

Alzheimer A. Über eine eigenartige Erkrankung der Hirnrinde. Allgemeine Z Psychiatrie Psychisch-Gerichtliche Med 1907; 64:146-8.

American Psychiatry Association. Diagnostic and Statistical Manual of Mental Disorders (DSM IV-Text Revision). 4th ed. Washington (DC): American Psychiatric Association; 2000.

Anstey KJ, Low LF. Normal cognitive changes in aging. Aust Fam Physician 2004; 33: 783-7.

Anstey KJ, Von Sanden C, Salim A, O’Kearney R. Smoking as a risk factor for dementia and cognitive decline: a meta-analysis of prospective studies. Am J Epidemiol 2007; 166: 367-78.

Areosa SA, Grimley EY. Effect of the treatment of type II diabetes mellitus on the development of cognitive impairment and dementia. Cochrane Database Syst Rev. 2002: CD003804.

Arvanitakis Z,Wilson RS, Bienias JS, Evans DA, Bennett D. Diabetes Mellitus and Risk of Alzheimer Disease and Decline in Cognitive Function. Arch Neurol 2004; 61: 661-6.

Barnett HJM, Meldrum HE and Eliasziw M. The appropriate use of carotid endarterectomy. CMAJ 2002; 166: 1169-79.

Beach TG, Wilson JR, Sue LI, Newell A, Poston M, Cisneros R, Pandya Y, Esh C, Connor DJ, Sabbagh M, Walker DG, Roher AE. Circle of Willis atherosclerosis: association with Alzheimer's disease, neuritic plaques and neurofibrillary tangles. Acta Neuropathol 2007; 113: $13-21$.

Beeri MS, Goldbourt U, Silverman JM, Noy S, Schmeidler J, Ravona-Springer R, Sverdlick A, Davidson M. Diabetes mellitus in midlife and the risk of dementia three decades later. Neurology 2004; 63: 1902-7.

Beeri MS, Rapp M, Silverman JM, Schmeidler J, Grossman HT, Fallon JT, Purohit DP, Perl DP, Siddiqui A, Lesser G, Rosendorff C, Haroutunian V. Coronary artery disease is associated with Alzheimer's disease neuropathology in APOE4 carries. Neurology 2006; 66: 1399-404.

Bikkina M, Levy D, Evans JC, Larson MG, Benjamin EJ, Wolf PA, Castelli P. Left ventricular mass and risk of stroke in an elderly cohort: the Framingham Heart Study. JAMA 1994; 272: $33-6$. 
Referências

Bottino CMC, Azevedo D, Tatsch M, Hototian SR, Moscoso MA, Folquitto J, Scalco AZ, Bazzarella MC, Lopes MA, Litvoc J. Estimate of dementia prevalence in a community sample from Sao Paulo, Brazil. Dement Geriatr Cogn Disord 2008, 26: 291-9.

Braak H, Braak E Neuropathological staging of Alzheimer-related changes. Acta Neuropathol 1991; 82: 239-59.

Braak H, Ghebremedhin E, Rub U, Bratzke H, Del Tredici K. Stages in the development of Parkinson's disease-related pathology. Cell Tissue Res 2004; 318: 121-34.

Breteler MM. Vascular risk factors for Alzheimer's disease: an epidemiologic perspective. Neurobiol Aging 2000; 21: 153-60.

BretelerMM, van Amerrongen NM, van Swieten JC et al. Cognitive correlates of ventricular enlargement and cerebral white matter lesions on MRI: the Rotterdam Study. Stroke 1994; 25: 1109-15.

Brunnstrom HR, Englund EM. Cause of death in patients with dementia disorders. Eur J Neurol 2009; 16: 488-92.

Burt VL, Whelton P, Roccella EJ, et al. Prevalence of hypertension in the US adult population: results from the Third National Health and Nutrition Examination Survey, 1988-1991. Hypertension 1995; 25: 305-13.

Bustamante SE, Bottino CM, Lopes MA, Azevedo D, Hototian SR, Litvoc J, Jacob-Filho W. Instrumentos combinados na avaliação de demência em idosos. Arq Neuropsiquiatr 2003; 61: 601-6.

Cairns NJ, Bigio EH, Mackenzie IR, Neumann M, Lee VM, Hatanpaa KJ, White CL 3rd, Schneider JA, Grinberg LT, Halliday G, Duyckaerts C, Lowe JS, Holm IE, Tolnay M, Okamoto K, Yokoo H, Murayama S, Woulfe J, Munoz DG, Dickson DW, Ince PG, Trojanowski JQ, Mann DM; Consortium for Frontotemporal Lobar Degeneration. Neuropathologic diagnostic and nosologic criteria for frontotemporal lobar degeneration: consensus of the Consortium for Frontotemporal Lobar Degeneration. Acta Neuropathol 2007; 114: 5-22.

Casale PN, Devereux RB, Milner M, Zullo G, Harshfield GA, Pickering TG, Laragh JH. Value of echocardiographic left ventricular mass in predicting cardiovascular morbid events in hypertensive men. Ann Intern Med. 1986; 105: 173-8.

Chen X, Wen W, Anstey KJ, Sachdev PS. Prevalence, incidence, and risk factors for lacunar infarcts in a community sample. Neurology 2009; 73: 266-72.

Chui HC, Zarow C, Mack WJ, Ellis WG, Zheng L, Jagust WJ, et al. Cognitive impact of subcortical vascular and Alzheimer's disease pathology. Ann Neurol 2006; 60: 677-87.

Crooks VC, Buckwalter JG, Petitti DB. Diabetes mellitus and cognitive performance in older women. Ann Epidemiol 2003; 13: 613-9.

Cumming J. Alzheimer's disease. N Engl J Med 2004; 351: 56-67. 
Referências

Cummings JL. The neuropsychiatric burden of neurological disease in the elderly. Int Psychogeriatr 2005; 17: 341-51.

Dai W, Lopez OL, Carmichael OT et al. Mild cognitive impairment and Alzheimer disease: patterns of altered cerebral blood flow at MRI imaging. Radiology 2009; 250:856-66.

DATASUS, Brasil, 2009. Informações de saúde demográficas e socioeconômicas. Disponível em: http://tabnet.datasus.gov.br (acessado em 08/2009).

de La Torre. How do heart disease and stroke become risk factors for Alzheimer's disease? Neurol Res 2006; 28: 637-44.

DeKosky ST. Statin therapy in the treatment of Alzheimer disease: what is the rationale? Am J Med 2005; 118: 48S-53S.

Den Heijer T, Launer LJ, Prins ND, van Dijk EJ, Vermeer SE, Hofman A et al. Association between blood pressure, white matter lesions, and atrophy of the medial temporal lobe. Neurology 2005; 64: 263-7.

Devereux RB, de Simone G, Koren MJ, Roman MJ, Laragh JH Left ventricular mass as a predictor of development of hypertension. Am J Hypertens. 1991; 4: 603S-607S.

Dik MG, Penninx B, Comijs HC ET al. The metabolic syndrome, inflammation and cognitive decline. Alzheimer's and Dementia. 2006; 2 (suppl 1): S414.

Dubois B, Feldman HH, Jacova C, DeKosky ST, Barberger-Gateau P, Cummings J, Delacourte A, Galasko D, Gauthier S, Jicha G, Meguro K, O’Brien J, Pasquier F, Robert P, Rossor M, Salloway, Stern Y, Visser PJ, Scheltens P. Research criteria for the diagnosis of Alzheimer's disease: revising the NINCDS-ADRDA criteria. Lancet Neurol 2007; 6: 734-46.

Dufoil C, Richard F, Fievet N, et al. APOE genotype, cholesterol level, lipid-lowering treatment and dementia. Neurology 2005; 65: 1531-8.

Dufouil C, Kersaint-Gilly A, Besançon V, Levy C, Auffray E, Brunnereau L et al. Longitudinal study of blood pressure and white matter hyperintensities: The EVA MRI cohort. Neurology 2001; 56: 921-6.

Elias MF, Sullivan LM, Elias PK, D'Agostino RB Sr, Wolf PA, Seshadri S, Au R, Benjamin EJ, Vasan RS. Left ventricular mass, blood pressure, and lowered cognitive performance in the Framingham offspring. Hypertension 2007; 49: 439-45.

Elias PK, Elias MF, D'Agostino RB, et al. Alcohol consumption and cognitive performance in the Framingham Heart Study. AmJ Epidemiol. 1999; 150: 580-9.

Farfel JM. Fatores relacionados à senescência e à senilidade cerebral em indivíduos muito idosos: um estudo de correlação clinicopatológica [tese]. São Paulo; 2008.

Fassbender K, Simons M, Bergmann C, et al. Simvastatin strongly reduces levels of Alzheimer's disease beta-amyloid peptides Abeta 42 and Abeta 40 in vitro and in vivo. Proc Natl Acad Sci USA 2001; 98: 5856-61. 
Referências

Fathi R, Marwick TH. Noninvasive tests of vascular function and structure: why and how to perform them. Am Heart J 2001; 141: 694-703.

Ferman TJ, Boeve BF. Dementia with Lewy Bodies. Neurol Clin 2007; 25: 741-60.

Fernando MS, Ince PG; MRC Cognitive Function and Ageing Neuropathology Study Group. Vascular pathologies and cognition in a population-based cohort of elderly people. J Neurol Sci 2004; 226: 13-7.

Ferraz-Alves TCT, Bussatto GF. Regional cerebral blood flow reductions, heart failure and Alzheimer's disease. Neurol Res 2006; 28: 579-87.

Ferri CP, Prince M, Brayne C, Brodaty H, Fratiglioni L, Ganguli M, Hall K, Hasegawa K, Hendrie H, Huang Y, Jorm A, Mathers C, Menezes PR, Rimmer E, Scazufca M and for Alzheimer's Disease International. Global prevalence of dementia: a Delphi consensus study. Lancet 2006; 366: 2112-7.

Finch CE. Developmental origins of aging in brain and blood vessels: an overview. Neurobiol Aging 2005; 26: 281-91.

Ford ES, Giles WH, Dietz WH. Prevalence of metabolic syndrome among US adults: findings from the third National Health and Nutrition Examination Survey. JAMA 2002; 287: 356-9.

Forette F, Seux ML, Staessen JA, Thijs L, Babarskiene MR, Babeanu S et al. The prevention of dementia with antihypertensive treatment: new evidence from the Systolic Hypertension in Europe (Syst-Eur) study. Arch Intern Med 2002; 162: 2046-52.

Freitag MH, Peila R, Masaki K, et al. Midlife pulse pressure and incidence of dementia: The Honolulu-Asia Aging Study. Stroke 2006; 37: 33-7.

Friedland RP, Fritsch T, Smyth KA, et al. Patients with Alzheimer's disease have reduced activities in midlife compared with healthy control-group members. Proc Natl Acad Sci US. 2001; 98: 3440-5.

Fu C, Chute DJ, Farag ES, Garakian J, Cummings JL, Vinters HV. Comorbidity in dementia. Arch Pathol Lab Med 2003; 128: 32-8.

Galanis D, Joseph $\mathrm{C}$, Masaki $\mathrm{KH}$, et al. A longitudinal study of drinking and cognitive performance in elderly Japanese American men: The Honolulu-Asia Aging Study. Am J Public Health. 2000; 90: 1254-9.

Geldmacher DS, Whitehouse PJ. Evaluation of dementia. N Engl J Med 1996; 335: 330-6.

Go AS; Hylek EM; Phillips KA et al. Prevalence of Diagnosed Atrial Fibrillation in Adults: National Implications for Rhythm Management and Stroke Prevention: the Anticoagulation and Risk Factors In Atrial Fibrillation (ATRIA) Study. JAMA 2001; 285: 2370-5.

Goetz CG, Emre M, Dubois B. Parkinson's disease dementia: definitions, guidelines, and research perspectives in diagnosis. Ann Neurol 2008; 64: S81-S92.

Gorelick PB. Risk factors for vascular dementia and Alzheimer disease. Stroke 2004; 35:26202. 
Grinberg LT, Ferretti REL, Farfel JM, Leite R, Pasqualucci CA, Rosemberg S, Nitrini R, Saldiva PHN, Jacob-Filho W for Brazilian Aging Brain Group. Brain bank of the Brazilian Aging Study Group - a milestone reached and more than 1,600 collected brains. Cell Tissue Banking 2007; 8: 151-62.

Grinberg LT, Ferretti REL, Leite REP, Farfel JM, Santos EB, Andrade MC, Oliveira KC, Caetano-Junior A, Santos ET, Polichiso L, Suemoto-Zoriki CK, Pasqualucci CA, Jacob-Filho W, Nitrini R. Vascular dementia, an avoidable disease, may be much more common than presumed: a postmortem study in a large population-base series. Alzheimer's and Dementia 2009; 5 (Suppl 1): 164.

Grodstein F, Chen J, Wilson RS, et al. for the Nurse Health Study. Type 2 diabetes and cognitive function in community-dwelling elderly women. Diabetes Care 2001; 24: 1060-5.

Hachinski VC, Iliff LD, Zilhka E, Du Boulay GH, McAllister VL, Russel RW, Symon L. Cerebral blood flow in dementia. Arch Neurol 1975; 32:632-7.

Haroutunian V, Perl DP, Purohit DP, Marin D, Khan K, Lantz M, Davis KL, Mohs R. Regional distribution of neuritic plaques in the nondemented elderly and subjects with very mild Alzheimer disease. Arch Neurol 1998; 55: 1185-91.

Haroutunian V, Purohit DP, Perl DP, Marin D, Khan K, Lantz M, Davis KL, Mohs R. Neurofibrillary tangles in nondemented elderly subjects and mild Alzheimer disease. Arch Neurol 1999; 56: 713-8.

Hassing LB, Johansson B, Nilsson SE, et al. Diabetes mellitus is a risk factor for vascular dementia, but not for Alzheimer's disease: A population-based study of the oldest old. Int Psychogeriatr 2002; 14: 239-48.

Heart Protection Study Collaborative Group. MRC/BHF Heart Protection study of cholesterol lowering with simvastatin in 20536 high-risk individuals. Lancet 2002; 360: 7-22.

Hernán MA, Alonso A, Logroscino G. Cigarette smoking and dementia - potential selection bias in the elderly. Epidemiology 2008; 19: 448-50.

Herrera Junior E, Caramelli P, Nitrini R. Estudo epidemiológico populacional de demência na cidade de Catanduva - estado de São Paulo - Brasil. Rev Psiq Clin 1998; 25: 70-3.

Hewer W, Mussell M, Rist F, et al. Short-term effects of improved glycemic control on cognitive function in patients with type 2 diabetes. Gerontology. 2003; 49: 86-92.

Hoffman LB, Schmeidler J, Lesser GT, Beeri MS, Purohit DP, Grossman HT, Haroutunian V. Less Alzheimer disease neuropathology in medicated hypertensive than nonhypertensive persons. Neurology 2009; 72: 1720-6.

Hofman A, Ott A, Breteler MM, Bots ML, Slooter AJC, Harskamp F, van Duijn CN, Van Broeckhoven C, Grobbee DE. Atherosclerosis, apolipoprotein E, and prevalence of dementia and Alzheimer's disease in the Rotterdam Study. Lancet. 1997; 349: 151-154.

Honig LS, Kukull W, Mayeux R. Atherosclerosis and AD: analysis of data from the US National Alzheimer's Coordinating Center. Neurology 2005; 64: 494-500. 
Hughes CP, Berg L, Danziger WL, Coben LA, Martin RL. A new clinical scale for the staging of dementia. Br J Psychiatry 1982; 140: 566-72.

Iadecola C, Gorelick PB. Converging pathogenic mechanisms in vascular and neurodegenerative dementia. Stroke 2003; 34: 335-7.

Instituto Brasileiro de Geografia e Estatística (IBGE). Censo demográfico do ano de 2000: População residente, por tipo de deficiência, segundo a situação do domicílio e os grupos de idade. Disponível em: http://www.ibge.gov.br/home/estatistica/populacao/censo2000/ populacao/deficiencia_Censo2000.pdf (acessado em 08/2009).

Irina A, Seppo H, Arto M, Paavo R, Hilkka S. B-amyloid load is not influenced by the severity of cardiovascular disease in aged and demented patients. Stroke 1999; 30: 613-8.

Isella V, Villa L, Russo A, Regazzoni R, Ferrarese C, Appolonio IM. Discriminative and predictive power of an informant report in mild cognitive impairment. J Neurol Neurosurg Psychiatry 2006; 77: 166-71.

Ivan CS, Seshadri S, Beiser A. Dementia after stroke: the Framingham Stidy. Stroke 2004; 35 : 1264-8.

Jellinger KA. Morphologic diagnosis of "vascular dementia" - a critical update. J Neurol Sci 2008; 270: 1-12.

Jennings JR, Muldoon MF, Ryan C, Price JC, Greer P, Sutton-Tyrrell K et al. Reduced cerebral blood flow response and compensation among patients with untreated hypertension. Neurology 2005; 64: 1358-65.

Jick H, Zornberg GL, Jick SS, Seshadri S, Drachman DA. Statins and the risk of dementia. Lancet 2000; 356: 1627-31.

Johnson NA, Jahng GH, Weiner MW et al. Pattern of cerebral hypoperfusion in Alzheimer disease and mild cognitive impairment with arterial spin-labeling MRI imaging: initial experience. Radiology 2005; 234: 851-9.

Johnston SC, O'Meara ES, Manolio TA, Lefkowitz D, O'Leary DH, Goldstein S et al. Cognitive impairment and decline are associated with carotid artery disease in patients without clinically evident cerebrovascular disease. Ann Intern Med 2004; 140: 237-47.

Jorm AF, Jacomb PA. The Informant Questionnaire on Cognitive Decline in the Elderly (IQCODE): sócio-demographic correlates, reliability, validity and some norms. Psychol Med 1989; 19: 1015-22.

Jorm AF. The Informant Questionnaire on Cognitive Decline in the Elderly (IQCODE): a review. Int Psychogeriatr 2004; 16: 275-93.

Kähönen-Väre M, Brunni-Hakala S, Lindroos M, Pitkala K, Strandberg T, Tilvis R. Left ventricular hypertrophy and blood pressure as predictors of cognitive decline in old age. Aging Clin Exp Res 2004; 16: 147-52.

Kalache A, Veras RP, Ramos LR. O envelhecimento da população mundial: um novo desafio. Rev. Saude Publica 1987; 21: 200-10. 
Kalaria RN, Maestre GE, Arizaga R, Friedland RP, Galasko D, Hall K, Luchsinger JA, Ogunniyi A, Perry EK, Potocnik F, Prince M, Stewart R, Wimo A, Zhang ZX, Antuono P for the World Federation of Neurology Dementia Research Group. Alzheimer's disease and vascular dementia in developing countries: prevalence, management, and risk factors. Lancet Neurol 2008; 7: 812-26.

Kalback W, Esh C, Castaño EM, Rahman A, Kokjohn T, Luehrs DC, Sue L, Cisneros R, Gerber F, Richardson C, Bohrmann B, Walker DG, Beach TG, Roher AE. Atheroscelrosis, vascular amyloidosis and brain hypoperfusion in the pathogenesis of sporadic Alzheimer's disease. Neurol Res 2004; 26: 525-39.

Kalmjin S, Foley D, White L, et al. Metabolic cardiovascular syndrome and risk of dementia in Japanese-American elderly men. The Honolulu-Asia Aging Study. Arterioscler Thromb Vasc Biol 2000; 20: 2255-60.

Kannel WB, Wolf PA, Garrison RJ. Framingham Study: An Epidemiological Investigation of Cardiovascular Disease. Section 34. NIH Publication No.87-2703. Bethesda, National Heart, Lung and Blood Institute; 1987.

Katz S, Doens TD, Cash HR, Grotz RC. Progress in the development of Index of ADL. Gerontologist 1970; 10: 20-30.

Kearney PM, Whelton M, Reynolds K, Muntner P, Whelton PK, He J. Global burden of hypertension: analysis of worldwide data. Lancet 2005; 365:217-23.

Kivipelto M, Helkala E-L, Laakso MP, et al. Apolipoprotein E epsilon4 allele, elevated midlife total cholesterol level, and high midlife systolic blood pressure are independent risk factors for late-life Alzheimer disease. Ann Intern Med 2002; 137: 149-55.

Kivipelto M, Helkala EL, Laakso MP, et al. Midlife vascular risk factors and Alzheimer's disease in later life: Longitudinal, population-based study. BMJ 2001; 322: 1447-51.

Kivipelto M, Ngandu T, Fratiglioni L et al. Obesity and vascular risk factors at midlife and the risk of dementia and Alzheimer's disease. Arch Neurol 2005; 62: 1556-60.

Lakatta EG, Levy D. Arterial and Cardiac Aging: Major Shareholders in Cardiovascular Disease Enterprises. Part I: Aging Arteries: A "Set Up" for Vascular Disease. Circulation 2003a; 107:139-46.

Lakatta EG, Levy D. Arterial and cardiac aging: major shareholders in cardiovascular disease enterprises: Part II: the aging heart in health: links to heart disease. Circulation 2003b; 107: $346-54$.

Lauer MS, Anderson KM, Levy D. Influence of contemporary versus 30-year blood pressure levels on left ventricular mass and geometry: the Framingham Heart Study. J Am Coll Cardiol. 1991; 18: 1287-94.

Launer LJ, Ross GW, Petrovitch H, et al. Midlife blood pressure and dementia: The HonoluluAsia aging study. Neurobiol Aging 2000; 21: 49-55. 
Lawton MP, Brody EM. Assessment of older people: self-maintaining and instrumental activities of daily living. Gerontologist 1969; 9: 179-86.

Lebrão ML, Laurenti R. Saúde, bem-estar e envelhecimento: o estudo SABE no município de São Paulo. Rev Bras Epidemiol 2005; 8: 127-41.

Leeuw FE, Groot JC, Bots ML, Witteman JCM, Oudkerk M, Hofman A, van Gijn J, Breteler MMB. Carotid atherosclerosis and cerebral white matter lesions in a population based magnetic resonance imaging study. J Neurol 2000; 247: 291-6.

Levy D, Anderson KM, Savage DD, Kannel WB, Christiansen JC, Castelli WP. Echocardiographically detected ventricular hypertrophy: prevalence and risk factors. Ann Intern Med 1988; 108:7-13.

Levy D, Anderson KM, Savage DD, Kannel WB, Christiansen JC, Castelli WP. Echocardiographically detected ventricular hypertrophy: prevalence and risk factors. Ann Intern Med 1988; 108:7-13.

Levy D, Garrison RJ, Savage DD, Kannel WB, Castelli WP. Prognostic implications of echocardiographically determined left ventricular mass in the Framingham Heart Study. $N$ Engl J Med. 1990; 322: 1561-6.

Li G, Higdon R, Kukull WA, et al. Statin therapy and the risk of dementia in the elderly. Neurology 2004; 63: 1624-8.

Lithell H, Hansson L, Skoog I, Elmfeldt D, Hofman A, Olofssom A et al. The study on cognition and prognosis in the elderly (SCOPE): principal results of a randomized double-blind intervention trial. J Hypertens 2003; 21: 875-86.

Logroscino G, Kang JH, Grodstein F. Prospective study of type 2 diabetes and cognitive decline in women aged 70-81 years. BM] 2004; 328: 548.

Luchsinger JA, Reitz C, Honig LS, et al. Aggregation of vascular risk factors and risk of incident Alzheimer disease. Neurology 2005; 65: 545-51.

MacKnight C, Rockwood K, Awalt E, McDowell I. Diabetes mellitus and the risk of dementia, Alzheimer's disease and vascular cognitive impairment in the Canadian Study of Health and Aging. Dement Geriatr Cogn Disord 2002; 14: 77-83.

Mahley RW, Weisgraber KH, Huang Y. Apoliprotein E4: a causative factor and therapeutic target in neuropathology, including Alzheimer's disease. PNAS 2006; 103: 5644-51.

Manolio TA, Burke GL, O’Leary DH, Evans G, Beauchamp N, Knepper L, Ward B. Relationships of cerebral MRI findings to ultrasonographic carotid atherosclerosis in older adults. The Cardiovascular Health Study. Arterioscler Thromb Vasc Biol 1999; 19: 356-65.

Mathiesen EB, Waterloo K, Joakimsen O, Bakke SJ, Jacobsen EA, Bonaa KH. Reduced neuropsychological test performance in asymptomatic carotid stenosis: the Tromso study. Neurology 2004; 62: 695-701. 
McGuiness B, Todd S, Passmore AP, Bullock R. Systematic review: blood pressure lowering in patients without prior cerebrovascular disease for prevention of cognitive impairment and dementia. J Neurol Nuerosurg Psychiatry 2008; 79: 4-5.

McGuinness B, Craig D, Bullock R, Passmore P. Statins for the prevention of dementia. Cochrane Database of Syst Rev 2009; 2: CD003160.

McKeith IG. Consensus guidelines for the clinical and pathologic diagnosis of dementia with Lewy bodies (DLB): report of the consortium on DLB international workshop. J Alzheimers Dis 2006; 9 (3 Suppl): 417-23.

Mielke R, Heiss WD. Positron emission tomography for diagnosis of Alzheimer's disease and vascular dementia. J Neural Transm Suppl 1998; 53: 237-50.

Miller RA. The Biology of Aging and Longevity. In: Hazzard WR, Blass JP, Halter JB, Ouslander JG, Tinetti ME. Principles of Geriatric Medicine and Gerontology. Fifth Edition. Columbus: McGraw Hill; 2003, p.3-15.

Mirra SS, Heyman A, McKeel D et al. The consortium to establish a registry for Alzheimer's disease (CERAD). Part II. Standardization of the neuropathologic assessment of Alzheimer's disease. Neurology 1991; 41: 479-86.

Montaño MBMM, Ramos LR. Validação da versão em português da Clinical Dementia Rating. Rev Saude Pública 2005; 39: 912-7.

Moroney JT, Tang MX, Berglund L, et al. Low-density lipoprotein cholesterol and the risk of dementia with stroke. JAMA 1999; 282: 254-60.

Morris JC. Dementia Update 2005. Alzheimer Dis Assoc Disord 2005; 19: 100-17.

Morris JC. The Clinical Dementia Rating Scale (CDR): current version and scoring rules. Neurology 1993; 43: 2412-3.

Mudher A, Lovestone S. Alzheimer's disease - do tauists and Baptists finally shake hands? Trend Neurosci 2002; 25: 22-5.

Mukherjee D, Yadav JS. Carotid artery intimal medial thickness: indicator of atherosclerotic burden and response to risk factor modification. Am Heart J 2002; 144:753-9.

NCEP: Third Report of the National Cholesterol Education Program Expert Panel on Detection, Evaluation, and Treatment of High Blood Cholesterol in Adults (Adult Treatment Panel III) final report. Circulation. 2002; 106: 3143-421.

Newman AB, Fitzpatrick AL, Lopez O et al. Dementia and Alzheimer's disease incidence in relationship to cardiovascular disease in the Cardiovascular Health Study cohort. J Am Geriatr Soc 2005; 1101-7.

Ngandu T, von Strauss E, Helkala EL, Winblad B, Nissinen A, Tuomilehto J, Soininen H, Kivipelto M. Education and dementia - What lies behind the association? Neurology 2007; 69: 1442-50. 
Nitrini R, Bottino CMC, Albala C, Capuñay NSC, Ketzoian C, Rodriguez JJL, Maestre GE, Ramos-Cerqueira ATA, Caramelli P. Prevalence of dementia in Latin America: a collaborative study of population-based cohorts. Int Psychogeriatr 2009; 21: 622-30.

Nitrini R, Caramelli P, Herrera E Jr, Bahia VS, Caixeta LF, Radanovic M, Anghinah R, Charchat-Fichman H, Porto CS, Carthery MT, Hartmann AP, Huang N, Smid J, Lima EP, Takada LT, Takahashi DY. Incidence of dementia in a community-dwelling Brazilian population. Alzheimer Dis Assoc Disord 2004; 18: 241-6.

Nitrini R, Caramelli P, Herrera Junior E, et al. Mortality from dementia in a communitydwelling brazilian population. Int J Geriatr Psychiatry 2005; 20: 247-53.

Niwa K, Kazama K, Younkin L, Younkin SG, Carlson GA, Iadecola C. Cerebrovascular autoregulation is profoundly impaired in mice overexpressing amyloid precursor protein. Am J Physiol Heart Circ Physiol. 2002; 283: H315-H323.

Nobili F, Brugnolo A, Calvini P et al. Resting SPECT-neuropsychology correlation in very mild Alzheimer's disease. Clin Neurophysiol 2005; 116: 364-75.

Nunes PV, Forlenza OV, Gattaz WF. Lithium and risk for Alzheimer's disease in elderly patients with bipolar disorder. Br J Psychiatry 2007; 190: 359-60.

Ostchega Y, Paulose-Ram R, Dillon CF, Gu Q, Hughes JP. Prevalence of peripheral arterial disease and risk factors in persons aged 60 and older: data from the National Health and Nutrition Examination Survey 1999-2004. J Am Geriatr Soc 2007; 55: 583-9.

Ott BA, Breteler MM, de Bruyne MC, van Harskamp F, Grobbee DE, Hofman A. Atrial fibrilation and dementia in a population-based study. The Rotterdam Study. Stroke 1997; 28: $316-21$.

Packard CJ, Perry IJ, Stott DJ, Sweeney BJ, Twomey C, Westendorp RG; PROSPER study group. Pravastatin in elderly individuals at risk of vascular disease (PROSPER): A randomized controlled trial. Lancet 2002; 360: 1623-30.

Pappolla MA, Bryant-Thomas TK, Herbert D, Pacheco J, Fabra Garcia M, Manjon M, Girones X, Henry TL, Matsubara E, Zambon D, Wolozin , Sano M, Cruz-Sanchez MM, Thal LJ, Petanceska SS, Refolo LM. Mild hypercholesterolemia is an early risk factor for the development of Alzheimer amyloid pathology. Neurology 2003; 61: 199-205.

Pereira JC, Barreto SM, Passos VM. The profile of cardiovascular health of elderly Brazilian people needs to improve: a population-based study. Arq Bras Cardiol 2008; 91: 1-10.

Petrovitch H, Ross GW, Steinhorn SC, Abbott RD, Markesberry W, Davis DG, et al. AD lesions and infarcts in demented and nodemented Japanese-American men. Ann Neurol 2005; 57: $98-103$.

Pico F, Dufouil C, Lévy C, Besançon V, Kersaint-Gilly A, Bonithon-Kopp C, Ducimetière P, Tzourio C, Alpérovitch A. Longitudinal study of carotid atherosclerosis and white matter hyperintensities: The EVA-MRI Cohort. Cerebrovas Dis 2002; 14: 109-15.

Pike CJ, Walencewicz AJ, Glabe CG, Cotman CW. In vitro aging of beta-amyloid protein causes peptide aggregation and neurotoxicity. Brain Res. 1991; 563: 311-4. 
Referências

Population Division of the Department of Economic and Social Affairs of the United Nations Secretariat, World Population Prospects: The 2008 Revision. Disponível em: http://www.esa.un.org/unpp (acessado em 08/2009)

Posner HB, Tang MX, Luchsinger J, Lantigua R, Stern Y, Mayeux R. The relationship of hypertension in the elderly to AD, vascular dementia, and cognitive function. Neurology 2002; 58:1175-81.

Price JL, McKeel DW Jr, Buckles VD, Roe CM, Xiong C, Grundman M, Hansen LA, Petersen RC, Parisi JE, Dickson DW, Smith CD, Davis DG, Schmitt FA, Markesbery WR, Kaye J, Kurlan R, Hulette C, Kurland BF, Higdon R, Kukull W, Morris JC. Neuropathology of nondemented aging: presumptive evidence for preclinical Alzheimer disease. Neurobiol Aging 2009; 30: 1026-36.

Qiu C, von Strauss E, Winblad B, et al. Decline in blood pressure over time and risk of dementia: A longitudinal study from the Kungsholmen project. Stroke 2004; 35: 1810-5.

Qiu C, Winblad B, Marengoni A, Klarin I, Johan F, Fratiglioni L. Heart failure and risk of dementia and Alzheimer disease. Arch Intern Med 2006; 166: 1003-8.

Ravid R, Van Zwieten EJ, Swaab DF. Brain banking and the human hypothalamus - factors to match for, pitfalls and potentials. Prog Brain Res 1992; 93: 83-95.

Rea TD, Breitner JC, Psaty BM, et al. Statin use and the risk of incident dementia. Arch Neurol 2005; 62: 1047-51.

Reed BR. Vascular dementia. Arch Neurol 2004; 61: 433-5.

Refolo LM, Pappolla MA, Malester B, et al. Hypercholesterolemia accelerates the Alzheimer's amyloid pathology in a transgenic mouse model. Neurobiol Dis 2000; 7: 321-31.

Rockwood K, Kirkland S, Fisk J, et al. Use of lipid lowering agents and the risk of cognitive impairment, not dementia, in relation to apolipoprotein E status. Neurobiol Aging 2004; 25 (Suppl. 2): S27.

Rockwood K, Kirkland S, Hogan DB, MacKnight C, Merry H, Verreault R et al. Use of lipidlowering agents, indication bias, and the risk of dementia in community-dwelling elderly people. Arch Neurol 2002; 59: 223-7.

Roe CM, Xiong C, Miller JP, Morris JC. Education and Alzheimer disease without dementia Support for the cognitive reserve hypothesis. Neurology 2007; 68: 223-8.

Roher AE, Esh C, Rahman A, Kkjohn TA, Beach TG. Atherosclerosis of cerebral arteries in Alzheimer disease. Stroke 2004; 35 (suppl I): 2623-7.

Roher AE, Esh C, Rahman A, Kokjohn TA, Kalback W, Luers DC et al. Circle of Willis atherosclerosis is a risk factor for sporadic Alzheimer's disease. Arterioscler Thromb Vasc Biol 2003; 23: 2055-62.

Roher AE, Garami Z, Alexandrov AV, Kokjohn, Esh CL, Kalback WM, Vedders LJ, Wilson JR, Sabbagh MN, Beach TG. Interaction of cardiovascular disease and neurodegeneration: transcranial Doppler ultrasonography and Alzheimer's disease. Neurol Res 2006; 28: 672-8. 
Román GC. Vascular dementia prevention: a risk factor analysis. Cerebrovasc Dis 2005; 20 (suppl 2): 91-100.

Román GC. Vascular dementia: distinguishing characteristics, treatment, and prevention. $J$ Am Geriatr Soc 2003; 51: S296-S304.

Rovio S, Kareholt I, Helkala EL, et al. Leisure-time physical activity at midlife and the risk of dementia and Alzheimer's disease. Lancet Neurol 2005; 4: 705-1.

Ruitenberg A, de Heiker T, Bakker SL. Cerebral hypoperfusion and clinical onset of dementia: the Rotterdam study. Ann Neurol 2005; 57: 789-94.

Ruitenberg A, den Heijer T, Bakker SLM, van Swieten JC, Koudstaal PJ, Hofman A, Breteler MMB. Cerebral Hypoperfusion and Clinical Onset of Dementia: The Rotterdam Study. Ann Neurol 2005; 57: 789-94.

Ruitenberg A, Skoog I, Ott A, et al. Blood pressure and risk of dementia: results from the Rotterdam Study and the Gothenburg H- 70 Study. Dement Geriatr Cogn Disord 2001; 12: 339.

Saito Y, Ruberu NN, Sawabe M et al. Staging of argyrophilic grains: an age-associated tauopathy. J Neuropathol Exp Neurol 2004; 63: 911-8.

Salerno-Kennedy R, Cashman KD. Relationship between dementia and nutrition-related factors and disorders: an overview. Int J Vitam Nutr Res 2005; 75: 83-95.

Sanz C, Andrieu S, Sinclair A, Hanaire H, Vellas B for the REALFR Study Group. Diabetes is associated with a slower rate of cognitive decline in Alzheimer disease. Neurology 2009; 73: 1359-66.

Schnaider Beeri M, Goldbourt U, Silverman JM, et al. Diabetes mellitus in midlife and the risk of dementia three decades later. Neurology 2004; 63: 1902-7.

Schneider JA, Wilson RS, Bienias JL, Evans DA, Bennett DA. Cerebral infarctions and the likehood of dementia from Alzheimer's disease pathology. Neurology 2004; 62: 1148-55.

Selvetella G, Notte A, Maffei A, Calistri V, Scamardella V, Frati G, Trimarco B, Colonnese C, Lembo G. Left ventricular hypertrophy is associated with asymptomatic cerebral damage in hypertensive patients. Stroke. 2003; 34: 1766-70.

Serviço de Verificação de Óbitos da Capital - Universidade de São Paulo. Estatística em número de autópsias realizadas 1994-2008. Disponível em: http://www.svoc.usp.br/estatistica.htm (Acessado em 08/2009)

Shah R, Wilson R, Bienias J, et al. Relation of blood pressure to risk of incident Alzheimer's disease and change in global cognitive function in older persons. Neuroepidemiology 2006; 26 : $30-6$.

Sheetz MJ, King GL. Molecular understanding of hyperglycemia's adverse effects for diabetic complications. JAMA 2002; 288: 2579-88. 
SHEP Cooperative Research Group. Prevention of stroke by antihypertensive drug treatment in older persons with isolated systolic hypertension. Final results of the systolic hypertension in the elderly program (SHEP). JAMA 1991; 265: 3255-64.

Shepherd J, Blauw GJ, Murphy MB, Bollen EL, Buckley BM, Cobbe SM, Ford I, Gaw A, Hyland M, Jukema JW, Kamper AM, Macfarlane PW, Meinders AE, Norrie J, Pico F, Dufouil C, Lévy C, Besaçon V, Kersaint-Gilly A, Bonithon-Kopp C, Ducimetière P, Tzourio C, Alpérovitch. Longitudinal study of carotid atherosclerosis and white matter hyperintensities: the EVA-MRI Cohort. Cerebrovasc Dis 2002; 14: 109-15.

Simons M, Schwarzler F, Luthjohann D, et al. Treatment with Simvastatin in normocholesterolemic patients with Alzheimer's disease: A 26-week, randomized, placebocontrolled doubleblind trial. Ann Neurol 2002; 52: 346-50.

Singh-Manoux A, Britton AR, Marmot M. Vascular disease and cognitive function: evidence from the Whitehall II Study. J Am Geriatr Soc 2003; 51: 1445-50.

Sinha S. The role of beta-amyloid in Alzheimer's disease. Med Clin North Am. 2002; 86: 62939.

Skoog I, Gustafson D. Update on hypertension and Alzheimer's disease. Neurol Res 2006; 28 : 605-11.

Skoog I, Lernfelt B, Landahl S, Palmertz B, Andreasson LA, Odén A, Svanborg A. 15-year longitudinal study of blood pressure and dementia. Lancet. 1996; 347: 1141-5.

Snowdon DA, Greiner LH, Mortimer JA, et al. Brain infarction and the clinical expression of Alzheimer disease: the NUN study. JAMA 1997; 277: 813-7.

Sonnen JA, Larson EB, Crane PK, Haneuse S, Li G, Schellenberg GD, Craft S, Leverenz JB, Montine TJ. Pathological correlates of dementia in a longitudinal, population-based sample of aging. Ann Neurol 2007; 62: 406-13.

Strassburger TL, Lee HC, Daly EM et al. Interactive effects of age and hypertension on volumes of brain structures. Stroke 1997; 28: 1410-7.

Swan GE, Lessov-Schlaggar CN. The effects of tobacco smoke and nicotine on cognition and the brain. Neuropsychol Rev 2007; 17: 259-73.

Swerdlow RH. Is aging part of Alzheimer's disease, or is Alzheimer's disease part of aging? Neurobiol Aging 2007; 28: 1465-80.

The National Institute on Aging, and Reagan Institute Working Group on Diagnostic Criteria for the Neuropathological Assessment of Alzheimer's Disease - Consensus recommendations for the postmortem diagnosis of Alzheimer's disease. Neurobiol Aging 1997; 18: S1-S2.

Tomlinson BE, Blessed G, Roth M. Observations on the brains of demented old people. $J$ Neurol Sci 1970; 11: 205-42.

Troncoso JC, Zonderman AB, Resnick SM, Crain B, Pletnikova O, O'Brien RJ. Effect of infarcts on dementia in the Baltimore Longitudinal Study of Aging. Ann Neurol 2008; 64: 16876. 
Tzourio C, Anderson C, Chapman N, Woodward M, Neal B, MacMahon S, Chalmers J; PROGRESS Collaborative Group. Effects of blood pressure lowering with perindopril and indapamide therapy on dementia and cognitive decline in patients with cerebrovascular disease. Arch Intern Med 2003; 163: 1069-75.

Van den Berg E, de Craen AJM, Biessels GJ, Gussekloo J, Westendorp RGJ. The impact of diabetes mellitus on cognitive decline in the oldest of the old: a prospective population-based study. Diabetologia 2006; 49: 2015-23.

Van Dijk EJ, Breteler MMB, Schmidt R, Berger K, Nilsson L, Oudkerk M et al. The association between blood pressure, hypertension, and cerebral white matter lesions. Hypertension 2004; 44: 625-30.

van Exel E, Gussekloo J,Houx P, de Craen AJM, Macfarlane PW, Bootsma-van der Wiel A, Blauw GJ, Westendorp RGJ. Atherosclerosis and cognitive impairment are linked in the elderly. The Leiden 85-plus Study. Atherosclerosis 2002; 165:353-9.

Van Oijen A, de Jong FJ, Witteman JCM, Hofman A, Koudstaal PJ, Breteler MMB. Atherosclerosis and risk for dementia. Ann Neurol 2007; 61: 403-10.

Verghese J, Lipton RB, Katz MJ, et al. Leisure activities and the risk of dementia in the elderly. N Engl J Med. 2003; 348: 2508-16.

Waldstein SR, Katzel LI. Stress-induced blood pressure reactivity and cognitive function. Neurology 2005; 64: 1746-49.

White L, Launer L. Relevance of cardiovascular risk factors and ischemic cerebrovascular disease to the pathogenesis of Alzheimer disease: a review of accrued findings from the Honolulu-Asia Aging Study. Alzheimer Dis Assoc Disord 2006; 20: S79-83.

Whitmer RA, Sidney S, Selby J, Johnston SC, Yaffe K. Midlife cardiovascular risk factors and risk of dementia in late life. Neurology 2005; 64: 277-81.

Willis T. De anima brutorum quae hominis vitalis ac sensitiva est. Oxonii: Ric Davis.A Apordage S (Transl) In: Dring T, Harper C, Leigh J. Practice of Physics: Two Discourses Concerning the Soul of Brutes. London: 1672, 1684.

Wilson RS, Krueger KR, Arnold SE, et al. Loneliness and risk of Alzheimer disease. Arch Gen Psychiatry 2007; 64: 234-40.

Wolf PA, Lewis A. Contributions of epidemiology to the prevention of stroke. Circulation. 1993; 88: 2471-83.

Wolozin B, Kellman W, Ruosseau P, et al. Decreased prevalence of Alzheimer's disease associated with 3-hydroxy-3-methylglutaryl coenzyme A reductase inhibitors. Arch Neurol 2000; 57: 1439-43.

World Health Report 2003 - Shaping the future. Geneva: WHO, 2003.

Xu WL, Qui CX, Wahlin A. et al. Diabetes mellitus and risk of dementia in the Kungsholmen Project: a 6-year follow-up study. Neurology 2004; 63: 1181-6. 
Yaffe K, Barnes D, Nevitt M, et al. A prospective study of physical activity and cognitive decline in elderly women: Women who walk. Arch Intern Med. 2001; 161: 1703-8.

Yaffe K, Blackwell T, Kanaya AM, et al. Diabetes, impaired fasting glucose, and development of cognitive impairment in older women. Neurology 2004; 63: 658-63.

Yaffe K, Haan MN, Blackwell T. Metabolic syndrome and cognitive decline in elderly latinos: findings from the SALSA study. J Am Geriatr Soc 2007; 55: 758-62.

Yaffe K, Kanaya A, Lindquist K, Simonsick EM, Harris T, Shorr RI, Tylavsky FA, Newman AB. The metabolic syndrome, inflammation, and risk of cognitive decline. JAMA 2004; 292: 2237-42.

Yamada M, Kasagi F, Sasaki $\mathrm{H}$, et al. Association between dementia and midlife risk factor: The Radiation Effects Research Foundation Adult Health Study. J Am Geriatr Soc 2003; 51: 410-4.

Yin KJ, Lee JM, Chen SD, Xu J, Hsu CY. Amyloid-beta induces Smac release via AP-1/Bim activation in cerebral endothelial cells. $J$ Neurosci. 2002; 22: 9764-70. 